\title{
CONSCIOUSNESS OF GOD AS GOD IS: \\ THE PHENOMENOLOGY OF CHRISTIAN CENTERING PRAYER
}

BY

BENNO ALEXANDER BLASCHKE

\begin{abstract}
A dissertation
submitted to the Victoria University of Wellington in fulfilment of the requirements for the degree of

Doctor of Philosophy
\end{abstract}

Victoria University of Wellington

(2017) 


\begin{abstract}
In this study I aim to give an alternative approach to the way we theorise in the philosophy and comparative study of mysticism. Specifically, I aim to shift debate on the phenomenal nature of contemplative states of consciousness away from textual sources and towards reliable and descriptively rich first-person data originating in contemporary practices of lived traditions.

The heart of this dissertation lies in rich qualitative interview data obtained through recently developed second-person approaches in the science of consciousness. I conducted in-depth phenomenological interviews with 20 Centering Prayer teachers and practitioners. The interviews covered the larger trajectory of their contemplative paths and granular detail of the dynamics of recent seated prayer sessions. I aided my second-person method with a "radical participation" approach to fieldwork at St Benedict's Monastery in Snowmass. In this study I present nuanced phenomenological analyses of the first-person data regarding the beginning to intermediate stages of the Christian contemplative path, as outlined by the Centering Prayer tradition and described by Centering Prayer contemplatives.

My presentation of the phenomenology of Centering Prayer is guided by a synthetic map of Centering Prayer's (Keating School) contemplative path and model of human consciousness, which is grounded in the first-person data obtained in this study and takes into account the tradition's primary sources. This includes: (1) an outline of the stages of the contemplative path; (2) the levels of consciousness (ordinary, spiritual and divine) and the type of experiential content (coarse, subtle and very subtle/divine presence) proper to each stage of the path; and (3) corresponding types of self (false, true and separate-self sense).

My study addresses three meta-issues in the field pertaining to method, description and theory. First, I offer a new framework for the comparative study of contemplative practices and experiences, alongside a sound second-person method for collecting firstperson data from contemplative practitioners. Second, I provide an effective framework for developing phenomenological accounts that are descriptively faithful, analytically transparent and theoretically useful. Third, I draw on the phenomenological accounts developed in this study to reconsider important theses advanced in the contemporary philosophy and comparative study of mysticism.

On this basis, I argue that practitioners phenomenally apprehend union states, specifically prayer of full union, through experiential primitives, such as a "sense of presence", and without a "God-identification element". Consequently, union states are phenomenologically of an unidentified reality and therefore not theistic, in Katz's and Pike's senses. However, there might be some sense in which they are phenomenologically of God,
\end{abstract}


because they could be practitioners' consciousness of God as God is; but this would empirically disconfirm received views of how God should be experienced. This finding challenges arguments for a unique theistic experience, designed to uphold a fundamental distinction between theistic and nontheistic experiences. Since Christian practitioners do not necessarily have unique theistic experiences in union, in the way that Katz and Pike require, there is at least some sense in which contemplatives from different traditions and cultures could have experiences similar in content and structure. 


\section{Acknowledgements}

First and foremost I want to thank my adviser, Dr Michael Radich, for being patient, honestly caring, and professionally available in many exceptional ways ever since I first met him in his office. Without his humble presence in my life and a critical meeting during my first undergraduate year at Victoria University, I would have decided against placing trust in academia to further my intellectual and philosophical development. Additionally, I want to thank him for diligently walking me through this dissertation as my supervisor, and all the advice I have received from him, which was plentiful. Finally, I want to thank him for placing trust in me to succeed and for backing me in this work from beginning to end, during a divorce and cancer diagnosis, and even though he understood that this project had a reasonable chance of failure due to significant challenges involved in method and getting access to hard-to-reach expert communities.

I owe Prof Joseph Bulbulia a great debt for sharing his experience and pragmatic perspective at a time I needed to make difficult decisions; to Prof Chris Marshall's example; to Dr Cei Maslen, who offered expedient support and feedback when I trained in philosophy many years ago; to Prof John Dunne for opening my eyes to the fact that I am misplaced in religious studies; to Prof Andrew Dreitcer for introducing me to Centering Prayer at the Mind and Life Summer Research Institute 2011; and to Prof (retraité) Maurice Legault for training me in the Explicitation Interview Method.

I am further and much indebted to the teachers, practitioners and spiritual communities of Pointing Out Way Tibetan Buddhist Mahamudra and Christian Centering Prayer for having received me, taught me and shared with me. I give special thanks to a few senior teachers and advanced practitioners (who cannot be named here) for introducing me to new ways of analysing and talking about contemplative states of consciousness, and for indulging my interest in comparative research. Many practitioners cross-practice and some teachers have taught for decades in each faith, Buddhist and Christian. I give thanks to them for receiving data from me that originated in the other tradition, which was not of their current affiliation, and then discussing with me the farther reaches of their respective contemplative paths, also by way of detailed comparative analyses of "awakened awareness" (Tibetan) and the "presence of God" (Christian).

I also want to thank my logical family. I give thanks to my twin brother, Tom, for reminding me of my own humanity, giving me joy and making me play; and to my sister, Sarah-May, for caring after me, seeing the best in me, giving me advice when needed, and being an excellent researcher who can see what I see, and sometimes more. I want to express my deep gratitude to Angela Mellish for her friendship and care for me, and for having 
enabled me for many years throughout my studies. Without her, my life as I know it today, and the future that stands before me, would not be possible. I give special thanks to Sarah Barnett, who immeasurably enriches my life and loves me for who and how I am. I thank her for wrestling with me and for me, and for having helped me come to terms with my personal existence. With her help I've become a member of the LBGTQ family, completely re-oriented my personal life and finally made peace with my place in the world. This I consider an invaluable gift, especially in light of the shorter life I will live due to terminal illness.

My academic endeavours are an act of gratitude in response to a gift I received from Dr David R. Hawkins. I hope my present and future work can do this gift justice. Finally, I thank the presence of God for awareness of existence, and its experiential content I know as life. 
Glória in excélsis Deo 


\section{Table of Contents}

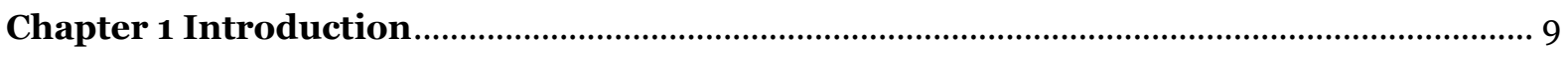

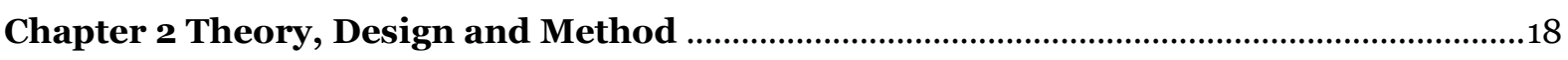

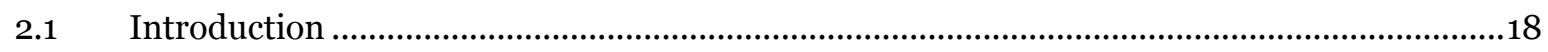

2.2. A New Framework for the Comparative Study of Contemplative Practices and Experiences ......................................................................................................

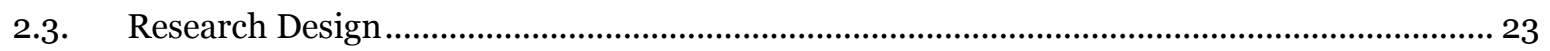

2.4. Revising Phenomenology as a Second-Person Method for Qualitative Research in Contemplative Studies .............................................................................................. 26

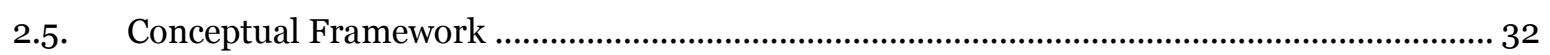

2.6. Fieldwork and the Scholar-Practitioner Perspective .................................................... 48

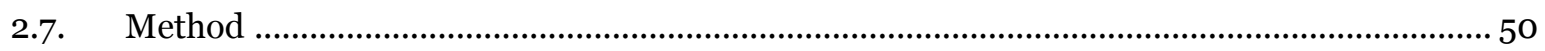

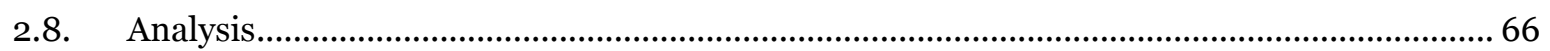

Chapter 3 The Contemplative Path of Centering Prayer …................................................73

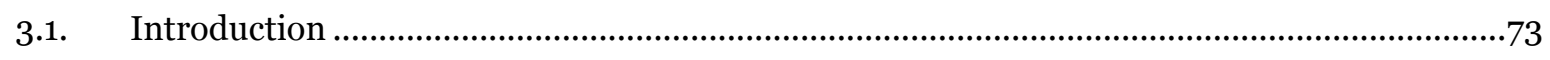

3.2. Apophatic and Path-Oriented Contemplative Practice .......................................................74

3.3. The Keating School's Model of Levels of Awareness and Self ............................................80

3.4. Centering Prayer's "Language of the Centre" .................................................................. 8. 87

3.5. Pennington's Soteriological Vision of God as Pure Consciousness....................................... 89

3.6. The Keating School Model of the Christian Contemplative Path........................................ 92

3.7. The Keating School's Soteriological Vision of the Farther Reaches of the Christian Contemplative Path .................................................................................................... 108

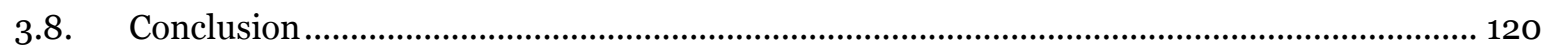

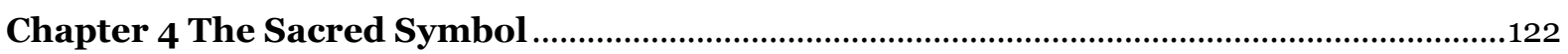

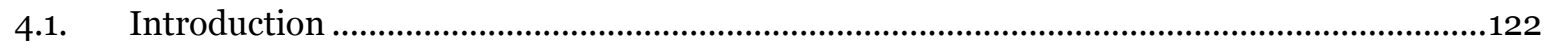

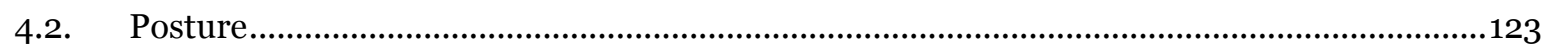

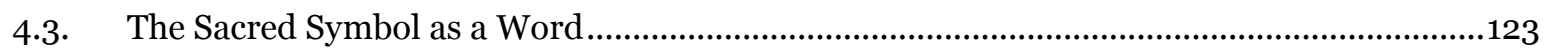

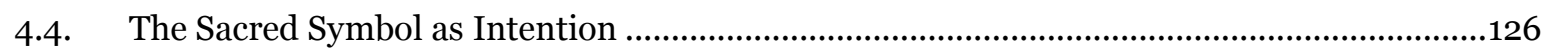

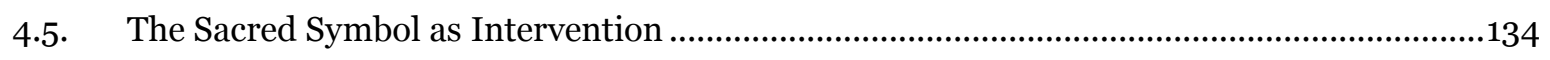

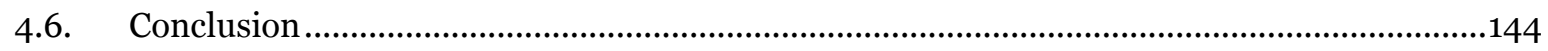

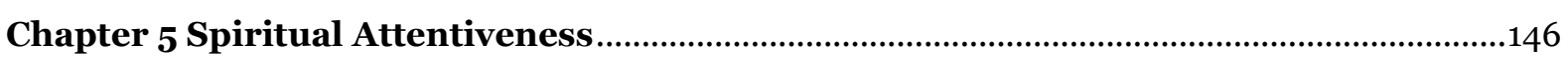

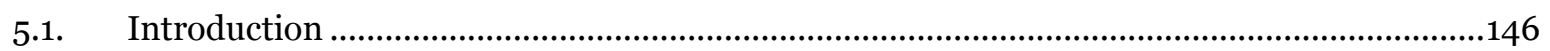

5.2. Stabilising the Basis of Operation in Spiritual Awareness ..............................................147

5.3. The Dual-mode Awareness of Spiritual Attentiveness .......................................................156

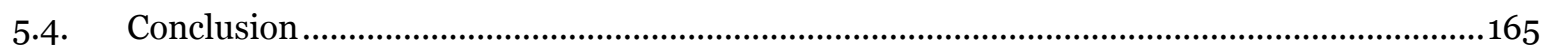

Chapter 6 The Stages of Absorption: Infused Recollection and Prayer of Quiet .............166

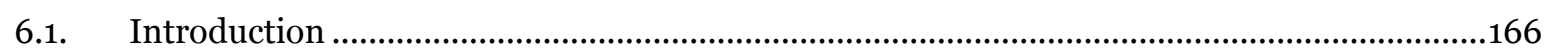

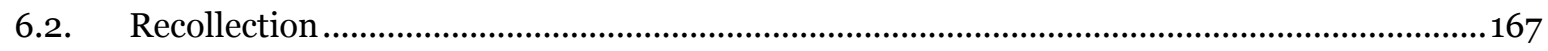

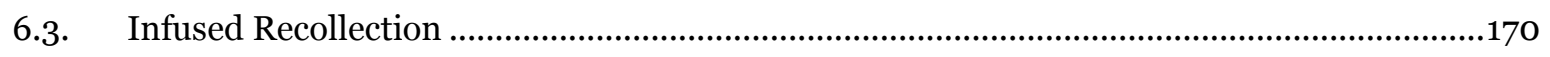

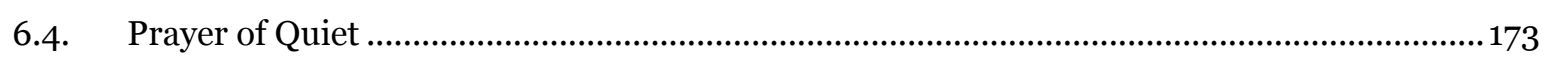

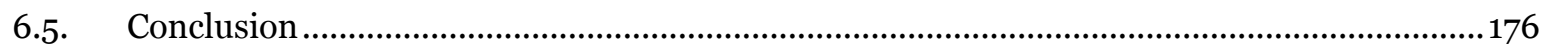


Chapter 7 The Stages of Absorption: Prayer of Union...........................................................178

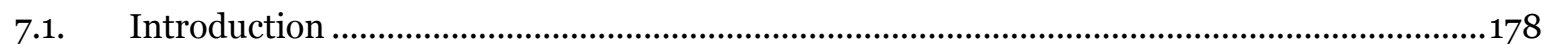

7.2. Rachel's Experience of God's Presence in Nothingness ..........................................................179

7.3. Pike's and Frenette's Accounts of "Prayer of Union" ................................................................184

7.4. Carol's Witnessing-Presence is God's Presence .................................................................185

7.5. The God-identification Element in the Phenomenologically Given ...................................... 190

7.6. Joseph's Sense of Presence in Prayer of Union ....................................................................... 191

7.7. The Dualistic Structure of "Prayer of Union" and Joseph's Paradoxical Language...............193

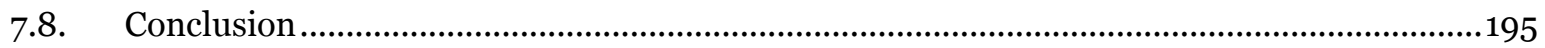

Chapter 8 The Stages of Absorption: Prayer of Full Union ....................................................197

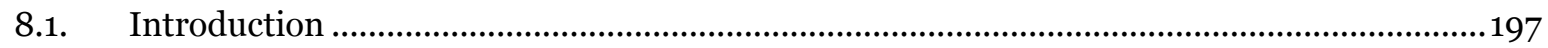

8.2. Lawrence's Realisation of Nothingness …….....................................................................198

8.3. Martin's "Liminal Space" When He Rests in God ............................................................. 201

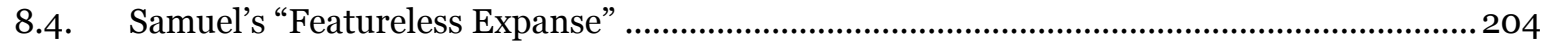

8.5. Lucidity and the Phenomenal Character and Structure of Full Union ................................. 210

8.6. Lucidity in the Wider Centering Prayer Tradition ...........................................................214

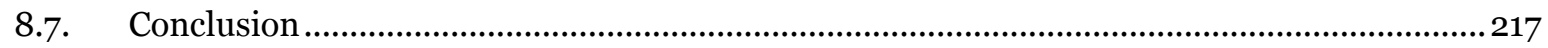

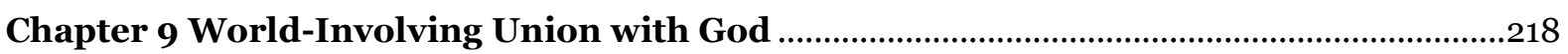

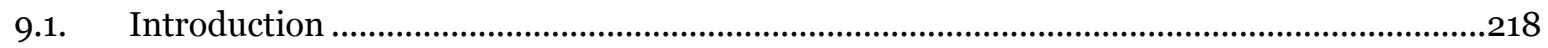

9.2. Joseph's World-Involving Sense of God's Presence …............................................................219

9.3. The Structure of Joseph's World-Involving Union with God...................................................221

9.4. The Phenomenal Structure and Character of World-Involving Union................................... 224

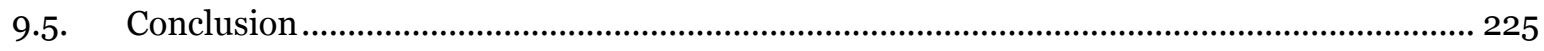

Chapter 1o Implications for the Philosophy and Comparative Study of Mysticism ....... 227

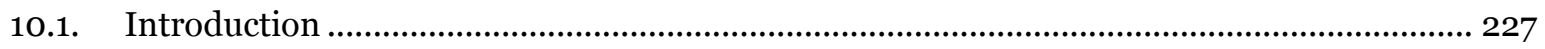

10.2. Theological Language in Description and the Critical Error of Constructivism ................... 229

10.3. Prayer of Union and Full Union are not Phenomenologically Theistic ................................ 234

10.4. World-Involving Union and Stace's Introvertive and Extrovertive Types of Mystical Experience.............................................................................................................. 236

10.5. Prayer of Full Union as a Paradigm Instance of Stace's Introvertive Type of Mystical Experience................................................................................................................. 239

10.6. Prayer of Full Union as a "Pure Consciousness Event" .............................................................241

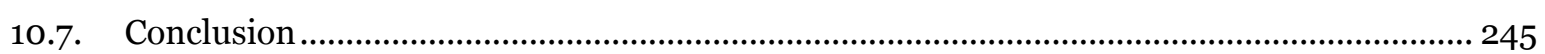

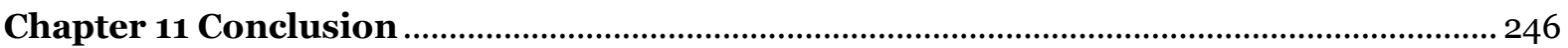

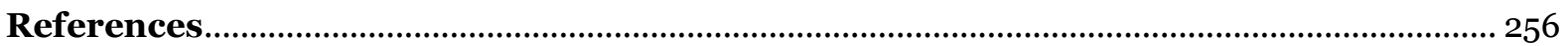




\section{List of Figures}

\section{Chapter 2}

Figure 1. Taves' and Lindahl's Framework of the Contemplative Path..................................................21

Figure 2. Expanded Framework of the Contemplative Path .................................................................. 22

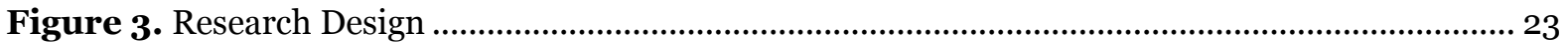

Figure 4. Three-fold Structure of Qualitative Research....................................................................... 29

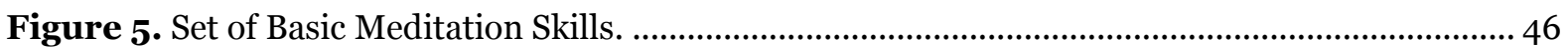

Figure 6. Model of In-Depth, Phenomenological Interviewing.............................................................. 51

Figure 7. Joseph's Practice Sequence .............................................................................................. 71

\section{Chapter 3}

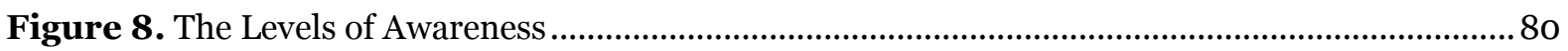

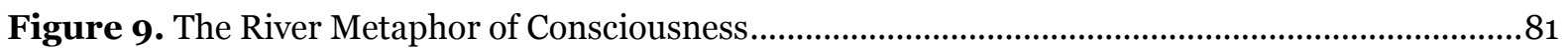

Figure 10. The Shift to God-centred Consciousness ............................................................................. 90

Figure 11. The Keating School Model of the Christian Path ............................................................... 93

Figure 12. Continuum of Effort and Grace (Absorption) ......................................................................101 


\section{Chapter 1}

\section{Introduction}

"Divine presence or "presence" - just call it presence. All presence is divine." ${ }^{1}$

Contemplative forms of religion concern themselves with the experiential underpinnings of their tradition and conceive their specific soteriological goals as transformed states of consciousness for which there is something it is like to undergo them. Religion so lived rests on three axioms: (i) the soteriological goal has phenomenal character, being fundamentally an "experiential" and first-personal affair; (ii) the first-person perspective is the domain where "salvation" or "liberation" happens; (iii) consciousness is the central arena of the spiritual life. Thus Father Thomas Keating, one of the three founders of Centering Prayer, views Christianity as a contemplative religion in which "God looks for experiencers more than theorists." 2

The spiritual life unfolds through progressive states of consciousness that track the practitioner's progress on the contemplative path. ${ }^{3}$ Contemplative traditions concerned with path-oriented practice typically outline a developmental trajectory for the transformation of consciousness and prescribe a system of training to affect required changes to the practitioner's "phenomenal architecture", which is delineated in specific stages. 4 For example, in Pointing Out Way Tibetan Buddhist Mahamudra the stages are referred to as "stages of meditation" and the developmental trajectory outlined traverses "levels of mind". 5 Analogously, in Christian Centering Prayer we find "stages of prayer" and the developmental trajectory outlined covers multiple "levels of awareness". ${ }^{6}$

Since the spiritual life explores consciousness and purportedly uncovers its innate capacities, a vast literature in the philosophy and comparative study of mysticism has debated the metaphysical ("phenomenal") nature of consciousness for over a century.7 This ongoing debate has to date solely relied on textual sources to provide the descriptive

\footnotetext{
${ }^{1}$ Lily, Interview \#33.1, p.2.

${ }^{2}$ Thomas Keating, Reflections on the Unknowable (New York: Lantern Books, 2014), 137.

${ }^{3}$ Nelson Pike, Mystic Union (Ithaca, NY: Cornell University Press, 1992), ix.

${ }^{4}$ I define "phenomenal architecture" in Section 2.2.1 (p.20).

${ }^{5}$ Daniel P. Brown, Pointing Out the Great Way (Boston: Wisdom Publications, 2006), 8-12.

${ }^{6}$ Thomas Keating, Invitation to Love (New York: Boomsbury, 2014), 106; Intimacy with God (Snowmass, Colorado: The Crossroad Publishing Company, 2012), 30.

7 The terms "metaphysical" and "phenomenal" refer to the appearance side of the reality/appearance distinction such that the appearance side pertains to "experience" and how it appears to a subject.
} 
evidence on contemplative states of consciousness. ${ }^{8}$ In general, textual sources are a poor evidential base, for two main reasons.

First, Sharf points out that first-person accounts of contemplative states of consciousness are, against expectations, rare in Buddhist textual sources. 9 There is also a "paucity of personal testimonials" in Buddhist sources, even though "there is no shortage of prescriptive manuals". Furthermore, Sharf warns us that "scriptural materials present daunting philological and hermeneutic difficulties", because of the false assumption held by researchers that such texts present some form of "phenomenological analysis of the experiences" and practices of "meditators". ${ }^{10}$

Second, Pike clarifies that even though first-person accounts are more readily available in the Christian tradition, the "datum passages" are highly problematic, because (i) they are "embedded in contexts in which mystics are less concerned to describe the features of mystical phenomena than to extol the majesty of God", and (ii) where significant passages can be singled out, "the language is heavily metaphorical". ${ }^{11}$ Thus we find in specific examples of Buddhist and Christian textual traditions either a lack of or unreliable firstperson data.

However, first-person data are all important in the philosophy and comparative study of mysticism, because our descriptions of consciousness ("how things appear") have a close relationship to our theories of consciousness for the very fact that what seems to the subject is what that subject's consciousness consists of, namely the appearance quality. Hence theorising about the metaphysical (phenomenal) nature of contemplative states of consciousness proceeds by way of a direct approach to theorising. In a "direct approach", the researcher straightforwardly "reads off" hypotheses directly from the first-person descriptions such that first-person data "provides conclusive or near conclusive evidence in favour of one's hypothesis".12 In this way, first-person data is a "basic" source of evidence in this arena. ${ }^{13}$ This places a lot of weight on the quality and reliability of the evidence.

Scholars and philosophers have by and large: (i) failed to take seriously the role of description in their theorising, precisely because they have frequently blurred the line between descriptive and theoretical work (for the very reason that a close relationship exists

\footnotetext{
${ }^{8}$ Forman is an exception, because he has also relied on "autophenomenology" to provide descriptive evidence. In autophenomenology the theorist is also the informant of the first-person data. I define "autophenomenology" in Section 2.4.1 (p.27).

${ }_{9}^{9}$ Robert H. Sharf, "Buddhist modernism and the rhetoric of meditative experience," Numen 42, no. 3 (1995): 235-36.

${ }^{10}$ Ibid., 232-36.

${ }^{11}$ Pike, Mystic Union, xii.

12 Maja Spener, "Using first-person data about consciousness," Journal of Consciousness Studies 18, no. 1 (2011): 171.

13 "Basic" evidence is does not rely on other sources to be conferred with evidential power. Alvin I. Goldman, "Epistemology and the evidential status of introspective reports," ibid.11, no. 7-8 (2004): 5-6.
} 
between description and theory); and (ii) exercised insufficient rigour in respect to their sources of evidence. This has resulted in little theoretical progress since Stace published Mysticism and Philosophy in 1961, because "descriptions" relied upon in theorising have mostly been passages cited from normative religious texts that lack first-person accounts. The paucity of reliable/rich first-person data in the field has thus resulted in limited theorising. ${ }^{14}$ In this light, I agree with Komjathy that contemplative studies should pursue an alternative approach that focuses on contemporary practices and steers away from "the thorny issue of historical precedents". ${ }^{15}$ This study is a step in this direction.

In 2014, I started a project entitled Contemplative Responses to the Sense of Self, which is a comparative study of contemporary Buddhist and Christian contemplative traditions. I conducted immersive fieldwork and in-depth phenomenological interviews (up to 6 hours per practitioner) with 35 teachers and practitioners across Pointing Out Way Tibetan Buddhist Mahamudra and Christian Centering Prayer traditions. This yielded a database of over 1200 pages of transcripts with over 560,000 words. I originally conceived this project as a comparative study; however, limitations of time and space have meant that my doctoral dissertation will explore some of the material of a single tradition.

In this dissertation, therefore, I present only the phenomenology of Christian Centering Prayer. Specifically, I discuss the beginning and intermediate stages of the contemplative path outlined by this tradition. I have chosen Centering Prayer for two reasons: First, the qualitative data gathered from Centering Prayer contemplatives are most surprising (and possibly upsetting) to received views held by scholars in the philosophy and comparative study of mysticism. Second, Abrahamic traditions have received less attention by the academic community in the field of contemplative studies/science. ${ }^{16}$ Therefore, this study is a corrective to these issues.

Christian Centering Prayer is a challenging case study because it defies many preconceptions of Christian mysticism held by laypeople and scholars alike. Specifically, this contemplative tradition puts into question the received view held by Western scholars in the philosophy and comparative study of mysticism that Christians necessarily experience "union with God" as a face to face encounter with a personal and loving being. But the "Centering Prayer" tradition (henceforth capitalised to indicate the tradition) considers its method nothing new to the Christian contemplative tradition, even though it is presented in

\footnotetext{
${ }^{14}$ For a discussion of why bad descriptive data leads to bad theories, see Maja Spener, "Using first-person data about consciousness," ibid.18, no. 1 (2011): 176.

${ }^{15}$ Louis Komjathy, "Contemplative traditions," in Contemplative Literature, ed. Louis Komjathy (New York, Albany: State University of New York Press, 2015), 78.

16 "Approaching contemplative practice," in Contemplative Literature, ed. Louis Komjathy (New York, Albany: State University of New York Press, 2015), 33, 57.
} 
a new format. ${ }^{17}$ Pennington says, "It is a method that comes from our earliest Christian heritage [and] it has served Christians in all the intervening centuries." 18 Since the 1980 , then, Keating has presented "centering prayer" (henceforth written in lowercase to indicate the practice) in an "updated format" with new terminology, because he believes that people are prejudiced against contemplative prayer through miseducation: many are quickly put off by traditional Christian terminology. 19

The method of "centering prayer" has three Trappist founders who at the time of the method's first formulation in the mid-1970s resided together at St. Joseph's Abbey in Spencer, Massachusetts. Father William Meninger developed the first "how to" method of prayer, which he extrapolated from The Cloud of Unknowing, a Christian mystical and normative text on contemplation that was written in the fourteenth century by an anonymous Englishman. ${ }^{20} \mathrm{He}$ chose to call it "The Prayer of the Cloud". ${ }^{21}$ Meninger began teaching it to priests in the monastery's guest house at St Joseph's Abbey at around 1975. Shortly thereafter, Father Basil Pennington held his first workshop for religious superiors at a large retreat house in Connecticut. ${ }^{22}$ Father Thomas Keating refers to this event as the very first retreat. ${ }^{23}$ Then, in 1981, Keating resigned as Abbot of St Joseph's Abbey and moved his abode to St Benedict's Monastery in Snowmass, where he then experimented with centering prayer in Zen-like retreat settings and eventually began teaching it. ${ }^{24}$

The early period of retreating between 1983 and 1985 lead Keating to publish his first well received written work on his approach to centering prayer. In 1986, the book Open Mind, Open Heart turned out to be his first and seminal publication. Today it remains his most frequently referenced book by other writers on centering prayer and it is still read out loud during "silent" meal times at 10 day intensive retreats in Snowmass. Over the course of Keating's teaching, he adjusted the guidelines of the method of centering prayer. His own guidelines were made available through a pamphlet called The Method of Centering Prayer: The Prayer of Consent and his later book Intimacy with God published in 1994.25

\footnotetext{
${ }^{17}$ Murchadh Ó. Madagáin, Centering Prayer and the Healing of the Unconscious (New York: Lantern Books, 2007), cited ftn. 1, Anne A. Simpkinson, "Resting in God," www.centeringprayer.com/resting.htm.

${ }_{18}$ M. Basil Pennington O.C.S.O., Centered Living (Liguori, Missouri: Liguori/Triumph, 1999), xxv.

${ }^{19}$ Madagáin, Centering Prayer and the Healing of the Unconscious, xvi-xvii.

${ }^{20}$ William Johnston, The Cloud of Unknowing (New York: Image Books, 1996), 5.

${ }^{21}$ Pennington O.C.S.O., Centered Living, 56. See also Gustave Reininger, "The Christian contemplative tradition and Centering Prayer," in Centering Prayer in Daily Life and Ministry, ed. Gustave Reininger (New York: The Continuum Publishing Company, 1998), 40.

22 Pennington O.C.S.O., Centered Living, 57.

${ }^{23}$ Keating, Intimacy with God, xviii.

24 Ibid., xviii-xix.

${ }^{25}$ Keating's four guidelines are quoted as stated in his book Intimacy with God. Ibid., 16.
} 


\begin{abstract}
Rule One
Choose a sacred word as the symbol of your intention or consent to God's presence and action within.
\end{abstract}

\title{
Rule Two
}

Sitting comfortably and with eyes closed, settle briefly and silently introduce the sacred word as the symbol of your consent to God's presence and action within.

\section{Rule Three}

When you become aware of thoughts, return ever so gently to the sacred word.

\section{Rule Four}

At the end of the prayer period, remain in silence with eyes closed for a couple of minutes.

The method as outlined above is not considered contemplative prayer, but a preparation for it. Thus Keating's version of centering prayer outlines a larger system and contemplative path in which centering prayer, strictly speaking, is merely a preliminary practice and initial stage, followed by contemplative prayer and union states as described by St Teresa of Avilá.

Centering Prayer today is more than the three Trappist founders' (i.e, Meninger's, Pennington's and Keating's) thinking on the subject. David Frenette and Cynthia Bourgeault are two of Keating's most notable students, who actively teach and publish guidebooks on centering prayer and the Christian contemplative life. Their work adds important nuance to the practice and expands the groundwork laid by the three founders, especially Keating's thinking on centering prayer and the Christian path.

Frenette should be considered the successor of Keating's spiritual lineage, and his work is endorsed by Keating himself. ${ }^{26}$ Frenette's seminal publication The Path of Centering Prayer clarifies many aspects of the farther reaches of the contemplative journey as conceived by the "Keating School" of Centering Prayer.

Bourgeault's work, on the other hand, has distinguished itself as an independent approach. I refer to it as the "Wisdom School" of Centering Prayer. This school effectively rejects the way that centering prayer has been conceived and communicated by the Keating School, especially the developmental trajectory (the "path") that Keating has presented. Bourgeault believes that Keating draws on misconceptions about the Christian contemplative

\footnotetext{
${ }^{26}$ Father Theodore, Interview \#28, p.24.
} 
tradition and that these misconceptions have led to centering prayer being inadequately adapted for from the Christian heritage.

My intent for this study is to open a new line of thought and provide an alternative to the way we theorise in the philosophy and comparative study of mysticism. Specifically, I intend to shift debate on the metaphysical (phenomenal) nature of contemplative states of consciousness away from textual sources and towards descriptively rich and theoretically relevant first-person data that originate in lived traditions and contemporary practices. To this end, I have chosen to present the Keating School of Centering Prayer, because it stands in closest relationship to classic Christian mysticism and makes for a fascinating and important case study relevant to existing scholarship in the philosophy and comparative study of mysticism.

My primary aim for this study is to offer nuanced phenomenological analyses of the beginning to intermediate stages of the Christian contemplative path as they are described by contemporary centering prayer teachers and practitioners who have actually experienced them firsthand.

I have three secondary aims that address meta-issues in the field. My first, methodological aim is to offer a novel second-person method for collecting first-person data from contemplative practitioners. My second, descriptive aim is to provide an effective framework for developing phenomenological accounts that are descriptively faithful (fit the data), analytically transparent and theoretically useful. My third, theoretical aim is to draw on the phenomenological accounts I have developed in this study to reconsider important theses advanced in the contemporary philosophy and comparative study of mysticism. I will present the material in this study in the same order in which I have listed my secondary aims.

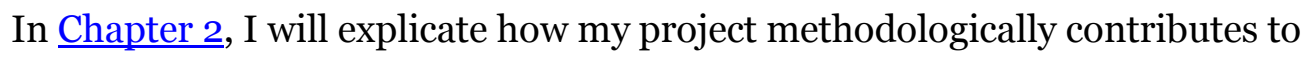
contemplative studies. I will begin by outlining a framework for the comparative study of contemplative traditions and defining the sense in which my study is phenomenological. To this end, I will introduce my own blended approach to phenomenology that consists of three elements: (1) a conceptual framework; (2) a technique for data collection; and (3) a method of analysis. Although I introduce the conceptual framework of this study before discussing the first-person data, this is merely an expository strategy. In this study, I discovered the value of these concepts during data collection, because practitioners pointed this out to me. Thus the concepts discussed are actually in the service of the data and not the other way around. In respect to my method, I will attempt to convince the reader of two things:

First, I aim to show that the method I have developed and applied to collect firstperson data is adequate. By "adequate" I do not mean perfectly executed, but good enough to warrant the conclusion that the way I have gathered data confers stronger evidential power 
on the descriptions I put forward than is possessed by descriptions that have been extracted from normative religious texts, and whose authors and contexts are inaccessible to us.

Second, I aim to show that the data I have obtained is faithful to the first-person perspective of the contemplative practitioners who have participated in this research. By "faithful" I do not mean perfectly accurate or apodictic. Like Hurlburt, I aim for the descriptions to be "nonsubstantially misleading" 27 so that the central features of experience described provide prima facie confirmation of the key arguments I intend to make about the metaphysical (phenomenal) nature of contemplative states of consciousness. ${ }^{28}$ I intend for my conclusions to be strong enough to convince the reader that significant and novel counterevidence is required to overturn my case.

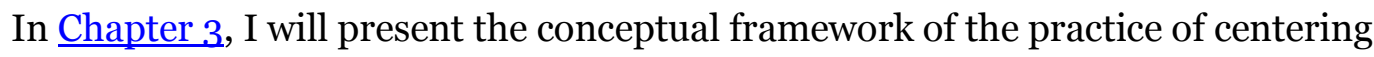
prayer, to lay the groundwork for the phenomenological data and analyses that will follow. I will first clarify that centering prayer is an apophatic and path-oriented contemplative practice, and then outline Centering Prayer's model of human consciousness and selfhood, which is undergirded by the tradition's leitmotif and Sprengmetapher of the "centre". I will then discuss Pennington's account of the soteriological project at work in centering prayer, which transforms consciousness in such a way that God is experientially revealed as pure consciousness. Next, I will synthesise multiple primary sources of the Centering Prayer tradition to present a coherent map of the Christian contemplative path, as conceived by this tradition. Although my expository strategy forces me to present things in this order, the map is grounded in the phenomenological accounts developed in this study and thus subservient to the first-person data I will present and analyse in the chapters that follow. I will conclude with an exposition of how the tradition conceives each stage, from the beginning to final attainment of the soteriological goal identified as "unity consciousness".

The next six chapters serve my descriptive aim. I will present first-person data on the practice of centering prayer and on the stages of the contemplative path as they are traversed in seated prayer. I will conduct phenomenological analyses in front of the readers' eyes and for all to scrutinise. This will yield phenomenological accounts of the beginning (stages one and two) and intermediate (Stage Three) phases of the contemplative path. The stages are: (1) the sacred symbol (by way of the method of centering prayer); (2) spiritual attentiveness; and (3) contemplative prayer (by way of "infused recollection", "prayer of quiet", "prayer of union" and "prayer of full union").

\footnotetext{
${ }^{27}$ The phrase "nonsubstantially misleading" acknowledges the fact that first-person data are never accurate in the absolute sense. Thus the goal is to correctly account for the most important and theoretically relevant features of experience.

${ }^{28}$ Russell Hurlburt and Eric Schwitzgebel, Describing Inner Experience (Cambridge, Massachusetts: The MIT Press, 2007), 155.
} 
More specifically, in $\underline{\text { Chapter } 4}$ I will discuss how practitioners apply the "sacred symbol". In Chapter 5 I will show how practitioners cultivate a "dual-mode awareness" also known as "spiritual attentiveness". In $\underline{\text { Chapter } 6}$ I will consider how the gift of contemplation is first received in minor states of absorption, such as "infused recollection" and "prayer of quiet". I will also examine how the "presence of God" is phenomenally apprehended for the

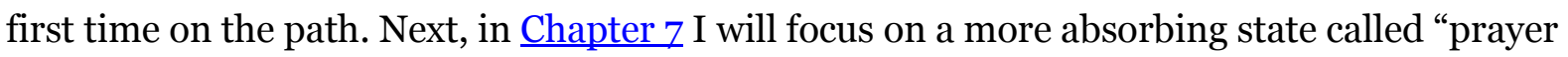
of union" and explicate how the "presence of God" is phenomenally apprehended through a dualistic awareness and by way of a "sense of presence".

In Chapter 8 I will turn to "prayer of full union", which is the zenith of contemplative prayer and so absorbing that practitioners completely lose cognitive access to anything but God as pure consciousness. I will critically assess how lucid ("wakeful”) practitioners are in full union and show that this stage of prayer, whether it is lucid or nonlucid, is not specifically and phenomenologically of the individual God, but of an unidentified reality.

Then, in Chapter 9 I will present and analyse a state of consciousness that I call "world-involving union". It is encountered off the cushion and amidst ordinary, waking life. World-involving union provides a glimpse into how complex union states can be when they occur outside of seated prayer and it is indicative of the type of union states that eventually abide in and outside of seated prayer in the farther reaches of the contemplative path (i.e., Stage Four, "transforming union”, and Stage Five, "unity consciousness").

In Chapter 10, I will draw on the phenomenological accounts developed in the preceding chapters to re-evaluate important theses advanced about the "metaphysical/phenomenal" nature of contemplative states of consciousness. ${ }^{29}$ The first thesis I will consider was formulated by Stace in 1961. He distinguished between "extrovertive" 30 (world-involving) and "introvertive"31 (world-excluding) types of mystical experience and claimed that both are universally experienced across traditions, cultures and time..$^{32}$ Specifically, he considered the introvertive type to be phenomenologically of an unidentified reality and this, he claimed, also obtains for Christian "union states". 33

\footnotetext{
${ }^{29}$ I am guided here by Zahavi's use of the term "metaphysical", which is equivalent to "phenomenal" in the case of consciousness, precisely because the fundamental nature of consciousness is investigated through its appearance. I understand "metaphysics" to pertain to the investigation of the fundamental nature of things and accounting for "what is there" and "what it is like". Given that consciousness is a "phenomenal" matter, discussion about its fundamental nature and what it is like falls into the domain of metaphysics. Dan Zahavi, "The experiential self: Objections and clarifications," in Self, No Self? Perspectives from Analytical, Phenomenological, and Indian Traditions, ed. Mark Siderits, Evan Thompson, and Dan Zahavi (Oxford, New York: Oxford University Press, 2011), 72.

30 I define "extrovertive" types of mystical experience in Section 10.4 (pp.236-238).

31 I define "introvertive" types in Section 10.4 (pp.236-238).

32 Walter T. Stace, Mysticism and Philosophy (London: Macmillian, 1961), 79.

33 Jerome Gellman, "Mysticism and religious experience," in The Oxford Handbook of Philosophy of Religion, ed. William J. Wainwright (New York: Oxford University Press, 2005), 145; Robert K. C. Forman, "Introduction:
} 
The second thesis I will consider is Katz's claim that Christians necessarily experience "union with God" in a way that is phenomenologically of a personal God and as a loving transcendental being. He claims that their experiences must be theistic because practitioners" "premystical" conditions construct it so.34

The third thesis I will re-evaluate is Pike's claim that union states, including full union, are theistic in the sense that they are phenomenologically of the individual God, because they include in the experience an additional, phenomenally apprehended ingredient which he calls the "God-identification element". 35 Thus both Katz and Pike favour a unique theistic experience and thereby attempt to uphold the distinction between theistic and nontheistic experiences.

The fourth thesis I will consider is Forman's claim that "pure consciousness events" 36 exist and that they are coterminous with Stace's introvertive type of mystical experience, being not of anything. Here I will evaluate the relationship between prayer of full union and Forman's pure consciousness event.

I will conclude that my phenomenological accounts of union (Chapter 7) and full union (Chapter 8) show that Centering Prayer practitioners experience union states to be phenomenologically of an unidentified reality. Specifically, they experience God in full union as pure consciousness. According to the Centering Prayer tradition, this is orthodox and denotes a consciousness of God as God is rather than how one might imagine God to be. I will show that Stace's full union is a paradigm instance of his introvertive type and Forman's pure consciousness event. Additionally, world-involving union (Chapter 9) is consistent with Stace's extrovertive type. Finally, since Christians do not necessarily have unique theistic experiences in union, at least not in the sense that Katz and Pike require, there is at least some sense in which contemplatives from different traditions and cultures could have experiences similar in content and structure.

\footnotetext{
Mysticism, constructivism, and forgetting," in The Problem of Pure Consciousness, ed. Robert K. C. Forman (New York: Oxford University Press, 1990), 8.

${ }^{34}$ Steven T. Katz, "General editor's introduction," in Comparative Mysticism, ed. Steven T. Katz (Oxford, New York: Oxford University Press, 2013), 4-8.

35 Pike, Mystic Union, 162.

${ }^{36}$ I define Forman's "pure consciousness event" in Section 10.6 (p.241).
} 


\title{
Chapter 2
}

\section{Theory, Design and Method: Toward Adequate Second-Person Methods in Contemplative Studies}

\author{
"It's hard to see what you are seeing with, to see what being is as an \\ activity through the instrument of whatever-it-is we have being in." ${ }^{37}$ \\ - Robert Hass, "Consciousness" \\ "Contemplative studies as an emerging interdisciplinary field utilises both third-person and critical first- \\ person approaches... the 'third-person'/'first-person' framework fails to include interpersonal, or 'second- \\ person' dimensions." ${ }^{38}$ \\ - Louis Komjathy
}

\subsection{Introduction}

In this chapter I will show how this project contributes to contemplative studies in design and method. I will offer a framework for the comparative study of contemplative traditions and discuss the second-person method I have developed to collect qualitative data.

In Section 2.2 I will present a new framework for comparative analyses. I will then outline the design of this study in Section 2.3. In Section 2.4 I will define the sense in which my study is phenomenological and introduce a blended approach to phenomenology that consists of three elements: (1) a conceptual framework; (2) a technique for data collection; and (3) a method of analysis.

The second half of the chapter will discuss these three elements in more detail. In Section 2.5, I will outline my conceptual framework (module 1). In Section 2.6 I will discuss how I conducted fieldwork with a "radical" participation model to aid the second-person

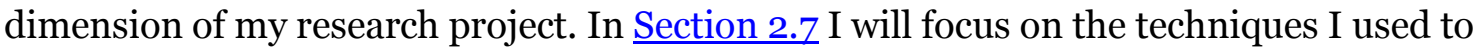
collect data (module 2). I will introduce the Explicitation Interview Technique and Expositional-Style Interviewing. I will then outline the Cyclical Evocation-Analysis Interview Method I have developed to collect rich, high quality descriptions from contemplatives. I will conclude by discussing the advantages, critical realist assumptions and limitations of my method. Finally, in Section 2.8 I will explain my approach to phenomenological analysis (module 3), which makes explicit to recipients of this research the relationship between descriptive evidence and theories developed about the metaphysical (phenomenal) nature of consciousness. I will conclude by summarising the strategies I have employed to validate my analysis.

\footnotetext{
${ }^{37}$ Robert Hass, Time and Materials: Poems 1997-2005 (New York: Ecco, 2007), 85, lines 64-67.

38 Komjathy, "Approaching contemplative practice," 34-35.
} 


\subsection{A New Framework for the Comparative Study of Contemplative Practices and Experiences}

Good comparative research goes beyond its subject and rethinks how to study contemplative traditions. ${ }^{39}$ In this section I will offer a rationale for a new framework. Its purpose is to render information useful for comparison. In the following section, I discuss the limitations of previous comparative studies of Buddhist and Christian traditions and then present my own expanded framework for comparison.

\subsubsection{Previous Comparative Studies of Buddhist and Christian Traditions}

Since 2000 a number of comparative studies of Buddhist and Christian traditions have contributed to developing a framework for comparison. Four, in particular, are noteworthy: Williams' monograph Denying Divinity (2000);40 Cattoi's doctoral thesis "Redeeming the Particular" (2006); ${ }^{41}$ Studstill's monograph The Unity of Mystical Traditions (2005);42 and Lindahl's doctoral thesis "Paths to Luminosity" (2010). 43

Williams's and Cattoi's projects focused their comparison on theological doctrines and concepts of ultimate reality. Studstill, on the other hand, considered the possibility that "what mystics do has as much an impact on the content of experience as what they believe."44 Consequently, he expanded comparison to preparatory practices. Lindahl's work then went a step further by comparing entire contemplative paths.

However, all these works have in common the limitation that they do not use the first-person perspective in their comparisons of contemplative practices, paths and goals. For example, Lindahl's latest work is still "based upon religious texts that do not offer firstperson accounts". 45 Thus most comparative work has to date solely relied on prescriptive,

\footnotetext{
39 Jared Ronald Lindahl, "Paths to luminosity: A comparative study of ascetic and contemplative practices in select tibetan Buddhist and Greek Chrisitan traditions" (PhD Dissertation, University of California Santa Barbara, 2010), 20.

40 J. P. Williams, Denying Divinity: Apophasis in the Patristic Christian and Soto Zen Traditions (Oxford: Oxford University Press, 2000).

${ }^{41}$ Thomas Cattoi, "Redeeming the particular: Maximos the confessor's critique of Oirgenism and the Tibetan debates on practice" (PhD Dissertation, Boston College, 2006).

${ }^{42}$ Randall Studstill, The Unity of Mystical Traditions: The Transformation of Consciousness in Tibetan and German Mysticism (Leiden: Brill, 2005).

${ }^{43}$ Lindahl, "Paths to luminosity: A comparative study of ascetic and contemplative practices in select tibetan Buddhist and Greek Chrisitan traditions."

${ }^{44}$ Studstill, The Unity of Mystical Traditions: The Transformation of Consciousness in Tibetan and German Mysticism, 73.

${ }^{45}$ Lindahl, "Paths to luminosity: A comparative study of ascetic and contemplative practices in select tibetan Buddhist and Greek Chrisitan traditions," 17.
} 
theological and historical texts, which has produced vague presentations of relevant Christian and Buddhist practices. ${ }^{46}$

Nevertheless, "Paths to Luminosity", in particular, has advanced comparative research in three ways. First, Lindahl followed Studstill's example to attend to the structure of the overall contemplative path and to take into account the transformative capacity that various practices have on our "phenomenal architecture". ${ }^{47}$ The term "phenomenal architecture" refers to how experience appears to a subject in respect to its phenomenal structure. This is unlike "cognitive architecture" which refers to fundamental mental processes on a subpersonal (non-experiential) level. Thus Lindahl's and Studstill's works focused on the appearance (what it is like) side of the appearance/reality divide.

Second, Lindahl expanded the framework of comparative inquiry by including early stages of contemplative practice. For example, he considered asceticism - specifically of the senses - as a preparatory regimen to mental training. In this way, Lindahl set up a comparative project that laid out the "structure of the transformative paths" side by side without unduly weighting one specific stage over others. ${ }^{48}$

Third, Lindahl set up a rationale for comparison by adopting Taves' method. Taves' approach stipulates points of analogy that function as intersections where similarities and differences can be explored. 49 Lindahl outlined two points of analogy: (i) the soteriological goals of the contemplative paths; and (ii) the specific practices that the traditions deem efficacious to attain those goals..$^{\circ} \mathrm{He}$ considered the practices critical contact points for comparison..$^{1}$

In sum, "Paths to Luminosity" expanded the framework of comparison, because it (1) took into view the contemplative life as a larger transformative system; (2) included preparatory practices; (3) put forward a rationale for comparison that stipulates two points

\footnotetext{
${ }^{46}$ Lindahl points out that "references to actual practices" in prior work is "often quite vague". Ibid. Unfortunately, his sole reliance on textual sources renders his own work equally vague.

47 Ibid., 18.

48 Ibid., 22. Lindahl relies on arguments made by Gimello and McGinn that mystical consciousness should not be isolated from the contemplative life. Rather, "mysticism" is a larger system within which mystical consciousness plays a specific but not sufficient role. Bernard McGinn, The Foundations of Mysticism (13001500). Vol. I of The Presence of God (New York: The Crossroad Publishing Company, 1991), xvi; Robert M. Gimello, "Mysticism in its contexts," in Mysticism and Religious Traditions, ed. Steven T. Katz (Oxford: Oxford University Press, 1983), 85.

${ }^{49}$ Ann Taves, Religious Experience Reconsidered (Princeton, New Jersey: Princeton University Press, 2011), 122-23; Lindahl, "Paths to luminosity: A comparative study of ascetic and contemplative practices in select tibetan Buddhist and Greek Chrisitan traditions," 27-29, 36-37.

50 "Paths to luminosity: A comparative study of ascetic and contemplative practices in select tibetan Buddhist and Greek Chrisitan traditions," 37-38.

51 lbid., 23.
} 
of analogy (goals and practices) that, together, constitute "path-oriented" 52 contemplative practices.

Despite this accomplishment, Lindahl's attempt to compare entire contemplative paths is unconvincing, because he relies on texts that lack first-person data relevant to two key aspects of his work.53 First, Lindahl aims to outline path structures. But contemplative paths are trajectories of the transformation of consciousness, and, as previously noted, are as such irreducibly first-personal. Normative accounts leave out this vantage point; only the lived vantage point of contemplatives can track the changes to their phenomenal architecture.

Second, Lindahl aims to describe specific practices, but practices are specific to states of consciousness and employed to affect specific changes to those states at particular stages on the path and not others. States of consciousness are also irreducibly first-personal. Therefore, discussion of practice must consider the first-person perspective, because only this provides access to the states of consciousness that make practice intelligible.

\subsubsection{An Expanded Framework for Comparison}

Taves and Lindahl reason that comparative research must set up points of analogy through which similarities and differences can be explored. To this end, they recommend paying attention to the contemplative path. Taves defines "path" as "practices deemed efficacious relative to a goal". ${ }^{44} \mathrm{Her}$ formulation includes two contact points: practices (as normative instructions) and goals (as soteriological concepts) (see Figure 1 below). 55

\section{Path}

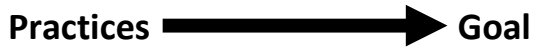

Figure 1. Taves' and Lindahl's Framework of the Contemplative Path

My own framework includes the first-person perspective of practitioners, or simply "experience" in the broadest of senses, as a third point of analogy. Figure 2 expands Taves' and Lindahl's approach. ${ }^{6}$

\footnotetext{
52 Religious Experience Reconsidered, 164; "Paths to luminosity: A comparative study of ascetic and contemplative practices in select tibetan Buddhist and Greek Chrisitan traditions," 38.

${ }^{53}$ Lindahl admits to "a paucity of reliable first-person 'reports of experience' in the literature" he worked with. "Paths to luminosity: A comparative study of ascetic and contemplative practices in select tibetan Buddhist and Greek Chrisitan traditions," 24.

${ }^{54}$ Religious Experience Reconsidered, 164.

55 I have simplified Figure 1 on the basis of Taves' own. Ibid., 141 (Figure 4.3).

56 The figure has been adapted from Corbin and Strauss's Basics of Qualitative Research (Thousand Oaks: Sage Publications, 2007), 99.
} 


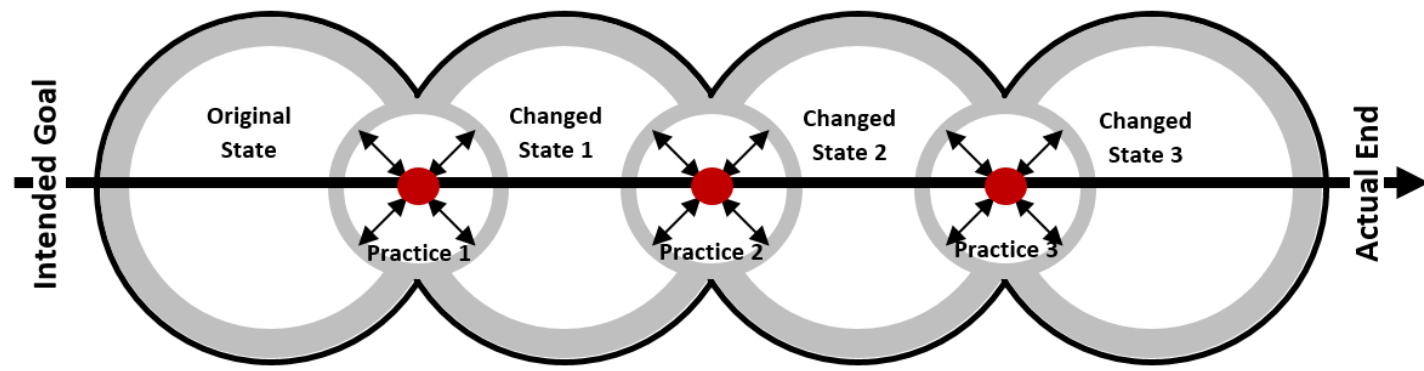

Straight Line $(\longrightarrow)$ : Sequence of evolving interaction of practices with states of consciousness through time Large Circles: $\quad$ States of consciousness (contexts) that practices engage with Red dots (O): $\quad$ Practice (active intervention)

Small Circles: Interaction of practices with states of consciousness that effect changes in those states. The changed states become part of new contexts for practice (conditional states 1-3) in which the next set of interventions are introduced.

Figure 2. Expanded Framework of the Contemplative Path

My framework expands upon Taves' through attending to practices, goals and states of consciousness. I attend to states of consciousness in two ways: First, I attend to the larger developmental trajectory of consciousness that tracks changes to practitioners' phenomenal architecture. Here states of consciousness denote permanent changes that track progress towards the soteriological goal, and they can be identified by way of specific stages on the contemplative path. Each stage has its own characteristic transformation of consciousness, and the transformative stages, in turn, can be used as contact points for comparison, because change takes place in multiple transitions and the sequence in which these occur can be set side by side.

Second, I attend to states of consciousness that unfold during prayer, and show that prayer is an activity that is used to affect specific changes. Here states of consciousness reflect temporary changes to the phenomenal architecture of the practitioner, and are encountered in seated prayer ("on the cushion"), only lasting for the duration of the prayer session. These temporary changes can be delineated into specific stages and illuminate the logic that specific interventions have. The logic of the interventions (practice) and the stages of the practice (states of consciousness) can also be set side by side for comparison.

In this way, my expanded framework of the contemplative path has three contact points for comparison. My rationale for including a third point of analogy (subjectivity) is that practices cannot be described, or their logic understood, without reference to the contexts (states of consciousness) in which they are performed and the changes they either intend to affect, or do affect, in the phenomenal architecture of practitioners.

Since subjectivity is critical to understanding practice, I have opted for a qualitative approach that can collect descriptively rich first-person accounts on all three points of analogy. 


\subsection{Research Design}

My qualitative approach is informed by my rationale for comparative analysis, ${ }^{57}$ which shows that no meaningful comparison of contemplative experiences and practices can take place without taking into account the first-person perspective..$^{8}$ Therefore, my study turns away from approaches that primarily rely on reading texts that appear to be accounts of what religious adepts experience.59 Instead, my study aims to adopt a qualitative method that better "fits the problem". 60

Setting up a comparative study with qualitative design has been very challenging, because we currently lack well-developed second-person methods for this kind of undertaking. ${ }^{61}$ This is true about all aspects of qualitative research, especially methods of data collection and analysis (I discuss this in Section 2.4.2 and Section 2.8.1).

I have responded to this challenge by combining two qualitative approaches to qualitative inquiry (Figure 3).

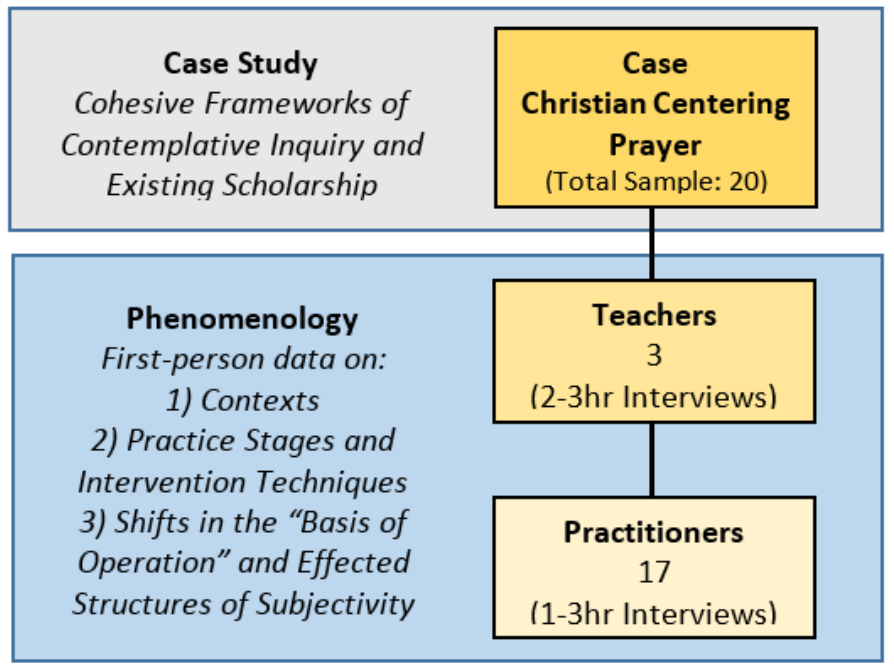

Figure 3. Research Design

\footnotetext{
${ }^{57}$ In my view, theoretical front-loading in no way compromises the exploratory nature of this project. As Corbin and Strauss point out, a solid theoretical grounding in the field of inquiry positively informs research and data analysis. There is also a difference between having an "open mind" during data collection and approaching it with an "empty mind". I agree that "the issue is not whether to use existing knowledge, but how." Ibid., 32-33.

58 I agree with Buehler that theorising about contemplative experiences and practices from the armchair leads to "far-reaching conclusions" that amount to "assertion without data". Arthur F. Buehler, "The twenty-firstcentury study of collective effervescence: Expanding the context of fieldwork," Fieldwork in Religion 7, no. 1 (2012): 78. For a discussion of why scholars need to qualitatively analyse actual experience, see Edith Turner, "The anthropology of experience: The way to teach religion and healing," in Teaching Religion and Healing, ed. Linda Barnes and Ines Talamantez (London: Oxford University Press, 2006), 193.

${ }^{59}$ I am guided here by Gavin Flood, Beyond Phenomenology: Rethinking the Study of Religion (London and New York: Cassell, 1999), 236. See also Komjathy, "Contemplative traditions," 72.

60 John W. Creswell, Qualitative Inquiry and Research Design, 3rd ed. (Thousand Oaks: Sage Publications, 2013), 48.

${ }^{61}$ Buehler, "The twenty-first-century study of collective effervescence: Expanding the context of fieldwork," 92.
} 
The first element in this approach is a case study approach, which treats Christian Centering Prayer as a "cohesive framework"62 of contemplative inquiry. The second element is an in-depth phenomenological approach that, by way of the interview method I have developed, focuses on describing and analysing contemplatives' first-person perspective on the three points of analogy.

My approach to Centering Prayer as a case study follows guidelines from Creswell, Miles and Huberman, and Patton and Flick.63 I pursued within-case, snowball sampling and interviewed 20 practitioners (10 female; mean age 65; average practice experience with current tradition 17 years; average total practice experience 27 years). ${ }^{64}$ My reliance on a case study approach afforded two advantages.

First, it allowed me to map out the territory to be investigated - the data of a single tradition - and I narrowed this territory further by relying on my expanded framework for comparison to provide the rationale for selecting the relevant variables (points of analogy). This combination of a cohesive framework of contemplative inquiry (case study) with a rationale for comparative analysis (points of analogy) "permits an eventual cross-case analysis" in future comparison. ${ }^{65}$

Second, it enabled a context-sensitive inquiry into contemplative practices and experiences. In my view, contemplative traditions as delimited units of analysis provide cohesive and bounded contexts that effectively situate the first-person, phenomenological data. ${ }^{66}$ This further helps data analysis and allows for a conversation between the qualitative data and other sources. Finally, it helps integrate the data with religious studies scholarship. ${ }^{67}$

My approach to phenomenology has been eclectic and creative since I found no preexisting phenomenological approach to qualitative research that would meet my needs. I originally chose a phenomenological approach because I set out to study anticipated changes to the structure of consciousness, and phenomenology was originally conceived for this very

\footnotetext{
62 By "cohesive framework" I mean one specific tradition that is internally consistent and can be clearly distinguished from other traditions. Each of the 20 single cases in my study (the individual practitioners) contribute to this overall "case study" of Christian Centering Prayer.

${ }^{63}$ Creswell, Qualitative Inquiry and Research Design, 97-102; Matthew B. Miles, A. Michael Huberman, and Johnny Saldana, Qualitative Data Analysis (United States: Sage Publications, 2014), 17-37; Michal Quinn Patton, Qualitative Research and Evaluation Methods (United States: Sage Publications, 2002), 230-47; Uwe Flick, An Introduction to Qualitative Research (Edition 5) (Thousand Oaks, California: Sage, 2014), 121; 424-25.

64 Miles, Huberman, and Saldana, Qualitative Data Analysis, 33-34. I overshot Creswell's advice to sample at least 3 to 15 participants for a phenomenological study. Creswell, Qualitative Inquiry and Research Design, 78.

65 Miles, Huberman, and Saldana, Qualitative Data Analysis, 20.

${ }^{66}$ Comparative projects are more promising when they are focused on specific traditions. McGinn, The Foundations of Mysticism (1300-1500). Vol. I of The Presence of God, 339.

${ }^{67}$ Komjathy, "Contemplative traditions," 12-13, 73-74; Miles, Huberman, and Saldana, Qualitative Data Analysis, 28.
} 
purpose ${ }^{68}$ Unfortunately, I did not foresee how serious the problems with phenomenology would be when applied as a second-person method in this domain. I encountered two major challenges.

First, existing phenomenological approaches are focused on interpretation (meaning and hermeneutics) rather than description. ${ }^{69}$ Since my primary concern is to faithfully describe the first-person perspective simpliciter, I rejected all approaches that were associated with the "hermeneutical" school of phenomenology. Instead, I opted for Giorgi's "descriptive" school of phenomenology (Giorgi's approach came with its own problems. I will discuss them further below). $7^{70}$

Second, phenomenology as a philosophy and second-person method has a series of problems (outlined below). I judge the problems to be substantial enough to warrant a new approach. Thus I opted for a blended approach for which I handpicked the best ideas and practices available. My blended approach consists of three elements: (1) a conceptual framework; (2) a technique for data collection; and (3) a method of analysis. Each module represents my effort to respond to the limitations I found with available phenomenological approaches.

For the conceptual framework (module 1), I have moved away from fundamental assumptions of philosophical phenomenology for two key reasons: (i) they are antithetical to the spirit of phenomenology, which is to return to the things themselves; (ii) they render second-person methods unable to investigate the phenomenal architecture of consciousness. I outline my own conceptual framework in Section 2.5.

For data collection (module 2), I have developed a method of interviewing to address the limited data collection protocols in contemporary second-person approaches to phenomenology. From my investigations, available second-person approaches to phenomenology fail to outline a method for data collection, and some are cavalier about how data are obtained. I am specifically referring here to popular and well received approaches in

\footnotetext{
${ }^{68}$ Creswell, Qualitative Inquiry and Research Design, 76-77, 103. Hurlburt and Overgaard believe that phenomenology has a lot to offer in the study of consciousness and that it is reasonable to turn to it when studying experience. Hurlburt and Schwitzgebel, Describing Inner Experience, 296; Morten Overgaard, "On the naturalizing of phenomenology," Phenomenology and the Cognitive Sciences 3, no. 4 (2004): 365. Phenomenology's focus on structure is also useful for discussing contemplative states of consciousness. David Smith Woodruff, "Phenomenology," http://plato.stanford.edu/entries/phenomenology/. Accessed 16th of August, 2010. Specifically, Sections 1 and 2.

${ }^{69}$ For example, van Manen's "hermeneutical phenomenology". Researching Lived Experience, 2nd ed. (Ontario, Canada: The Althouse Press, 1997), xi-xviii, 1-11.

${ }^{70}$ Amedeo Giorgi, Phenomenology and Psychological Research (Pittsburgh, PA: Duquesne University Press, 1985), vii-ix, 1-14. To review the difference between interpretive and descriptive analyses of experience, see The Descriptive Phenomenological Method in Psychology (Pittsburgh, Pennsylvania: Duquesne University Press, 2009), 125-28. Moustakas also discusses the difference between a hermeneutical approach and a descriptive approach to phenomenology with specific comparison of Van Manen's and Giorgi's ideas. Clark Moustakas, Phenomenological Research Methods (Thousand Oaks: Sage Publications, 1994), 8-32.
} 
the field, such as Van Manen, ${ }^{71}$ Moustakas, ${ }^{72}$ and Giorgi. ${ }^{73}$ The results of any phenomenological study are cogent only if the method of qualitative interviewing is

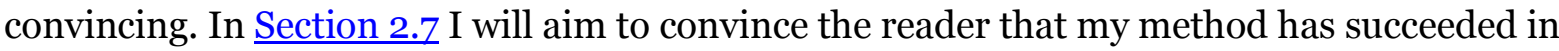
collecting high quality and descriptively rich reports of practitioners' vantage points.

For phenomenological data analysis (module 3), I have attempted to move beyond Giorgi's approach and instead developed a phenomenographically-inspired case study approach to analysis. The latter is a synthesis of practices and ideas extracted from Pike's, Brown's and Albahari's exemplary works in the phenomenology of religion. I discuss Brown's and Albahari's ideas in Section 2.5 and I explain my own approach to analysis in Section 2.8.

\subsection{Revising Phenomenology as a Second-Person Method for Qualitative Research in Contemplative Studies}

Literally, phenomenology investigates "phenomena" (the "appearance of things"). ${ }^{74}$ Today the term "phenomenology" is used in a general and a specific sense. The general sense refers to our conscious experience (=how things appear to us). The specific sense is an umbrella term that stands for a family of philosophical and practical approaches that aim to "give precise and coherent descriptions of events and structures in consciousness" and on their basis theorise about the metaphysical/phenomenal nature of consciousness.75 No single or uniform discipline of phenomenology exists; ${ }^{76}$ there are many versions. ${ }^{77}$ However, most approaches attempt to systematically study experience without losing depth. ${ }^{78}$

My study is phenomenological in both the general and specific sense. In respect to the general sense, my discussion of contemplative states of consciousness focuses on the appearance side of the reality/appearance divide. In respect to the specific sense, I rely on a phenomenological rationale that has been born out of an existing body of phenomenological thought and practice.

\footnotetext{
${ }^{71}$ Van Manen, Researching Lived Experience.

72 Moustakas, Phenomenological Research Methods.

${ }^{73}$ Giorgi, Phenomenology and Psychological Research; The Descriptive Phenomenological Method in Psychology.

${ }^{74}$ Woodruff, "Phenomenology".

75 Overgaard, "On the naturalizing of phenomenology," 365. For a discussion of phenomenology in relation to the appearance/reality distinction, and the implications this relationship has for phenomenology's proper domain of application (i.e., metaphysics), see Zahavi, "The experiential self: Objections and clarifications," 72. ${ }^{76}$ Woodruff, "Phenomenology" Section 1., "What is Phenomenology".

77 Ibid., Section 2., "The Discipline of Phenomenology"; Giorgi, Phenomenology and Psychological Research, 5. No plateau of consensus exists in phenomenology regarding its "proper" interpretation or practice. The Descriptive Phenomenological Method in Psychology, 23-24.

78 Phenomenology and Psychological Research, vii.
} 


\subsubsection{Phenomenology as a Philosophy without First-Person Method}

Many consider Husserl to be the founder of phenomenology as a philosophy. ${ }^{79} \mathrm{He}$ also conceived transcendental phenomenology, which is primarily an effort in self-description. ${ }^{80}$ That said, his phenomenological method was not developed to a point where it could be of substantial use to psychological research. Essentially, Husserl's "method" conists of a collection of suggestions about what attitude to adopt when reflecting on experience. ${ }^{81}$ It has consequently been accused of being a "lone-wolf" type of "autophenomenology". 82

The lone-wolf approach has resulted in philosophers reflecting on their own experience and coming to "understand" experience through a philosophical intuition. ${ }^{83}$ This has confined phenomenological work to philosophers who practice phenomenology logically, first-personally and as a philosophy. ${ }^{84}$ This approach has produced the widely accepted thesis of "intentionality" that holds consciousness to be always directed at objects, ${ }^{85}$ a thesis that was first formulated by Brentano and then appropriated by Husserl. ${ }^{86}$

Intentionality describes how the subjectivity of consciousness (noesis) is directed towards the "othered" (noema) in a way analogous to sense perception. ${ }^{87}$ Contemporary phenomenologists have expanded this thesis by distinguishing between a narrow and a broad sense. Narrow intentionality refers to the vectorial capacity of consciousness. Experiences that are so object-directed are those in which we are typically conscious of something: the object. Thus "object" means "something that stands before us". 88 Broad intentionality, on the other hand, is not defined in terms of object-directedness. Rather, it is defined as an "openness to the world" such that the subject is affected by it, though not straightforwardly directed at it. ${ }^{89}$ Phenomenologists insist that such non-object-directed experiences, too, are intentional, because consciousness remains open to what is other (alterity) and discloses our embeddedness in the world.90

\footnotetext{
79 The Descriptive Phenomenological Method in Psychology, 8-9.

80 Dermot Moran, Introduction to Phenomenology (London and New York: Routledge, 2000), 60.

${ }^{81}$ Giorgi observes that throughout his career, "I could never find someone who could articulate the method for me". The Descriptive Phenomenological Method in Psychology, xii.

82 Daniel Dennett, "Who's On First? Heterophenomenology Explained," Journal of Consciousness Studies 10, no. 9-10 (2003).

${ }^{83}$ Sartre argued that knowing is nothing but an intuition. Moran, Introduction to Phenomenology, 360. Sartre also claimed that "there is only intuitive knowledge" and that "deduction and discursive argument... are only instruments which lead to intuition." Being and Nothingness, trans. H. E. Barnes (New York: Philosophical Library, 1956), 172.

84 Phenomenology and Psychological Research, 44-46.

85 The Descriptive Phenomenological Method in Psychology, 34.

${ }^{86}$ Introduction to Phenomenology, 59.

${ }^{87}$ Edmund Husserl, Logical Investigations I-II, trans. J. N. Findlay (London: Routledge, 2001), 114.

${ }^{88}$ Evan Thompson, Mind in Life (Cambridge: The Belknap Press of Harvard University Press, 2007), 23.

89 Ibid., 316.

90 Ibid., 22.
} 
Contemporary phenomenology as a philosophy remains committed to the universal application of the intentionality thesis. Although intentionality has been broadened to explain a wider range of experiences, it still disallows that contemplatives experience the states of consciousness they report having. For example, a subclass of contemplative states of consciousness called "pure consciousness events" are not intentional in either the narrow or broad sense. ${ }^{91}$ Consequently, I have moved away from phenomenology as a philosophy and bracketed its most fundamental presuppositions, in order, ironically, to remain true to the spirit of phenomenology - to go back to the phenomena themselves and remain "open to all kinds of givenness [experiences] (no matter which ones they are)."92

\subsubsection{Phenomenology as a Second-Person Approach to Qualitative Research}

In the late $20^{\text {th }}$ century, phenomenology developed into a recognised qualitative research method through the works Researching Lived Experience (1997) by Van Manen, the more systematic Phenomenological Research Methods (1994) by Moustakas, and Giorgi's original Phenomenology and Psychological Research (1985), which he later refined in The Descriptive Phenomenological Method in Psychology (2009). 93

These works adapt key ideas of the "phenomenological method" originally developed as a philosophy and "practiced" through self-reliant reflection into a qualitative approach for psychological investigation. 94 Thus dialogical methods are employed to engage the interpersonal domain and obtain descriptions from others. The descriptions are then analysed in a more or less systematic way.

Later works discuss phenomenology as a second-person approach within a postmodern paradigm that views knowledge as constructed. Among those works are Kvale

\footnotetext{
${ }^{91}$ B. Alan Wallace, The Taboo of Subjectivity (New York: Oxford University Press, 2000), 118-20; Mark Wynn, "Towards a broadening of the concept of religious experience: some phenomenological considerations," Religious Studies 45, no. 02 (2009): 147-50; Forman, "Introduction: Mysticism, constructivism, and forgetting," 8; "Introduction: Mystical consciousness, the innate capacity, and the perennial psychology," in The Innate Capacity, ed. Robert K. C. Forman (New York: Oxford University Press, 2004), 24-27; Mysticism, Mind, Consciousness (New York: State University of New York Press, 1999), 11-30; Mark Wynn, "Phenomenology of religion," http://plato.stanford.edu/entries/phenomenology-religion/. Accessed 16th of August, 2010. See esp. Section 1.1. "Religious Experience as Encounter with God". Gellman, "Mysticism and religious experience," 146-52. For a discussion of first-person reports of "pure consciousness events" as evidence for or against the view that consciousness is dependent on the brain, see Evan Thompson, Waking, Dreaming, Being (New York: Columbia University Press, 2015), 89.

92 Anthony J. Steinbock, "Evidence in the Phenomenology of Religious Experience," in The Oxford Handbook of Contemporary Phenomenology, ed. D. Zahavi (UK: Oxford University Press, 2012), 588. Husserl's guiding theme of phenomenology is to go "back to the 'things themselves'". The Crisis of European Sciences and Transcendental Phenomenology, trans. C. Carr Evanston (Evanston, IL: Northwestern University Press, 1970), 252.

${ }^{93}$ Van Manen, Researching Lived Experience; Moustakas, Phenomenological Research Methods; Giorgi, Phenomenology and Psychological Research; The Descriptive Phenomenological Method in Psychology. ${ }^{94}$ Susan Gordon, ed. Neurophenomenology and Its Applications to Psychology(New York: Springer, 2013), xvii.
} 
and Brinkmann's Interviews: Learning the Craft of Qualitative Research Interviewing (2009) and Seidman's Interviewing as Qualitative Research (2013).95

Both the earlier and later works have advanced phenomenology in three ways. First, they have detached their approaches from the meandering style and insider vocabulary of continental philosophy. This has made the new kind of phenomenology more relevant to empirical and psychological research.

Second, third-person ways of handling first-person data have expanded the scope of inquiry. This makes new discoveries about the nature of consciousness more likely, because theorists are no longer the sole source of data for theorising. Now theorists collect firstperson data from an "independent pool of participants" and then subject that data to a thirdperson style analysis approached from an outside point of view ("investigator" in Figure 4 below). ${ }^{96}$ The data collected from others are then used as evidence in theorising. ${ }^{97}$

Third, first-person data used in a third-person way enhances reliability in ways lonewolf autophenomenology cannot. For example, investigators can recruit a large enough sample of subjects to "wash out" inaccuracies in reporting, while also accounting for individual differences..$^{8}$ This strengthens the case that the data are representative of human consciousness in general. 99 Theories built on larger data sets are therefore more powerful than theories that rely on self-description of a single subject who is also the theorist. ${ }^{100}$

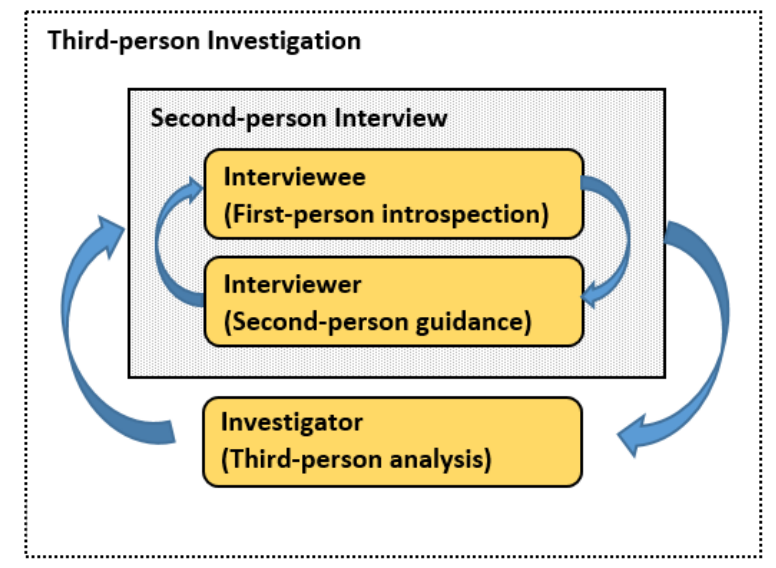

Figure 4. Three-fold Structure of Qualitative Research

\footnotetext{
95 Steiner Kvale and Svend Brinkmann, InterViews, 2nd ed. (US: Los Angeles: Sage Publications, 2009); Irving Seidman, Interviewing as Qualitative Research, 4th ed. (New York: Teachers College Press, 2013).

${ }^{96}$ I have derived this figure with slight adaptation from T. Froese, C. Gould, and A.K. Seth, "Validating and calibrating first- and second-person methods in the science of consciousness," Journal of Consciousness Studies 18, no. 2 (2011): 48.

97 Maja Spener, "Using first-person data about consciousness," ibid., no. 1: 171.

98 Ibid., 172-73.

99 Ibid., 174.

100 Ibid.
} 
Despite providing a rationale for approaching qualitative research with a phenomenological mind-set, earlier and later works often encounter three problems.

First, none of the earlier or later works offer a method for data collection. ${ }^{101}$ Beyond the initial rationale, little attempt is made to translate phenomenology from a philosophy into a sound and practical second-person interviewing technnique, and the second-person aspects are glossed over (the grey zone in Figure 4 above). ${ }^{102}$ Since second-person pragmatics are the biggest threat to validity and the battleground on which the most difficult questions of reliability are settled, the earlier and later works can be seen as being methodologically limited.

Second, earlier and later works accept the thesis of intentionality and analyse raw data in terms of this idea. ${ }^{103}$ In other words, in order for their analysis protocols to function, intentionality must obtain in the data. To date, none of these approaches show awareness that intentionality may extend beyond its narrow formulation, or that, in some cases, it may not obtain at all. These theoretical shortcomings render existing approaches inadequate for the investigation of contemplative states of consciousness, especially since presuppositions cannot be adequately bracketed a priori or a posteriori.

Third, Van Manen's Hermeneutical Phenomenology is too focused on questions of interpretation to meet the descriptive demands placed on the first-person data in this study. ${ }^{104}$ Moustakas' approach also moves too quickly into questions of interpretation, and both give too little attention to description. ${ }^{105}$

Giorgi's Descriptive Phenomenology differs from the above two approaches, because it emphasises description over interpretation. He defines description as "the use of language to articulate... objects". Interpretation, too, articulates objects, but it does so "with the help of some nongiven factor, such as an assumption, hypothesis, theory, or the like". ${ }^{106}$ Giorgi argues that qualitative researchers err when they apply interpretive strategies too soon in

\footnotetext{
${ }^{101}$ Evan Thompson points out that Dennett's heterophenomenology provides no first-person phenomenological procedures to investigate experience and must therefore be judged "phenomenologically incomplete". "Reply to commentaries," ibid., no. 5-6: 192. Unfortunately the same observation can be made about (i) transcendental phenomenology, (ii) Merleau-Ponty's "embodied" phenomenology, and (iii) Varela and Thompson's neurophenomenology.

102 For example, Giorgi's Descriptive Phenomenology assumes descriptions to have been collected through interviewing. He then dedicates only four pages (pp. 121-125) to a few general comments on interviewing. He also deems written reports/descriptions as acceptable (p. 96). However, this conflicts with lessons from consciousness science. Reliable and rich description cannot be obtained this way, because written reports are created without introspective guidance and Socratic-style questioning. Giorgi, The Descriptive Phenomenological Method in Psychology, 96; 121-25.

103 Ibid., 9, 34.

${ }^{104}$ Van Manen, Researching Lived Experience, ix-xviii, 1-13, 77-88.

105 Moustakas, Phenomenological Research Methods, 120.

${ }^{106}$ Giorgi adds "construction" as a third category. He defines it as an act of description that "is not satisfied to stay strictly with the given, but uses imagination or other nongiven factors to either present or account for the objects of experience". Giorgi, The Descriptive Phenomenological Method in Psychology, 89.
} 
analysis, because they distort descriptions by adding nongiven factors. Therefore, researchers who apply interpretive strategies treat descriptions like "texts" even though descriptions lack the features that texts have, which would justify the use of interpretive strategies. ${ }^{107}$

The task of phenomenology is first and foremost description, and descriptive analysis should "not try to go beyond the given". ${ }^{108}$ On this matter I agree with Giorgi and Hurlburt and the lessons from consciousness science: analysis should "neither add nor substract from what is present" in the same way that second-person settings should non-inductively guide informants' introspective processes and reporting. ${ }^{109}$

Giorgi's approach to analysis delays interpretive strategies in favour of descriptive work. It avoids introducing too early in the descriptive process "assumptions, theories, or other nongiven factors". ${ }^{110}$ Thus Giorgi's approach is more successful than the other works I've discussed. However, his protocols for description contain a specific issue that renders his approach unsuitable for my analysis of contemplative practices and experiences. The issue is so specific that I will discuss it in greater detail in Section 2.8.

In sum, earlier and later works that revise phenomenology for qualitative research encounter three limitations: First, they do not have a robust method for data collection; second, they rely on theoretical ideas that prevent researchers in contemplative studies to bracket presuppositions prior to, during and after data collection (and their protocols for data analysis require the data to conform to those presuppositions); third, their methods of analysis adopt interpretive strategies that compromise descriptive work. Although Giorgi's Descriptive Phenomenology provides superior protocols for analysis of descriptions, I encountered a specific problem that I will revisit in $\underline{\text { Section } 2.8}$.

To conclude, for this study I have turned away from recognised qualitative approaches to phenomenology. In their place, I have adopted a blended approach to phenomenology that consists of three elements: (i) a conceptual framework; (ii) a technique for data collection, and (iii) a method of analysis. I will discuss the modules in Section 2.5,

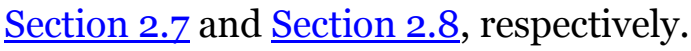

\footnotetext{
107 Ibid.

108 Ibid., 127.

${ }^{109}$ Giorgi believes that phenomenology's accountability lies in "the exhibition of the given". Ibid., 89. For a discussion of non-inductive second-person guidance, see Pierre Vermersch, "Describing the practice of introspection," Journal of Consciousness Studies 16, no. 10-1 (2009): 23.

${ }^{110}$ Giorgi, The Descriptive Phenomenological Method in Psychology, 127.
} 


\subsection{Conceptual Framework}

In this section I will draw on the thinkers in whose footsteps I follow in order to outline the specific set of phenomenological ideas I use to conceptually inform this study (module 1). ${ }^{111}$ The main exemplary works I have drawn from are: (i) Hurlburt's study of “inner experience" in consciousness science; ${ }^{112}$ (ii) Albahari's and Brown's analytical approaches to Buddhist phenomenology; ${ }^{113}$ and (iii) Pike's phenomenography of Christian mysticism. ${ }^{114}$

\subsubsection{Experience}

I use the term "experience" to refer to what subjects phenomenally live through. By "phenomenal" I mean that it has appearance quality. There is something it is like to undergo it. ${ }^{115}$ "Experience" is coterminous with "conscious experience" 116 and "consciousness" because it is phenomenally apprehended. ${ }^{117}$

The term "conscious" may suggest we are meta-cognitively conscious of our experience, or somehow self-aware in a "self-observational way". ${ }^{118}$ I do not necessarily indicate this. My definition of experience may refer to first-order lived-through phenomenal life where "feelings are felt" and "objects seen", or to the same experiences when they are lived-through by way of a second-order state (I define "state" below). Whenever secondorder conscious states are discussed, I will qualify the term experience as "second-order", "self-aware", "metacognitive" or "meta aware".

In this project, I use the term "experience" in the broadest sense, and to subsume all possible modes of "phenomenal apprehending" and all "species of conscious experiencing"

\footnotetext{
${ }^{111}$ I am guided here by Giorgi's view that it is not really possible to provide a "comprehensive yet precise definition of phenomenology" and that creating a framework for phenomenological inquiry does not require one to "straighten out the phenomenological movement", but to clarify the sense in which ones framework is phenomenological. My own approach originates in a specific body of work that can be located in the family of approaches broadly conceived as phenomenological. Ibid., 8.

112 Hurlburt and Schwitzgebel, Describing Inner Experience.

${ }^{113}$ Miri Albahari, Analytical Buddhism (New York: Palgrave Macmillan, 2006); Brown, Pointing Out the Great Way.

${ }^{114}$ Pike, Mystic Union.

${ }^{115}$ My definition of experience is synonymous with Block's definition of phenomenal consciousness, which is "what it is like for a subject to have an experience." Ned Block, "Perceptual consciousness overflows cognitive access," Trends in Cognitive Sciences 15, no. 12 (2011): 567. Albahari defines "phenomenal" as "something it is like to be undergoing the apprehension". Analytical Buddhism, 7-8.

${ }^{116}$ For a discussion of the concept of "conscious experience" and its relation to phenomenal consciousness that accords with my own position, see Analytical Buddhism, 90.

${ }^{117}$ I use the terms "experience" and "consciousness" in the same way Albahari uses the terms "witnessing" and "witness-consciousness". For our purposes those terms cover all possible "modes of apprehension". This excludes non-phenomenal types of cognition and processes, like subpersonal information processing. Ibid., 78.

${ }^{118}$ Describing Inner Experience, 15.
} 
whether accompanied by content or not; attentive or inattentive; lived-through as first-order states or by way of higher-order states. ${ }^{119}$

\subsubsection{The Structure of Experience}

I consider experience for the most part to have a subject-side and object-side. This is not a restatement of the intentionality thesis, because it relies on Edey's pre-theoretical formulation of "subject" and "object" that allows for nuances that classic phenomenological thought does not. ${ }^{120}$ Thus, "object" shall "refer to anything anyone might be aware of or pay attention to"; its metaphysical status is irrelevant. ${ }^{121}$ What is important is that, from an experiential perspective, it is anything that may be an object of attention or that could "pass in and out of awareness", including any discernible conditions or processes. "Subject" shall refer to the experiential "I" that is aware of objects, directs attention and that can distinguish itself from what it attends to. ${ }^{122}$

This distinction is not conceptual but experiential ("pre-theoretic"). Whenever the "I" is aware of an object, or directs its attention towards something, this "I" easily distinguishes itself from whatever it attends to. The "I" spontaneously and pre-theoretically knows this. As Edey points out, "You can distinguish yourself as subject from any object whatsoever ("physical" or "mental") any time you direct your attention to that object and realise that it is you who are aware and who pay attention, not the object.” Therefore, no special epistemic feats are required to "know which is obviously which". ${ }^{123}$

\subsubsection{Subject}

I will now turn to Albahari's phenomenological ideas on "subject" and "object" to expand on Edey's pre-theoretical formulation. Albahari's analysis suggests that the subject-side of experience is constituted by two important pre-theoretical (experiential) facts. Those are the "modus operandi" and the "perspective-creating locus". ${ }^{24}$

Albahari defines the modus operandi as our "realised capacity to observe, know, witness and be consciously aware". ${ }^{125}$ She also calls it "witnessing" or "witness-

\footnotetext{
119 I construe "experience" in Albahari's minimal sense of "witnessing", which she identifies as the "broadest mode of phenomenal apprehending". Albahari, Analytical Buddhism, 8.

${ }^{120}$ Mait Edey, "Subject and object," Journal of Consciousness Studies 4, no. 5/6 (1997). Online version (slightly different) at http://imprint.co.uk/online/edey.html

${ }^{121}$ Albahari, Analytical Buddhism, 6-7. Citing Edey, "Subject and object."

122 Albahari, Analytical Buddhism, 6-7.

123 Ibid.

${ }^{124}$ My discussion here follows Albahari very closely. Ibid., 7-8.

125 Ibid., 7.
} 
consciousness". These are umbrella terms for the "broadest mode of phenomenal apprehending”, and by "phenomenal apprehending” Albahari means two things. First, "phenomenal" means "there is something it is like to be undergoing apprehension". It is experientially lived-through. Second, "apprehension" refers to the "percipient" and "knowing" aspect; apprehension enables us to know we are perceiving some object or hearing a sound. ${ }^{126}$ I interpret Albahari's term "know" to capture how experience presents itself in an obvious and identifiably phenomenal way and by way of a first-order state "knowing" does not imply that experience is in some epistemically special way self-aware in a second-order or self-observational sense. ${ }^{127}$ In sum, "witnessing" identifies the consciousmaking feature of our subjectivity, and it is the "realised capacity" to "be consciously aware". This realised capacity is present in "all species of conscious experiencing" no matter what its mode is (e.g., thinking, feeling, perceiving, introspecting, etc.).

According to Albahari, witnessing can be realised in different ways. For example, witnessing can be "attentive" or "inattentive". Attentive witnessing points our conscious awareness towards objects, whereas inattentive witnessing diffuses conscious awareness. The former has a focal point; the latter holds objects in a peripheral awareness. ${ }^{128}$

In classic phenomenology, attentive witnessing is considered "thematic", which means that whatever is being spoken about is the theme of a subject's conscious experience. The theme is the focus and foreground of conscious attention. ${ }^{129}$ By contrast, inattentive witnessing is "nonthematic". This captures the way we are immersed in, and open to, the world as the implicit context of our living and acting; inattentive witnessing is the background that frames whatever we focus our attention on. ${ }^{130}$ The attentive (thematic)/inattentive (nonthematic) distinction is related to narrow and broad intentionality. In narrow intentionality consciousness is directed at an object through a subject-object structure. In broad intentionality consciousness is open to alterity, and this openness allows experience to be informed by what is not the immediate focus of consciousness. ${ }^{131}$

Albahari's pre-theoretical formulation of "subject" is more nuanced than classic phenomenological thinking, because it allows for the modus operandi of witnessing to occur

\footnotetext{
${ }^{126}$ Ibid., 8.

${ }^{127}$ For a discussion of the epistemic sense of awareness, see Hurlburt and Schwitzgebel, Describing Inner Experience, 15-74.

${ }^{128}$ Albahari, Analytical Buddhism, 8.

129 Thompson, Mind in Life, 22.

130 Husserl, The Crisis of European Sciences and Transcendental Phenomenology, 281.

${ }^{131}$ The distinction between attentive and inattentive witnessing is related to current debates in consciousness science on whether experience is "rich" or "thin". Hurlburt and Schwitzgebel, Describing Inner Experience, 74, $134,228$.
} 
without intentionality. To clarify how this is possible, I will now discuss Albahari's second experiential fact that constitutes a subject: the perspective-creating locus.

Albahari defines the perspective-creating locus as the spatio-temporal perspective that lends our modus operandi (witnessing) a point of view. It adds to our realised capacity to be aware of the feature that we are conscious from somewhere, and enables the subject side of experience to stand in relation to objects. When witnessing and perspective come together, Albahari admits a subject. She says: "A subject is hence defined as witnessing as it presents from a... perspective". ${ }^{132}$ I will call this feature "witnessing-from-a-perspective", "witnessing-perspective" or "perspectival witnessing". ${ }^{133}$

Perspectival witnessing is necessarily instantiated spatio-temporally, but may or may not be instantiated psycho-physically. For example, when dreaming, the witnessingperspective of the "self-as-dreamer" is psychologically and mentally but not physically instantiated from a pre-theoretical (experiential) perspective. ${ }^{134}$ The self-as-dreamer does not experience her perspective to be pre-reflectively realised by a physical body, but her perspective will be realised by way of a spatial relation and flow of time. In this state, successive moments of experiencing are witnessed from a spatio-temporal null-point of orientation.

We are now in a position to discuss witnessing without intentionality. Albahari's pretheoretical model of the subject - which combines our realised capacity to be consciously aware (modus operandi) with a spatio-temporal null-point of orientation (perspectivelending locus) - allows for the possibility that these constituents come apart. Albahari calls this "pure witnessing" or "objectless, aperspectival witnessing". ${ }^{135}$ In pure witnessing, conscious awareness is neither funnelled through a null-point of orientation nor has objects; witnessing occurs "without the perspectival confines necessary for a subject". ${ }^{136}$ Therefore, witnessing does not require a subject. For this reason Albahari calls pure witnessing also "pure subjectless witnessing”.

Albahari's pre-theoretical - hence properly phenomenological - model is very important for this study. It allows me to collect first-person data and theorise about the structure of consciousness in ways that "does not prematurely rule out" Centering Prayer's view on consciousness. ${ }^{137}$ In my view, Albahari's work is faithful to the contemplative dimension of her sources, which (i) implicitly construe witness-consciousness in a way that does not require it to have a spatio-temporal perspective, and (ii) considers witnessing-

\footnotetext{
132 Albahari, Analytical Buddhism, 8.

133 Ibid.

134 Thompson, Waking, Dreaming, Being, 109.

${ }^{135}$ Albahari, Analytical Buddhism, 8-9.

136 Ibid.

137 Ibid., 9.
} 
without-a-perspective (and without objects) "to be a genuine psychological possibility" realised by way of contemplative practice. ${ }^{138}$ In sum, I judge Albahari's phenomenological model to be faithful to the contemplative tradition I have set out to study.

\subsubsection{Object}

Albahari's analysis suggests the object-side of experience is pre-theoretically anything that perspectival witnessing can possibly attend to. "Attention" is the capacity to modulate the structure of conscious awareness from a diffuse openness (broad intentionality) to a focused gaze (narrow intentionality) that thematically apprehends a specific aspect in the field of experience. ${ }^{139}$ Aspects of experience that fall within the purview of diffuse awareness (inattentive witnessing) still count as objects, because those aspects could be attended to by focusing conscious awareness. The fundamental idea of the object, then, is something that can be attended to in such a way that the subject apprehends the object as decidedly separate from itself. ${ }^{140}$

The subject in the capacity of perspectival witnessing cannot itself become the object of its own attention. Thus the subject is marked by "elusiveness" because it remains forever outside of its own attentive purview. ${ }^{141}$ This does not entail that a subject cannot ever become aware of itself. If cognitive access is restricted to subject-object structured types of attention, then the subject can never become acquainted with itself, but if cognitive access is conceived in a broader sense, then it is possible for the subject to become "inattentively aware of itself". ${ }^{142}$ In this study, practitioners claim to have/report having cognitive access to contemplative states of consciousness through a non-object directed type of phenomenal acquaintance. In sum, for the purpose of this study I assume that elusiveness is a pretheoretical fact that accompanies object-directed types of reflection. I further assume that object-directed types of reflection do not exhaust the capacities of awareness, so that it can become acquainted with itself in a non-objectifying way. ${ }^{143}$

\footnotetext{
138 Ibid., 9-10.

${ }^{139}$ For a discussion of attention as a mental factor that focuses consciousness in the narrow sense of intentionality, see Thompson, Waking, Dreaming, Being, 38.

${ }^{140}$ Albahari, Analytical Buddhism, 10-11.

141 Ibid., 11-12, 146-47.

142 Ibid., 12.

143 I have expanded cognitive access through a "theory of disclosing" in my Master's thesis. Chapter 5, "SelfAwareness: First-Person Methodologies and the Theory of Disclosing" in Benno A. Blaschke, "The contemplative mind and life: First-person methods and the challenge of pure consciousness and phenomenal selfhood for the "neurophenomenological" research program" (Victoria University of Wellington, 2011), 11836. My theory of disclosing responds to the "object-knowledge thesis" that is endemic to Western philosophy and unchallenged. This thesis rules out capacities of consciousness uncovered by contemplative practice.

Analytical Buddhism, 167.
} 
In respect of self-consciousness, it is helpful to distinguish between the "self-assubject" and the "self-as-object". Gallagher defines the self-as-subject as "the one who is doing the reflecting" and the self-as-object as "the self that is reflected on or referred to". ${ }^{144}$ Legrand defines the self-as-subject as pre-reflective self-consciousness, which is more fundamental than object-consciousness, which can take as its object the self. In this case, object-directed reflection reveals the self-as-object and the self-as-subject is implicitly present as the subject who performs this act. 145 This, too, shows that the subject-side of experience is marked by elusiveness.

The distinction between self-as-subject and self-as-object helps us locate the subject in the right place, and I will revisit it when I discuss dreaming as an analogy for the way contemplatives navigate levels of awareness. For example, we can now identify the self-asdreamer as the self-as-subject and distinguish it from the self-within-the-dream (the dream ego or body), which is the self-as-object. ${ }^{146}$

\subsubsection{Subject and Object in Contemplative Traditions}

Albahari's framework enables us to engage contemplatives about witnessing in a way faithful to their vantage point. In this study, contemplatives by and large conceive witnessing as something that is psychologically and metaphysically basic and not a function of something else, like a subject. ${ }^{147}$ Consequently, where appropriate, I follow Albahari's lead to identify each pole of the divide as either the "subject-side" or the "object-side" of experience.

Reference to the "subject-side" does not posit a subject.

Describing contemplative states of consciousness requires description of both the subject- and object-side of experience. Since the subject-side (matters of self-awareness and state-awareness) is always present, whether contemplative traditions discuss "dualistic" or "nondualistic" structures of consciousness, it must be pointed out and accounted for. This poses two major challenges for this project. First, it is "naturally difficult to convey a phenomenal, subjective character that does not pertain to objects". ${ }^{148}$ Second, language of classic phenomenology is ill-equipped for this challenge, because it "is generally devoted to describing objects of experience". ${ }^{149}$ Therefore, technical language for description must be found elsewhere.

\footnotetext{
${ }^{144}$ K. Vogeley and S. Gallagher, "Self in the brain," in The Oxford Handbook of THE SELF, ed. Shaun Gallagher (Oxford, New York: Oxford University Press, 2011), 128.

145 Dorothée Legrand, "Pre-reflective self-as-subject from experiential and empirical perspectives," Consciousness and Cognition 16, no. 3 (2007): 583-87.

146 Thompson, Waking, Dreaming, Being, 109.

${ }^{147}$ Albahari, Analytical Buddhism, 10.

148 Ibid., 143.

149 Ibid.
} 
I will now discuss two alternative conceptual frameworks that apply subject- and object-side type analyses relevant to Centering Prayer. The first is Brown's system, which is rooted in Tibetan Buddhist meditative practice. The second is Pike's approach, which is grounded in Christian contemplative prayer.

In Pointing Out the Great Way, Brown put forward a framework to describe and analyse stages of meditation that accounts for the subject- and object-side of experience. This framework is also used in instruction protocols of Pointing Out Way Mahamudra practices. In "Differentiating Phenomena from Identity in Religious and Meditative Experience," Brown's student Dustin DiPerna extended this framework to religious experiences in general.

Brown inherited his conceptual framework from Denmo Locho Rinpoche, once abbot of Namgyal Monastery in Dharamsala, India, and later head of the dGe Lugs pa lineage (the Dalai Lama's lineage). ${ }^{150}$ The framework differentiates the subject-side from the object-side of experience. Although this is no news to classic phenomenology, its application to describing and analysing contemplative states of consciousness is new. Specifically, it was then novel for scholarship to undertake subject- and object-side type analyses of contemplative states that is sensitive to those states operating at different levels of awareness (I discuss "levels" below) and specific to different stages of meditation, and this still remains a rare (though effective) analytical strategy today.

Brown translated the framework he received into English and used the term "mindperspective" to refer to the subject-side and "event-perspective" to refer to the object-side. ${ }^{151}$ Most Pointing Out Way Mahamudra practitioners and teachers today refer to the subjectside of experience as the "awareness-perspective"; they use the term "awareness" rather than "mind" because they deem the former less metaphysically laden and more faithful to experience. Overall, Mahamudra practitioners and teachers who have extensive practice backgrounds in other traditions view this framework as highly effective for the purpose of describing their experience. For example, Patricia, a teacher of Pointing Out Way, told me:

\footnotetext{
[Pointing Out Way] is much clearer how it works [because you] have an awarenessperspective and an event-perspective: I found it very helpful, and the idea of levels of awareness was very helpful. It was as though it gave a context for a lot of what I had already experienced, but hadn't had a way of conceptualising, which hadn't stopped it from being meaningful, but it was harder to communicate to others. I was teaching [Theravada] and I didn't find it easy to teach in a way that helped others... When I got to
}

\footnotetext{
${ }^{150}$ Dustin DiPerna, "Differentiating phenomena from identity in religious and meditative experience" (Master's Thesis, Harvard University, 2012), vi.

${ }^{151}$ Brown, Pointing Out the Great Way, 154-55, 235, 38, 87.
} 
understand the [Pointing Out Way] system, I found that it was pretty easy to teach. The people that I taught seemed to do well. ${ }^{152}$

Brown's treatment of "awareness-perspective" and "mind-perspective" aligns with Albahari's analysis of subject-side and object-side. Thus Albahari's modus operandi (witnessing) and perspective-creating locus together constitute the awareness-perspective. DiPerna suggests that awareness-perspective describes "the subjective sense of where awareness is coming from". ${ }^{153}$ Brown describes it as the "observational perspective", "point of observation" or "vantage point". ${ }^{154}$ DiPerna adds the terms "sense of self" (as in self-assubject), "identity" and "awareness" to refer to this "locus of awareness" that "observes the events of religious and/or meditative experience". ${ }^{155}$

Brown describes the event-perspective as the "appearances", "objects" or "mental continuum's content". He also speaks of "activity", "movement" and "cognitions" that pertain to various types of content that changes at different levels of awareness. ${ }^{156}$ DiPerna refers to the correlation of specific types of content with respective levels of awareness as "changes in phenomena" or "changes in the field of experience". ${ }^{157}$ Both phrases refer to the object-side of experience or event-perspective. They indicate how things, objects and the field of experience appear to the subject (awareness-perspective).

The second conceptual framework that applies a subject- and object-side type of phenomenological analysis to contemplative states of consciousness is Pike's exemplary work on Christian mysticism, Mystic Union. Pike analyses St Teresa's stages of mystical prayer in a way that clearly distinguishes the subject-side from the object-side. He also tracks relevant changes to each side as the "states of mystic union" unfold. ${ }^{158}$

Teresa used the term "soul" in two different ways to distinguish between the objectside and subject-side. Pike coined the terms "soul*" and "soul+" to identify each side of the divide and organise Teresa's thinking. First, Pike defined "soul" as a "region" or "domain" to account for Teresa's "interior world" or "abiding place". ${ }^{159}$ These terms are location concepts that point to the "field of experience" or exterior horizon that the awareness-perspective stands in relation to. Hence soul* is the object-side of spiritual experience. In soul* we

\footnotetext{
152 Patricia, Interview \#17.1, pp. 19-20.

153 DiPerna, "Differentiating phenomena from identity in religious and meditative experience," 7.

154 Pointing Out the Great Way, 14-15.

155 "Differentiating phenomena from identity in religious and meditative experience," 7.

156 Pointing Out the Great Way, 14-15, 155, 235-40.

157 "Differentiating phenomena from identity in religious and meditative experience."

158 Pike, Mystic Union, ix.

159 Ibid., 6.
} 
encounter “objects", which may be "noncorporeal” or "spiritual”, such as God's presence (i.e., "God in his Divinity"). ${ }^{160}$

Second, Pike defines soul ${ }^{+}$as the "entity", the "substance of the soul" or "the self". It is that which thinks and perceives. ${ }^{161}$ Teresa used the terms "spiritual eyes" and "eyes of the soul", and Pike likewise refers to it as the "mind's eye". ${ }^{162}$ Soul+ is the place where "being aware" takes place. Although Pike's treatment has ontological connotations in respect to the existence of a self - he seems to imply that there is a substantial subject who performs the functions of being aware, thinking and perceiving, etc. - his demarcation holds pretheoretically, no matter how we conceive of the subject metaphysically.

In respect to the subject-side, "Soul+ is also within soul*."163 As the practitioner progresses through the "higher" stages of prayer, soul ${ }^{+}$(subject-side) penetrates the domain of soul* (object-side). In this way, soul* is the region (object-side) that the mind's eye of the practitioner stands in relation to. Pike goes on to analyse how soul ${ }^{+}$and soul* are structurally related at different stages of prayer.

In sum, Mystic Union is a case study in the phenomenology of Christian mysticism that shows how useful it is to apply a subject-side/object-side type of analysis to contemplative states of consciousness, and the value is not restricted to Buddhist traditions. Therefore, I have assimilated Albahari's, Brown's and Pike's approaches to phenomenological description and analysis. In this study, I use the phrases "awarenessperspective"/"subject-side" and "event-perspective"/"object-side" to track the structure of consciousness. This analytical strategy will carry us through the levels of awareness that accompany the stages of prayer outlined by Centering Prayer tradition.

\subsubsection{Awareness as more Fundamental than Consciousness}

I will now draw on Albahari's ideas to connect "awareness" with "phenomenal character" and "sense of presence". This will lay the groundwork for clarifying what contemplatives mean to describe by the term "presence".

Albahari defines "awareness" as "witnessing-consciousness with an intrinsic phenomenal character". ${ }^{64}$ By "intrinsic phenomenal character" Albahari means that witnessing has "a subjective character of its own that it brings to all conscious experience". ${ }^{165}$

\footnotetext{
160 Ibid., 4.

161 Ibid., 6.

162 Ibid., 4.

163 Ibid., 7.

${ }^{164}$ Albahari, Analytical Buddhism, 142. "Witness-consciousness: Its definition, appearance and reality," Journal of Consciousness Studies 16, no. 1 (2009): 63.

${ }^{165}$ Analytical Buddhism, 142.
} 
Hence the modus operandi - our realised capacity to be aware - is not derived from anything else, such as objects. Our conscious-making feature originates in the subject-side of experience.

This view stands in opposition to mainstream concepts of consciousness. ${ }^{166}$ In contemporary philosophy of mind, the phenomenal quality of consciousness is derived from and exhausted by objects. Albahari calls this view "phenomenal object consciousness" ${ }^{167}$ This view rules out the possibility that awareness qua witnessing with phenomenal character can occur without a perspective and objects, because phenomenal character (what it is like to be "aware simpliciter") is non-existent without objects. ${ }^{168}$

Albahari's framework stands against contemporary philosophy of mind, because it allows awareness to have intrinsic phenomenal character and to originate in the subject-side of the subject/object divide. Albahari calls this feature our modus operandi. ${ }^{169}$ This feature may or may not be coupled with a perspective. In cases where witnessing is perspectival, awareness is either attentive (directed to objects) or inattentive (non-directionally open and affected by a world). In either case, awareness is more fundamental than attention. ${ }^{170}$

When witnessing is aperspectival, awareness persists with phenomenal character and without consciousness of objects (attentive) or a world (inattentive). It is therefore a key distinction for this study that "consciousness" will be used to mean awareness in its intentional mode, be it narrow (attentive) or broad (inattentive); while "awareness", in contrast, can persist without intentional mode. This gives awareness qua witnessing a more fundamental status than consciousness.

In this study, "consciousness" and "awareness" may refer to witnessing funnelled through a perspective. But only the term "awareness" will refer to aperspectival witnessing with phenomenal character. When awareness refers to this latter, non-traditional and more fundamental sense of witnessing, I will prefix awareness with "pure" or "bare"; sometimes I will suffix awareness with "simpliciter", "only" or "itself". Should I use the term "consciousness", I will prefix it with "pure" or suffix it with "only".

\footnotetext{
166 Ibid., 144, 67.

167 Ibid., 147.

168 Ibid., 142.

169 Albahari's modus operandi is equivalent to Damasio's "proto self". His proto self is an unqualified sense of sheer existing that Damasio also describes as the "sense of one's own existence" (p. 165) and the "sense of pure existence" (p. 262). This deeper sense of presence exists "independently of any object with which it interacts" and denotes a "solid, wordless affirmation that I am alive" (p. 185; see also p. 101). It is only later in Damasio's neurobiological model of consciousness that a perspective is built on top of the proto self (pp. 185, 196). Therefore, aperspectival awareness (the felt-presence of existence) is more fundamental than perspectival awareness and any consciousness of objects. Self Comes to Mind (New York: Pantheon Books, 2010), 180-210.

${ }^{170}$ Analytical Buddhism, 143.
} 
Finally, "awareness" is also linked to the "sense of presence". Albahari lists thinkers from both East and West that have referred to aperspectival awareness as "conscious presence", "subjective sense of our existence", "lively sense of presence" and "background hum", and so on. Albahari calls this "background phenomenology" of experience "the subjective sense of presence" or simply "presence". This "sense of presence” is Albahari's (and this study's) core concept of awareness. First, it qualifies witnessing as an intrinsic capacity of the "subject" or subject-side of experience. ${ }^{171}$ Second, it locates in witnessing the origin of our sense that experience is unbroken from moment to moment. ${ }^{172}$ Third, it confers to our subjectivity “a 'positive' lived dimension". ${ }^{173}$

\subsubsection{The Sense of Self, Identification and Boundedness}

I follow Albahari's example to distinguish between "self" and "sense of self" ${ }^{174}$ "Self" shall refer to an enduring subject that is unified over time and has an unchanged identity. This notion is ontological because it implies that a "substantial" entity exists, has qualities and performs certain functions, such as witnessing, perceiving, thinking, and so on.

In this project, I bracket ontological questions about the existence of the self, because they do not address the pre-theoretical domain of our immediate experience. I also refrain from using the term "subject" in this strong sense. I consider it one thing to talk about having a "sense of self" in experience and an entirely different one to discuss the ontology of the self. Therefore, I steer clear from questions of "epistemic ascent" that concern how we move from appearance to reality. This project is uninterested in this; what I am concerned with is the appearance side of the appearance/reality distinction.

By "sense of self" I will mean perspectival witnessing marked by "entitification" which refers to the phenomenally felt sense that the awareness-perspective (subject-side) is "bounded" or "hemmed in", however subtle this impression is. Boundedness impresses upon the awareness-perspective the sense that it is cordoned off from the event-perspective (object-side). 175

I will now explain this definition in greater detail. To this end, I will draw on Albahari's two senses of identification: perspectival ownership and personal ownership.

\footnotetext{
171 Ibid., 144. I agree with Damasio that this innate capacity precedes language. Self Comes to Mind, 172.

172 This is, in a nutshell Albahari's and Damasio's answer to the problem of the "unity of consciousness". I agree with the basic tenets of this position.

${ }^{173}$ Albahari, Analytical Buddhism, 157.

${ }^{174}$ I acknowledge that William James vaguely discussed a similar kind of distinction, though he did not spell it out as clearly as Albharai has. William James, The Principles of Psychology I-II (New York: Henry Holt and Company, 1893), 289.

175 My reference to "bounded" is directly borrowed from Albahari and I will unpack it further. For her discussion of a "hemmed-in perspective", see Albahari, Analytical Buddhism, 57.
} 
Albahari defines "perspectival ownership" as the unique way that experience presents itself to a particular subject and no other subject. ${ }^{176}$ "Subject" does not mean a "self" in the ontological sense, but simply perspectival witnessing as defined by Albahari. Zahavi uses the term "subject" in the same way; it means the "experiential core self", which is a "mere point of view". ${ }^{177}$ Therefore, for Zahavi the "subject" is not "a separately existing entity", ${ }^{178}$ but rather is equivalent to the "first-personal presence of experience" (the "for-me-ness") defined by the specific way that phenomenal life is given "to me" or "my perspective" and not anyone else's. ${ }^{179}$

"Personal ownership", or entitification, ${ }^{180}$ builds on perspectival ownership by adding to witnessing-from-a-perspective (= the "subject" in Albahari's and Zahavi's senses) the felt sense that witnessing is a state or activity performed by a substantial entity. ${ }^{181}$ This is an additional identification that impresses upon the perspective-lending locus of witnessing the sense that it is "bounded" and "hemmed-in".

Identification of "personal ownership" furnishes substance to perspective. I call this act "entity making", which occurs when the perspective-lending locus identifies itself with the medium through which witnessing is funnelled. Identification with this medium causes witnessing to assign unto itself features of that medium so that it seems - from the perspective of the subject - that those features are "at one with the subject as a whole". ${ }^{182}$ Sometimes those features are of the "psycho-physical perspective" kind (waking); at other times those features are of the "psycho-mental perspective" kind (dreaming); yet at other times those features may be of the more subtle "spatio-temporal perspective" kind (meditation). Therefore, the medium with which the perspective-lending locus identifies can be more or less coarse, and this impresses upon witnessing feelings of boundedness that are more or less constricted and solid.

\subsubsection{States and Levels of Awareness}

The possibility that the awareness-perspective (subject-side) can be funnelled through different, more or less coarse, media leads us to levels of awareness. Centering Prayer relies

\footnotetext{
176 Ibid., 53.

177 Zahavi, "The experiential self: Objections and clarifications," 63.

178 Ibid., 59.

179 Ibid., 58-59.

${ }^{180}$ I use the term "entitification" instead of Albahari's term "personal ownership" because contemplative states of consciousness may be phenomenally bounded at the subject-side of experience without this being a "personal" affair. I also prefer the term "perspectivalness" to "perspectival ownership", because perspectival witnessing may occur without a sense of self. Such instances render notions of "ownership" meaningless. 181 "The experiential self: Objections and clarifications," 61-62.

182 Albahari, Analytical Buddhism, 57.
} 
on a model that delineates multiple levels of awareness, and its contemplative project requires the awareness-perspective to progress through those levels to reach the sought for soteriological goal. I will now draw on the phenomenological ideas covered so far to show the contemplative idea that there are different levels of awareness.

I begin with our ordinary day to day experience ("waking consciousness") where witnessing is identified with a psycho-physical perspective. Awareness flows outward from the body toward objects (narrow intentionality). It is also open and affected by the world (broad intentionality). Here the body-mind complex constitutes the self-as-subject (or "bodyas-subject"), ${ }^{183}$ and in this situation awareness is concerned with objects. Albahari calls this "awareness qua content”. ${ }^{184}$ According to Western philosophy of mind, awareness qua content exhausts our phenomenal consciousness.

Ordinary, nonlucid dreaming (“dream consciousness") is a similar situation. Witnessing is "identified with the dream ego as the I", ${ }^{185}$ and thus our experience is framed from the perspective of the dream ego and our awareness appears to flow outward from the dream body towards objects and the dream world. The dream body is the self-as-subject or the "dream-body-as-subject". This makes dream consciousness unlike waking consciousness; it is decidedly less coarse, and objects are less defined, vivid and solid. The medium through which witnessing occurs is also more vague. Nevertheless, dreaming is similar to waking in two ways: First, identification with the dream body creates a sense of border around witnessing. ${ }^{186}$ Second, awareness appears to be exhausted by its content. It is also an instance of awareness qua content.

In lucid dreaming we become aware of the changing content of our dreaming and of the dream state as a state. Our awareness no longer appears exhausted by content, because we are also aware of the mode of consciousness through which objects are apprehended. Albahari calls this "awareness qua awareness", and it is a second-order conscious state that belongs to the family of "metacognition" or "meta-awareness" ${ }^{187}$ In respect to the dream example, the meta-awareness is "state-aware" because the subject is aware of first-order conscious experiencing and the fact that experiencing is taking place in a different state.

State-awareness causes the awareness-perspective to shift to a higher-order conscious state. For example, in lucid dreaming the dream body (the "Me") and the dreamer

\footnotetext{
183 Ibid., 58.

184 Ibid., 33, 88-90.

185 Thompson, Waking, Dreaming, Being, 109.

${ }^{186}$ Albahari, Analytical Buddhism, 119.

187 Ibid., 33-88-90. For a discussion of types of metacognition as second- and higher-order conscious states, see Morten Overgaard and Kristian Sandberg, "Kinds of access: different methods for report reveal different kinds of metacognitive access," Philosophical Transactions of the Royal Society B: Biological Sciences 367, no. 1594 (2012): 1287-89. Evan Thompson connects lucid dreaming with meta-awareness. Thompson, Waking, Dreaming, Being, 138.
} 
(the "I") become dissociated. Awareness no longer comes from the dream body (now the "Me" or self-as-object) but from an observational point of view (the "I" or self-as-subject) that takes the dream body as its object. We must therefore distinguish between the "self-asdreamer" and the "self-within-the-dream". ${ }^{188}$

On the basis of this distinction, we can say that consciousness during nonlucid dreaming frames experience from the perspective-lending locus of the self-within-the-dream (the dream body). Here the self-in-the-dream (self-as-object or "Me") is felt to be in the same location as the self-as-dreamer (self-as-subject or "I"). For example, "I" look out of the eyes of the dream body and "I" might be running away, or flying or engaged in some activity in the dream from the first-person perspective. My awareness-perspective is identified with and funnelled through the medium of the dream body and thus appears placed at the subject-side of experience. The dream body ("Me") appears at-one with the subject ("I") who has assimilated features of the dream body unto itself.

On the other hand, consciousness during lucid dreaming frames experience from the perspective-lending locus of the self-as-dreamer (the more vague "psycho-mental point of view"). The vantage point of experience is outside of the dream body so that the "Me" is seen at a different place than the "I". For example, "I" watch myself as the person (dream body) within the dream running away from something, or flying or being engaged in some activity within the dream from the third-person perspective. Here my awareness-perspective is neither identified with nor funnelled through the dream body. Hence the dream body appears placed at the object-side of experience. ${ }^{189}$

Dreaming illustrates the dynamic interplay of subject and object and shows that witnessing can shift between different types of perspective-lending loci. According to Albahari, such identification plays a critical role in determining through which perspectivelending locus awareness comes from.

Specifically, lucid dreaming shows how the awareness-perspective can shift to a higher-order state and establish itself there as the new basis of operation from which seeing, perceiving, or phenomenal apprehending more broadly conceived takes place. The higherorder conscious state in lucid dreaming is analogous to what contemplative traditions mean by a "higher" or "deeper" level of awareness. Each level is accessed by funnelling awareness through the relevant perspective-lending medium, which shifts the basis of operation and imbues awareness with specific characteristics. The event-perspective (object-side) also changes when the basis of operation shifts to a different level of awareness. Therefore, shifting the basis of operation (the point of view) to a different level of awareness changes

\footnotetext{
188 Waking, Dreaming, Being, 109.

189 Ibid., 110, 34.
} 
both how phenomena appear in the field of experience (object-side) and the phenomenal character of witnessing (subject-side). ${ }^{190}$

\subsubsection{Mental Pliancy as a Technique to Deliberately Shift Levels of Awareness}

Brown outlines "basic skills" of meditation relevant to this study. ${ }^{191}$ He explains those skills by way of an analogy to driving a car. A driver must simultaneously apply a set of four skills: (i) steer; (ii) adjust speed; (iii) change gear; and (iv) keep vigilant about how each task is performed (see Figure 5 below).

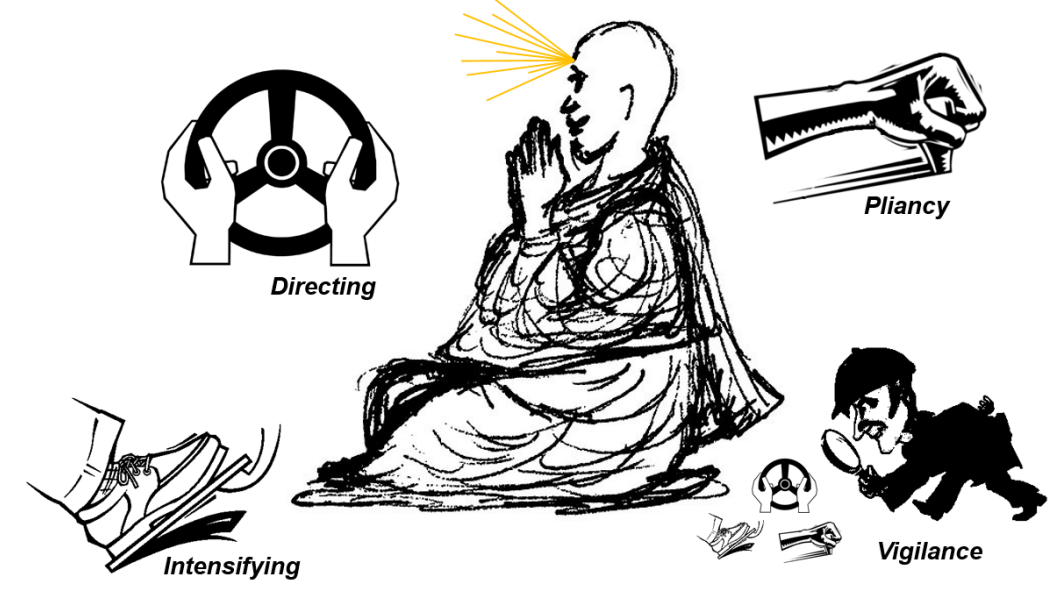

Figure 5. Set of Basic Meditation Skills.

Meditation requires a similar skill set of skills (refer to Figure 5). The first is "directing" where practitioners direct attention to a specific object, and at the beginning, attention has to be repeatedly brought back to the intended object. The second skill is "intensifying" which helps practitioners stabilise attention on the object by increasing or decreasing the energy (effort) supplied to the act of observing. The third skill is "pliancy". Pliancy determines how well practitioners can work with perspective. First, it reflects practitioners' abilities to hold onto a specific perspective at the subject-side despite marked changes in content at the object-side. Second, practitioners learn to hold attention on a specific object in the eventperspective while at the same time shifting their witnessing-perspective to a different level of awareness. This shift is analogous to relocating ones perspective-lending locus from the dream body (object-side) to the vaguer point of view of the dreamer as "I" (subject-side). The final skill is "vigilance" through which the practitioners keep watch over the meditation process so that they can adjust and work towards actualising the best qualities.

\footnotetext{
190 DiPerna, "Differentiating phenomena from identity in religious and meditative experience."

${ }^{191}$ I closely follow Brown's own exposition. Brown, Pointing Out the Great Way, 153-57.
} 
The relevant skill for this study is "mental pliancy", which is the ability to shift perspective between different levels of awareness. According to Brown, this skill is critical for advancing on the contemplative path:

\footnotetext{
I began to appreciate that the depth of realisation possible during ordinary concentration and special insight meditation was enhanced remarkably by shifting to the very subtle or extraordinary level of mind [awareness]. In other words, the issue became less about concentration on the intended meditation object and much more about the level of mind [awareness] brought to the concentration, and that, from the mindperspective [subject-side], shifting... the vantage point during meditation quickly brought the meditation practice within the range wherein awakening the mind was a definite possibility. ${ }^{192}$
}

During my fieldwork at a Pointing Out Way Tibetan Buddhist Mahamudra retreat, Patricia (a teacher) said:

\begin{abstract}
At the beginning the basis of operation functions like a state because it comes and goes. It's not stable. This is why the awareness-perspective is really important. If you do the practice from your ordinary event-perspective it doesn't work. It works because we are progressively deepening our experience of awareness. So post concentration we are progressively refining our understanding of what the awareness is. The basis of operation is what it's about. That's what you are looking for. That it becomes stable. Realisation is not a state if by states we mean experiences that are transitory. It is more like holding a perspective, the awareness-perspective. ${ }^{193}$
\end{abstract}

What both Brown and Patricia point out here is that practitioners must progressively shift their witnessing-perspective through "higher" or "deeper" levels of awareness - and then stabilise this seat of identity (basis of operation) at the "highest" or "deepest" possible level (in Centering Prayer it is the "divine" level of awareness) - to reach the soteriological goal. In Chapters 4 to 8 I will show how Centering Prayer contemplatives use mental pliancy to shift their basis of operation from the "ordinary" to the "spiritual" and then, finally, to the "divine" level of awareness at the centre, which is the place where God is.

\footnotetext{
192 Ibid., xxiii.

193 Patricia, Participant \#17, quote from fieldnotes written down during retreat.
} 


\subsubsection{Summary}

My conceptual framework rests on a set of phenomenological ideas that conceives "experience" to subsume all possible modes of "phenomenal apprehending". This includes "consciousness" in the sense of perspectival witnessing, which has a subject-side and objectside, and "awareness" in the sense of aperspectival witnessing, which can persist without an object-side.

Albahari suggests that the subject-side of experience is constituted by two important pre-theoretical facts: a modus operandi and a perspective-creating locus. The modus operandi is our realised capacity to be aware, which is also referred to as "witnessing" or our "basis of operation". Since witnessing and perspective can come apart, as shown by the example of lucid dreaming, awareness can persist with phenomenal character in the absence of an object-side of experience. This innate capacity to be aware also links to our "subjective sense of presence" that constitutes this study's core concept of awareness.

Finally, my framework relies on two phenomenological ideas to explain how contemplative practitioners navigate the levels of awareness delineated by their tradition: First, our basis of operation, or witnessing, can be funnelled through different perspectivecreating loci that grant cognitive access to different levels of awareness. Second, contemplative practitioners take advantage of this by cultivating "mental pliancy", a critical meditation skill described by Brown that enables practitioners to shift their bases of operation (witnessing) to different levels of awareness. These shifts relocate their perspectives so that their witnessing is funnelled through different perspective-lending media.

In sum, this conceptual framework, especially the phenomenological ideas on navigating levels of awareness, will inform my analyses of practitioner's first-person accounts throughout Chapters 4 to 10.

\subsection{Fieldwork and the Scholar-Practitioner Perspective}

In this study, I have turned away from scholarship that primarily examines texts and grounded my work in the phenomena themselves. To achieve this, I have used fieldwork as a means to access contemplative states of consciousness "as fully and openly as possible". ${ }^{194}$ Thus I have put into practice Wulff's dictum that “disciplined phenomenological study" must

\footnotetext{
194 David M. Wulff, "Mystical Experience," in Varieties of Anomalous Experience, ed. Etzel Cardeña, Seven Jay Lynn, and Stanley Krippner (Washington, DC: American Psychological Association, 2007), 430.
} 
whenever possible directly access the phenomena and only when this is not possible do so vicariously. ${ }^{195}$

Since my project relies on first-person data as evidence, obtained from others (vicariously) and through second-person techniques, I have had to navigate the interpersonal and intersubjective domain where meaning is calibrated "inter the views" of researcher and collaborators. ${ }^{196}$ To be successful in this task, I have taken on board Froese's and Buehler's advice to acquaint myself directly with the type of experiences under study. Their advice is well-founded.

First, direct acquaintance with the first-person methods in question (contemplative practices) helps me facilitate interpersonal exchange and guide practitioners' introspective processes during the interview. ${ }^{197}$ A shared familiarity with the subjective phenomenon also changes subsequent inter-subjective exchange; if I am familiar with the experience of my collaborator, "there is an entirely different quality to the subsequent interaction". ${ }^{198}$

Second, direct acquaintance enhances my ability to clarify through Socratic-style inquiry what terms mean to describe and better organise the introspective descriptions obtained. ${ }^{199}$ In the ideal case the investigator becomes familiar with the subjective phenomenon "before comparing notes with collaborators" in "extensive" interviews. ${ }^{200}$

To directly familiarise myself with the phenomena under study, I have adopted Buehler's "radical participation" approach to fieldwork in religious studies. It is "radical" because it pushes participation to the limit "by temporarily dissolving the boundary between participant and observer". ${ }^{201}$ In 2015, I dissolved this boundary early in my data collection phase by fully participating in an intensive retreat run in the United States by authorised teachers of Centering Prayer. I visited St Benedict's Monastery in Snowmass, Colorado, and participated in a 10 day Christian Centering Prayer Intensive Retreat.

My familiarity with contemplative practice extends beyond this retreat. I began serious "path-oriented"202 contemplative practice at the age of 17 and then lived a full-time contemplative life between the ages 20 and 22. My study and practice was self-directed and uncommitted to any specific religious worldview. This approach has continued ever since.

\footnotetext{
195 Ibid.

196 Kvale and Brinkmann, InterViews, 2-3.

197 Tom Froese, Cassandra Gould, and Adam Barrett, "Re-viewing from within: A commentary on first- and second-person methods in the science of consciousness," Constructivist Foundations 6, no. 2 (2011): 258. ${ }^{198}$ Buehler, "The twenty-first-century study of collective effervescence: Expanding the context of fieldwork," 83.

${ }^{199}$ Froese, Gould, and Barrett, "Re-viewing from within: A commentary on first- and second-person methods in the science of consciousness," 258.

${ }^{200}$ Buehler, "The twenty-first-century study of collective effervescence: Expanding the context of fieldwork,"

92.

201 Ibid., 91.

202 I define "path-oriented" practice in Section 3.2.2.
} 
Hence I came to fieldwork with a set of "basic skills" as outlined by Brown (see $\underline{\text { Section }}$ 2.5.9). While I am not affiliated with the traditions under study, I have engaged Centering Prayer from a "scholar-practitioner" perspective. ${ }^{203}$ This means I do not consider myself an outsider to the contemplative life, or a disinterested academic who has explored territory unfamiliar to myself. In respect to the emic/etic divide, I have one foot in each camp, unapologetically so.

Fieldwork played a major role in formulating the interview method, and my exposure to specific practices, and my dialogues with practitioners, refined the conceptual framework that informed the method. Thus I completed a series of 5 pilot interviews prior to fieldwork and then refined my conceptual framework during and after fieldwork. My interview method matured towards the end of my data collection, a fact that affects validity and reliability.

\subsection{Method}

In this section I will introduce the second module of my blended approach to phenomenology. I will begin with my approach to in-depth, phenomenological interviewing. Next, I will discuss the Explicitation Interview Technique and then Expositional Interview style interviewing. Finally, I will explain how I have combined these two methods into a Cyclical Evocation-Analysis Interview Method.

\subsubsection{A Model of In-depth, Phenomenological Interviewing}

My model for in-depth interviewing is inspired by Seidman's “Three-Interview Series" that structures interviewing into three phases: context, experience and meaning. ${ }^{204}$ I covered all three phases in a single interview with 20 Centering Prayer contemplatives, and each interview lasted 1 to 3 hours.

In the first phase I focused on the "autobiographical" sense of self. ${ }^{205}$ I let practitioners narrate as uninterruptedly as possible. ${ }^{206}$ They shared their contemplative story and any other information they deemed contextually relevant. This included goals, practices and significant experiences in broad strokes, up to the time of the interview. When possible,

\footnotetext{
203 I conceive this to be analogous to the "scientist-practitioner" model advocated in clinical psychology today. For a brief discussion of what place "scholar-practitioner" contributions have in contemplative studies, see Komjathy, "Approaching contemplative practice," 33-35; "Contemplative traditions," 78.

${ }^{204}$ Seidman, Interviewing as Qualitative Research, 21, 24.

205 For a discussion of the "autobiographical self", see Damasio, Self Comes to Mind, 210-13. Vogeley and Gallagher use the term "narrative" to qualify the same sense of self. "Self in the brain," 128.

${ }^{206}$ Seidman, Interviewing as Qualitative Research, 23.
} 
I gathered information on the first point of analogy, which is their soteriological outlook in the past (intended goal).

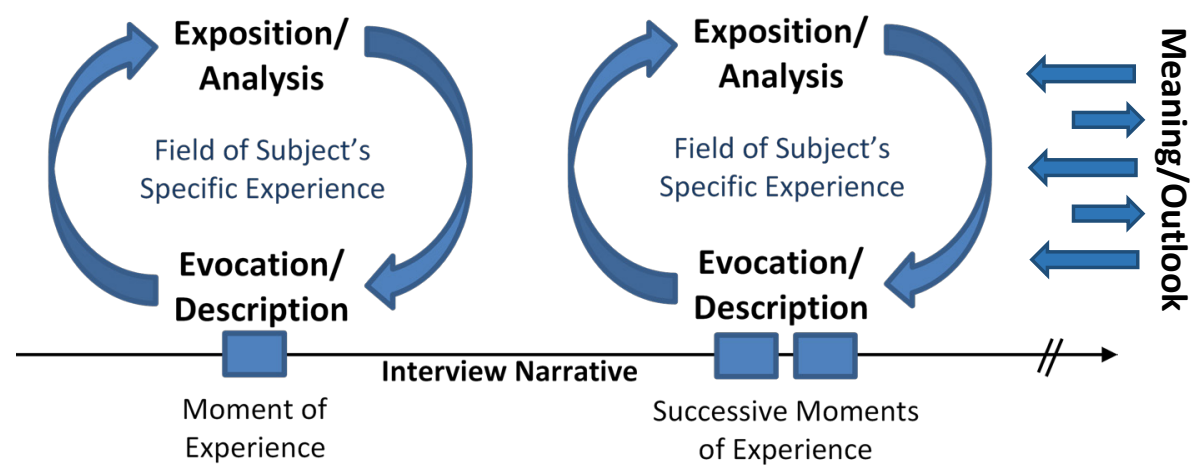

Figure 6. Model of In-Depth, Phenomenological Interviewing

In the second phase I focused on details of experiences alluded to by participants. I applied the Cyclical Evocation-Analysis Interview Method to shift the mode of interviewing towards description of specific practice occasions and moments of experience (see evocationanalysis loops in Figure 6). This includes: (i) significant experiences in the past; (ii) the most recent practice session completed on the day of the interview (often within a few hours of the interview itself). Together, this provided rich description on the second and third points of analogy (practices and states of consciousness).

In the third phase I focused on the meaning contemplatives gave to their experiences and practices to date and looking into the future (refer to top right arrows in Figure 6). ${ }^{207}$ When possible, I obtained information on the first point of analogy, which was their present motivations and soteriological outlook.

At the beginning of each interview, I explained that the interview will proceed in three phases and that the style of interviewing will change accordingly. This gave participants a sense of structure and progress during the interview. ${ }^{208}$

\subsubsection{Cognitive Access and Reportability}

The second phase of the interview is particularly vulnerable to challenges of cognitive access and reportability, because it focuses on obtaining faithful descriptions.

\footnotetext{
207 Ibid., 22.

208 This counteracts some of the dynamics responsible for diminishing returns in extended interviews. For Seidman's discussion of diminishing returns, see ibid., 24.
} 
Cognitive access is vulnerable to the limits of working memory and memory in general. ${ }^{209}$ For example, asking practitioners to describe experiences they have had in the distant past imposes high demands on memory.

Reportability is vulnerable to limits in the ability to conceptualise and verbalise experience. ${ }^{210}$ For example, lack of “differential reinforcement" of our “inner" experience throughout life results in inadequate conceptual tools to describe experience. "Differential reinforcement" describes how a community reinforces certain verbalisations made by individuals when they are made in the presence of specific stimuli and not otherwise. ${ }^{211}$ Unfortunately, due to its subjective and internal nature, speech about inner experience (e.g., "I thought" and "I feel") cannot be differentially reinforced with the same level of precision that speech about external events can be. This is especially true for contemplative states of consciousness.

\subsubsection{The Explicitation Interview Technique and the Challenge of Cognitive Access}

Pierre Vermersch developed the Explicitation Interview Technique and published L'Entretien d'explicitation en formation initiale et en formation continué in $1994 .{ }^{212} \mathrm{His}$ method received a lot of attention from the English speaking scientific community after Varela and Shear published their coedited book The View from Within in $1999 .{ }^{213}$ It has been since debated in the Journal of Consciousness Studies and pitted against Hurlburt's Descriptive Experience Sampling ("DES”) method as one of the two most highly regarded and "most common second-person methods in the science of consciousness". ${ }^{214}$

\footnotetext{
${ }^{209}$ For a discussion on how memory can quickly compromise "phenomenal judgments", see B. J. Ramm, "Dimensions of Reliability in Phenomenal Judgment," Journal of Consciousness Studies 23, no. 3-4 (2016): 11014.

${ }^{210}$ For a discussion on how limits to our conceptual systems pose serious concerns for reporting experience, see ibid., 114-16.

${ }^{211}$ Burrhus Frederic Skinner, Science and Human Behavior (New York: Macmillan, 1953), 258-59.

212 Pierre Vermersch, L'Entretien d'explicitation en formation initiale et en formation continué (ESF Editeur, 1994).

${ }^{213}$ Vermersch's and Petitmengin's articles in this volume have specifically contributed to raising the public profile of the method. "Introspection as practice," in The View From Within: First-Person Approaches to the Study of Consciousness, ed. F. Varela and J. Shear (UK: Imprint Academic, 1999); Claire Petitmengin-Peugeot, The Intuitive Experience, ed. F. Varela and J. Shear(UK: Imprint Academic, 1999). For a discussion of the recent reception of the Explicitation Interview Technique, see Froese, Gould, and Seth, "Validating and calibrating first- and second-person methods in the science of consciousness," 45.

214 "Validating and calibrating first- and second-person methods in the science of consciousness," 39. The Explicitation Interview Technique has been recommended for projects that require "more detailed phenomenological investigation... than has been done so far". Thompson, Waking, Dreaming, Being, 317-18.
} 
Vermersch developed the Explicitation Interview Technique to help participants become more aware of their experience. ${ }^{215}$ Proponents argue that memory specific challenges to cognitive access can be thereby effectively mitigated. Explicitation style interviewing achieves this by guiding participants into an "evocation stance" in which they are present to a past experience in a "relived" and "reevoked" way. Reevoking experience means the past experience "becomes lived as if present", ${ }^{216}$ and a marker of successful "evocation" is that relived past experience becomes more present to the participant than the interviewer and the interview situation. ${ }^{217}$ The overall aim of evocation is to: (i) enhance cognitive access to a past experience; (ii) direct participants away from theorising about their experience, or making causal conjectures about it; (iii) encourage participants to describe experiential primitives. ${ }^{218}$

I trained in the Explicitation Interview Technique with Professor (retraité) Maurice Legault, Université Laval, who today provides training through the Canadian branch of the Groupe de recherche sur l'explicitation (GREX). ${ }^{219}$ My training was conducted over three sessions by Skype and it covered: (i) the logic and practical steps of the technique; (ii) a discussion of its application to the domain of inquiry; (iii) an application to myself (the researcher) in the role of interviewee (informant) on the subject under study; and (iv) feedback on pilot interviews. My training was completed before fieldwork commenced.

\subsubsection{Evocation, Cognitive Access and Memory}

Proponents of explicitation apply the method in situations when they need to obtain introspective descriptions of experiences from the distant past. ${ }^{220}$ This places a high demand on memory. Proponents of explicitation believe that the method still succeeds, arguing on the basis of: (1) an empirical observation and (2) a theoretical explanation of this observation. I will discuss each step in turn.

\footnotetext{
215 "Validating and calibrating first- and second-person methods in the science of consciousness," 45.

${ }^{216}$ Ibid.; Maryse Maurel, "The explicitation interview: Examples and applications," ibid.16, no. 10-1 (2009): 5960.

${ }^{217}$ Claire Petitmengin, "Describing one's subjective experience in the second person: An interview method for the science of consciousness," Phenomenology and the Cognitive Sciences 5, no. 3 (2006): 244-45.

${ }^{218}$ For a discussion of evocation as an act of being present to past experience as a lived experience and not "thinking about" it, see Maurel, "The explicitation interview: Examples and applications," 60. Evan Thompson also points out that explicitation style interviewing minimises "after-the-fact interpretation and memory reconstruction". Waking, Dreaming, Being, 317.

219 "The explicitation interview: Examples and applications," 87-88. For a list of faculty members of the GREX institute, see www.grex2.com.

${ }^{220}$ Russell Hurlburt and E. Schwitzgebel, "Presuppositions and background assumptions," ibid.18, no. 1 (2011): 214. For a discussion of why the Explicitation Interview Technique is more suitable than Descriptive Experience Sampling for investigating experiences of the distant past, see T. Froese, C. Gould, and A.K. Seth, "Validating and calibrating first- and second-person methods in the science of consciousness," ibid., no. 2: 42-43.
} 
Empirical observation shows that participants who successfully enter evocation remember significantly more details than expected. Those participants also recognise those details as ones they did in fact experience but could not access prior to evocation. This surprises and amazes them. ${ }^{221}$

The theoretical explanation proponents of the method offer for this observation is that consciousness is more complex than cognitive psychology allows. The traditional model divides consciousness into "conscious" and "unconscious" modes, but Vermersch argues that this model must be expanded. He suggests a trichotomy: (i) an unconscious mode; (ii) a prereflectively conscious mode; and (iii) a reflectively conscious mode. Reflective consciousness is unlike pre-reflective consciousness because it "takes into view" lived experience. ${ }^{222}$ If Vermersch's model of consciousness is correct, then evocation extends cognitive access to the pre-reflective domain and this explains why participants in evocation can recollect more than anticipated.

Whether explicitation style interviewing ultimately enhances cognitive access is debated. Hurlburt argues that evocation, like memory recall, is constructive and unreliable. ${ }^{223}$ Specifically, memory of details remains highly problematic in any experience reported later than 24 hours.

My view is that both proponents and opponents overstate their case. My research showed that contemplatives are indeed amazed about how much they can recall and they are genuinely surprised by details. Some even revise their self-theories. Thus I am sympathetic to the claim that evocation enhances cognitive access.

Despite this, proponents of explicitation underestimate the memory problem in respect to the details of experience. During my training, the method was applied on myself and I am confident that memory construction on my part (as informant) took place. The subtleties involved in contemplative states of consciousness exacerbate this problem.

Memory problems notwithstanding, I regard explicitation to be one of the best methods available for obtaining minimally misleading and faithful first-person data on the most important features of past experiences.

\footnotetext{
${ }^{221}$ Pierre Vermersch, "Describing the practice of introspection," ibid.16, no. 10-1 (2009): 34.

222 Ibid.

${ }^{223}$ Russell Hurlburt, "Descriptive experience sampling, the explicitation interview, and pristine experience in response to Froese, Gould and Seth," ibid.18, no. 2 (2011): 71-72.
} 


\subsubsection{The Steps of Explicitation}

In phase two I follow a protocol to guide contemplatives into evocation and obtain descriptions of specific moments of experience. I inform practitioners that I will transition into the second phase and change the mode of our exchange. I then action seven steps: ${ }^{224}$

1. I state my intent to investigate a specific experience alluded to by the practitioner in the first phase of the interview: "I am interested in experience $\mathrm{X}$ when you talked about Y. I would like to explore experience X further.”

If a practitioner spoke in general terms, I will ask them to return to the last time they experienced the phenomenon, or choose a specific instance most salient to them. ${ }^{225}$

2. I ask the practitioner to enter into a communication contract: "Are you willing to return to this experience and describe it to me in great detail?"

Practitioners are unlikely to enter into evocation without a communication contract. The contract makes them aware that theories and narratives are no longer interesting and that they are required to go back to a specific moment and relive it.

3. I direct attention to a specific moment and the sensorial associations of this past experience to set the conditions for a "provoked awakening recall" (evocation):226 "Can you share some of the context of that experience with me? Where are you? What time of day is it? What are you doing? What about your surroundings?"

Behavioural cues indicate evocation. Good proxies are loss of eye contact and change of sitting posture. Gestures may also originate in being present to the past as a lived experience. Vermersch calls this "embodied discourse position".227 I apply a three strike policy: if a practitioner resists returning to a specific moment three times in a row, I let it go.

4. I guide the practitioner's attention through her reevoked field of experience to help her access specific aspects and thereby clarify awareness-perspective (subject-side) and event-perspective (object-side).

\footnotetext{
${ }^{224}$ My outline is a synthesis of Maurel's presentation and my training with Maurice Legault. Maryse Maurel, "The explicitation interview: Examples and applications," ibid.16, no. 10-1 (2009): 59.

225 Pierre Vermersch, "Describing the practice of introspection," ibid.: 43-44.

${ }^{226}$ For a discussion of the importance of sensorial association in guiding a subject into evocation, see ibid., 42 .

227 Ibid., 38.
} 
This step explores the structure of experience. To this end, the practitioner "shift[s] [her] view inside the past lived experience". ${ }^{228} \mathrm{I}$ ask, "Where is awareness coming from?" instead of the traditional question, "Who are you in this experience?"229

5. I encourage the practitioner to verbalise the experience.

In this step I reassure practitioners, because evocation may result in a loss for words and this causes insecurities. It is a common experience and it occurs for non-special reasons. ${ }^{230}$

6. I explore the dynamic nature of experience by repeatedly guiding the practitioner back to the last moment she attended to. I feed back what she said and prompt: "What happens then?"

To explore temporally extended experience in agent neutral terms, I ask "What happens next?" instead of the traditional questions "What do you do next?", "When you do X, what do you do?” or “When you do Y, what do you start with?”231 My agent neutral approach places practitioners' attention just as well at the edge of the reevoked moment of practice.

7. I remain present to the practitioner for a suitable period of time when the collaborative effort in evocation ends.

Once the moment[s] of experience are exhausted, I stop task-oriented interactions and allow the practitioner to recollect. I may begin a new cycle of evocation-analysis or end the second phase. Intermissions are important, because evocation can be emotionally demanding.

\footnotetext{
228 Ibid., 33.

${ }^{229}$ My second question is derived from DiPerna's definition of the awareness-perspective. "Differentiating phenomena from identity in religious and meditative experience," 7.

230 The inability to articulate experience is by and large a disruption caused by being present to felt-experience rather than any special relationship that exists between language and the type of experience in question. Marion Hendricks, "Experiencing level: An instance of developing a variable from a first person process so it can be reliably measured and taught," Journal of Consciousness Studies 16, no. 10-1 (2009): 135-37.

${ }^{231}$ Maryse Maurel, "The explicitation interview: Examples and applications," ibid.: 60-62.
} 


\subsubsection{The Expositional Interview Style and the Challenge of Reportability}

In the late 1970 s Russell Hurlburt set out to create a method for exploring "inner, conscious experience" that could provide "largely correct descriptions". ${ }^{232}$ He considered the methodological shortcomings of introspective psychology and developed Descriptive Experience Sampling ("DES"), which is a method that randomly samples moments of experience and collects descriptions within 24 hours through an Expositional Interview. ${ }^{233}$

In the early 1990 s Hurlburt published two books on his method. ${ }^{234}$ Then, in 2007, he and Erik Schwitzgebel published Describing Inner Experience? Proponent Meets Skeptic in which they demonstrated, scrutinised and evaluated the method. Their work received enough attention from the scientific community that a 2009 topical issue of the Journal of Consciousness Studies discussed DES and pitted it against Vermersch's Explicitation Interview technique. While debated, both are considered the most common and best secondperson methods available. ${ }^{235}$

Unfortunately, DES cannot investigate experiences that are: (i) dynamic (successive moments); (ii) in the distant past; (iii) not repeatable; and (iv) specific targets of investigation (non-random). ${ }^{236}$ This makes DES unsuited for this study. ${ }^{237}$ However, I adopted two things from DES. First, I conducted Evocation-Analysis Interviews within 24 hours of a target experience (last practice session) to reduce memory demand. ${ }^{238}$ Second, I adopted Hurlburt's interview style for the analysis component of my cyclical EvocationAnalysis Interview Method (see "exposition/analysis" in Figure 6 above).

I use Hurlburt's Expositional Interview in the analysis step of the evocation-analysis cycle to flesh out initially sketchy reports. It is a "Socratic" and analytical style of inquiry that clarifies distinctions and draws out implications. ${ }^{239}$ I do this by "candidly facing the subject" and persistently inquiring into the details. ${ }^{240}$ Thus I make explicit what participants mean to describe when they use certain terms, ${ }^{241}$ and I continue the dialogue until clarity is

\footnotetext{
${ }^{232}$ Hurlburt and Schwitzgebel, Describing Inner Experience, 7. For a discussion of "faithful" rather than perfectly accurate descriptions (apodicticity) as a means to collect "nonsubstantially misleading" descriptions of the central features of experience, see ibid., 155.

${ }^{233}$ Froese, Gould, and Seth, "Validating and calibrating first- and second-person methods in the science of consciousness," 44.

${ }^{234}$ R. T. Hurlburt, Sampling Normal and Schizophrenic Inner Experience (New York: Plenum Press, 1990); Sampling Inner Experience in Disturbed Affect (New York: Plenum Press, 1993).

235 "Validating and calibrating first- and second-person methods in the science of consciousness," 39.

236 Ibid., 41-42.

237 On whether DES should be limited to moments of experience or be expanded to temporally extended experience, see John Sutton, "Time, experience, and descriptive experience sampling," ibid., no. 1: 118-24.

${ }^{238}$ Hurlburt and Schwitzgebel, Describing Inner Experience, 285.

${ }^{239}$ Charles Siewert, "Socratic introspection and the abundance of experience," Journal of Consciousness Studies 18, no. 1 (2011): 63.

${ }^{240}$ Describing Inner Experience, 243, 97.

241 Ibid., 61.
} 
achieved.242 This counteracts inadequate differential reinforcement over a lifetime that leaves informants with a poor vocabulary and impoverished conceptual resources to report their experience.

When I initiate a Socratic style inquiry it shifts the mode of interviewing and pulls the practitioner out of evocation. Consequently, the steps for explicitation (see prior section) must have been completed first and the verbalisations made, no matter how rough. However, once evocation has accessed the raw experience and delivered a basic level verbalisation, it is then necessary further to collaboratively analyse the experience, for two reasons.

First, analysis separates descriptions from erroneous interpretations. On the researcher's side, background context cannot be used to infer the meaning of terms, because practitioners use terms differently despite shared contexts (language is differently reinforced between individuals) and individual differences also exist at an experiential level despite common contexts. ${ }^{243}$ On the practitioner's side, false generalisations and self-theories do not faithfully describe experiences as they are misleading interpretations based on inferences rather than descriptions of experiential primitives based on recall. ${ }^{244}$ Socratic dialogue exposes errors of both researcher and practitioner.

Second, collaborative analysis adds granularity and nuance to description by developing "raw reports" into “exposed reports”. Raw reports are participants' naïve and unaided verbalisations (made during evocation). Exposed reports are conceptually clarified accounts (made through analysis). ${ }^{245}$

In sum, collaborative analysis is the process through which "raw" first-person data becomes "rich" and theoretically relevant first-person data.

\subsubsection{The Cyclical Evocation-Analysis Interview}

One cycle of evocation-analysis consists of two steps. First, I access the target experience through the seven steps of explicitation. Second, I analyse it through expositional-style interviewing. If experience is dynamic (temporally extended), I complete multiple cycles until description is exhaustive and clear.

\footnotetext{
242 "Socratic introspection and the abundance of experience," 64.

${ }^{243}$ For a discussion of how empirical observations force us to accept individual differences in people's experiences despite shared contexts, see Describing Inner Experience, 253-54.

${ }^{244}$ For guidelines on how to detect false generalisations and self-theories, see ibid., 141-42; 255.

245 Ibid., 254.
} 


\subsubsection{The Evocation Step}

Consider Lawrence as an example. ${ }^{246}$ Towards the end of interview phase one (narrative), Lawrence talked about his practice in general terms.

I don't know whether this is good or not, but I am starting to get glimpses of the thoughts going by and I am not attached to them. It's like - I wouldn't say out-of-body experience - but it's an experience where thoughts are just running by and I make no effort. $^{247}$

In phase two I return to Lawrence's pointer. I initiate step one and state my intent to investigate a specific experience Lawrence alluded to.

Interviewer: When was the last time that happened?

Lawrence: Today! It happened today!

Interviewer: Could we go back to that practice session?

Lawrence: $\quad$ Mh-hm [affirming]. ${ }^{248}$

I ask further questions to locate the exact practice session and then try to establish a communication contract (step two).

Interviewer: Which session was that?

Lawrence: It was the last we did today. The session today, I came in, in the last sit, and it was marvellous.

Interviewer: Okay, could we go back to that one?

Lawrence: $\quad$ Mh-hm [affirming]. ${ }^{249}$

\footnotetext{
${ }^{246}$ I discuss Lawrence's practice in greater detail in Section 5.2.1, Section 5.2.3, Section 6.4 and Section 6.5.

247 Lawrence, Interview \#21.1, p.11.

248 Ibid.

${ }^{249}$ Ibid., pp.11-12.
} 
At the start of the interview I explained that I would switch the mode of interviewing in phase two. Lawrence knows this and agrees. Consequently, I direct his attention to this moment (step three) by pointing him towards sensorial associations. This helps him enter evocation and adopt an embodied discourse position.

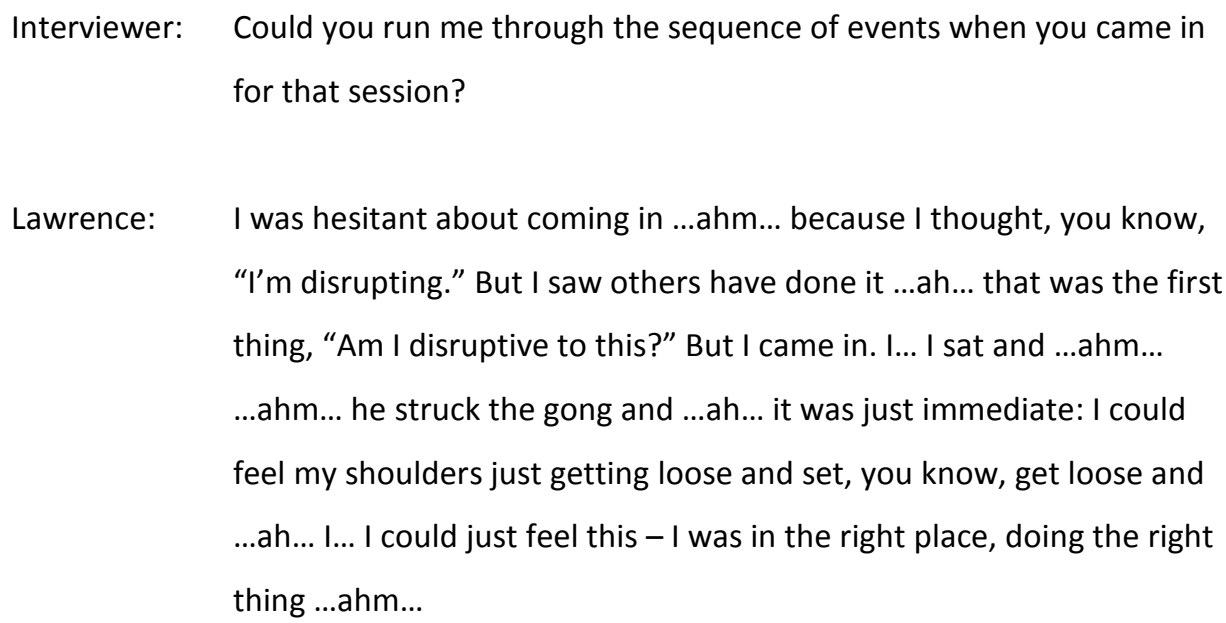

Interviewer: Your shoulders loosened.

Lawrence: My shoulders loosened ...ahm... I... I sat through that session motionless. Didn't move my hands. I don't even remember if I swallowed. ${ }^{250}$

Lawrence changes his posture as he speaks to resemble how he sat during prayer. He sits with a straight back and palms face down on his upper legs. He closes his eyes and adjusts his shoulders as he mentions them. I feedback this non-inferred sensorial information to: (i) keep him at the edge of that moment; (ii) heighten his provoked awakening recall; (iii) reinforce his embodied discourse position. When he is motionlessness and less present to the interview situation, I explore details in his reevoked field of experience (step four). These details are implicit but not yet denoted or verbalised (for example, his eyes).

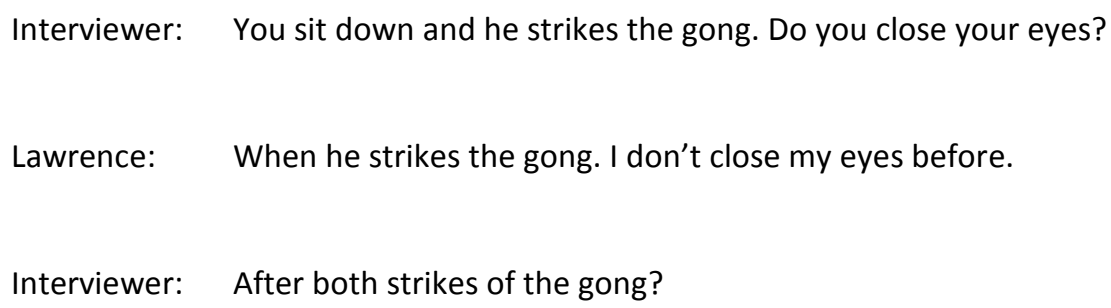

250 Ibid., p.12. 


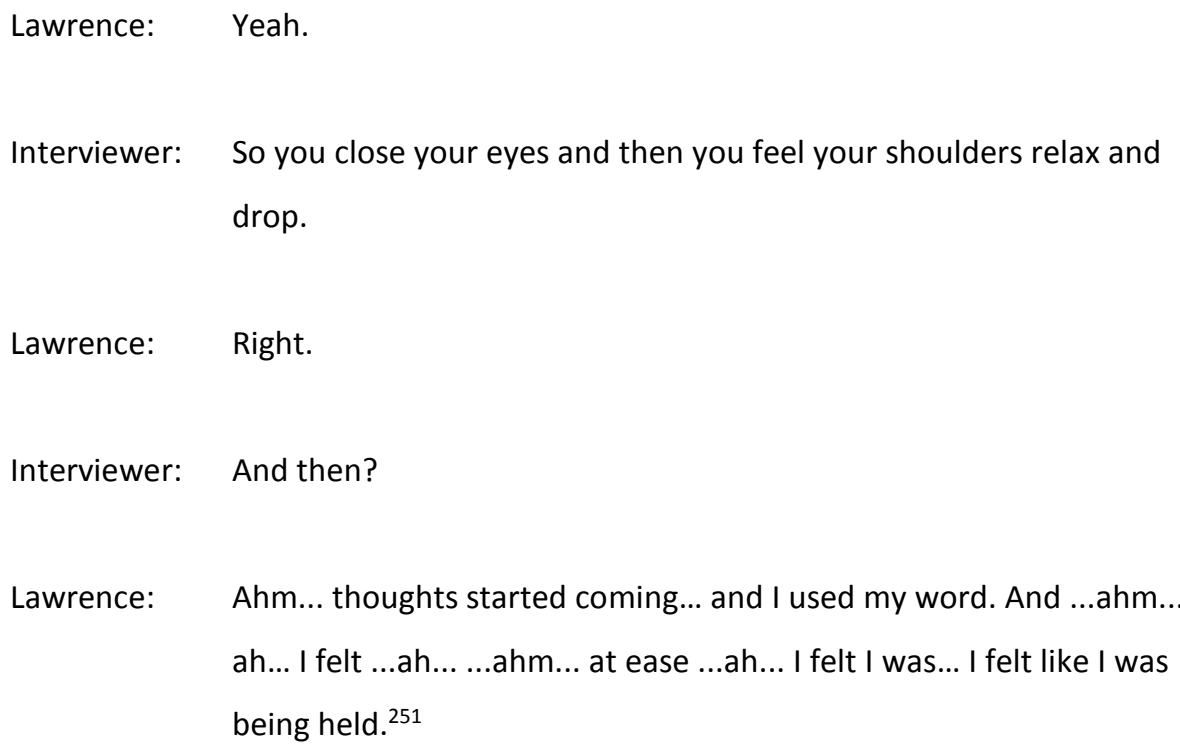

I ask Lawrence about his eyes. I do not introduce this content. Rather, I direct his attention to an aspect of his experience that is already present. This encourages Lawrence to verbalise his experience (step six). Since he has cognitive access to this aspect, he tells me exactly when he closes his eyes. I do not need to prompt or encourage him. The task is still easy, because the details I asked for are straightforward.

Next, I repeat back information he provided and follow up with, "And then?" to explore the dynamic nature of his experience (step six). Now Lawrence's language begins to break up and he reports how he felt, not just bare facts. This indicates that his introspective process has arrived at a genuine experience-level: evocation has been obtained.252

\subsubsection{The Analysis Step}

To avoid a hermeneutical crapshoot, I end Lawrence's evocation and initiate collaborative analysis. Here are two examples.

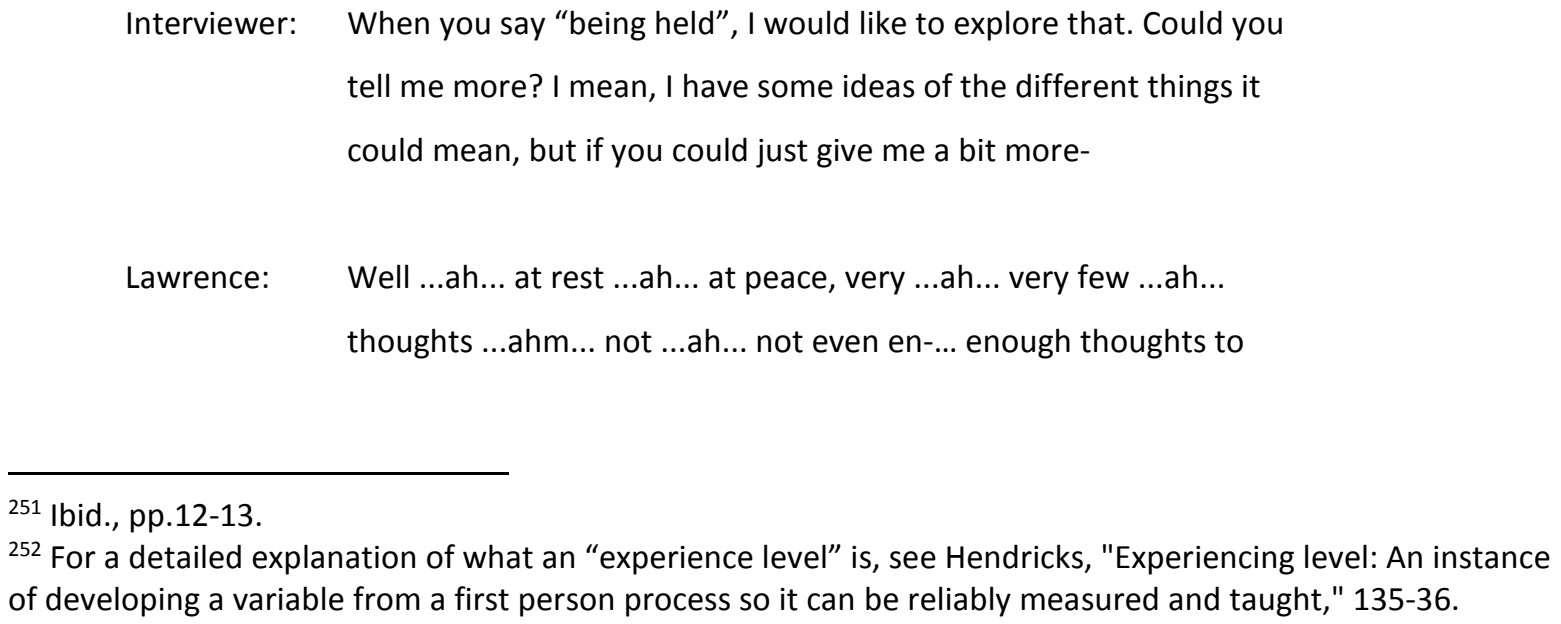

252 For a detailed explanation of what an "experience level" is, see Hendricks, "Experiencing level: An instance of developing a variable from a first person process so it can be reliably measured and taught," 135-36.

251 Ibid., pp.12-13. 
call for me to use my word. Ah... so I just ...ahm... just felt like I was just being held, right here, you know, and this was... this was fine. And so ...ahm... safe, trusting ...ahm... ...ahm... yeah.

Interviewer: So "being held" could mean that you feel like your body is actually like locked, like held in place, physically.

Lawrence: $\quad$ Yeah, I did feel like... because I didn't move, you know, I didn't change my hands. But "locked" is tight... a tight word. I didn't feel like it. I just felt like I was "in place".

Interviewer: "In place." Okay, mh-hm. Unmovingly in place?

Lawrence: Mh-hm.

Interviewer: So not something externally holding it?

Lawrence: No, no, no.

Interviewer: Okay. Did you feel like something was enclosing you? I am just trying to get a sense of what "held" might mean.

Lawrence: $\quad$ Ah... no, it was almost ...ahm......ahm... [chuckle] almost like sitting on a cloud.

Interviewer: Alright!

Lawrence: Just sitting. Just safely ...ahm... yeah.

Interviewer: That is a good metaphor. So what happens then? [chuckle] ${ }^{253}$

In the second example, I clarify Lawrence use of the term "swift" to describe how he experienced the duration of his prayer session.

Interviewer: "Swift." Was it swift in the sense that it was short, or did you literally have a loss of the sense of time passing?

253 Lawrence, Interview \#21.1, p.13. 
Lawrence: There: loss of time passing.

Interviewer: Loss of time passing?

Lawrence: Yeah, yeah, yeah. ${ }^{254}$

In both examples Lawrence and I clarify what he means to describe by the terms he uses through an additional "expositional/analytical" step in the interview process. Our Socratic dialogue develops his initial "raw" descriptions into "exposed" descriptions. The clarity achieved is critical for later theorising.

\subsubsection{The Analysis Step and Leading Questions}

Practitioners use terms in different ways to describe "inner" experience, but "some speakings cannot be adequately differentially reinforced, and we should therefore be very cautious." 255 Ordinary scenarios, such as "thinking" and "feeling", are already highly variable. For example, "thinking" can mean something completely non-cognitive and "feeling" can refer to cognitive events. ${ }^{256}$ Contemplative phenomena only exacerbate the issue. ${ }^{257}$ It is therefore important to clarify "over and over, in as many different forms as necessary" what practitioners experienced, ${ }^{258}$ and they should be given repeated opportunity to speak accurately about their experience. ${ }^{259}$

The analytical step in Evocation-Analysis Interview Method helps practitioners "clean up their descriptions" through Socratic questioning. ${ }^{260}$ This approach checks their descriptions and validates my interpretations during the interview process itself (the "selfcorrecting interview"). ${ }^{261}$ However, it is often "difficult if not impossible to ask questions that are perfectly non-leading, so the next best strategy is to ask questions that lead mildly in many different directions, some likely and some not." ${ }^{262}$ Consequently, I sometimes give practitioners multiple interpretations of their descriptions and offer them with true interest

\footnotetext{
254 Lawrence, Interview \#21.1, p.14.

255 Hurlburt and Schwitzgebel, Describing Inner Experience, 18.

256 Ibid.

${ }^{257}$ For a discussion of how serious impoverished differential reinforcement is, see ibid., 18-22; 61.

258 Ibid., 22.

259 Ibid., 18.

260 Ibid., 125.

${ }^{261}$ Kvale and Brinkmann, InterViews, 111; 35-36; 64; 95-96.

262 Hurlburt and Schwitzgebel, Describing Inner Experience, 87.
} 
in their experience, which is critical to the communication contract. ${ }^{263}$ This achieves two things. First, it is non-inductive because it targets already supplied facts about participants' experiences. Second, it communicates to participants that the descriptions supplied are not clear enough to avoid misconceptions. Third, it prompts them to clarify and, if necessary, to push back.

\subsubsection{Advantages, Assumptions and Limits of Cyclical Evocation-Analysis}

The Cyclical Evocation-Analysis Interview Method is underpinned by several deliberately avowed assumptions, and has certain natural advantages and limitations.

\subsubsection{Assumptions}

My qualitative approach to the comparative study of religion realises Perovich's advice to move away from questions of meaning (hermeneutics) and towards questions of reference.264 This is only possible within a realist worldview that can accommodate two empirical observations: (i) Individual differences exist despite broadly uniform contexts (not possible if context constructs experience); and (ii) people use terms differently because of impoverished differential reinforcement (an issue of reference).

Together (i) and (ii) demonstrate that context, language and inner experience rarely match up perfectly, even though strict constructivist worldviews require that they must. The strong constructivist position holds that context determines both language and experience by way of a one way causal relationship from the former to the latter, a fact that the empirical evidence from consciousness science has persistently disconfirmed over the last 30 years. ${ }^{265}$

My study and interview method are built on critical realist assumptions about the relationship between language and reality (the term "reality" includes the world and subjective experience). A specific version of the correspondence theory of truth must obtain for my method to work, which is: "It is the nature of the world [or inner experience] which makes sentences true or false." ${ }^{266}$ This does not mean that an isomorphic relationship must exist between language and the world (and by "isomorphic" I mean that the world and

\footnotetext{
${ }^{263}$ Claire Petitmengin, "Describing the experience of describing? The blindspot of introspection," Journal of Consciousness Studies 18, no. 1 (2011): 54.

${ }^{264}$ Anthony N. Perovich, Jr., "Mysticism and the philosophy of science," The Journal of Religion 65, no. 1 (1985): 69.

265 Hurlburt and Schwitzgebel, Describing Inner Experience, 253-54. For a discussion of how subjectivity defines context (environment) and why this entails that there is no such thing as a "shared environment" (p.110) in in respect to meaning, see Peter Fonagy et al., Affect Regulation, Mentalization, and the Development of Self (New York: Other Press, 2004), 97-142.

${ }^{266}$ A. Callinicos, Theories and Narratives (Durham, NC: Duke University Press, 1995), 82.
} 
sentences resemble each other - that in some special metaphysical way language as a "thing" reflects the nature and structure of the world as a "thing"). All the correspondence theory says is that concepts refer to phenomena and that the nature of these phenomena, whatever they may be, constrain what can be said about them. ${ }^{267}$

\subsubsection{Advantages}

The Cyclical Evocation-Analysis Interview Method synthesises the strengths of two respected qualitative methods in consciousness science. It has the following five advantages.

First, explicitation enhances cognitive access to past experiences through evocation. Second, explicitation has the technical expertise to investigate dynamic experience. ${ }^{268}$ Third, explicitation can non-inductively explore a practitioner's "field of experience". This means I can direct the attention of practitioner's who is in evocation to the event-perspective (objectside) or awareness-perspective (subject-side) and thereby expose the structure of consciousness for investigation.

Fourth, evocation and analysis, together, enhance reliability and clarity of descriptions, because evocation yields higher quality raw reports. Descriptions are clearer, because analysis develops "raw" reports into "exposed" reports and the latter are selfcorrected.

Fifth, my interview style heeds Hurlburt's advice to identify in vivo when subjects report false generalisations (through "subjunctifiers", such as "always", "usually", "typically" and "generally") and self-theories (for example, terms like "since" or "because"). This allows me to separate interpretations from descriptions during the interview and use that knowledge to guide practitioners away from theorising and towards describing.

\subsubsection{Limitations}

The Cyclical Evocation-Analysis Interview Method has three specific limitations or threats to validity.

First, my interviewing skill is the most critical factor for evaluating the quality and reliability of the first-person data. Two factors have significant bearing on the quality of the data I have obtained: (i) My training in the Explicitation Interview Technique was minimal; (ii) I began this project with no prior experience in qualitative interviewing. I have mitigated

\footnotetext{
267 Joseph A. Maxwell, A Realist Approach for Qualitative Research (Thousand Oaks, California: Sage Publications, 2012), 13.

${ }^{268}$ Hurlburt, "Descriptive experience sampling, the explicitation interview, and pristine experience in response to Froese, Gould and Seth," 68-75.
} 
the impact of these two factors by basing my conclusions on felicitous rather than accurate first-person data. ${ }^{269}$ Thus the goal is not accuracy in the sense of apodicticity. In my view, the data I have obtained are felicitous in the sense that they are minimally misleading and largely correct about the key features of the experiences under study.

Second, some of the first-person data are on experiences of the distant past, which involves a high demand on memory. Likelihood of errors and memory reconstruction is high. I cannot evaluate how significant this factor is, but it should be considered by the consumer of this research. I have mitigated this factor by basing my theorising primarily on firstperson data of prayer sessions completed within 24 hours prior to the interview.

Third, most of the first-person data are on dynamic experience (entire prayer sessions) rather than a single time slice (moment). Reporting dynamic experience is more error-prone. This drawback is unavoidable. I have mitigated this problem by switching back and forth between evocation and analysis. Thus most analytical work during interviewing is based on "raw" reports by participants whose speakings originated in evocation (an "embodied discourse position"). Evocation is non-inductive and theory deterring.

\subsection{Analysis}

In this section I will introduce the third module of my blended approach to phenomenology. Specifically, I will discuss how I analyse practice as a process. By "process" I mean phenomenal experience as temporally extended and dynamic. ${ }^{270}$ As promised earlier in this chapter (end of Section 2.4.3), I will begin with the problems I have identified in the analytical procedures of Giorgi's descriptive phenomenology. Next, I will discuss my own approach to analysis. Finally, I will conclude with four strategies I have employed to deal with validity threats.

\footnotetext{
${ }^{269}$ To consider "faithful" versus "accurate" first-person data, see fn.232 (p.57).

270 I exclude from this definition "cognitive processes" of the "cognitive architecture" kind, which are subpersonal (=not experientially lived through). This study neither makes causal conjectures about subpersonal processes nor explains underlying mechanisms. For a discussion of the range of conscious events that count as "personal-level" (=phenomenally apprehended), see Goldman, "Epistemology and the evidential status of introspective reports," 15. For a discussion of why we cannot expect introspective data to reveal subpersonal process, see Maja Spener, "Using first-person data about consciousness," ibid.18, no. 1 (2011): 173. For a discussion that reconsiders the possibility that introspection provides cognitive access to fundamental mental processes (subpersonal phenomena), see Claire Petitmengin et al., "A gap in Nisbett and Wilson's findings? A first-person access to our cognitive processes," Consciousness and Cognition 22, no. 2 (2013): 654, 65-68; Spener, "Using first-person data about consciousness," 173; Tom Froese, "Interactively guided introspection is getting science closer to an effective consciousness meter," Consciousness and Cognition 22, no. 2 (2013).
} 


\subsubsection{The Analytical Shortcomings of Descriptive Phenomenology}

Giorgi's "descriptive phenomenology" contains a theory of how to treat descriptions. ${ }^{271}$ His approach is unlike others because it delays interpretive leaps in the analysis, ${ }^{272}$ and thus description takes precedence over hermeneutics (interpretation). ${ }^{273}$

Giorgi offers a systematic procedure for description in post-interview data analysis. ${ }^{274}$ It consists of four steps: (i) read the entire transcript to obtain a sense of the whole; (ii) select meaning units (choose sections) of the transcript relevant to the phenomenon under study; (iii) transform the practitioner's description into psychological language so that it expresses psychological insights; (iv) synthesise the "transformed meaning units" into a single and coherent statement. ${ }^{275}$

In the study of contemplative experiences and practices, Giorgi's third step creates unfaithful first-person descriptions, because it is performed in a way that remains hidden from view. This renders opaque the relationship that exists between the evidence and the theory.

Specifically, Giorgi's approach rewrites practitioners' descriptions with the researcher's own language. The transformation occurs in the researchers own mind and by way of "a process of reflection and imaginative variation". ${ }^{276}$ Imaginative variation involves transposing oneself into the place of the other and then removing (in one's own mind) aspects of the phenomenon described to "test" whether specific aspects play an essential role in defining the phenomenon. ${ }^{277}$ This process arrives at a general category described in a different language.

Giorgi's procedure has two problems. First, imaginative variation is performed outside of the second-person exchange, where the researcher does not have cognitive access to the practitioner's vantage point, which poses serious threats to validity. Imaginative

\footnotetext{
${ }^{271}$ Giorgi, Phenomenology and Psychological Research, 2.

272 Giorgi is concerned with "adequate" description, but he is uninterested in how descriptions are obtained. Ibid., 3. Like Maurice Legault, I disagree with a cavalier approach to data collection, because, in our view, it is the most important step in obtaining reliable first-person descriptions.

${ }^{273}$ My training with Maurice Legault's in the Explicitation Interview Technique emphasised that interpretation should happen as late as possible in analysis and only once descriptions are rich and clear. It is for this reason that descriptions need to be separated from interpretations during interviewing. Patton discusses this process as a "basic tenet of research" so that "description comes first" in quality inquiry. Patton, Qualitative Research and Evaluation Methods, 438.

${ }^{274}$ Giorgi, Phenomenology and Psychological Research, 3.

${ }^{275}$ Giorgi outlines his 4-step procedure in one paragraph on page 10. He then goes on to discuss each step in greater detail. Ibid., 10-21. See also The Descriptive Phenomenological Method in Psychology, 125-37.

276 Phenomenology and Psychological Research, 17; The Descriptive Phenomenological Method in Psychology, 97.

277 The Descriptive Phenomenological Method in Psychology, 69, 97.
} 
variation is also a constructive process that leads to inaccurate and unfaithful descriptions. ${ }^{278}$ In respect to the subject matter of this project, apophatic contemplative states of consciousness are neither commonly observed nor accessed by way of imagination. This renders imaginative variation error prone.

Second, transformation of language makes it impossible for critical recipients of the research to evaluate how faithful the descriptions are, because the theoretical leap has already occurred in the analysis (the "transformation") and it has been built into the presented first-person descriptions. The process by which those descriptions have been transformed is also hidden from view, which renders opaque to recipients of the research the exact relationship between the descriptions offered as evidence and the phenomenological theory endorsed.

Both problems are exceptionally thorny in the comparative study of religion and the philosophy of mysticism. Theoretical debates in these fields concern just how descriptions are transformed into phenomenological accounts, because those descriptions have a close relationship to theorising on the metaphysical (phenomenal) nature of consciousness. For this reason "datum passages" must be laid out in the open and for all to view, ${ }^{279}$ and must also be faithful first-person descriptions true to the "emic" perspective and thus "experiencenear". ${ }^{280}$ Then the step-by-step transformation from "emic" to "etic" - from "raw description" to "phenomenological account" - must be performed in a way that is transparent.

\footnotetext{
${ }^{278}$ For a discussion of why descriptions cannot be simply ascribed to people and why religious experiences must be specified and interpreted "without unduly violating the lived experience of those within them", see Taves, Religious Experience Reconsidered, 126. For a discussion of why one can only specify something as an experience if and only if it is described from the participant's own vantage point, see Wayne Proudfoot, Religious Experience (Berkley: University of California Press, 1985), 180-81. For a discussion of why "descriptive validity" only obtains if and only if descriptions are faithful to the emic perspective, see Maxwell, $A$ Realist Approach for Qualitative Research, 138.

${ }^{279}$ Here is an example of what I am talking about: Katz argues that all mystical experiences are determined and shaped by context (Katz never specifies exactly what this context is). To this end, Katz appeals to "empirical evidence". "Language, epistemology and mysticism," in Mysticism and Philosophical Analysis, ed. Steven T. Katz (New York: Oxford University Press, 1978), 33-36. However, Pike shows that the recipient of Katz's reasoning must infer the evidence, because "Katz fails to tell us exactly what they [the datum passages] are or where to find them". Mystic Union, 201-04. The problem here is that the recipient must peruse those "datum passages" to conclude for himself whether he is willing to accept Katz's reasoning. This is an example where theoretical debate in the philosophy of mysticism requires evidence and analytic work to be explicitly laid out for all to view.

280 Maxwell points out that accounts should be first based on the framework of those whose experiences are in question and only then engaged from a different perspective. A Realist Approach for Qualitative Research, 138.
} 


\subsubsection{A Phenomenographically Inspired Case Study Approach to Analysis}

My approach to analysis follows Pike's example in Mystic Union. I conduct phenomenological analyses and theorise in a way that can be scrutinised by others. I begin with untransformed "emic" first-person descriptions by making them available to the recipient of my reasoning. I then develop a transparent phenomenological account by drawing on the conceptual framework I have outlined (module 1). It is by means of this framework that I transform "raw"/“exposed” descriptions into phenomenological accounts.

My analysis consists of: (i) a case study approach; (ii) a connecting analysis strategy that is focused through (iii) a rationale for comparison (which guides within-case analysis); and (iv) a conceptual framework employed to (v) phenomenologically analyse the "raw"/"exposed" descriptions in a way that explicitly spells out the relationship between the descriptive evidence and the theory developed.

I began analysis by organising the data into cases for in-depth study, ${ }^{281}$ where each contemplative represented a single case ("unit of analysis"). I worked with 20 cases. ${ }^{282} \mathrm{I}$ pulled together the raw data for each case by transcribing interviews verbatim and in full (255,609 words in total), and then constructed a case record for each practitioner that included all the information I had available. ${ }^{283}$ This included personal and demographic information obtained through a preinterview questionnaire and any additional comments or written material (e.g., publications on the topic authored by practitioners).

Next, I wrote case studies taking Patton's advice to select cases that were most instructive (10,000 to 30,000 words per case; 120,000 words in total). ${ }^{284} \mathrm{I}$ began with three information-rich typical cases to illustrate the basic tenets of the method of centering prayer "to those unfamiliar with the setting". 285 These cases covered the early stages of the Christian contemplative path, as conceived by the Centering Prayer tradition (outlined in Section 3.6).

Then I wrote two variant cases to consider how the method of centering prayer changes in the intermediate stages of the contemplative path. I also applied the following logic to analysis: any patterns that may become salient despite variation strengthens the case for the existence of a core phenomenon or process common to centering prayer across cases and contexts. ${ }^{286}$

\footnotetext{
281 Patton, Qualitative Research and Evaluation Methods, 447.

282 For a discussion of "units of analysis", see ibid., 228-30.

283 Ibid., 449-50.

284 Ibid., 233.

285 Ibid., 236.

286 Ibid., 234-35.
} 
Finally, I also wrote two advanced case studies that covered the higher reaches of Christian contemplation, as outlined by the Centering Prayer tradition. ${ }^{287}$ This includes "transforming union" and "unity consciousness". However, due to space constraints, I have excluded how Centering prayer contemplatives experience the higher reaches of Christian contemplation, as conceived by them, from this work.

Each case study consisted of four sections: (1) biography and context; (2) significant experiences; (3) present practice; and (4) summary. Section 1 consisted of a narrative account of the practitioner's life and explored contextual influences (past experiences, relationships, education, upbringing, etc.). I also included data on the first point of analogy of my comparative framework (goals and motivations).

Sections 2 and 3 described and analysed practitioners' experiences and practices in a way analogous to Pike's phenomenographical approach. ${ }^{288}$ I applied my conceptual framework to discuss the second and third points of analogy (practice and states of consciousness). I included theoretical reflections that: (i) drew practitioners into dialogue with primary sources; and (ii) related their descriptions to theoretical discussions in the science of consciousness and philosophy of mysticism.

I used a broad connecting strategy to analyse practices and past experiences as temporally extended and dynamic phenomena. The "connecting approach" analyses experiences and practices as sequences of interrelated conscious events. This approach enabled me to chronologically present the experiences and practices and preserve the local web of networks between (a) conscious events and (b) conscious events and their situating states of consciousness. ${ }^{289}$ The connecting strategy does not offer a causal explanation.

Rather, it is a "descriptive precursor" to causal reasoning that accounts for how practitioners experience the activity as a temporally unfolding sequence (depicted in Figure 7 below). ${ }^{290}$

Section 4 summarised the practice and considered how it might have changed over time. I included a practice sequence diagram that I adapted from an "event-state network" or "event-listing matrix". The diagram is a "visual and processual adaptation and representation" that "organises events chronologically" (For example, ${ }^{291}$ Figure 7). ${ }^{292}$ It is not a causal model.

\footnotetext{
${ }^{287}$ The cases I chose are considered by the emic "community of the adequate" to be accomplished.

288 I discussed Pike's approach in Section 2.5.5.

${ }^{289}$ Maxwell, A Realist Approach for Qualitative Research, 35-44; 115-24.

290 Miles, Huberman, and Saldana, Qualitative Data Analysis.

${ }^{291}$ I discuss Joseph's practice in Section 4.3.2, Section 4.4.1.1, Section 4.4.2.1, Section 4.5.2.2, and Section 7.6.

292 Miles, Huberman, and Saldana, Qualitative Data Analysis, 209-11; 39-40.
} 


\section{Figure 7. Joseph's Practice Sequence}

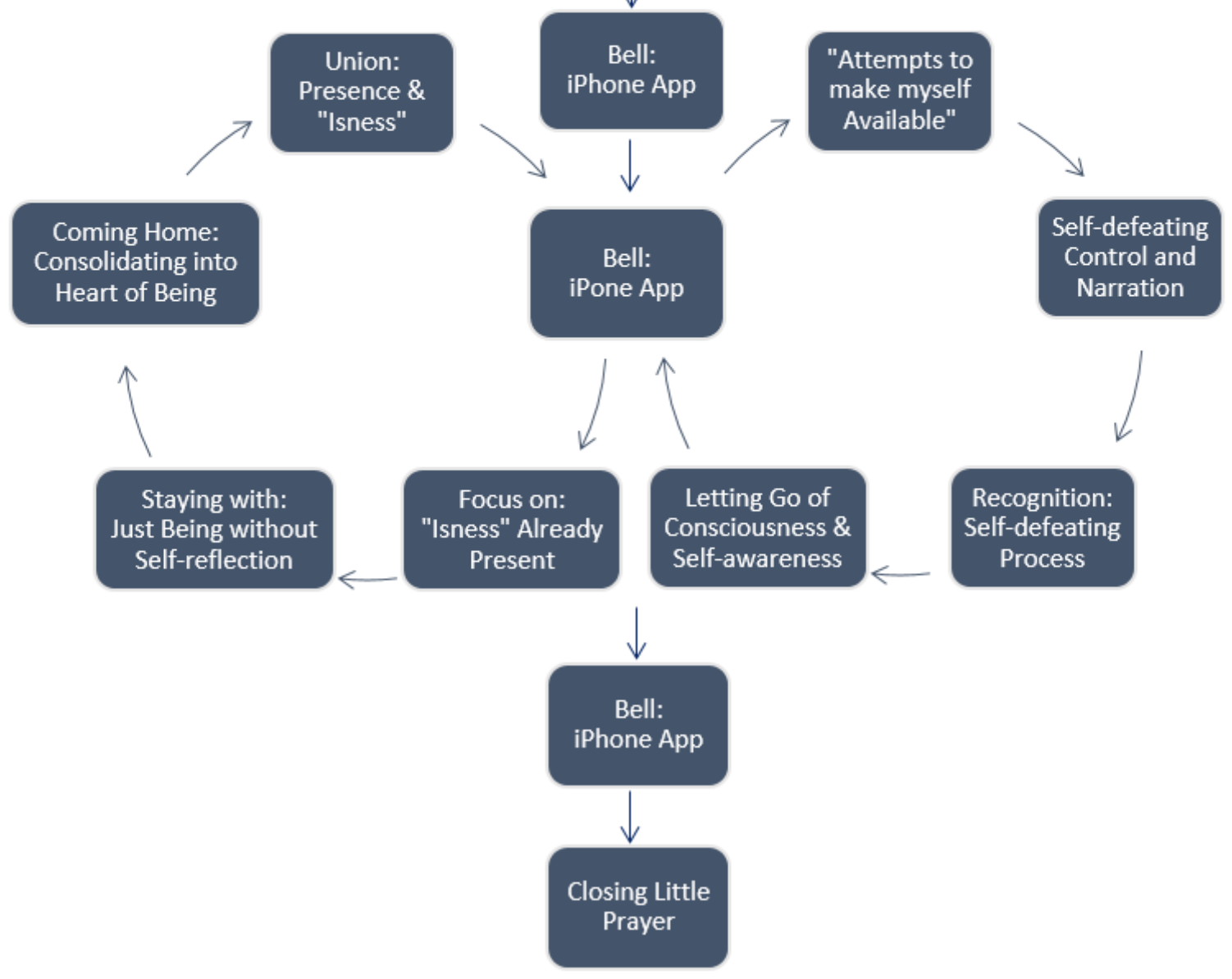




\subsubsection{Strategies of Validation}

I have employed four strategies to strengthen the validity of evidence and theorising: (1) selfcorrecting interviews; (2) peer review and debriefing; (3) member-checking; and (4) triangulation.

My first strategy incorporates a collaborative and Socratic-style inquiry into the interview process that refines descriptions and validates interpretations in vivo. This is known as the "self-correcting interview".293

My second strategy relies on an external checking-mechanism whereby someone other than the researcher cross-checks and questions the principal researcher's analysis. ${ }^{294}$ The backbone of my own analysis are case studies and they have left a trail of my analytic process that has been peer reviewed and debriefed by my advisor, Michael Radich. He perused the first-person data presented in the case studies and observed how I transformed them into phenomenological accounts. He played "devil's advocate" to keep me honest and raised questions about the relationship that exists between description and theory.

Third, I shared the case studies with the respective practitioners who then provided feedback and confirmed the descriptions and analyses. "Member checking" is "the most crucial technique for establishing credibility". ${ }^{295}$ I negotiated the emic/etic divide by giving "members of the group" the opportunity to respond to the material and judge its accuracy and credibility. ${ }^{296}$

Fourth, I compared ("triangulated") first-person descriptions with evidence from other sources. This established a feedback loop between primary sources and the data bank generated by committed centering prayer practitioners. In this way, my project initiates a conversation between practitioners' vantage points and: (i) traditional source material; (ii) guidebooks to practice; and (iii) theoretical debates about the nature of contemplative experiences and practices in etic scholarship. This has produced a rich picture wherein multiple sources of information mutually inform each other. ${ }^{297}$

\footnotetext{
293 Kvale and Brinkmann, InterViews, 111; 35-36; 64; 95-96.

${ }^{294}$ Creswell, Qualitative Inquiry and Research Design, 251.

295 Yvonna S. Lincoln and Egon G. Guba, Naturalistic Inquiry (California: Beverly Hills: Sage Publications, 1985), 314.

296 Ibid., 314-16; Creswell, Qualitative Inquiry and Research Design, 252.

297 Naturalistic Inquiry, 304-07, 15-16; Qualitative Inquiry and Research Design, 251.
} 


\title{
Chapter 3
}

\section{The Contemplative Path of Centering Prayer: A New Christian Soteriological Vision}

\begin{abstract}
"A little experience of Satori in Buddhism, or prayer of quiet or union in Christianity, is simply a taste of something that is inviting you to ever deeper self-surrender. At THAT point there is no effort. Everything is grace. But before that appropriate effort is necessary, and one is a meditation practice and a conceptual background for it from whatever tradition you are from." 298
\end{abstract}

- Father Theodore

\subsection{Introduction}

In this chapter I will synthesise the conceptual framework of the practice of centering prayer from multiple primary sources to lay the groundwork for the phenomenological data. This will culminate into an entire map of the Christian contemplative path, as outlined by the Keating School of Centering Prayer. Although my expository strategy forces me to present this conceptual overview prior to the first-person data and phenomenological analyses, my discussion of the path and its stages is informed by the phenomenological accounts developed in this study and thus subservient to the first-person data I will present and analyse in the chapters that follow.

In $\underline{\text { Section } 3.2}$ and Section 3.3 I will begin by considering centering prayer as an apophatic and path-oriented contemplative practice, to then outline Centering Prayer's model of human consciousness and selfhood. I will follow this up in Section 3.4 with a discussion of Centering Prayer's leitmotif and Sprengmetapher of the "centre", which undergirds the model and identifies the place where God is.

I will then turn to Pennington's account of the soteriological project at work in centering prayer (Section 3.5). In his view, centering prayer leads to a transformation of consciousness that experientially reveals God as pure consciousness.

Next, I will draw on Keating and Frenette in Section 3.6 to map out the Christian contemplative path as envisioned by the Centering Prayer tradition. I will begin with the initial stages of prayer that are encountered “on the cushion”. The Keating School considers these initial stages - including all species of the "genus of union experiences" 299 - to be transitory stepping stones on the Christian journey.

Finally, in Section 3.7 I will continue to draw on Keating and Frenette to discuss their view of the higher reaches of the Christian path (transforming union) and its soteriological

\footnotetext{
298 Interview \#28.1, p.7.

${ }^{299}$ Pike, Mystic Union, 114.
} 
goal (unity consciousness). Both later stages are distinct from the earlier stages of prayer, which cultivate temporary union states, because they are abiding union states that persist "on and off the cushion".

\subsection{Apophatic and Path-Oriented Contemplative Practice}

\subsubsection{Centering Prayer as Apophatic Practice}

In this section I focus on apophatic and kataphatic forms of mysticism. I will begin by defining what I mean by a "form of mysticism".

I use the term "mysticism” in McGinn's and Gellman's broad senses, not restricted to rare types of direct experience. I agree with McGinn that mysticism is a larger "process or way of life" that prepares for, and reacts to, the immediate consciousness of the presence of God, or ultimate reality however defined. ${ }^{300}$ Gellman defines mysticism in a similar way, as "a constellation of distinctive practices, discourses, texts, institutions, traditions, and experiences aimed at human transformation". ${ }^{01}$ Both definitions conceive mysticism as a larger system that engages an ongoing process before and after aimed for mystical experiences. By a "form" of mysticism, then, I shall mean the way this larger process operates.

The apophatic versus kataphatic distinction helps characterise this process. ${ }^{302} \mathrm{I}$ divide this process into three main steps: (i) how we speak of the resulting experience; (ii) how we cognise in the moment of the experience; and (iii) how we practice to prepare the ground. I will speak of kataphasis in terms of "speaking with", "cognising with" and "practicing with" the human faculties, and I will speak of apophasis in terms of "speaking away from", "cognising without" and "practicing without" the human faculties. Let us first consider kataphatic forms of mysticism, which proceed by way of affirmation and rely on the human "faculties" to react to, mediate and prepare for mystical experiences. I will discuss these steps in the order I have presented them, being the reverse in which things occur.

In reaction to consciousness of God's presence, kataphatic approaches (understood as "speaking with") use positive language to speak about God. This includes "positive language of presence". ${ }^{303}$ Images may describe God directly and in non-metaphorical ways. ${ }^{304}$ The

\footnotetext{
300 McGinn, The Foundations of Mysticism (1300-1500). Vol. I of The Presence of God, xv-xvii.

301 Jerome Gellman, "Mysticism," http://plato.stanford.edu/entries/mysticism/. Accessed 6th of February, 2017.

${ }^{302}$ For example, Centering Prayer utilises this distinction to explain how its method and process work.

${ }^{303}$ Michael A. Sells, Mystical Languages of Unsaying (Chicago and London: The University of Chicago Press, 1994), 3; McGinn, The Foundations of Mysticism (1300-1500). Vol. I of The Presence of God, xviii.

${ }^{304}$ Sells, Mystical Languages of Unsaying, 3; Paul C. Martin, "The Art of Mysticism: An Inquiry into the Notion of Ineffability in (Cataphatic) Mystical Experience" (University of Queensland, 2006), 3.
} 
traditional study of Christian mysticism has so far, by and large, restricted itself to this step of the mystical process. Thus traditional literature, including McGinn's seminal work on The Presence of God, understands kataphasis to mean how language is positively and reactively employed to talk about God and the consciousness of God's presence.305

However, Martin has recently argued that kataphasis defines a form of mysticism that engages the human faculties to realise the mystical experience itself. The "cognitive powers of the imagination and understanding” play a necessary role in making God's presence cognitively accessible. "God as seen by, and indeed as, the divine light," Martin claims, "is realized by the power of the imaginary (i.e., imagination plus understanding) to be the presence of God, after which it is recognized", and it is only then that an experience is available "to be enunciated" with affirmative language. ${ }^{306}$ In Martin's account, then, kataphasis (as in "cognising with") also describes the way the human faculties are involved in the consciousness of God.

Gellman has recognised that the Centering Prayer tradition has gone a step further by treating kataphasis and apophasis as modes of contemplation and thus as descriptive of the kind of "preparatory regimen" involved in "getting into position for mystical consciousness". ${ }^{307}$ In this respect, kataphatic contemplation (as in "practicing with") is conceived as practice that uses "positive" techniques. ${ }^{308}$ The term "positive" points to how the preparatory regimen draws on "human faculties" such as reason, memory, imagination, visualisation and affection to access mystical consciousness. ${ }^{309}$

While kataphatic forms of mysticism (to now follow the actual order in which things occur) "practice with" human faculties, "cognise with" imagination and understanding, and "speak with" images directly about God, apophatic forms of mysticism do-away-with the human "faculties" and related imagery to prepare for, mediate and react to, mystical experiences. I will once more discuss the steps in reverse order in which things occur and begin with the reaction.

In reaction to consciousness of God's presence (or absence), apophatic approaches (understood as "speaking away from") add negative language to speak about God and the resulting experience, especially by way of the "more paradoxically and dialectically simultaneous" negative language of presence and absence. ${ }^{310}$ McGinn observes that the

\footnotetext{
305 McGinn's understands "cataphatic" and "apophatic" as "verbal strategies" that mystics use to symbolise their mystical transformation and in this way "convey their message". The Foundations of Mysticism (13001500). Vol. I of The Presence of God, xviii.

306 "The Art of Mysticism: An Inquiry into the Notion of Ineffability in (Cataphatic) Mystical Experience," 2.

${ }^{307}$ Gellman, "Mysticism", Section 2.4.

308 Ibid.

${ }^{309}$ Cynthia Bourgeault, Centering Prayer and Inner Awakening (United Kingdom: Cowley Publications, 2004), 31; Thomas Keating, Open Mind, Open Heart (New York: Bloomsbury Academic, 2006), 5.

${ }^{310}$ The Foundations of Mysticism (1300-1500). Vol. I of The Presence of God, xviii.
} 
addition of absence in the dialectic not only reflects "the modern consciousness" of an "absent God", but it is also a way for practitioners to refuse to make God yet another "thing" that, like everything else we experience, presents itself to us. Thus McGinn raises the question: "Is not a 'present' God just one more thing?"311 To talk about the "real God", then, practitioners make sure to negate the "many false gods (even the God of religion)" and in this way point out how the many false images of God are absent. ${ }^{312}$ In the chapters that follow, I will show that McGinn's observation applies to the kind of apophatic discourse Centering Prayer practitioners engage in.

McGinn also argues that the discourse of God's presence-absence is prima facie paradoxical. The paradox lies in the fact that apophatic discourse tries to linguistically accommodate for the fact that language is unable to name or ascribe attributes to the "real God". Apophasis concludes that the presence-absence of God is ultimately ineffable and anything said about God - be it positive or negative - must be followed by correcting statements ad infinitum. Thus apophatic discourse accepts linguistic regress: anything said is followed by a statement that turns back on itself. Apophasis, then, is a dynamic series of retractions that are propositionally unstable. ${ }^{313}$

According to the Centering Prayer tradition, apophatic forms of mysticism go beyond matters of language to also "pass beyond" 314 or "bypass" 315 our human faculties (e.g., reason, memory, imagination) in the mystical consciousness itself, which comes forth unmediated. Here apophasis (as in "cognising without/beyond”) describes the way consciousness of God's presence-absence is realised without involvement of the human faculties. The type of consciousness involved is typically described as "formless", "imageless" or "of no thing". McGinn refers to this as the "consciousness of God as negation" because awareness of God is not mediated by the human faculties attuned to detecting the presence of objects. Rather, consciousness of God as negation reveals the "absence of God". ${ }^{316}$ In this spirit, Frenette claims that, "The only way to 'see' God face to face is to remain in the darkness of unknowing." ${ }^{17}$ The "darkness of unknowing" is his way of speaking about "seeing" without the human faculties. He also refers to this way of seeing as "contemplative unknowing", which has as its object "God's unseen presence within" - another way of speaking about God's presence-absence. 318

\footnotetext{
311 Ibid.

312 Ibid.

${ }^{313}$ Sells, Mystical Languages of Unsaying, 2-3.

${ }^{314}$ Keating, Open Mind, Open Heart, 5.

315 Bourgeault, Centering Prayer and Inner Awakening, 32.

${ }^{316}$ McGinn, The Foundations of Mysticism (1300-1500). Vol. I of The Presence of God, xviii.

317 David Frenette, The Path of Centering Prayer (Boulder, Colorado: Sounds True, 2012), 72.

318 Ibid.
} 
Finally, Centering Prayer treats apophasis as the mode of contemplation (as in "practicing without") that prepares the practitioner to become conscious of God's presenceabsence. Gellman presents Keating as claiming that, "apophatic preparation involves a practice of 'emptying' out of other conscious content in order to 'make room' for the apprehension of God, who is beyond our discursive, sensual natures." ${ }^{19}$ This is unfortunately an unfaithful representation of the method, because Keating clearly spells out that practitioners should avoid manipulating their experience to either "have no thoughts" or "make the mind a blank". ${ }^{20}$ Instead, Keating and Bourgeault recommend a "laissez-faire attitude" toward any content of consciousness. This translates into a simple "Four R" formula: "resist no thought; retain no thought; react to no thought; return to the sacred word." ${ }^{21}$ Since this preparatory regimen does not rely on the coarse "faculties", practitioners report practice to be "a dark path". ${ }^{222}$ Bourgeault explains that the state might feel "amorphous", like an “emptiness" or "nothingness". ${ }^{223}$

To conclude, centering prayer is an apophatic contemplative practice that "does away with" the human faculties in the lead up to the immediate consciousness of God's presenceabsence. In reaction to this consciousness, published teachers of centering prayer employ apophatic discourse to talk about God and their consciousness of God's presence-absence. In this way, Centering Prayer, as a tradition, has contributed to the study of mysticism by expanding the notions of kataphasis and apophasis to be descriptive of the entire system of mysticism, especially the preparatory regimen. ${ }^{324}$ I will continue to use the term apophasis in this broad sense, which includes, but is not limited to, a linguistic reaction that aims to communicate the transformation of consciousness.

\subsubsection{Centering Prayer as Path-oriented Practice}

Path-oriented contemplative practice distinguishes itself in three ways from secular, decontextualised meditation practices. ${ }^{325}$ First, path-oriented practice is teleological in the sense that it is practiced for a spiritual purpose. Its directive principle is a soteriological goal

\footnotetext{
${ }^{319}$ Gellman, "Mysticism", section 2.4.

320 Open Mind, Open Heart, 180.

${ }^{321}$ Centering Prayer and Inner Awakening, 39-40; Open Mind, Open Heart, 104. For Keating's broad definition of thought, see ibid., 178.

322 Jason, Interview \#20.1, p.13.

${ }^{323}$ Centering Prayer and Inner Awakening, 32.

${ }^{324}$ I agree with Keating that scholarship which presents the two approaches as singular and self-contained expressions of the contemplative life is in error. Keating, Intimacy with God, 126.

325 My view of "path-oriented" practice is similar to Komjathy's view of "religiously-committed" forms of practice. "Approaching contemplative practice," 22. See also Lindahl's "goal-oriented contemplative path". "Paths to luminosity: A comparative study of ascetic and contemplative practices in select tibetan Buddhist and Greek Chrisitan traditions," 38.
} 
specified by the tradition (I discuss "unity consciousness" in Section 3.7.2). Second, pathoriented practice has a developmental trajectory outlined by the tradition. This path has

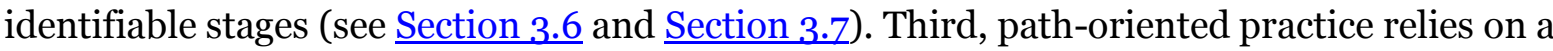
system of training that actualises the process of transformation. I will now discuss the system of training I see at work in centering prayer.

In Analytical Buddhism, Albahari argues that the system of training involved in Theravada Buddhism consists of a twofold project: the first stream of the training regimen "dismantles the co-dependent sense of self and tanhā [desire]"; the second stream "simultaneously uncovers the real character of the native awareness such that it comes to reflexively know itself as it is in itself." ${ }^{26}$ My view is that the system of training involved in path-oriented contemplative practices involves analogous twofold projects. The training regimens follow the same logic. I will now discuss how such a twofold system of training is at work in centering prayer.

According to Father Theodore, centering prayer fosters (1) a "deep awareness of the self" combined with (ii) "the motivation to put up with the purification process" ${ }^{327}$ Keating's major works Open Mind, Open Heart, Invitation to Love, Intimacy with God and Manifesting God also present centering prayer as having two streams in its system of training.

The first, phenomenological stream navigates the domain of consciousness through "spiritual attentiveness". Spiritual attentiveness is a capacity specific to consciousness and concerns the awareness of the presence of God. This awareness structurally changes as practitioners progress through the stages of contemplative prayer. Keating says, "As we climb the ladder of consciousness... our idea of God expands and God ceases to relate to us at the other levels." ${ }_{228}$ Thus the phenomenological stream transforms consciousness in ways necessary to come to a consciousness of God as God is. ${ }^{329}$

The second, psychological stream navigates the psychodynamics of the "false" self though "divine therapy". Divine therapy is a process of purification that progressively heals misguided "emotional programmes for happiness". Keating's psychology lists three such programmes that attempt to meet unmet needs in the areas of: (i) survival and security; (ii) affection and esteem; and (iii) power and control. Each area is driven by desire. Events that

\footnotetext{
${ }^{326}$ Albahari, Analytical Buddhism, 207.

${ }^{327}$ Father Theodore is a Trappist monk, respected teacher of Keating School Centering Prayer and a collaborator in this study. Interview \#28.1, p.29.

${ }^{328}$ Keating, Intimacy with God, 69.

${ }^{329}$ The Cloud points to this phenomenological project by urging the practitioner to take the following approach: "See that nothing remains in your conscious mind save a naked intent stretching out toward God. Leave it stripped of every particular idea about God (what he is like in himself or in his works) and keep only the simple awareness that he is as he is. Let him thus, I pray you, and force him not to be otherwise." See Johnston, The Cloud of Unknowing, 138.
} 
frustrate this desire cause afflictive emotions such as anger, grief, fear, pride, greed, envy, lust and apathy.330

The goal of the psychological stream is to progressively withdraw emotional investment from these distracting emotional programmes in order to stabilise awareness "on" the presence of God. ${ }^{31}$ This remedies the original error of these emotional programmes to compensate for the "absence of the sense of God's presence" in different ways. 332 To withdraw emotional investment, internal resistances and distractions have to be addressed through psychodynamic and affect regulation work that initially takes place in the centering prayer practice itself. Keating refers to this work as "divine psychotherapy".333

The key idea of this "divine therapy" is that a relaxed and loving attention (cultivated by the relational quality of centering prayer) reduces ego defences and invites repressed emotional content to rise. This content is then healed through acts of transference where God replaces the therapist as the recipient of transference. In the earlier stages of divine therapy, practitioners experience the purification process of repressed emotional trauma by way of a phenomenon called "unloading of the unconscious". "Unloading" occurs sporadically during practice and has specific marks that identify its occurrence (e.g., a sudden emotional and/or physical discomfort that has no apparent cause or reference). As practice advances, purification becomes more subtle so that it goes on all the time in and outside of seated prayer without its identifiable marks. 334

Eventually, as the practitioners advance in this psychodynamic work, they pass through three specific and developmentally critical stages called "dark nights". Those are: the "night of sense", the "night of spirit" and, finally, the "night of self". Passing through these dark nights is necessary to stabilise awareness in God's presence-absence and to enter into the farthest reaches of the Christian contemplative path, as conceived by the Keating School of Centering Prayer.

In this way, centering prayer progressively dismantles the false self through attention to the psychodynamics of desire (psychological stream). This, in turn, frees the basis of operation (witnessing) from distracting content (event-perspective) so that it can progress through the levels of awareness until it comes to an abiding consciousness of God's presence-absence as God is (phenomenological stream).

This study exclusively focuses on centering prayer's phenomenological stream of path-oriented practice. This does not reflect a negative judgment on the value of the psychological system of training, which is just as important to the entire system of path-

\footnotetext{
${ }^{330}$ Keating, Invitation to Love, 24.

${ }^{331}$ Open Mind, Open Heart, 16.

332 Intimacy with God, 42.

333 Ibid., 24.

334 Ibid., 68.
} 
oriented practice. I have a practical and theoretical reason for sectioning off the psychological stream. First, focus on one stream allows me to offer a detailed and in-depth account otherwise unrealisable, given space and time limitations of this study. Second, the phenomenological stream is highly relevant to contemporary debates in consciousness science and the philosophy of mysticism, among others. First-person data of this stream contribute to the debates.

\subsection{The Keating School's Model of Levels of Awareness and Self}

Centering Prayer's conceptual framework rests on a simple model of consciousness and selfhood that carves out the terrain to be traversed on the contemplative path. Keating depicts the terrain through a bull's-eye diagram of the "levels of awareness" (see Figure 8 below). 335

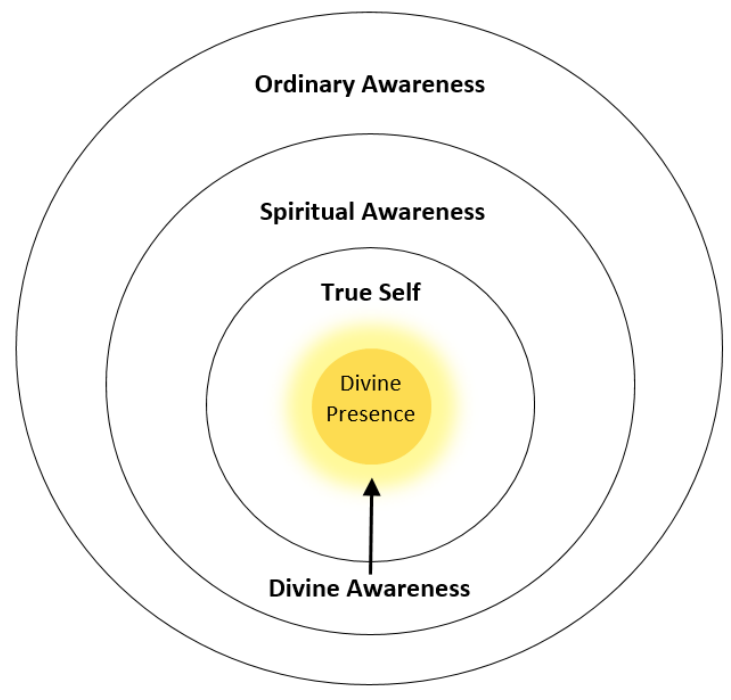

Figure 8. The Levels of Awareness

I will focus on the model of consciousness first and then consider the self. In respect to consciousness, Keating distinguishes between three levels of awareness. Each has its own type of content. The levels are: (i) ordinary awareness; (ii) spiritual awareness; and (iii) divine awareness (Bourgeault points out that the "divine presence" at the centre should be understood as our "divine awareness" and thus the third level of awareness. ${ }^{336}$ ). I will treat each in turn.

The first level, "ordinary" awareness, pertains to the mode of consciousness operative in daily life. This is the domain where we experience psychological content. In fact, ordinary

\footnotetext{
335 The figure is adapted from ibid., 30.

${ }^{336}$ I consider Bourgeault to faithfully represent Keating on divine presence/awareness. Centering Prayer and Inner Awakening, 9, 13.
} 
awareness is experienced as the very content it comprises. Keating lists the content this consciousness may consist of: sense perceptions, feelings, images, memories, reflections and commentaries, and the like.337 My etic term for this type of content is "coarse-level" 338 .

Keating draws on a river metaphor to further describe his model of consciousness (Figure 9 below). 339 He compares consciousness to a stream that flows toward the sea. Ordinary awareness is then interchangeably compared to the "surface of the river" and the boats that float on it. Thus ordinary content "flows along the surface of our awareness like boats on a river". ${ }^{340}$ It is ambiguous what exactly equates to ordinary awareness in the metaphor (surface versus boats). In my view, Keating's descriptions of ordinary awareness suggest "surface of awareness" to means just the multitudes of content (Figure 9A). Consider the following analogy to rain. At first only a few drops hit a flat piece of glass, one by one, and each resounding contact is detected as a distinct content of awareness (a boat on the river). If we increase the amount of drops that hit the glass surface, the gap between each sound of a drop hitting the glass surface will decrease until, at some point, there is an experience of a continuous, unified sound of rain (not individual drops) hitting the glass surface. This ongoing and apparently gapless experience constructs a unified sense of "surface consciousness". I interpret Keating's ordinary awareness in this way, because he frequently points to the boats to describe the surface of our awareness.

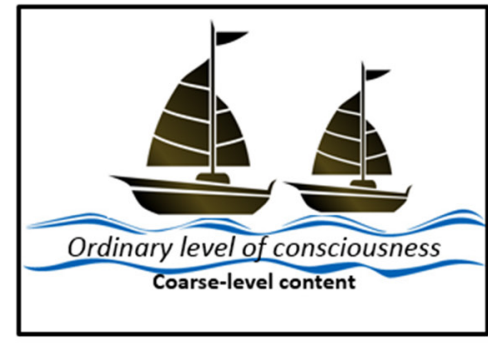

$9(A)$

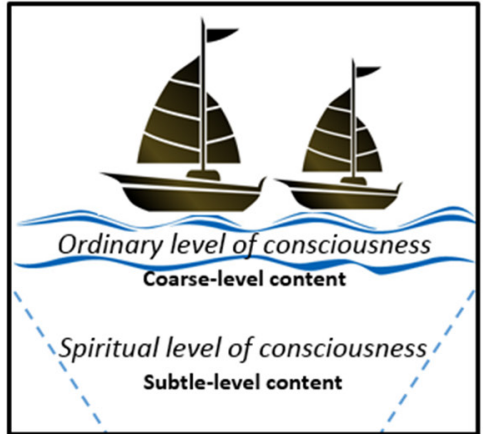

9(B)

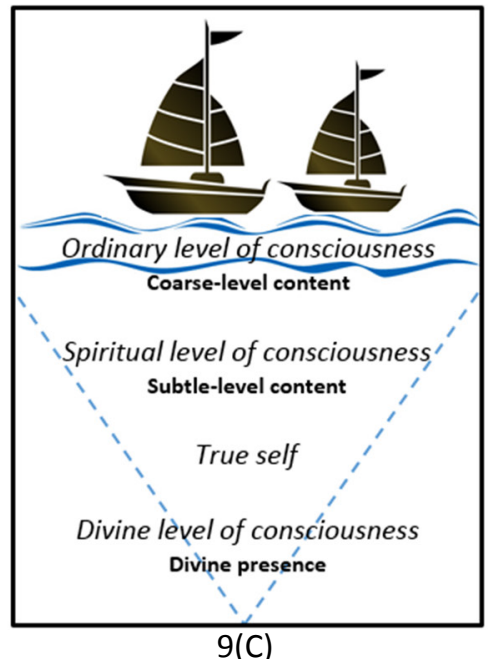

Figure 9. The River Metaphor of Consciousness

\footnotetext{
337 Intimacy with God, 25.

${ }^{338}$ My use of the term "coarse" has been inspired by Brown's delineation of levels of mind and his statement that, "The coarse level pertains to mental content, such as thoughts, sense perceptions, and emotions." Pointing Out the Great Way, 9.

${ }^{339}$ The figure is adapted from Intimacy with God, 25.

340 Ibid.
} 
This is not to deny that consciousness underlies this experience as an a priori condition of its possibility. But this prior consciousness is just what Keating would identify as the second level of "spiritual" awareness (Figure 9B). ${ }^{341}$ He says, "The river itself stands for the spiritual level".342 The practitioner becomes aware of this deeper level of awareness by a repeated "shift of awareness from the boats and objects on the surface to the river itself". Keating views this river to be "that which sustains our faculties and is their source", and he clarifies that the shift is a "turning" of awareness from "forms to the formless" and from "images to the imageless". 343

The notions "formless" and "imageless" suggest that an apophatic form of mysticism is at work in the preparatory regimen. This regimen relies on the psychological and phenomenological systems of training running in tandem. For example, a practitioner withdraws awareness from objects to settle into interior silence (phenomenological move). To achieve this, objects must be divested of emotional investment (psychological move). Thus the first stream explores the levels of awareness by way of attention; the latter cultivates freedom from attachment through psychodynamics. Through non-attached attention, the practitioner can then stabilise her basis of operation (witnessing) in the interior, formless silence (depths of the river). This stabilisation improves with purification, driven by repeated acts of surrender ("letting go").344 In sum, the goal is not detachment (rejection or suppression of content) but non-attachment (freedom of awareness).345

The dual process of exploring the levels of awareness and cultivating a non-attached disposition eventually gives birth to "spiritual attentiveness". Keating defines it as "the ability to be conscious of two levels of awareness at the same time". ${ }^{346}$ It is a dual-mode awareness where the practitioner is simultaneously conscious of the coarse-level content of ordinary awareness and, what I call, the "subtle-level" 347 content of spiritual awareness, which includes interior stillness, silence and spaciousness. Keating says, "You can be aware of the noise in or around you, and yet you recognise that your spirit is grasped by something at a deeper level... a substantial silence." 348

\footnotetext{
${ }^{341}$ Keating says, "The river itself is the participation God has given us in His own Being. It is that part of us on which all the other faculties rest, but we are ordinarily unaware of it." See Open Mind, Open Heart, 47. 342 Intimacy with God, 25.

${ }^{343}$ Open Mind, Open Heart, 47, 122.

344 Ibid., 44.

345 Ibid., 46.

346 Ibid., 44.

347 My use of the term "subtle" has been inspired by Brown's levels of mind (see $\underline{\mathrm{fn} .338}$ on p.81) and Frenette's use of the term to refer to how the "awareness of God's presence within" is experienced at the spiritual level of awareness. The Path of Centering Prayer, 178, 205. Frenette identifies the relevant subtle-level content as interior "silence", "stillness", and "spaciousness". Ibid., 81, 83, 91.

348 Open Mind, Open Heart, 44.
} 
The third level, "divine" awareness, is deeper still. Practitioners use a "language of the centre" to describe how a "sense of presence" dwells at the "source" or "ground" of their being (Figure 9C). ${ }^{349}$ This is "very subtle" 350 content for which apophatic discourse becomes more predominant. References to both God's presence and absence emerge and interact with the concept of the centre. The centre is considered the domain where "union with God" takes place and the "presence of God" is experienced (both states are initially dualistic). Thus Keating answers the question, "What happens when we hit the center?" with, "Divine union". ${ }^{351}$ According to the Centering Prayer tradition, the experience of the presence of God (as the core of our own existence) is possible because of the thesis of the divine indwelling. The thesis holds that the centre of our being is also the centre of God and thus where God is.

I will now turn to the place of the self in this model. Keating discusses three different types of self. Those are: (i) the false self; (ii) the true self; and (iii) the separate-self sense. The false and true selves must be understood in Jungian and psychodynamic terms. Hence they fall under the working of the psychological stream of centering prayer's twofold system of training. In contrast, the separate-self sense must be understood in respect to structures of consciousness, not its content. Hence the experiential issue of the separate-self sense must be examined by way of awareness itself. This project falls under the emphasis of the phenomenological stream of centering prayer's system of training. ${ }^{352}$ I will clarify this distinction by discussing each type of self in turn.

I will begin with the false self. In the glossary of terms in Open Mind, Open Heart Keating defines the false self thus:

\footnotetext{
The self developed in our own likeness rather than in the likeness of God, and thus the distortion of the image of God in which we are created. It seeks happiness in gratifying the instinctual needs of survival/security, affection/esteem, and power/control, and it bases its self-worth and identity on cultural and group identification. ${ }^{353}$
}

The false self is not innate but acquired. ${ }^{354}$ It is gradually constructed throughout childhood on the basis of accumulated trauma once consciousness has differentiated itself from its environment (self-reflective consciousness). The trauma that then accumulates from growing

\footnotetext{
349 Intimacy with God, 29.

${ }^{350}$ My use of the term "very subtle" has been inspired by Brown's levels of mind (see fn.338 on p.81) and Frenette's use of this term to describe the sense of "God's indwelling presence" in union states. The Path of Centering Prayer, 175-76, 209.

${ }^{351}$ Intimacy with God, 51.

352 Keating clarifies that his terminology of the false and true self "reflect a Jungian viewpoint". They are closely tied to ideas about positive and negative energies that reside in the unconscious. Practitioners engage them psychodynamically. To consider Keating's link to Jungian thought, see ibid., 64 .

353 Open Mind, Open Heart, 187.

${ }^{354}$ Intimacy with God, 64-72.
} 
up in dysfunctional families and societies represses negative and positive elements of the psyche into the unconscious. On the one hand, repression sets misguided processes in motion. Those are the programmes of happiness through which the false self seeks fulfilment in domains other than the felt sense of the presence of God. On the other hand, repression rearranges psychic structures into a malformed sense of self, which Keating refers to as a "distorted image" that we ourselves create. $355 \mathrm{He}$ also refers to the false self as the "idealised image of ourselves" (the psychoanalytic "super-ego").356 Thus unconscious repression forms a unique constellation of contents and patterns of behaviour that consciousness can be reflectively aware of as being of the "self". However, what consciousness is aware of here is a "false" image that is no longer as originally created by God. The image is acquired by us to cope with emotional trauma and past frustrations of our instinctual needs. 357

The true self in contrast is defined in Reflections as "who we really are" and "God manifesting God-self in us". ${ }^{358}$ In Open Mind, Open Heart, Keating clarifies that this Godself is "our participation in the divine life" but, and most importantly, it is also "manifested in our uniqueness" ${ }^{359}$ Thus our true self is a personal and individuated affair. It is not a "universal" or "impersonal" self. Who we personally really are is our unique constellation of psychodynamic contents and processes freed from maladaptation to trauma. This is a psychological sense of self. Keating draws here on Jungian thought in which the self can return to authenticity by way of a process called "individuation". Individuation gradually separates what is innate from what is erroneously acquired. The product of this process is the "unique individual [as] he was intended to be". ${ }^{600}$ Keating calls this the "true" self. The process that Keating recommends to achieve this is by way of the Christian path of purification, which he has reconceived in psychodynamic terms. Hence deconstructing the false self in favour of unveiling the true (and still personal) self is primarily achieved through the psychological stream of path-oriented contemplative practice.

The psychological system of training through which Keating proposes to unearth the true (personal) self is not solely psychodynamic but also theurgic. In theurgy (from the Greek theourgia), a contemplative seeks to activate God's grace in practice. The kind of

\footnotetext{
355 Invitation to Love, 6-37.

${ }^{356}$ Open Mind, Open Heart, 2.

357 Ibid.

${ }^{358}$ Reflections on the Unknowable, 119.

359 Open Mind, Open Heart, 190.

${ }^{360}$ Jeffrey C. Miller, The Transcendent Function: Jung's Model of Psychological Growth through Dialogue with the Unconscious (New York: State University of New York Press, 2004), 59. In Jung's account the process of "individuation" is the psychodynamic grind that gradually unveils the innate self and allows it to function authentically. In other words, the self is properly "individualised" such that it exists as intended (Keating would say "as created by God" and "in his likeness"). Jung's individuated self also takes on archetypal characteristics of "wholeness" and "totality", which he refers to as a "God-image". Ibid., 71. Keating draws on this way of speaking of the self to affirm the true self's divine origin and nature.
} 
psychodynamic regimen that Keating prescribes is theurgic in the sense that God replaces the therapist as the object of therapeutic transference and it is by "God's action within" that the purification is effected. Thus the primary objective in Keating's approach to centering prayer is to "consent" to the action of God's presence within. He says, "We know the divine presence is already there. We do not create it. All we have to do is consent." 361 This consent is critical to activating God's grace, and it becomes practically possible because, although God's grace is a gift, Keating claims, "It is a gift that has already been given. Its powers are present but hidden in the unconscious." 362

This brings us once more to the important thesis of the divine indwelling. Keating's approach seeks to activate this indwelling presence and by means of it become "divinised". ${ }^{363}$ This is why Keating's own guidelines to the method of centering prayer (second rule) include references to "consent" and "God's action within". ${ }^{64}$ My conjecture here is that Keating puts a strong emphasis on the psychological ("psychotheurgic" to be precise) stream of centering prayer's system of training. I also conjecture that this is because Keating conceives centering prayer as a practice for beginners for whom deconstruction of the false self is of primary concern. Deconstruction of the false self is thus an early stage objective.

The Christian contemplative path, as outlined by the Keating School, does not end with unveiling the true self. This is just a stepping stone to the farther reaches of the journey. Keating is adamant that, ultimately, the true self is not real, no matter how authentic that personal self might be. He says, "Our personal sense of 'me' is an illusion." 365 This is so because the third type of self, the separate-self sense, underpins both the false and true self. Keating clarifies below that it is this third type of self that becomes the final obstacle to Centering Prayer's soteriological goal, even after the false self has been dismantled:

\footnotetext{
Spiritual evolution is the path of liberation from the false self, the ego, and the separateself sense. [This includes:] our emotional programs for happiness, our over-identification with and excessive dependency on the various groups to which we belong, and... the separate-self sense - that is, ... attachment to any self at all. ${ }^{366}$
}

Above Keating insists that the soteriological goal requires freedom from any self, be it psychologically authentic or not. Ultimately, phenomenal selfhood must be resolved, which Keating defines as the "sense of an 'I". This "I" is consistent with Albahari's analysis of the

\footnotetext{
${ }^{361}$ Keating, Intimacy with God, 79.

${ }^{362}$ Reflections on the Unknowable, 97.

363 Intimacy with God, 66.

364 Ibid., 16.

${ }^{365}$ Reflections on the Unknowable, 118.

366 Ibid., 76-77.
} 
phenomenal sense of self (see Section 2.5.7).367 Therefore, the separate-self sense is a phenomenological matter and not a psychological one, because it is about the structure of consciousness and not its content. The issue is consequently not what exactly the self consists of, but the very fact of self.

The problem of phenomenal selfhood was conceived in this exact way by the anonymous English author of the Cloud of Unknowing. In this important classic source the author offers a nuanced phenomenological analysis of the fact of self. .36

\begin{abstract}
Surely it is beginner's fare, and I consider him hopelessly stupid and dull who cannot think and feel that he is; not how or what he is, but that he is. Such elemental selfawareness is obviously proper to the dumbest cow or most unreasonable beast... And so, go down to the deepest point of your mind and think of yourself in this simple, elemental way. (Others will mean the same thing, but because of their experience, speak of the mind's "pinnacle," and of this awareness as the "highest human wisdom.") In any case, do not think what you are but that you are... Step up bravely, then, and take this medicine. Lift up your sick self, just as you are, to the gracious God, just as he is. Leave behind all inquiry and profound speculation into your being or his. Forget all these qualities and everything about them, whether they be pure or defiled, natural or gracegiven, divine or human. Nothing matters now except that you willingly offer to God that blind awareness of your naked being in joyful love, so that grace can bind you and make you spiritually one with the precious being of God, simply as he is in himself. ${ }^{369}$
\end{abstract}

The author of the Cloud spells out the matter clearly: whatever the properties of the personal self are - and no matter whether the self is false or true - the very fact that there is an elemental self-awareness (which Keating defines as the sense of "I" and the Cloud's author as a "blind awareness of naked being") denotes a final obstacle to transcend if the soteriological goal is to be attained.

Keating identifies the dismantling of this obstacle as "the narrow gate". ${ }^{370}$ The system of training involved in this narrow gate is once again twofold. The first, phenomenological stream is concerned with the phenomenal fact of the sense of "I" as a structure of consciousness. As Keating and Frenette point out, the separate-self sense as a structure of consciousness "does not exist outside of our particular consciousness". ${ }^{371}$ It is for this reason

\footnotetext{
367 Ibid., 82.

${ }^{368}$ I agree with Bourgeault that the Cloud is "the ealiest Christian exploration of the phenomenology of consciousness". Cynthia Bourgeault, The Heart of Centering Prayer (Boston, Massachusetts: Shambhala, 2016), 7.

369 Johnston, The Cloud of Unknowing, 140-42.

370 Keating, Reflections on the Unknowable, 87.

371 Ibid., 123.
} 
that the contemplative path requires a "restructuring of consciousness" that "gradually brings freedom from the separate-self sense". ${ }^{372}$ The restructure is accomplished, on the one hand, through a more phenomenological (and contemplative rather than philosophical) type of inquiry into consciousness that cultivates alternative ways of being aware. On the other hand, a self-structure still remains in place until it is completely uprooted, and the remnants of this self-reflective tendency has a psychological response to its own diminishment. Here the second, psychological stream trains the practitioner to endure the felt sense of dying, as "being in God's Being" without reflective self-awareness takes precedence over "resting in God's presence", which has inbuilt into it a self-reflective "I". 373 The psychodynamics involved in enduring and embracing this death is referred to by Keating as the "night of self". Together the two streams effect a transformation at the deepest centre. It is in this deepest centre of consciousness (or highest point of the spirit) that the separate-self sense is gradually uprooted without reference to the self's psychological content.

\subsection{Centering Prayer's "Language of the Centre"}

Centering Prayer draws on "language of the centre" to talk about the relationship that exists between human beings and the divine. For example, Pennington says:

Beneath all our feeling, beneath our reasoning, beneath all our limitations, there is a deep Center, the Center and ground of our being, and we can pass through that center in to the very Center of God. Indeed, the two Centers are one - constituting the very Center of all that is. ${ }^{374}$

Pennington tells us that the ground of our being is the "centre of God". It is not surprising, then, that it is the goal of centering prayer to bring the practitioner to the centre of his being, because this is where God is.

Pennington goes a step further. His reference to the "ground of being" originates in Meister Eckhart (1260 - 1328), a German theologian and mystic. Pennington draws on Eckhart's thought to suggest that the centre of our being is not merely in likeness of God, but in fact shares substantially in His being. Keating and Bourgeault also draw on Eckhart's "language of the ground" to affirm the same metaphysical view. ${ }^{375}$ In fact, Keating greatly

\footnotetext{
372 Open Mind, Open Heart, 2; Frenette, The Path of Centering Prayer, xxi.

373 The Path of Centering Prayer.

${ }^{374}$ Pennington O.C.S.O., Centered Living, 21.

375 Bourgeault explicitly spells out the metaphysical implications of this idea. Bourgeault, Centering Prayer and Inner Awakening, 14. Keating shares Bourgeault's view on the matter. He says, "Grace is a participation in the Divine nature, it is not just something added on like an overcoat." Elena Mannes and Peter C. Jones, Thomas Keating: A Rising Tide of Silence (Temple Rock, 2014), DVD Documentary, 00:01:20-00:01:30.
} 
admires Eckhart's thinking and prizes it above traditional Christian theology, which he considers unclear and undeveloped from a contemplative point of view.

The "language of the ground" employed by the founders (Pennington and Keating) and present time representative teachers (Bourgeault) of the Centering Prayer tradition has similarities to Eckhart's "mysticism of the ground". "Mysticism of the ground" is a phrase coined by McGinn "to help locate the form of mysticism initiated by Eckhart". ${ }^{376}$ Thus McGinn believes that the form of mysticism Eckhart initiated is unique, even for the Christian mystical tradition, and it gave birth to "powerful new forms of speech" that used the term "ground" (Grunt) as their leitmotif. "Grunt," McGinn says, "can be described as a master metaphor, because of the way it focuses and integrates a whole range of creative language - strategies employed to describe the relationship between God and the human person." 377 A lot more can be said about Eckhart's use of the term ground, and I will restrict myself to one further observation by McGinn.

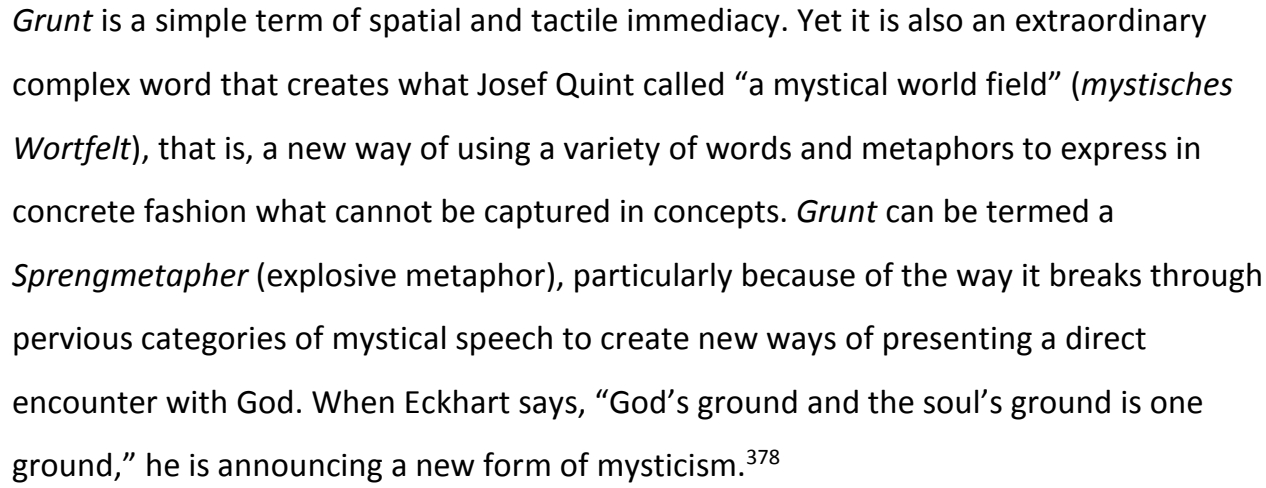

In the same way that the term Grunt serves as a master metaphor in Eckhart's "mysticism of the ground" so the term "centre" serves as an explosive metaphor and leitmotif in the teachings of Centering Prayer. McGinn points out how semantically rich the term Grunt is. This is also true for the term "centre". Thus Pennington conceives the "centre" as an "imageless image" that can carry many meanings. 379 It offers great linguistic freedom and flexibility. In this way, the term “centre”, like Eckhart’s “ground of being”, enables Centering Prayer contemplatives to develop new forms of speech.

Not all works written in Eckhart's tradition employ the term Grunt. However, they still “use typical Eckhartian language, such as 'empty being' and 'without form', which belong

\footnotetext{
${ }^{376}$ Bernard McGinn, The Harvest of Mysticism in Medieval Germany (1300-1500). Vol. IV of The Presence of God (New York: The Crossroad Publishing Company, 2005), 84.

377 Ibid., 85-86.

378 Ibid., 85.

${ }^{379}$ Pennington O.C.S.O., Centered Living, 57.
} 
to the vocabulary of the mysticism of the ground". ${ }^{380}$ In the same way, centering prayer practitioners, too, develop their own vocabulary and their ways of speaking has many affinities with the vocabulary of Eckhart's mysticism of the ground.

The concept of the "centre" also has theological roots in the Spanish contemporaries St Teresa of Avila (1515-1582) and St John of the Cross (1542-1591). Keating explicitly acknowledges their influence, among others, in the formulation of centering prayer, and he acknowledges that the contemplative path-structure he developed - which he also refers to as the "levels of mystical prayer", 381 "stages of prayer", ${ }^{382}$ or "stages of the process" 383 - is grounded in St John's and St Teresa's prior thinking on the matter. ${ }^{884}$

In sum, the Centering Prayer tradition uses "language of the centre" to affirm the thesis of the divine indwelling as the theological basis for contemplative prayer. The tradition locates the theological roots of this leitmotif and Sprengmetapher in Christian mysticism. Despite those roots, Centering Prayer understands itself, by and large, to be in tension with the kind of traditional Christian theology that places God "out there" and as the "wholly other". ${ }^{885}$ Contrary to this, Keating says, "As we sit in centering prayer, we are connecting with the divine life within us: it is already there waiting to be activated." 386 Consequently, God's presence and God's being are conceived to already aboriginally and substantially exist in our centre. For this reason Keating prefers an "awakening" paradigm over a "discovering" paradigm of God's presence, because the latter "suggests searching outside of ourselves for what is already present within". 387

\subsection{Pennington's Soteriological Vision of God as Pure Consciousness}

Pennington is one of the founders of the Centering Prayer tradition and his vision of the soteriological goal "puts God experientially at the Center". Keating agrees that "union with God" is experienced at the centre. But how exactly is God meant to be experienced there?

Pennington is a good place to start, because his account is straightforward and will immediately bracket off many received views about how "union with god" is believed to be experienced by contemporary scholars of mysticism - scholars who rely solely on texts and

\footnotetext{
${ }^{380}$ McGinn, The Harvest of Mysticism in Medieval Germany (1300-1500). Vol. IV of The Presence of God, 91.

${ }^{381}$ Keating, Open Mind, Open Heart, 138.

382 Invitation to Love, 106.

${ }^{383}$ Reflections on the Unknowable, 111.

384 "Contemplative Outreach: Vision and foundations," Sewanee Theological Review 50, no. 3 (2007): 371.

${ }^{385}$ Keating identifies this as the "Western Model of the self-outside-of-God". He acknowledges that the divine indwelling "represents a 180-degree turn from the Western Model" that conceives "of God 'out there". Intimacy with God, 6-14.

${ }^{386}$ Reininger, "The Christian contemplative tradition and Centering Prayer," cited ftn 24, Keating, Intimacy with God, 33.

${ }^{387}$ Keating, Reflections on the Unknowable, 96.
} 
abstract, theological ideas to construct hypothetical pictures of experience. Pennington's account challenges these constructs.

Pennington explains centering prayer's soteriological project as one that moves "from self-consciousness to God-consciousness". ${ }^{888}$ By "move" Pennington means a "shift of consciousness" or a "transformation of consciousness" through which the practitioner comes to "know by experience that God does dwell within us". ${ }^{389}$ The transformation or shift in question passes through self-centredness - which includes the whole gamut of self: false self, true self and separate-self sense - to God-centredness (Figure 10 below). 390

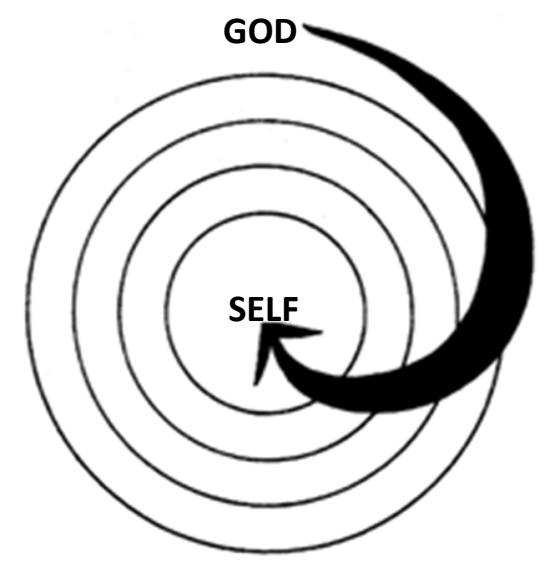

Figure 10. The Shift to God-centred Consciousness

In Pennington's view, when we shift to the centre, God-consciousness or God-centredness ensues: "We come to an experiential knowledge of God dwelling at the Center of our being”. ${ }^{391}$ This experiential knowledge unfolds in a progressive continuum, which he divides into two phases.

The first phase of the experience is marked by a sense that a distinction remains between self and God's presence. It is an "I-Thou" relation. Pennington refers to this experience as "union" or "God-consciousness": the self is aware of the presence of God as "other".392

The second phase of the experience is marked by a "new level of intimacy" where we are brought "into a unity with God that is beyond any union". Pennington refers to this final experience as "unity with God", "unity of love" and "unity-consciousness" (the common denominator being the term "unity" rather than "union"). Here the self no longer

\footnotetext{
388 Pennington O.C.S.O., Centered Living, 83.

389 Ibid., 89.

390 I have adapted this figure from ibid.

391 Ibid., 94.

392 Ibid.
} 
experiences "God" or "love" as "other" but "as our own" such that there really is "nothing else".393

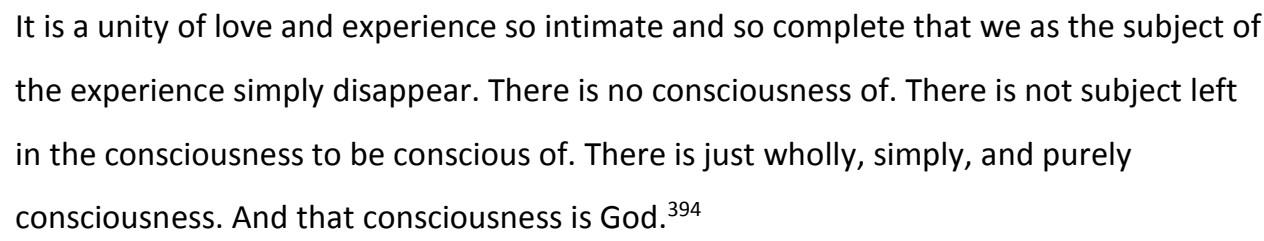

Pennington frames unity consciousness experientially as pure consciousness and identifies this consciousness as God. Pennington also claims that, "God is known in pure consciousness." 395 This is unlike the views of scholars who require an experience of God to be one where a personal and loving entity presents itself to the self from the outside and as "other". Specifically, Katz claims that no Christian mystic experiences an unidentified reality and then labels it as God after the experience. ${ }^{396}$ But Pennington tells a different story here and it is one that will continue to be retold again and again by the contemplatives who have participated in this study. They insist that they experience God, but not according to Katz's image of him.

Pennington understands pure consciousness to have four characteristics. The first is that "unity" is an undivided and "total presence" in which there is no reflection back onto oneself. This unlike "union" where we "become aware of ourselves as being to God" through a split in consciousness. 397 In union we not only sense a distance towards God, but we also become alienated from ourselves. Pennington says, "we stand outside and see ourselves as an object: someone who is with God." 398 The self that we might consider the subject, then, is in fact an objectified "subject of awareness". Pennington demonstrates phenomenological nuance here by distinguishing the self-as-object from the self-as-subject. The self-as-object is exactly what Pennington describes as "this 'I' [that] has become an object of perception; we are watching ourselves have an experience. We are divided in ourselves". ${ }^{399}$ In pure consciousness, then, this objectified subject (the self-as-object) that can be watched undergoing an experience drops out. There is no self-reflection. Pennington says, "There [is] no reflexive consciousness watching and recording."

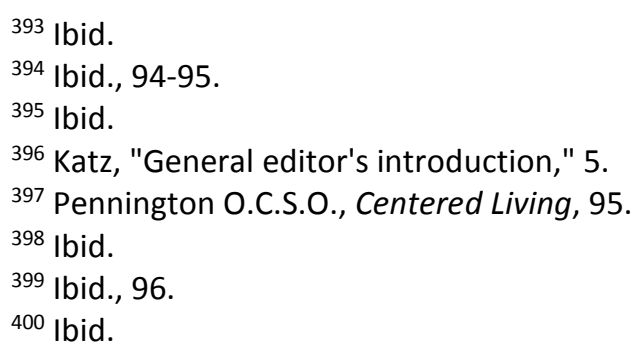


The second characteristic of pure consciousness is that it is objectless. "There were no objects of which we were conscious." 401 It is so contentless that it even excludes the self-asobject and any other type of content that could be the object of an act of "consciousness of".

The third characteristic is timelessness. It is "a moment outside of time" and typically short-lived in external time. ${ }^{402}$

The fourth characteristic is that the self-as-subject is also absent. The experience is not given to any "I" (=entitification). ${ }^{403}$ As Pennington says, "There is no subject left in the consciousness to be conscious of." 404 Consequently, "we cannot report to ourselves what occurred", because reflective consciousness was not active in pure consciousness. ${ }^{405}$ Nonself-awareness, then, is coupled with a peculiar lack of cognitive access to experience, because no "particular" experience is occurring. Thus Pennington says, "There was only pure consciousness." ${ }^{406}$

To conclude, Pennington tells us that the transformation of consciousness sought by centering prayer shifts self-centred consciousness to God-centred consciousness, which begins with the experience of a subject-object structured "union". The transformation can culminate into "unity": a temporary state of pure consciousness that has no subject-object structure. This pure consciousness is how God is "experienced" and "known". Pennington even claims that pure consciousness is what God is.

With Pennington's help I have now introduced the possibility that Centering Prayer practitioners, being representatives of the Christian contemplative tradition, may not experience or speak about God in ways contemporary scholars of mysticism hypothesise they should. To the contrary, Pennington introduces the idea that - in the farther reaches of the Christian path - God may not be experienced as a personal being that is "other" and "out there", but as pure consciousness. 407

\subsection{The Keating School Model of the Christian Contemplative Path}

No single primary source of Centering Prayer offers a full account of the path. Consequently, I will draw on multiple sources to construct a cohesive and overarching model of the Christian contemplative path, as outlined by the Keating School. The sources I will primarily

\footnotetext{
401 Ibid.

402 Ibid., 96-97.

${ }^{403}$ I define "entitification" in Section 2.5.7 (pp.42-43).

404 Pennington O.C.S.O., Centered Living, 95.

405 Ibid., 96.

406 Ibid.

${ }^{407}$ Keating agrees with Pennington about how God is experienced in the farther reaches. He says, "You can be aware of the undifferentiated presence of God and not have any explicit reflection about it. Pure awareness is the immediacy of the experience." Open Mind, Open Heart, 87.
} 
rely on are Keating's and Frenette's published works, an unpublished guidebook for students that I obtained during fieldwork, and interviews on this subject with senior teachers and monks at St Benedict's Monastery. My discussion of the specific stages is also informed by the phenomenological accounts developed in this study and thus subservient to the firstperson data I will present and analyse in the chapters that follow.

Figure 11 below offers a model of the contemplative path as outlined by the Keating School of Centering Prayer. ${ }^{408}$ I will use this model to guide my discussion.

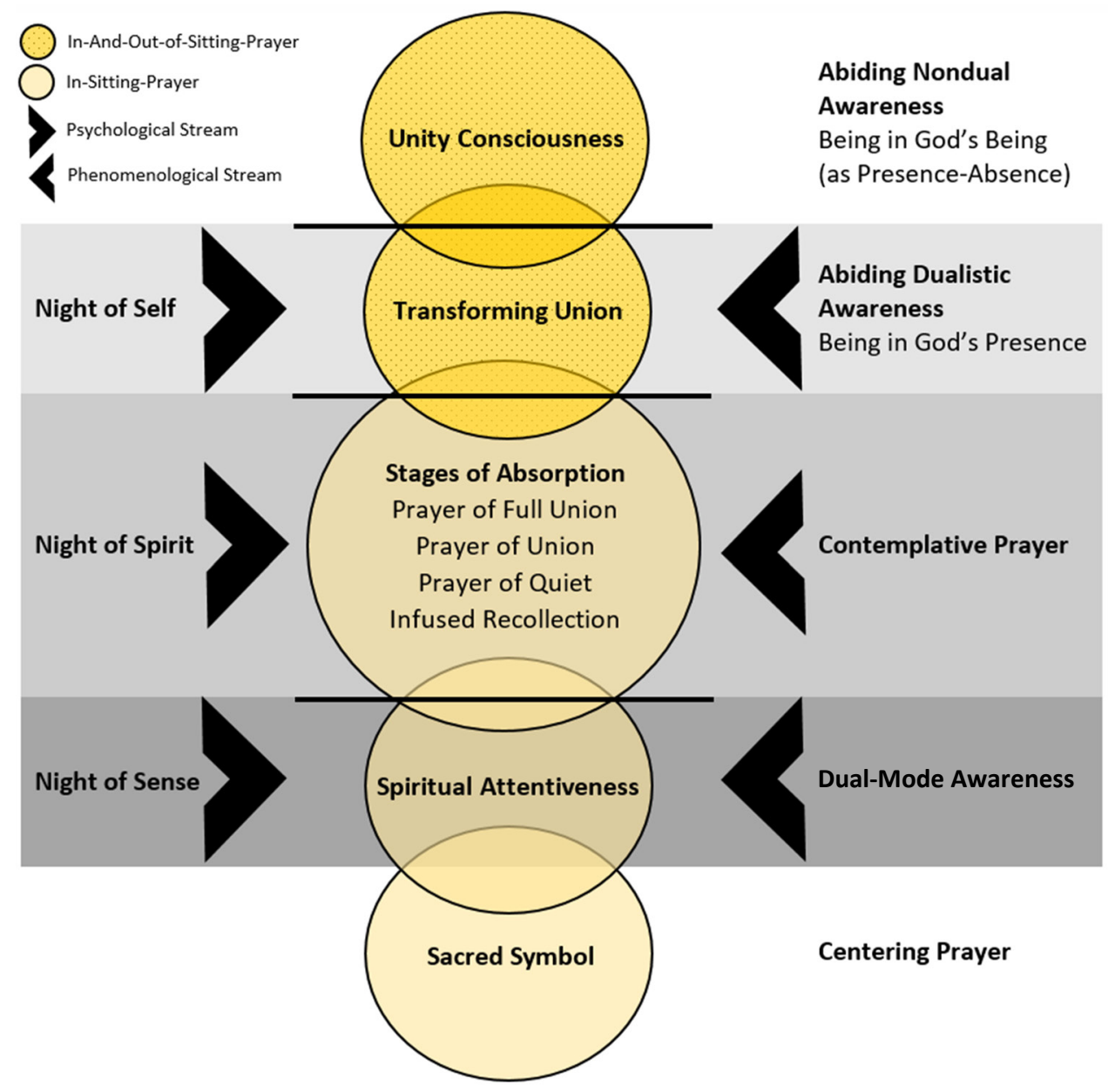

Figure 11. The Keating School Model of the Christian Path

The Keating School explains centering prayer as a path-oriented contemplative practice that includes a soteriological goal, a contemplative path and a system of training. Figure 11

\footnotetext{
${ }^{408}$ Figure 4 is inspired by Keating's "Model of Christian Growth" presented in an unpublished guidebook available at the Retreat House at St Benedict's Monastery. The Spiriutal Journey: A Guide Book (Being A Contemporary Presentation of Christian Growth and Transformation) (Contemplative Outreach, unpublished), 45 (Appendix I). The outline of the path-structure is guided by Keating's following statement: "The movement from the takeoff point of sacred symbol to spiritual attentiveness, to ever-deepening absorption of the faculties in God, and to the purification of the unconscious terminates in the transforming union. The latter involves a restructuring of consciousness that perceives a new dimension to all reality." Invitation to Love, 118.
} 
accounts for all three components. First, the soteriological goal is identified in the top circle as "unity consciousness". Consequently, Figure 11 should be read bottom to top: the top is the goal, and practitioners start from the bottom. Second, the developmental path-structure is laid out with identifiable stages by way of the connected circles. Third, the twofold system of training is identified by the arrows facing inward on the path. The right-facing arrows depict the activity of the psychological stream (=the night of sense, spirit and self) and the left-facing arrows depict the activity of the phenomenological stream (centering prayer, dualmode awareness, contemplative prayer, abiding dualistic awareness and abiding nondual awareness).

My discussion that follows will focus on the phenomenological stream of this contemplative path. I will begin with the first three stages traversed in seated prayer: (i) the sacred symbol by way of the method of centering prayer; (ii) developing spiritual attentiveness by cultivating dual-awareness; and (iii) entering into ever deepening levels of absorption by receiving the gift of contemplation, also referred to by Keating as the "stages of contemplative prayer" or the "levels of mystical prayer". ${ }^{409}$

\subsubsection{Stage One: The Sacred Symbol and Centering Prayer}

In the first stage practitioners pick up centering prayer as a contemplative practice and apply the method for 20 minutes once (ideally twice) per day during formal prayer sessions. No ascetic preparatory regimen is required to begin the practice or reap its fruits..$^{410}$

The basic practice involves first choosing a single word as the sacred symbol. This could be anything from "You", "Love" or "Sophia" (examples from this study). What is important is not the word itself, but the meaning it is imbued with, because the practice is conceived to be a matter of "intention" rather than "attention". This distinction emphasises, on the one hand, the affective aspect of desire to attend to (or "be in") God above all else and, on the other hand, the willingness to endure the process of purification that is activated through "consent to the action of God's presence within". ${ }^{111}$ Both streams - attention to God and purification - are undergirded by surrender.

\footnotetext{
409 Open Mind, Open Heart, 138; Manifesting God (New York: Lantern Books, 2005), 107.

${ }^{410}$ The founding Trappists discovered that asceticism is an unnecessary prerequisite for the spiritual life and that it has no bearing on whether practitioners can or cannot advance on their contemplative journey. Intimacy with God, xiii-xiv. In this study, no contemplative discussed ascetic practices. This disconfirms Lindahl's text-based treatment of contemplation that argues that asceticism is "a necessary prerequisite for contemplation". "Paths to luminosity: A comparative study of ascetic and contemplative practices in select tibetan Buddhist and Greek Chrisitan traditions," 21-22.

${ }^{411}$ Intimacy with God, 30-31, 48.
} 
I will now clarify "intention" and "attention" by discussing how centering prayer (by way of surrender) is conceived to work on a methodological level and how practitioners are instructed to use the "sacred symbol".

Centering prayer is a method that trains attention despite the tradition's claim otherwise. The question is not whether or not it does so, but how centering prayer envisions that this training should be achieved. My view is that centering prayer's emphasis on "intention" above "attention" is heuristic. I will explain by taking a closer look at how centering prayer works with "attention" and "awareness". ${ }^{412}$ My explanation will highlight the "intentional" aspect of the method.

Stage One of the path aims to come to a "relaxed but alert awareness". ${ }^{413}$ To this end, attention must be unhooked from the surface of awareness ("ordinary consciousness") and redirected to the depths of the river ("spiritual awareness" and beyond). Centering prayer avoids classic "concentration methods" or "awareness methods" to do this, ${ }^{414}$ but relies on a "surrender method" to release awareness from content and "extract the lucidity out of experience". ${ }^{415}$

I will now draw on Brown's treatment of meditation skills (see Section 2.5.9) and Bourgeault's thinking on concentration, awareness and surrender methods to illuminate the inner workings of these practices and clarify how the source literature conceives the surrender method of centering prayer to work. 416

Let us begin with concentration methods that anchor attention on an object (e.g., the breath, a mantra, an image or external object). ${ }^{417}$ The basic idea is that if attention is successfully fixated on an object, then attention's chaotic and distracting quality (ordinary consciousness) can be cancelled out. When this is effected, the "deeper waters" of awareness (the "knowing" quality or "lucidity" of awareness) behind attention can consolidate and become salient. As the deeper waters are intuited, attention (now more laser-like and refined) can detect subtler content in the event-perspective (object-side) specific to the

\footnotetext{
412 I define "attention" in Section 2.5.4 (p.36) and "awareness" in Section 2.5.6 (pp.41-42).

413 Intimacy with God, 34.

${ }^{414}$ Open Mind, Open Heart, 47.

${ }^{415}$ I owe this phrase to a teacher of the Pointing Out Way Tibetan Buddhist Mahamudra tradition. See Saul, Interview \#7.3, p.3.

416 Bourgeault, Centering Prayer and Inner Awakening, 20-21.

417 The neuroscientific literature on meditation has taken John Dunne's lead in respect to its current taxonomy and thus defines this type of meditation as focused attention (or "FA"). Antoine Lutz, John D. Dunne, and Richard J. Davidson, "Meditation and the neuroscience of consciousness: An introduction," in The Cambridge Handbook of Consciousness, ed. Philip D. Zelazo, Morris Moscovitch, and Evan Thompson (New York: Cambridge University Press, 2007), 511-13. F. Travis and Jonathan Shear, "Focused attention, open monitoring and automatic self-transcending: Categories to organize meditations from Vedic, Buddhist and Chinese traditions," Consciousness and Cognition 19, no. 4 (2010): 1113; Wendy Hasenkamp et al., "Mind wandering and attention during focused meditation: A fine-grained temporal analysis of fluctuating cognitive states," Neurolmage 59, no. 1 (2012): 751.
} 
deeper levels of awareness. Thus each level of awareness has a subject-side and an objectside with its own type of content. As attention becomes brighter and more stable, the practitioner's "basis of operation" 418 shifts of its own accord to a more subtle level (spiritual or divine). Concentration methods of this kind rely on "intensifying" and "easing up" as the key meditation skills, because these skills regulate the supply of energy to, and the quality of, attention.

In contrast, awareness methods work with a reversed logic. They aim to directly anchor the practitioner's basis of operation in the lucidity of awareness by (i) emphasising and holding on to the awareness-perspective (subject-side) and (ii) withdrawing involvement from the chaotic nature of attention and its contents (object-side) while (iii) maintaining a high level of clarity of the content. 419 The basis of operation (modus operandi) of the practitioner is thus directly shifted into the "deeper waters" of awareness.

The mechanic of awareness methods requires practitioners to allow attention to do what it does without getting distracted, drawn in or perturbed by it. Eventually, the practitioner's basis of operation stabilises and remains disengaged from the plethora of content that parades on the surface of the river (ordinary consciousness). An "inner observer", "watcher" or "knower" emerges that remains unmoved by this ongoing, chaotic activity. As the basis of operation is released from attention, the lucidity of the awarenessperspective becomes like an "unshakable presence" that can intentionally sink with a highlevel of clarity into the depths of consciousness (spiritual and divine levels). The object-side of experience then changes without direct intervention, because the level of awareness that the basis of operation shifts into contains its own type of content. Gradually attention settles without direct intervention. In this way, awareness methods rely on "mental pliancy" to shift between levels of awareness. It is a skill that does not require high levels of concentration.

Surrender methods differ from concentration and awareness methods in two ways. First, they focus on letting go of content ("gestures of release") rather than cognitive access to content. ${ }^{420}$ Thus clarity of attention is not as important. Thus surrender-with-intention has precedence over effort-with-attention. Consequently, objects of attention can be let go of without going through their full cycle of existence (arising, experiencing and dissipating). A deep process of surrender may even let go of content before it fully forms into something knowable. Second, surrender methods are driven by a desire to let go for the sake of a more valuable alternative (e.g., God). There is hence an affirmation (kataphatic undercurrent) in

\footnotetext{
${ }^{418}$ I define "basis of operation" (modus operandi) in Section 2.5.3 (pp.33-34).

${ }^{419}$ This kind of meditation has been defined in the neuroscientific literature as "open monitoring" (or "OM"). Lutz, Dunne, and Davidson, "Meditation and the neuroscience of consciousness: An introduction," 513-17; Travis and Shear, "Focused attention, open monitoring and automatic self-transcending: Categories to organize meditations from Vedic, Buddhist and Chinese traditions," 1113.

${ }^{420}$ Bourgeault, Centering Prayer and Inner Awakening, 21; Keating, Intimacy with God, 30.
} 
negation (apophatic practice). William James described it as "a denial made on behalf of a deeper yes". ${ }^{21}$

Centering prayer is such a surrender method for two reasons. First, it requires the additional ingredient that the practitioner "turn" to God or "be in" God's presence. Keating says, "In centering prayer the purpose is not to let go of all thoughts but to deepen our contact with the divine indwelling." ${ }^{222}$ In the same spirit, Pennington advises to "return to the Lord with the use of the prayer word". 423

Second, the "turn" to God is depicted as an act of surrender-with-intention rather than effort-with-attention. I consider this characterisation valid although overstated. It is overstated, because, as Bourgeault points out, "Of course, even in the more concentrative practices, intention underlies attention." ${ }^{2} 4$ Thus intent to approach an ultimate reality is not unique to surrender methods. But it is also valid, because centering prayer does disproportionately emphasise intention, which results in two notable qualitative differences: (1) Centering prayer has a comparatively "murkier" and "dreamy quality" than concentration and awareness methods, because it disregards the details of specific content in ongoing experience; ${ }^{425}$ (2) centering prayer reduces effort to a bare minimum. ${ }^{426}$

We are now in a position to summarise the inner workings of centering prayer as a surrender method and spell out its difference to concentration and awareness methods. In centering prayer, practitioners are instructed to repeatedly "release" attention from the object-side of experience (event-perspective). This strategy aims to naturally place their basis of operation at the subject-side of experience (awareness-perspective), which is not actively placed at the subject-side but indirectly positioned there as a consequence of "abstracting away" from the ordinary (psychological) level of awareness.427 "Abstracting away" should reorganise attention from the specific to the general and effortlessly allow the basis of operation to sink into deeper levels of awareness. Practitioners report that this "sinking" motion often leads to low clarity and diminished cognitive access to ordinary consciousness.

The characteristics of effortlessness and low clarity appear to distinguish centering prayer from other methods that apply a great deal of effort to either (i) "place and hold" attention on a single item in the event-perspective with great clarity (concentration methods), or (ii) "place and hold" the basis of operation (modus operandi) in the awareness-

\footnotetext{
${ }^{421}$ William James, The Varieties of Religious Experience (New York: The Modern Library, 2002), 453.

422 Keating, Open Mind, Open Heart, 35.

${ }^{423}$ M. Basil Pennington O.C.S.O., Centering Prayer (New York: Image Books, 1982), 52.

${ }^{424}$ Bourgeault, Centering Prayer and Inner Awakening, 21.

425 Ibid.

${ }^{426}$ Keating, Intimacy with God, 34.

427 The term "abstract" is emic and used by Keating in its Latin meaning "pulled away" or "detached". Thus the basis of operation "withdraws from", "steps away from", "pulls back from", "draws back from", or "steps out of". It does not mean a state that is more "in the head" and "thought-laden" than usual. Ibid.
} 
perspective while maintaining a high level of clarity of roaming content in the eventperspective (awareness methods). Centering prayer as a surrender method is not designed to "place and hold" with effort. Instead, it aims to "allow" shifts to happen indirectly by gently letting go. "Letting go" is operationalised through the "Four R" formula: resist not; retain not; react not; return to the sacred word. The first three "Rs" release attention from content in the event-perspective and the fourth " $\mathrm{R}$ " indirectly shifts the modus operandi back to the awareness-perspective. In this way, surrender is facilitated by "gestures of release".

In Stage One the sacred symbol is used to make these "gestures of release". It is only meant to be used when and only when attention becomes fixated. Therefore, the sacred symbol should not be continually repeated like a mantra. As long as the practitioner's basis of operation remains poised (non-resisting; non-retaining; non-reacting) with a quivering intent for God at the subject-side of experience (awareness-perspective), it should "sink into interior silence" (shift to a deeper level). When the practitioner's state becomes "dreamy", "murky" or "dull" in the process, cognitive access to ordinary consciousness appears to progressively diminish. ${ }^{228}$

The symbol employed in Stage One is discussed in the source literature in two ways. ${ }^{429}$ First, it is a word or image that represents the practitioner's intent - hence "symbol". Second, it is an intervention in practice that, over time, is divested of its symbolic nature (word or image) and applied as a mere formless intent.430 The sacred symbol as intervention has two components: "letting go" $43^{1}$ and "returning". Both components are meant to be realised by acts that "release" and "allow" rather than "cause", "place" or "hold". It is for this reason that Keating identifies centering prayer as a receptive practice (surrender method) rather than effort-driven practice (concentration and awareness methods). ${ }^{42}$

\subsubsection{Stage Two: Spiritual Attentiveness}

Repeated application of the sacred symbol is centering prayer's way to release attention from fixation. Over time, this should shift and stabilise the practitioner's basis of operation (modus operandi) at a deeper level of awareness. Stabilisation, even if it is partial, becomes the springboard to Stage Two: spiritual attentiveness.

\footnotetext{
428 Open Mind, Open Heart, 41.

${ }^{429}$ Intimacy with God, 74-75.

${ }^{430}$ Keating and Frenette refer to the simple act of "turning inwardly" or "gently turning to God's unseen presence within" as the "sacred glance". Manifesting God, 107; Frenette, The Path of Centering Prayer, 59-62. 431 Letting go is aided by the psychological stream, because it gets involved in the psychodynamics of various contents that arise.

432 Keating, Intimacy with God, 15-20.
} 
Spiritual attentiveness involves two levels of awareness running in tandem. The first level is ordinary awareness that contains in its event-perspective (object-side) the passing "coarse-level" content of our every-day psychological experience. This is the surface of the river. The second level is spiritual awareness that contains in its event-perspective "subtlelevel" content characteristic of the deeper waters of awareness, such as formlessness, interior spaciousness, interior silence, interior stillness and peace. 433 These constitute the river upon which the surface rests.

The spiritual level of awareness is the inner stream of consciousness that is a priori to our day-to-day, psychological experience (coarse-level). In spiritual attentiveness the activity of ordinary awareness continues but does not conceal spiritual awareness (subtle-level). Therefore, spiritual attentiveness is meant to grant the practitioner cognitive access to both levels of awareness at once.

As you persevere, you will gradually develop new habits and new capacities, one of which is the ability to be conscious of two levels of awareness at the same time. You can be aware of the noise in or around you, and yet you recognize that your spirit is grasped by something at a deeper level that is impossible to define but is nonetheless real.

The ability to disregard noises during this prayer is a phenomenon that you may experience fairly soon in regard to external sounds. If you fully accept the noise, it scarcely bothers you. If you fight it, struggle with it, or wish it were not there, you will get all wrapped up in particular sounds. Although you may not succeed right away, eventually you will experience a substantial silence at a deep level even though noise is going on around you. ${ }^{434}$

Above Keating describes how the experience of spiritual attentiveness involves two levels of awareness running simultaneously. I call this phenomenon "dual-mode awareness".

Eventually, the practitioner should come to a point when she "slip[s] in and out of interior silence" during seated prayer. The interior silence is not a blank mind, but the mind (as in thinking and perceiving) continues at the ordinary level, without pulling the practitioner's basis of operation (modus operandi) out of spiritual awareness. 435 Noise and silence coexist; silence is no longer disrupted by noise; and the noise is now witnessed from a position anchored in a deeper level of awareness. We could also say that ordinary awareness is known by spiritual awareness, because the modus operandi should be located and stabilised at this deeper level.

\footnotetext{
${ }^{433}$ Open Mind, Open Heart, 22-23, 38.

434 Ibid., 44.

435 Ibid., 46.
} 
When the practitioner gets "wrapped up" in ordinary consciousness, her modus operandi shifts back into ordinary awareness and she loses cognitive access to the more subtle interior silence of spiritual awareness. In this way, being caught up with psychological experience (coarse-level) is understood to conceal the deeper waters of awareness (subtlelevel). Once the practitioner notices this involvement, she is instructed to intervene with the sacred word to "return", that is, shift awareness away from the surface and back to the interior depths.

The process of progress towards stabilisation is meant to be aided by the psychological stream of training, which is referred to at stages one and two as the "night of sense". The night of sense is viewed as a process that weans the practitioner from seeking hedonic reward in her psychological experience and by way of the human faculties and the senses. Thus hedonic payoff of psychological experience is not consumed and the need for hedonic reward remains unmet. Over time this should lead to anhedonia. Some signs of this anhedonia are considered to be dryness in prayer and a sense of dissatisfaction with ordinary experience (and prayer). If the weaning process (purification) is endured, its fruition should allow the practitioner to discover an alternative source of hedonic reward processing. This alternative is meant to be discovered in the hedonically rewarding nature of the depths of the river (spiritual and divine awareness). The discovery of this alternative and spiritual source of reward announces the next stage of the path (Stage Three), which is also conceived to be gifted through contemplation prayer.

In sum, when spiritual attentiveness stabilises and the modus operandi is firmly anchored in spiritual awareness - facilitated by the night of sense - the conditions are considered met to sink deeper into spiritual and divine awareness during formal prayer sessions. It is in seated prayer that practitioners seem to first receive the gift of contemplation, which is reported as increasing and initially hedonically rewarding levels of absorption.

\subsubsection{Stage Three: The Levels of Absorption in Contemplative Prayer}

Spiritual attentiveness is a dual-mode awareness in which practitioners appear to have cognitive access to coarse-level content of ordinary awareness and subtle-level content of spiritual awareness. Subtle-level content reveals a "substantial inner silence" into which the practitioner's basis of operation can further sink. When the modus operandi delves into the depths of consciousness, interior silence is reported to become progressively dominant until it takes complete hold of the practitioner. In this process, cognitive access to ordinary consciousness seems to diminish proportional to the degree that the practitioner gets 
absorbed in spiritual awareness. Thus prayer apparently becomes absorbing at ever increasing levels of intensity, and, eventually, to the exclusion of all else.

Stage Three of the path is conceived to begin with the onset of an absorbing or "drawing" quality in seated prayer. The practitioner leaves behind all methods, including centering prayer, and allows the classic stages of contemplative prayer to unfold on their own terms. Thus "the action of the spirit" takes over. ${ }^{436}$ The minimal effort that was expended earlier on to apply the method of centering prayer should give way to receptivity and grace (see Figure 12 below).437

Figure 12. Continuum of Effort and Grace (Absorption)

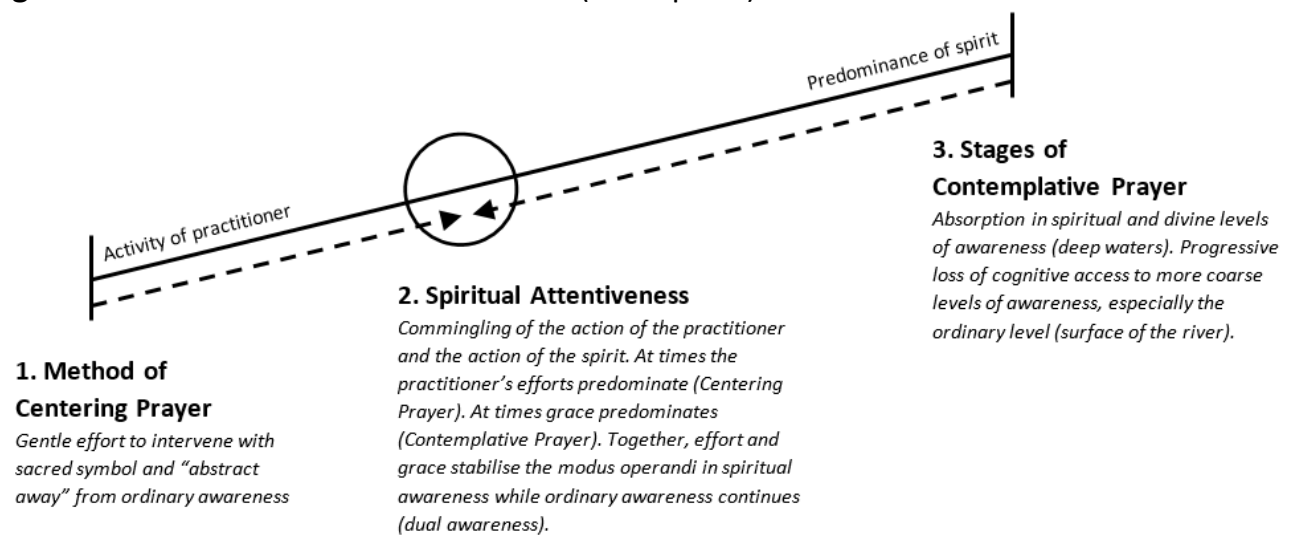

Figure 12 shows on the left hand side how the early stages of the path (Stage One and Two) rely on the method of centering prayer, which appears to require some effort. 438 The right hand side shows how contemplative prayer should take over as prayer matures and the night of sense takes effect. Effort should be gradually replaced by grace (absorption), which is understood as the "activity of the Holy Spirit". 439

The onset of absorption signals that the psychological stream of training by way of the night of sense (Stage One) is showing fruits. Ordinary awareness should grab attention less. This seems to help the practitioner deemphasise ("abstract away from") ordinary awareness and emphasise ("sink into") deeper levels of awareness. The newfound freedom from (or "in") attention should allow the practitioner to "rest" and get absorbed in the deeper, spiritual and divine levels.

\footnotetext{
436 Intimacy with God, 16.

${ }^{437}$ Figure 5 has been adapted from Keating's “Diagram 1. The Dynamics of Centering Prayer". Ibid., 17.

${ }^{438}$ Even though centering prayer is a very receptive approach, effort still has its place. Keating says, "In this practice our activity has a part, but it is an extremely gentle one. Our contribution begins by being minimal and finishes by being almost imperceptible." Ibid., 16.

${ }^{439}$ Keating claims that this gift of grace has always already been given and that it is up to the practitioner to be receptive to this available gift. Reflections on the Unknowable, 97.
} 
Stage Three is the end of the road of the traditional method of centering prayer. The founders designed it for beginners to help them start their contemplative journey and prepare them for more subtle and advanced practices, such as contemplative prayer.440 "The practice of centering prayer, therefore, is not contemplation in the strict sense of the term but a preparation for it." ${ }^{411}$ Father Theodore agrees with this assessment. He says, "Centering prayer is only for beginners, really." ${ }^{4} 2$ When I asked Father Theodore whether he himself practiced centering prayer, he said:

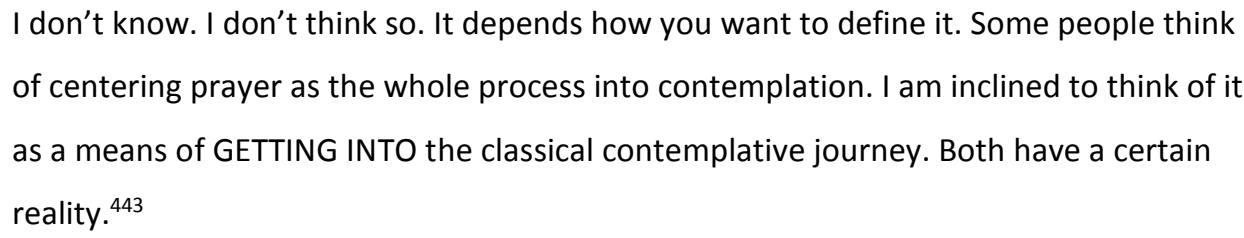

In this study, I treat the method of centering prayer as a preliminary step toward contemplation, for three reasons. First, centering prayer is conceived by advanced practitioners and Keating as preparation for the intermediate and advances stages of the contemplative journey. ${ }^{444}$ Second, the guidelines of the method of centering prayer focus on the sacred word, which has no methodological application in later stages. Finally, the intermediate stage (contemplative prayer) and the advanced stages (transforming union and unity consciousness) make up the bulk of the Christian path, as outlined by the Keating School of Centering Prayer, and those stages do not draw on the method of centering prayer.

Keating borrows directly from Teresa of Avila to delineate the stages of contemplative prayer and presents them as temporary absorption states encountered in seated prayer. For example, he says, "St Teresa of Avila describes in The Interior Castle the states of prayer... They are levels of absorption of the faculties." 445 At the heights of these levels of absorption practitioners experience "union with God".

The Keating School discusses two types of union states: temporary and abiding. ${ }^{446}$ Temporary union states are considered very absorbing and primarily encountered in seated prayer. They are comparable to transitory states of illumination (satori) and deep concentration (samādhi) cultivated in meditation practices of other traditions. For example,

\footnotetext{
440 Open Mind, Open Heart, 113-14.

441 Intimacy with God, 15.

${ }^{442}$ Father Theodore, Interview \#28.1, p.12.

443 Ibid., p.12; Keating, Reflections on the Unknowable, 45.

${ }^{444}$ Keating considers centering prayer in the "broad sense of the term" as "the first step on the ladder of contemplative prayer" or "a school through which we may pass to come to contemplative prayer". Intimacy with God, 15; Open Mind, Open Heart, 114.

445 Intimacy with God, 19-20.

${ }^{446}$ Open Mind, Open Heart, 110.
} 
Father Theodore says, "Nonduality can be permanent unlike union (at least in the sense of Teresa of Avila) and satori, or the various other names that Buddhists and the Hindus give the different levels of samādhi." 447 Another example is Keating's explicit treatment of Teresa's writing. In his mind, Teresa does not discuss union with God as an abiding state of consciousness at all (For this, he says, we have to look to other sources, such as Meister Eckhart.). ${ }^{448}$ Rather, she discusses the stages of prayer as absorptions that increase in intensity and, at their unitive heights, alter the structure of consciousness for short periods of time. Keating points to intensity and structure to identify specific levels that reflect Teresa's delineation: (i) infused recollection; (ii) prayer of quiet; (iii) prayer of union; and (iv) prayer of full union. ${ }^{449}$ Stages (iii) and (iv) are considered temporary union states.

Abiding union states are viewed by Centering Prayer as the curriculum of the higher reaches of the Christian contemplative path. The higher reaches include transforming union (Stage Four) and unity consciousness (Stage Five). These states should completely restructure consciousness and persist in and outside of seated prayer without being absorbing. Since they are not absorbing, practitioners should be able to engage in everyday activities while remaining uninterruptedly in a state of "union with God" equally profound, if not more, than temporary absorption states encountered earlier on the path during formal prayer sessions. 450

I will now discuss the stages of contemplative prayer as temporary states of increasing absorption and union. I will discuss each stage in turn.

\subsubsection{Infused Recollection}

Infused recollection is considered "infused" in two senses. First, it should be given rather than artificially produced by the practitioner. Second, it should be an affective elevation of prayer that has formerly been "dry". Before the onset of infused recollection, prayer is typically described to have become barren for a period of time. This outcome is ascribed to the persistent letting go of content that led to non-involvement in ordinary experience and thus anhedonia (night of sense). The psychological stream of training thus seems to have made scarce the pleasures typically found in the pursuit of experiences. Consequently, as the night of sense neared completion - by way of reducing the pleasures and emotional rewards extracted from stimulating the faculties - prayer is described as dry and no longer exciting. Infused recollection changes this, because it is meant to breathe fresh air into barren prayer

\footnotetext{
${ }^{447}$ Father Theodore, Interview \#28.1, p.9.

448 Thomas Keating, Consenting to God as God is (New York: Lantern Books, 2016), 112.

${ }^{449}$ Open Mind, Open Heart, 138; Intimacy with God, 19.

${ }^{450}$ Open Mind, Open Heart, 110.
} 
and affectively elevate the activity by way of a silence that wells up from the depths with "delicious spiritual savour". ${ }^{41}$ Thus resting in the interior silence of spiritual awareness should become hedonically rewarding and replace the payoffs extracted from content at the ordinary level of awareness.

At this stage, interior silence should be pleasurable but not absorbing. Thus practitioners should feel drawn to sink deeper, but they can resist. Keating says, "We can get up and walk away." ${ }^{52}$ Since infused recollection is understood to be hardly absorbing, ordinary experience should continue. Practitioners report that they retain cognitive access to ordinary consciousness and that their faculties still operate: content seems to continue to pass by like boats on the surface of the river. Hence infused recollection is spiritually attentive, because ordinary and spiritual levels of awareness appear to run in tandem (dualmode). ${ }^{453}$ Infused recollection should also add to spiritual attentiveness an enhanced hedonic steady-state, because now the depths of spiritual awareness should supply an alternative source of affective reward in more subtle ways (joy, peace, delicious savour, etc.).

\subsubsection{Prayer of Quiet}

Prayer of quiet should be more absorbing. Practitioners report feeling grasped by the state. Though they could break free from the embrace, they appear to have no desire to, because the interior depths of spiritual awareness seem to have become too rewarding and attractive. In Christian parlance "the will is grasped by the spirit". Practitioners may also experience "consolations of God" (=hedonic reward that wells up from inside). Consolation is conceived as a two edged sword. On the one hand, it may further the psychological stream of training and the healing of the unconscious. 454 On the other hand, the practitioner can become attached to the delight and fall into the "trap of spiritual gluttony". 455 Thus consolations are subjected to the "Four R" formula: resist not; retain not; react not; and return (to the centre).

\subsubsection{Prayer of Union}

In prayer of union the practitioner's basis of operation should sink another level deeper, into divine awareness. Prayer should now be so absorbing that the faculties of imagination and

\footnotetext{
451 Invitation to Love, 106.

452 Ibid., 107.

${ }^{453}$ Keating similarly describes the structure of infused recollection and spiritual attentiveness. For example, infused recollection is a matter of "being aware of thoughts while being free from engaging with them"; at the same time "interior silence becomes more profound, pervasive and peaceful". Manifesting God, 109.

454 Ibid., 111.

455 Invitation to Love, 107.
} 
memory are suspended and cognitive access to contents of the kind that rest upon those faculties diminished. Consequently, the event-perspective of ordinary consciousness and the objects it contains (memories; images, narratives, inner commentary, etc.) should recede from view, especially if practitioners have their eyes closed and are in an environment that provides little to no sensory stimulation. Now the event-perspective of the divine level of awareness seems to come to the foreground alongside the content it contains. Practitioners report sensing a "presence of something real, but it has not a form, image, or concept". ${ }^{456}$ This "sense of presence" should appear in the event-perspective (object-side) as something "other" and in the awareness-perspective (subject-side) as the practitioner's witnessingpresence of which the practitioner is reflectively aware. 457 Therefore, prayer of union appears to have a dualistic structure: at the subject-side is the "subjective sense of presence" of the self-aware knower who is positioned at the place from where awareness comes; at the objectside is "objective sense of presence" of the known "other" to which awareness is directed.

The structural differentiation between self and God's presence seems to underpin the dualistic awareness of prayer of union. This structural marker of the divine level of awareness in prayer of union is so important that I will now discuss its subject-side (awareness-perspective) and object-side (event-perspective) in greater detail.

The subject-side of divine awareness, in prayer of union, is identified by Frenette as the "spiritual witness". ${ }^{48}$ It is the "sense of self as a subject of experience united with God".459 There is something behind the experience of union, "a subtle, hidden veil of self" that is self-aware and "witnesses the deepest states of prayer". It is thus a reference point that "remains fully aware of this union". ${ }^{460}$ Being a reference point, it is like Pennington's "subject of awareness" that is reflectively aware of itself (see Section 3.5). The reflective aspect splits consciousness and thus creates (i) a sense of distance toward God (as "other") and (ii) a peculiar sense of standing outside and watching oneself. This removed and watchful position toward oneself is an act of self-reflection that objectifies the self in such a way that what was prior an implicit subject (self-as-subject) becomes in the act of reflection

\footnotetext{
456 Ibid.

${ }^{457}$ Manifesting God, 112.

${ }^{458}$ Frenette, The Path of Centering Prayer, 92.

459 Ibid., 74.

460 Ibid., 90-91.
} 
an explicit subject (self-as-object). ${ }^{461}$ The explicit subject, then, "silently witnesses the contents of awareness, or its lack of contents in a still, silent interior spaciousness" ${ }^{462}$

The object-side of divine awareness, in prayer of union, appears to imbue this "silent interior spaciousness", which is the subtle-level content of spiritual awareness, with God's presence-absence. Frenette describes this as "a kind of encompassing inner stillness filled with God's empty spacious presence". ${ }^{463}$ Keating adds that the "presence" may "descend from above" or "arise from below", or it may "envelop" the knower (spiritual witness).464 In any case, the presence is meant to be located at the object-side of experience (eventperspective). Union so conceived is dualistic and incomplete. 465

\subsubsection{Prayer of Full Union}

Finally, in prayer of full union absorption is conceived to reach zenith. At this level there should be no resistance from the practitioner, because the will should not only be grasped but so absorbed in God (divine level of awareness) that it is absent. All the faculties should come to rest. ${ }^{466}$ Cognitive access to ordinary and spiritual levels of awareness, including their respective content, should also be lost. Therefore, the object-side of the divine level of awareness, in full union, appears to lack coarse-level (ordinary) and subtle-level (spiritual) content. Coarse-level content of ordinary awareness would have included objects from the environment, sensory stimuli and contents of the mind. Subtle-level content of spiritual awareness would have included formless spaciousness, stillness and silence. Frenette points out that full union should not contain any content at the object-side of experience no matter the level of awareness. He says, "Interior silence, stillness, spaciousness and the absence of thoughts, valuable that they are, are experiences in consciousness, not pure consciousness itself." 467 Frenette thus advises to "move from the awareness of deep interior silence into pure consciousness." 468

\footnotetext{
${ }^{461}$ I consider the persistence of self-reflection in "union with God" to be precisely what the author of the Cloud points to when he discusses the final obstacle to perfecting the contemplative state. He says, "Long after you have successfully forgotten every creature and its works, you will find that a naked knowing and feeling of your own being still remains between you and your God. And believe me, you will not be perfect in love until this too, is destroyed." The author continues to explain that acts of self-reflection hinder the practitioner from fully uniting with the Divine. "For as often as he would have true knowing and a feeling of God in purity of spirit (insofar as that is possible in this life) and then feels that he cannot-for he constantly finds his knowing and feeling... In a word, he feels the burden of himself... At the same time, however, he desires unceasingly to be freed from the knowing and feeling of his being." [Emphasis mine] Johnston, The Cloud of Unknowing, 92-93. 462 The Path of Centering Prayer, 90-91.

463 Ibid., 90.

${ }^{464}$ Keating, Invitation to Love, 108.

${ }^{465}$ Frenette, The Path of Centering Prayer, 74.

466 Invitation to Love, 108.

467 The Path of Centering Prayer, 91.

468 Ibid.
} 
Even the sense of God's presence is considered absent from the event-perspective of divine awareness, because there should be no object-side (event-perspective) to the state. Father Theodore says, "God is beyond a sensible experience and an intellectual experience. He is the source of everything, so he is the source of those things. The best experience of God as He is - beyond concepts, feelings, enjoyment - is no experience.”469 It is not viewed as an "experience" in the typical sense of the word, because it should be event-perspective excluding. Thus Frenette refers to full union as "God's presence in pure awareness" and he states unequivocally that full union manifests within as pure consciousness. 470 Keating agrees with Frenette. He claims that pure awareness is the "immediacy of experience" of "the undifferentiated presence of God". ${ }^{471}$ Recall also Pennington's view (see Section 3.5 ) that God is known as pure consciousness. 472

The subject-side of divine awareness, in full union, should no longer be self-aware in two senses. First, it should not be self-aware in the self-as-subject sense, because it should no longer reflect back on itself. 473 Hence no self-aware subject should be present. Frenette says that the state should be "beyond any subjectivity or selfhood in you" and "the silent witness [should] fall[s] away." 474 Therefore, there should not be any "fixed point of self-reference".475 Second, it should not be self-aware in the state-aware sense. The practitioner is meant to lose cognitive access to her awareness of no thought and even her awareness of the union state itself. ${ }^{776}$ Keating says, "One is not even aware that one is in this state until it is over. Afterwards, one knows." 477 Frenette explains this loss of cognitive access by way of the absence of an "indirect sense of self that is conscious of being aware." 478 Thus self-awareness appears critical to conscious experience. Arguably, the practitioner has no cognitive access to any level of awareness in full union.

In sum, the structure of full union is conceived to have no subject-side (no spiritual witness, knower or separate-self sense) and no object-side (any object, including God's presence as a sensible experience). Full union with God appears objectless and subjectless. Therefore, the structure of full union seems monistic, because it is viewed as eventperspective excluding. In absence of any structural differentiation, the state should be of a singularity.

\footnotetext{
${ }^{469}$ Father Theodore, Interview \#28, 13. Keating agrees with Father Theodore. Consenting to God as God is, 112.

470 The Path of Centering Prayer, 17, 20, 93.

${ }^{471}$ Keating, Open Mind, Open Heart, 87.

472 Pennington O.C.S.O., Centered Living.

${ }^{473}$ Keating, Manifesting God, 112.

474 The Path of Centering Prayer, 92.

475 Ibid., 93.

476 Ibid., 92.

477 Manifesting God, 112.

478 The Path of Centering Prayer, 91.
} 
In this monograph I present and discuss the phenomenological data on the first three stages of the contemplative path as outlined so far. These initial (sacred symbol and spiritual attentiveness) and intermediate (contemplative prayer) stages are specific to seated prayer and culminate into temporary union states. My report leaves out the first-person data on the higher reaches of the Christian journey that concern abiding union states in and outside of seated prayer. The phenomenological data I will present in the chapters that follow will support the analysis of full union offered here: centering prayer contemplatives phenomenally apprehended God in full union as pure consciousness.

\subsection{The Keating School's Soteriological Vision of the Farther Reaches of the Christian Contemplative Path}

In this section, I will discuss the higher reaches of the Christian contemplative path, as outlined by the Keating School of Centering Prayer. While this thesis does not present firstperson data nor phenomenological analyses of the final stages, it is essential to clarify how the tradition conceives of them to conceptually orientate, situate and make intelligible the path-oriented function of the early and intermediate stages. In contrast to the early and intermediate stages, the two final stages of the higher reaches are traversed in and outside of seated prayer, and aim to permanently transform consciousness. The two stages are: (i) transforming union (Stage Four) and (ii) unity consciousness (Stage Five). I will discuss each stage in turn.

\subsubsection{Stage Four: Transforming Union and the Night of Spirit}

In the early stages of the path, centering prayer should help practitioners develop spiritual attentiveness so that they can receive the gift of contemplative prayer. In intermediate stages contemplative prayer should then become the springboard to abiding union states. 479 Thus the absorptions (Stage Three) are meant to introduce practitioners to temporary union states in seated prayer, and the later stages then aim to extend union into everyday life. 480

The curriculum of the farther reaches seems to draw on the two streams of pathoriented practice. The first, phenomenological stream apparently employs subtle skills to navigate and clarify consciousness. ${ }^{481}$ First, practitioners attempt to cultivate the right kind of "receptivity" 482 required for contemplative prayer outside of seated prayer. Second,

\footnotetext{
479 Open Mind, Open Heart, 114.

480 Ibid., 70-71.

481 lbid., 82.

482 Keating is adamant that we are not exempt in practice from appropriate effort, which is "receptivity". He says, "Receptivity is not inactivity. It is real activity but not effort in the ordinary sense of the word. If you want
} 
practitioners work with "mental pliancy" to shift their basis of operation into deeper levels of awareness in everyday life. Both skills should have been cultivated at earlier stages.

Specifically, mental pliancy should be already exercised in Stage One and Stage Two to develop spiritual attentiveness. This should enable them to (i) abstract away from ordinary awareness and (ii) shift their basis of operation (modus operandi) to the spiritual level of awareness. Thus mental pliancy is critical to receiving the gift of contemplation, and it is through contemplative prayer (Stage Three) that practitioners seem to first become aware of God's presence for short periods of time. Acquaintance with God's presence then appears to activate in them a capacity that can also be aware of God's presence outside of seated prayer and in everyday life. 483

If temporary union states are experienced more frequently and for longer periods of time, the modus operandi should gradually stabilise at the divine level of awareness while spiritual and ordinary levels continue to operate. Thus Keating describes how an "undifferentiated and peaceful presence" begins to establish itself inside. ${ }^{484}$ It is a presence that becomes the "fourth dimension" to all experience in and outside of seated prayer. ${ }^{485}$ In this way, key contemplative skills are meant to be honed earlier on the path and become relevant at later stages to cultivate union on and off the cushion. Such abiding union states appear to consist of a multi-mode awareness that reveal a silent and spacious (spiritual level) awareness of God's presence-absence (divine level) alongside everyday experience (ordinary level).

The second, psychological stream aims to wean practitioners off hedonic reward extracted from spiritual awareness (spiritual consolations), which is considered absorbing since it draws practitioners into the depths of awareness. ${ }^{486}$ Absorption also seems to diminish cognitive access to ordinary consciousness and this encourages practitioners to sink deeper. ${ }^{487}$ The process by which practitioners are meant to be weaned off this absorbing quality is called the "night of spirit". This night should help integrate contemplation and action by working with temporary union states in two ways: First, it is meant to enhance cognitive access to ordinary consciousness through cultivating dispassion towards the absorbing quality of spiritual awareness; second, it should calm the affective system associated with ordinary consciousness. Thus practitioners are instructed to let go of both ordinary experiences (sensory pleasure of ordinary awareness) and spiritual consolations

\footnotetext{
to call it effort, keep in mind that it is totally unlike any other kind of effort." Ibid., 65-66; Manifesting God, 109.

${ }^{483}$ Open Mind, Open Heart, 33-34.

484 Ibid., 66.

${ }^{485}$ Invitation to Love, 130.

${ }^{486}$ Manifesting God, 104-06; Invitation to Love, 133.

${ }^{487}$ Open Mind, Open Heart, 59, 71, 74, 83.
} 
(spiritual joy and delight of spiritual awareness) for hedonic reward.488 The weaning process related to ordinary consciousness is known as the night of sense; the weaning process related to spiritual awareness is known as the night of spirit. As both nights come to fruition, temporary union states are meant to mature into a "permanent abiding state of union with God" in which ordinary consciousness remains operative and awareness of God's presence begins to abide. 489 This denotes the onset of transforming union. ${ }^{490}$ Its peace is viewed as non-sentimental and to transcend spiritual consolations (joy, delight, etc.).491

Transforming union is conceived as a "restructuring of consciousness" effected by regular creative practice not restricted to seated prayer and a willingness to endure the night of spirit.492 The goal of the Christian journey, as outlined by the Keating School of Centering Prayer, is therefore not conceived as a temporary experience afforded by contemplative prayer, but a "contemplative state", which is thought of as a permanent transformation of consciousness that frames all experience. ${ }^{493}$ The transformation discussed entails an apparent stabilisation of a multi-mode awareness as the new structure of consciousness with three levels of awareness that run in tandem: divine, spiritual and ordinary. Specifically, the divine level of awareness is meant to be experienced by way of a dualistically structured awareness of God's presence-absence. 494 Like prayer of union, the "sense of presence" is divided into an objective sense of presence that is phenomenally apprehended as "outside" and "other" and a subjective sense of presence that is the reflective reference point of the experience. The latter is also called the spiritual witness and it is the subject who is aware.495 Unlike prayer of union, the abiding dualistic awareness of God's presence-absence does not compromise cognitive access to ordinary consciousness. Thus psychological experience of everyday life should continue unimpaired.

The Keating School views transforming union as the pinnacle of classic Christian mysticism, but also claims there exist still further reaches of the path beyond it. For example, Father Theodore says:

\footnotetext{
Transforming union is a kind of bridal mysticism where we sort of marry to God or become one in such a way that we give ourselves completely to him, but there is still two in a marriage. Transforming union is what is meant to be the Christian goal, but it is
}

\footnotetext{
${ }^{488}$ Frenette, The Path of Centering Prayer, 88.

489 Open Mind, Open Heart, 59, 102.

490 Intimacy with God, 70.

491 Invitation to Love, 130.

492 Open Mind, Open Heart.

493 Ibid., 70, 102. Keating says, "To evolve into that state as permanent is our destiny." Reflections on the Unknowable, 135; Keating, Manifesting God, 106.

${ }^{494}$ I discuss "God's presence" and "God's presence-absence" within the context of apophatic practice in Section 3.2.1 (pp.74-77).

495 The Path of Centering Prayer, 79.
} 
the beginning of the further journey and not the end. It is certainly from the point of

view of a personal God the peak, because what it constitutes is that total gift of self that

might be symbolised in a perfect marriage of a couple: they totally want to

interpenetrate each other. ${ }^{496}$

Father Theodore explains that transforming union is relational and for this very reason not the end of the road. Although it is the farthest point practitioners can go while maintaining a relationship with a personal God. Centering Prayer's soteriological vision is more radical than this, however, and broaches territory rarely charted in classic Christian mysticism, and totally unaccounted for by traditional Christian theology.

\subsubsection{Stage Five: Unity Consciousness and the Night of Self}

Unity consciousness is a Christian soteriological vision that Centering Prayer has explicated with full understanding that it does not conform to traditional Christian theology. It is the Keating School's point of view that traditional theology is limited and that it does not account for the farthest reaches of the Christian path.

According to Centering Prayer, the soteriological goal must be verified through direct experience. It cannot be inferred from primary literature. Thus contemplatives of this tradition divest primary literature of authority and take a sober attitude towards it. They are guided first and foremost by study "from within" (first-person inquiry) and this trumps study "from without" (armchair inquiry). ${ }^{497}$ Furthermore, study "from without" is only realisable if guided by study "from within”. Keating says, "Scripture can't be properly understood without contemplative prayer." 498 If aided by contemplative prayer, Keating still doubts that the meaning and intent of source literature can be clearly known. It should therefore be consulted with caution.

\footnotetext{
We believe that scripture is inspired by God, but that does not mean that God agrees with everything that is said there... To give to scripture an absolute authority and the final voice in everything is a form of idolatry. It is to worship words rather than the God who inspired them. ${ }^{499}$
}

\footnotetext{
${ }^{496}$ Father Theodore, Interview \#28.1, pp.10-11.

497 Pike, Mystic Union, xii.

${ }^{498}$ Keating, Reflections on the Unknowable, 107, 09. Bourgeault also reacts against how traditional theology and scholarship on Christian mysticism have contextualised God. She says, 'That God 'out there,' the God of scholasticism and of a Newtonian universe, is precisely what is countermanded by the contemplative experience itself." Centering Prayer and Inner Awakening, 76.

${ }^{499}$ Reflections on the Unknowable, 108-09.
} 
Father Theodore points out that traditionally, transforming union has been viewed as the end of the Christian path, but argues that this reflects the limits of most Christian theology.

Transforming union is the beginning of the further journey and not the end. The further journey is the disappearance of any difference so that we are totally united to God and ARE God. You get to know the impersonal side of God and this is not too clear yet in most Christian theology, but IS in Eckhart. So even God is a distraction for someone who is thoroughly united. Beyond transforming union the Spirit becomes predominant rather than Jesus Christ, because Jesus as Jesus has limitations: historical; he is a human being. So, as Christians, we are meant to go through identification with Christ and to his Divinity. ${ }^{500}$

Above Father Theodore introduces us to two important markers of unity consciousness. Those are: (1) a disappearance of difference and (2) an acquaintance with God's impersonal nature. Keating adds two further markers that distinguish unity consciousness from transforming union. Those are: (3) "nonduality" and (4) "no self". ${ }^{501}$ I will discuss each marker in turn.

\subsubsection{Mark One: Disappearance of Difference}

The first marker of unity consciousness is "total unity" or "disappearance of any difference" to the effect that the practitioner "Is God".

\footnotetext{
What do you do when you become God? You can't have a relationship with who you are exactly, unless you fall back into self-consciousness. But to realise that you are of the Self - with a capital " $S$ " - then so is everybody else and every other thing, and you are what the Ultimate Reality is. ${ }^{502}$
}

Father Theodore points out that total unity recontextualises the Christian idea of "relationship with God". Even though centering prayer is presented to newcomers as constituting just such a relationship, the Keating School teaches that, ultimately, there is no difference between self and God. Thus unity consciousness lacks the constituents for a relationship. Instead, the kind of unity proposed reframes what "relationship" means.

\footnotetext{
500 Interview \#28.1, pp.10-11.

${ }^{501}$ Keating, Intimacy with God, viii-ix; Reflections on the Unknowable, 76-77, 82, 87, 105-06, 16-23; Consenting to God as God is, 110, 23.

${ }^{502}$ Father Theodore, Interview \#28.1, p.12.
} 
Why look in the mirror if you already know who you are? As Eckhart says in some of his

extreme statements - but they are not extreme if you see what he is talking from - you

don't even have a relationship with God, because you are God. ${ }^{503}$

If the final stage of unity consciousness reveals that "I am God", then the notion of having a "relationship with God" cannot mean a dualistic structure of consciousness where God presents Himself to a self (subject-side) as "other" (object-side). Thus Father Theodore insists that "duality disappears" and that "our ideas of what the words mean changes as we go up the ladder of consciousness." 504 Specifically, when the practitioner moves from transforming union into unity consciousness, what "relationship" means appears to change as the structure of the state changes. 505

Centering prayer is still considered a "relationship with God" in the dualistic (selfother) sense, but only at the early stages of the path. Unity consciousness "doesn't mean you reject where you started, because it needed to start someplace. It is just that you have outgrown that stage."506 Therefore, centering prayer starts out as a "relationship with God" but this relationship appears to change - and may disappear entirely - as practice matures.

\subsubsection{Mark Two: God's Impersonal Nature}

Father Theodore's second marker of unity consciousness is awareness of God's impersonal nature. This has three implications. First, transforming union is not the zenith of the Christian path, because it depends on a personal God.

But it [unity consciousness] totally transcends transforming union as separation. There is no separation in unity consciousness. Whereas there is still a certain duality [in transforming union] even though it is inter-penetration of God's spirit and our spirit. ${ }^{507}$

Father Theodore tells us that inter-penetration is still duality, because it presupposes two separate parts that interact with each other. Such separation should be transcended in unity consciousness and dependency on a personal God as "other" should fall away. Therefore, God as God is - according to the Centering Prayer tradition - is not considered limited to

\footnotetext{
503 Ibid.

504 Ibid., p.13.

${ }^{505}$ Father Theodore also claims that "relationship" over time evolves into "nonduality". Ibid., p.8.

506 Ibid., p.13-14.

507 Ibid., pp.1, 15.
} 
the personal domain..$^{08}$ Representatives of Centering Prayer consequently appreciate and embrace impersonal ways of conceiving the absolute.

I think the impersonal viewpoint of Buddhism is very valuable PROVIDED it realises that God is also personal [chuckle]. So it is not one thing or the other. And those who think that anybody who doesn't believe in the personal God or theism is a heretic that's not it AT ALL. They just haven't moved to a further step where God adjusts Himself to wherever the level of consciousness, the being, exists. ${ }^{509}$

Above we see that the Keating School affirms God's nature to be impersonal and personal, and that the revelation of God's impersonal nature is the pinnacle of the Christian path. The second implication of God's impersonal nature is that God's presence as "other" distracts practitioners who aim to be totally united with God.

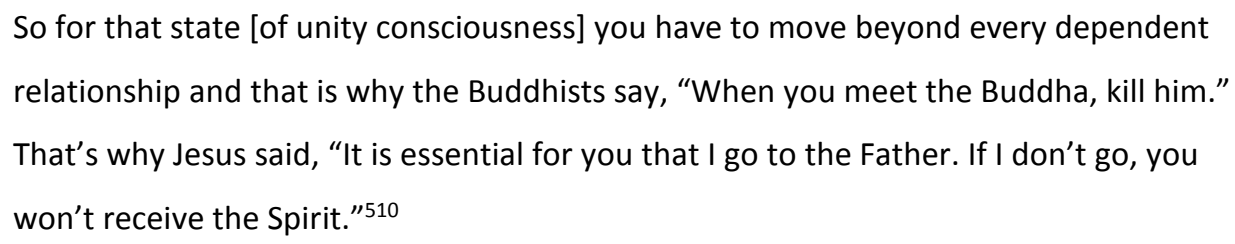

Father Theodore compares a Buddhist teaching with Jesus's own to point out how any objectification of God is a limitation, because it project's God's presence “out there". Thus objectification is thought to bifurcate consciousness into a subject-side with a sense of self and an object-side with a sense of God's presence, and this apparently introduces a reflective "I" as reference point that witnesses God's presence-absence at a distance. Thus the state is considered divided. Father Theodore conceives this reflective "I" (spiritual witness) as a stepping stone to the soteriological goal and not the goal itself.

\footnotetext{
It is a stage on the way to unity consciousness, but the witness is not quite there yet, because what is witnessing? Well, as long as there is anything except the one it is not unity consciousness. But it is getting there. For most people it is the most comprehensive kind of presence that prepares you for "no presence". 511
}

The phrase "prepares you for "no presence" shows how centering prayer draws on apophatic language to discuss unity consciousness. It is prima facie paradoxical and dialectically

\footnotetext{
508 Ibid., p.12.

${ }^{509}$ Father Theodore, Interview \#28.1, pp.22-23.

510 lbid., p.12.

511 Ibid., p.20.
} 
simultaneous in respect to its negative language of presence and absence. Unity consciousness, then, is meant to be a direct consciousness of "God's presence-absence".

The third implication of God's impersonal nature is that unity consciousness is not mediated by Jesus Christ (who is "God in his Humanity") or God's presence as an object. Rather, it is existentially more immediate: it is "being in God's Being" 512 (where God's Being refers to "God in his Divinity"). 513 To be in God's Being, practitioners are instructed to adopt God's stance and view reality from the eye of His Being. ${ }^{514}$ Now God - as God is - should no longer be an object and thus not experienced as such, because God should be the subject that is looking. ${ }^{515}$

Frenette uses the phrase "being in God's Being" to refer to unity consciousness and "resting in God's presence" for transforming union. Resting in God's presence has a dualistic structure, because God's presence seems to manifests itself to a subject rather than in or as the subject. Being in God's Being, on the other hand, apparently does not objectify God's Being, because God's Being is the place from where awareness "comes from" rather than "goes to". 516

Resting in God has a quality of dualistic effort to it; you as a subject are resting in the awareness of an object: God's presence. In resting there is still separation between you and God, a split between the activity of your mind and God. ${ }^{517}$

Being aware of God's presence appears structurally analogous to being aware of an object. It is for this reason that Frenette views God's presence as yet another stepping stone to the final soteriological goal. He says, "Felt experiences of God's presence are not a goal, but a gift that, like a compass, orients you on the spiritual path into God's Being." When the practitioner's modus operandi shifts into God's Being - thereby adopting God's point of view - "there is no presence of God to find or yield to.” ${ }^{18}$ Keating agrees:

\footnotetext{
512 "Being in God's Being" is Frenette's way of speaking about unity consciousness. Frenette distinguishes between God's presence and God's Being. God's presence is what is encountered in transforming union and he associates it with an activity called "resting in God's presence". Resting entails a subtle subject and activity in the contemplative state. In contrast, "God's Being is a greater reality than God's presence." It contains no subject and requires no activity. "There is no presence of God to find or yield to. God's Being just is." The Path of Centering Prayer, 176.

513 Pike, Mystic Union, 4.

${ }^{514}$ Bourgeault quotes Eckhart to capture this point: "The eye with which you seek God is the eye with which God seeks you." Centering Prayer and Inner Awakening, 75; Frenette, The Path of Centering Prayer, 207.

${ }^{515}$ Mannes and Jones, Thomas Keating: A Rising Tide of Silence, 00:00:42-00:01:01; Keating, Reflections on the Unknowable, 79.

${ }^{516}$ Bourgeault also discusses "pure awareness" in this way. She says, "Bit by bit you'll discover that this inner spaciousness is no longer 'a place you go to' but a 'place you come from'." Bourgeault, The Heart of Centering Prayer, 27.

517 Frenette, The Path of Centering Prayer, 180.

518 Ibid., 176.
} 
The highest experience of God is no experience. It just is. We no longer see the face of

Christ because we have in some way become that face. ${ }^{519}$

The soteriological goal, then, is not conceived as an experience of God's presence manifested "out there" and related to as "other" and "personal". Rather, it is viewed as a contemplative state anchored in God's Being.

\subsubsection{Mark Three: Nonduality}

Keating's third marker of unity consciousness is "nonduality". Transforming union seems to have a dualistically structured divine awareness with a reflective sense of self (subject-side) and a felt-presence of a personal God (object-side). In contrast, the divine level of awareness in unity consciousness apparently excludes the sense that there is a reflective self at the subject-side and God's presence "out there" at the object-side. Unfortunately, little information about unity consciousness and nonduality is available. I will thus restrict my discussion of nonduality to four key points, three are raised in the primary literature and one derived from practitioner's reports.

First, nonduality is unlike the monistic structure of prayer of full union encountered in seated prayer. ${ }^{20}$ Full union is monistic because the state appears to be of a singularity. The practitioner has no apparent cognitive access to: (i) the levels of awareness other than the divine level (and possibly not even to the divine level); (ii) any event-perspective, which means that nothing presents itself to the practitioner from the object-side of experience. Descriptions of unity consciousness do not share these features. Both Keating and Frenette are clear that unity consciousness integrates prayer and activity. It should be an abiding, restructured state of consciousness that includes ordinary psychological experience. Therefore, the source material of the Keating School suggests that unity consciousness has cognitive access to multiple levels of awareness at once. It is in this way similar to transforming union where multiple levels of awareness run in tandem.521

Second, the source material suggests a point of difference between "union" and "unity". In unity (or "total unity") the divine level of awareness should no longer be dualistically structured and thus monistic. Its singularity (non-relational structure) is meant to reveal the impersonal side of God. Both temporary full union (absorption in seated prayer)

\footnotetext{
519 Keating, Reflections on the Unknowable, 98. Consider how Keating quotes scripture to convey his thinking: "You have died, and your life is hidden with Christ in God." (Colossians 3:3) In another passage Keating says, "There is no other when you have become the other and the other is you." Ibid., 120. 520

521 The Path of Centering Prayer, 201-10.
} 
and unity consciousness (abiding state in and out of seated prayer) apparently share this feature. The term "unity" is also reliably used in the source literature to capture this type of divine awareness.

Third, the term "nonduality" is only used to refer to the soteriological goal and never to the type of unity encountered in full union. ${ }^{222}$ Hence nonduality appears to be a unique marker of unity consciousness and it demarcates this abiding state from the temporary type of unity encountered in seated prayer (full union). Note also that both temporary unity (full union) and abiding unity (unity consciousness) share the feature that the divine level of awareness is singular/monistic. However, full union, unlike unity consciousness, excludes both an event-perspective and levels of awareness other than the divine level. Therefore, "nonduality" appears to relate to this capacity of monistic divine awareness to function in tandem with an event-perspective as well as other levels of awareness (spiritual and ordinary).

Fourth, the phrase "disappearance of any difference" seems to refer to the divine level awareness only. Practitioners in this study describe how the structural differentiation between subjective sense of presence (reflective "I") and objective sense of presence (God's presence) in divine awareness disappears. At the same time, perception of multiplicity (sensory awareness) is reported to continue at the ordinary level of awareness. Thus they seem to have cognitive access to ordinary consciousness, and this ordinary level of awareness retains a dualistic (intentional) structure. Therefore, ordinary psychological experience apparently continues in unity consciousness, but in a new way: everything is now perceived as "the divine manifesting". "Everything is in God and God is in them." ${ }^{23}$ This means that there is a felt sense of unity in multiplicity. Ordinary consciousness continues to process content through a structurally differentiated ordinary level of awareness, but the perceived content is now imbued with a unifying awareness. In other words, ordinary consciousness is held within the context of divine awareness, because the practitioner's basis of operation is anchored in, and phenomenally apprehends from, the divine level of awareness.

There is no other when you have become the other, and the other is you... one and yet distinct from everything. The Ultimate Reality is the capacity for infinite relationship. In

\footnotetext{
522 Father Theodore says, "St John of the Cross's book on the living flame of love is about life after transforming union. So I think he would be sympathetic to the idea of "no self" or "unity consciousness". But there wasn't any... that much terminology about it in his time. So nobody understood Eckhart. So we really have had to wait for Buddhist-Christian dialogue and for Christians to go to India and study with the Vedantic Hindu masters." Interview \#28.1, pp.15-16. Bourgeault treats the term "nonduality" in a similar way, because she uses it to describe an abiding shift or restructure of the entire "field" or "hardwiring" of perception. Her working definition is: "You see oneness because you see from oneness." Bourgeault, The Heart of Centering Prayer, 48-50.

${ }^{523}$ Keating, Reflections on the Unknowable, 111.
} 
this becoming, everything comes into being. Only Ultimate Reality matters, and for that

very reason everything matters... God, who is always here, is always coming in each precious moment together with its content. God... is infinitely detailed and infinitely diverse. ${ }^{524}$

Keating describes here how ordinary consciousness is recontextualised in unity consciousness, which reveals content as "one and yet distinct". Thus content is viewed to arise as phenomenally unified in God's presence. It would appear that the divine level of awareness in unity consciousness is marked by "disappearance of any difference" and the ordinary level of awareness is marked by "unity in differentiation". Specifically, the latter appears drenched through by a sense of presence, which is phenomenally unifying. The term "nonduality" seems to capture this unifying feature, which reveals coarse- and subtle-level content as being of the same God-nature.

\subsubsection{Mark Four: No Self}

Keating's fourth marker of unity consciousness is "no self". He says, "our personal sense of 'me' is an illusion". ${ }^{25}$ By "me" Keating means the third type of self in his model, which is the separate-self sense. It is the phenomenal fact of the sense of "I" as a structure of consciousness and not the psychological content associated with the self, be it authentic (true self) or inauthentic (false self). It is what the author of the Cloud identifies as "elemental selfawareness". It is the feeling that one is (self-as-subject) rather than how or what one is (selfas-object). Keating insists that this phenomenal fact of " $\mathrm{I}$ " is absent in unity consciousness. Therefore, unity consciousness is marked by two absences: (1) God's presence as an object outside of the self; and (2) the reflective self (spiritual witness) to whom God's presence manifests. As both the sense of self-as-subject and God's-presence-as-object disappear practitioners should "lose any fixed point of self-subjectivity in the subjectivity of what is called the Godhead." 526 Therefore, unity consciousness is considered to have no reference point to which experience refers.

\subsubsection{Unity Consciousness and Centering Prayer's System of Training}

The source literature does not discuss how this highest experience of God can be cultivated. Father Theodore explains that Centering Prayer is very young and that not enough time has

\footnotetext{
524 Ibid., 120-21.

525 Ibid., 118.

${ }^{526}$ Frenette, The Path of Centering Prayer, 199.
} 
passed for enough practitioners to have concerned themselves with this final stage of the Christian path.527 The Christian contemplative heritage also cannot help, because it lacks awareness and resource to engage this final stage. ${ }^{228}$ Consequently, no prescribed phenomenological stream of training has been developed by the Keating School of Centering Prayer.

Father Theodore hints at what such a system of training should focus on. He says, "Reduce separate self-sense and you have got nonduality." ${ }^{29}$ Thus the self-reflective "I" must be dealt with in order to move from transforming union to unity consciousness.

[Recall that] transforming union is the [dualistic] inter-penetration of our being. That's wonderful, but you still have your own self-awareness: there is an "I" that is experiencing this. Though you just assume, "Forget about it." You can't! Because it still hasn't been quite laid to rest. This I venture to call the night of self. ${ }^{530}$

Father Theodore clarifies here that the phenomenal fact of the sense of "I" as a structure of consciousness needs to be engaged to transform the dualistic structure of the divine level of awareness into a monistic one. The aim of the system of training, then, is to restructure consciousness in such a way as to exclude from it the separate-self sense (self-reflection).

While no phenomenological training regimen has been made available to engage this structure, some pointers can be found in the literature about the psychological stream of training. Unlike at prior stages, the psychological stream deals with the psychodynamics involved in letting go of the phenomenal fact of self rather than its psychological content. The psychodynamics address how the remaining self-structure, however subtle, responds to its own demise. Keating describes this demise as a final dismantling of the self by way of "letting go of self-consciousness" and the "death of the ego". ${ }^{3{ }^{1}}$ Frenette also identifies this as the "death of the separate-self sense." ${ }^{2}{ }^{2} \mathrm{He}$ describes the dying process as one where "God as an object outside of you falls away just as your own sense of self as a subject who apprehends God dies." 533

The process through which the practitioner endures and embraces his own death is referred to by Keating as the "night of self". 534 The night of self is a kind of "purification"

\footnotetext{
${ }^{527}$ Father Theodore, Interview \#28.1, pp.3, 28.

528 In respect to Centering Prayer, Father Theodore says, "Its chief purpose is to emphasise the love of God and His personal invitation to become God too. [It's] something that's been kind of lost as upfront teaching, which I think is pretty clear on the Gospels and in the early Fathers of the Church." Ibid., pp.3, 25.

529 Ibid., pp.3, 10.

530 Ibid., pp.14-15.

${ }^{531}$ Keating, Reflections on the Unknowable, 87, 125.

532 The Path of Centering Prayer, 180.

533 Ibid., 197.

${ }^{534}$ Keating himself conceived of this night and added it to the Christian path.
} 
process that "includes transformation of the deeper structures of consciousness where the separate-self lives." 535 This deep level of purification is met with resisting emotions, contemplative dread and the darkness of the void. ${ }^{336}$ As the separate-self sense gradually lessens, a "deeper sense of emptiness or void" emerges, because "the fullness of God is experienced as emptiness by the separate self”. 537 The sense of the void then triggers feelings of diffuse to strong anxiety and a sense of unnerving desolation. The psychological system of training, Frenette suggests, involves "embracing God in the feeling, not the feeling alone". ${ }^{538}$ As God is embraced in the emotions and the fear, the practitioner can remain present to the emptiness behind those feelings. Gradually, "God's subtle presence in the emptiness of the separate-self sense... com[es] to life" and "God's presence embraces you in emptiness".539 In this way, "dualism dies in the darkness" of the night of self.540 And the final state that ensues is "presence in emptiness". ${ }^{441}$

\subsection{Conclusion}

Centering prayer is a path-oriented contemplative practice that has: (i) a soteriological goal (unity consciousness); (ii) a developmental trajectory (the Keating School stages of the contemplative path); and (iii) a system of training that consists of a phenomenological and psychological stream. Centering prayer is also an apophatic contemplative practice, because its method does-away-with the human faculties to approach God as God is.

The path can be divided into two phases. The first phase is traversed in seated prayer and covers the first two "early" stages (sacred symbol and spiritual attentiveness) and the third, "intermediate" stage (contemplative prayer). At the end of the intermediate stage, practitioners are meant to enter into temporary union states during formal prayer. The zenith of this phase is the complete absorption of prayer of full union in which God is experienced as pure consciousness.

The second phase is meant to be traversed in and outside of seated prayer and covers the last two "advanced" stages (transforming union and unity consciousness). These final stages denote the farther reaches of the Christian journey, which is concerned with abiding union states. Its curriculum focuses on permanently restructuring consciousness. At first, in transforming union, the sense of God's presence should become the fourth dimension to all

\footnotetext{
535 The Path of Centering Prayer, 190.

536 Ibid., 186-87, 90.

537 Ibid., 191.

538 Ibid., 190.

539 Ibid., 191-92.

540 Ibid., 199.

541 Ibid., 195.
} 
experience and remain structurally differentiated from the self. Thus transforming union is understood to be marked by an abiding dualistic awareness of God's presence. Practitioners are then encouraged to enter the night of spirit to gradually dismantle the phenomenal fact of self and reveal God's impersonal nature. This should culminate into unity consciousness in which God's presence-absence is no longer structurally differentiated from the self. Unity consciousness is thus conceives as an abiding nondual awareness of God's presence.

In the chapters that follow, I will present first-person data on the first phase of the contemplative path to discuss how seated prayer evolves from the basic method of centering prayer (sacred symbol) into contemplative prayer (absorption). I will cover all the states of absorption and investigate how exactly God's presence-absence is phenomenally apprehended in pure consciousness. 


\section{Chapter 4}

\section{The Sacred Symbol: "Intention" and "Attention" in the Method of Centering Prayer}

There is nobody out there. It's a sense of "coming home" to the one who is already at the very heart of my being, because I am all. So to come home to that holy presence within, it's also to come home to "me". So when I use the sacred word I talk about "putting it out", but paradoxically it's also "a taking it in": "Abide in me as I am already abiding in you." ${ }^{542}$

- Joseph

Rather than using my centering prayer word as sort of like "a cat catching a mouse", I am returning to my intention; or I am returning my ATTENTION to God's presence and then saying my word, "I am here." 543

- Rachel

Presence. It's really more about MY becoming present. ${ }^{544}$

- Samuel

\subsection{Introduction}

In this chapter I will present first-person descriptions on the first stage of the contemplative path. I will illustrate how the "surrender method" of centering prayer works. My outline of the basic method will lay the foundation for grappling with what centering prayer aims to achieve: the birth of spiritual attentiveness and the ongoing progression of the practitioner's basis of operation (modus operandi) through the levels of awareness until consciousness of God's presence-absence as God is abides.

I will begin with posture and return to descriptions thereof at relevant junctions of practitioners' prayer sits. I will then turn to how practitioners use the sacred symbol as a word, as an intent and then as an intervention. My discussion of the sacred symbol will clarify what role "attention" and "intention" play in the method. Specifically, I will focus on the experiential structure of attention/intention and how that structure is reinforced through intervention. I will conclude with how practitioners shift their basis of operation by "abstracting away" from ordinary consciousness.

\footnotetext{
542 Joseph, Interview \#5.1, pp.24-25.

543 Rachel, Interview \#26.1, p.13.

544 Samuel, Interview \#24.1, p.19.
} 


\subsection{Posture}

Since the Centering Prayer tradition does not prescribe a specific posture, practitioners adopt positions of their own choosing. At the 10 Day Intensive, I witnessed practitioners sitting in chairs, on prayer stools, on a cushion and some even sat in a Burmese lotus position (cross-legged and with the right hand folded into the left, thumbs touching), but with eyes closed. There are trends: sitting in a chair or on a prayer stool is common, and postures generally hold a comfortable position that is neither lax nor rigid, with a straight back and eyes closed.

\subsection{The Sacred Symbol as a Word}

Practitioners begin centering prayer by choosing a word as their sacred symbol. Even though Keating allows for other techniques to fulfil the same function (e.g., focus on the breath), most long-term contemplatives continue to rely on a word as their symbol of intent, but they experience its application differently. I will now present sections of prayer sits in which the sacred symbol is applied, at least in part, as a "word".

\subsubsection{Carol's Centering Prayer Sit on the Morning of the Interview}

\subsubsection{Context and Posture}

Carol is 87 years old, retired, and lives in a town on the North Island of New Zealand. She has contemplatively prayed for 37 years and she has been practicing centering prayer for 7 years.

Carol's morning sit happened at home alone in a bedroom. She sat down on a chair, composed herself and lit a candle. She started to think of her upcoming conversation with me on that same day and thought, "No, there is nothing here." 545

\subsubsection{Carol's Sacred Word "Silence"}

Carol's sit began with a "naked intent towards God... just like that". ${ }^{546}$ Her intent is followed by a settling period.

${ }^{545}$ Carol, Interview \#11.1, p.5.

546 Ibid. 
And things come in and I say, "No! Attention, attention, attention." And my sacred word

is "silence". So it was a case of just "being": being in the present. [I make] a few cries

out, "Sophia. Sophia. Wisdom. I'd like a bit of help here please." Yeah and just being. I

catch myself thinking about the camellias and wandering off, but then come back again.

It is a constant process of just "in and out". ${ }^{547}$

Carol describes a process that moves "in and out" where "in" denotes "just being" or "being in the present". When she is "out”, Carol's prayer is unsettled.

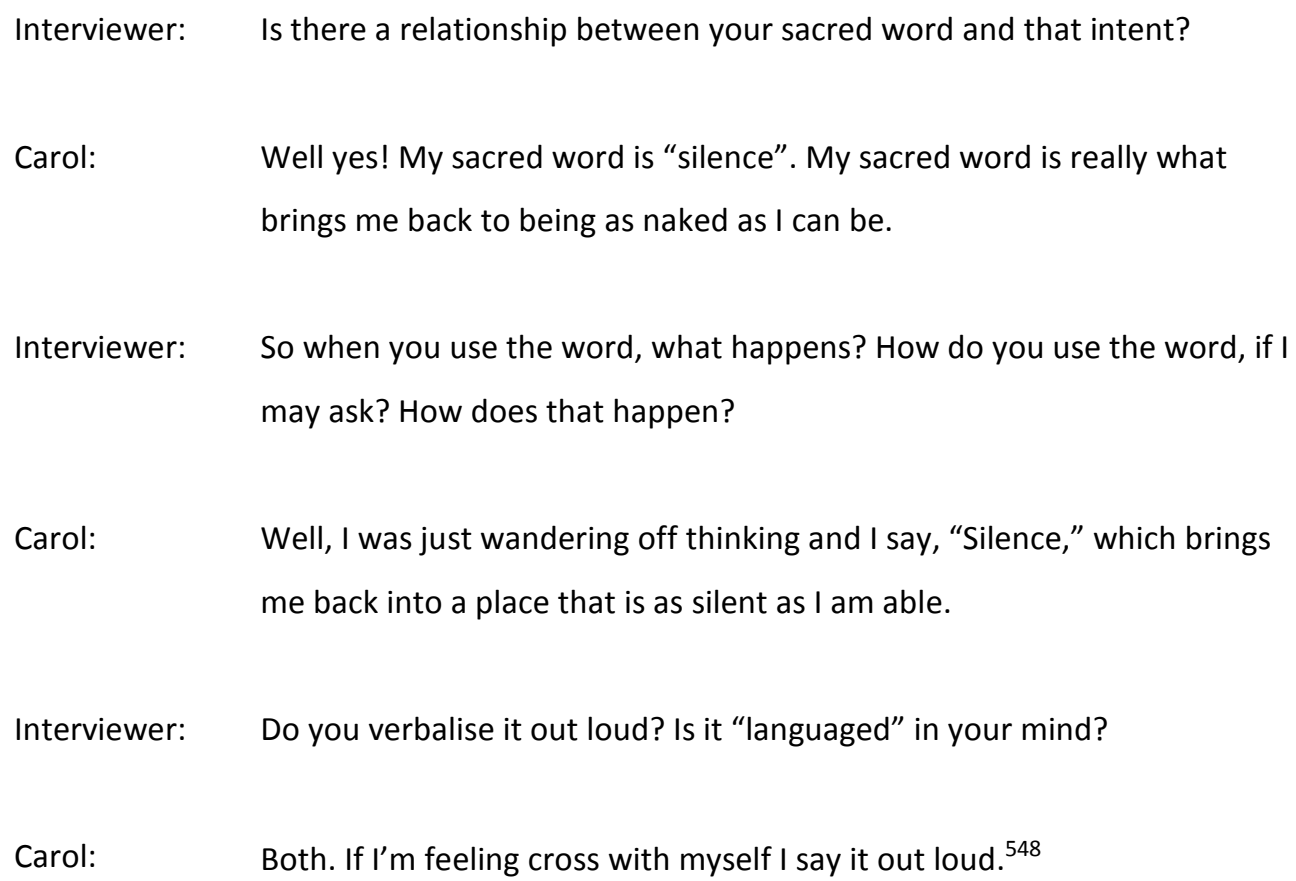

Carol clarifies that she experiences her sacred symbol through language in her mind. It is not an image or picture and there are times when she verbalises "silence" out loud.

Clearly her sacred symbol is more than just a word. It also expresses her intent and she uses it to intervene in her practice. I will return to these aspects later. Let us first consider another example in which the sacred symbol is, at least in part, a "word".

\footnotetext{
547 Ibid.

548 Ibid., p.16
} 


\subsubsection{Joseph's Centering Prayer Sit on the Morning of the Interview}

\subsubsection{Context and Posture}

Joseph is 68 years old and lives in a small town on the South Island of New Zealand. Joseph has been engaged in contemplative practice for over 50 years. His practice history includes exposure to Christian meditation. He has practiced centering prayer for 7 years.

Joseph's morning sit began with a few stretches. He then sat down on a prayer stool on a little mat in his study at home, which is overlooked by a Christ Pantocrator. His eyes were closed. His face was in a straight ahead pose and his hands loosely folded, knuckles connecting with his upper legs. His legs were wrapped around the prayer stool with knees and shins touching the floor. Joseph took a big breath and then listened for a few seconds to his heart's desire to be with God. This sharpens his intent. Next, he focused on making himself fully available without prejudice to the moment. To do so, he verbally and nonverbally rejected unhelpful motives for doing a sit at that very moment.

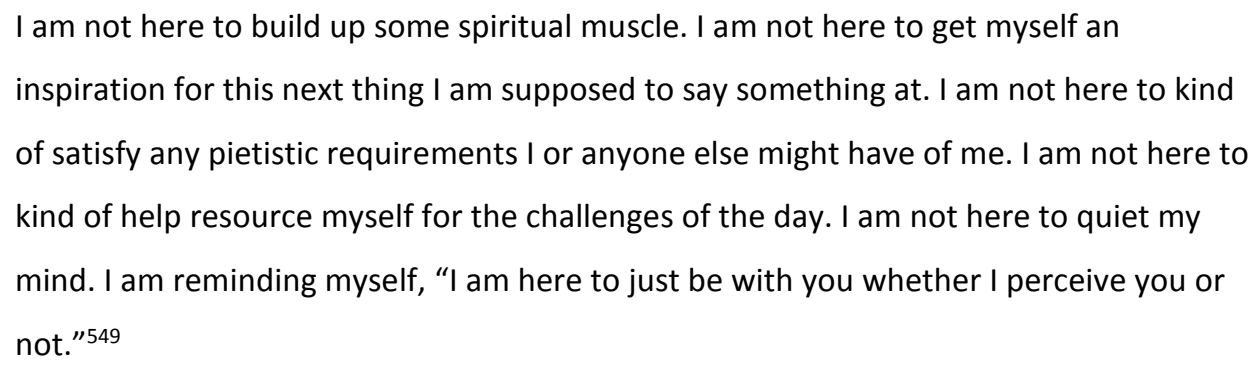

Then Joseph sounded the bell.

\subsubsection{Joseph's Sacred Word "You"}

After the bell, Joseph started with his "little word", which, he says, "is made sacred simply by its use, not by any inherent thing in the word itself. I use that as a tool to say, 'I am available. I am giving you this little word as a sign of my desire to be with you." ${ }_{550}^{\circ}$ This is how he experiences his sacred word:

\footnotetext{
I don't listen to it. The specific word I use is just " $Y$ ", "O", " $U$ ", "You." I don't see letters.

It kind of sounds in my mind but it is an intention of the heart. It's a reaching out - yeah, we said that - it's a desire for connection, "It is you I want." I kind of hear it, but it's
}

\footnotetext{
549 Joseph, Interview \#5.1, p.16

550 Ibid.
} 
something that isn't like an English word " $Y$ ", "O", " $U$ ". It's a desire of the heart that's

just focusing itself on this [sigh] not even word but on this something [laugh] that I am using as a token of my desire, "to be in union with you: to know you." 551

Joseph tells us that his sacred word "sounds" in his mind. He kind of hears it, but doesn't "listen to it", because it is "not even a word". He also does not visually see the word in his mind. He says, "I don't see letters." Joseph's account indicates that his sacred symbol is not a mere word, but a medium through which he "intends", "desires" and "reaches out".

\subsection{The Sacred Symbol as Intention}

Carol's and Joseph's examples above show that experienced centering prayer practitioners may still apply the sacred symbol as a word. However, the way they apply their sacred symbol indicates that it is more than a "word", whether it is spoken out loud, silently verbalised, or sounded in mind. It also has an intentional component.

I divide intent into two dimensions: mode and structure. The mode is about the manner in which the intent operates: by attraction or aversion; by affirmation or denial. The structure is about how the intent is directed and what its object is. For example, is Joseph's "reaching out" an instance of narrow intentionality (subject directed to object) or broad intentionality (open to but not directed at alterity)?

I will now discuss these two intentional dimensions of the sacred symbol by way of practitioners' accounts. I begin with one example on the mode of the sacred symbol's intent and then turn to three examples of how the intent is structured.

\subsubsection{The Mode of Intent: Affirmation}

\subsubsection{Joseph's Desire for Union with God}

I return to Joseph. He said earlier that his sacred symbol is "a desire of the heart that focuses itself on 'this something". His prayer is thus framed by a strong desire for union with God.

It is kind of like a magnetic pull in me. It's a sense that, "All I want is you." It's a strong desire with the sense that the "you" I desire is completely unorganisable [chuckle], [un]map-able, [un]controllable, [un]persuadable [laugh], [un]programmable. It is

551 lbid., p.24 
utterly beyond "me". The sense of union is always a gift. The only thing I can do is

make myself available. ${ }^{552}$

Apart from making himself available, Joseph works with a specific intent in practice that he finds expressed in one of John the Baptist's sayings, "I decrease that He may increase."

I think that is the intent in my practice: to get this reductionist "me" out of the way

and be open in this "bigger-self-I-am" to what my heart most desires, which is union

with the presence of God. ${ }^{553}$

Thus Joseph says that "coming to prayer is a declaration of my desire for God alone".554 This affirmative context frames and drives his prayer. As Keating points out, the purpose of prayer is not to simply let go of content, "but to deepen our contact with the divine indwelling".555 Joseph's desire illustrates this principle. His prayer is not merely about letting go, but more importantly about letting go on behalf of a more valuable alternative, which is God. The apophasis at work is hence undergirded by affirmation.

\subsubsection{The Structure of Intent: Openness}

I will now attend to the structure of the sacred symbol's intent and present three cases to show that the intent of practitioners is of an atypical and non-relational kind.

First, it is not directed outward to God as an "other", but inattentively consolidated as practitioners' own indwelling sense of presence, which is identified as God's presence within (the "divine indwelling").

Second, this "presence" is not self-enclosed even though it is not directed at an object (narrow intentionality). The sense of presence is open towards alterity, and, therefore, an instance of broad intentionality. Broad intentionality is receptive and can be affected by the other. Classic phenomenologist describe phenomenal apprehending (subjectivity) in such cases as "open" and practitioners describe their own presence as "available".

The structure of this type of intent belies the relational language used by practitioners to describe how they intend. Careful questioning clarifies that the relational language used tries to capture their open and available intent, which is a receptive sense of presence not directed towards otherness.

\footnotetext{
552 Ibid., p.13.

553 lbid., p.7.

554 Ibid., p.8.

${ }^{555}$ Keating, Open Mind, Open Heart, 35.
} 


\subsubsection{Joseph's "Isness" is the Presence}

I return to Joseph with the aim to clarify where we can find the object of his intent (the "presence of God") and how his intent is "directed" towards it.556

I will begin by exploring the earlier distinction he made between a "reductionist me" and a "bigger-self-I-am". I will then connect the "bigger-self-I-am" to the presence of God as the object he intends. Let us begin with Joseph's distinction.

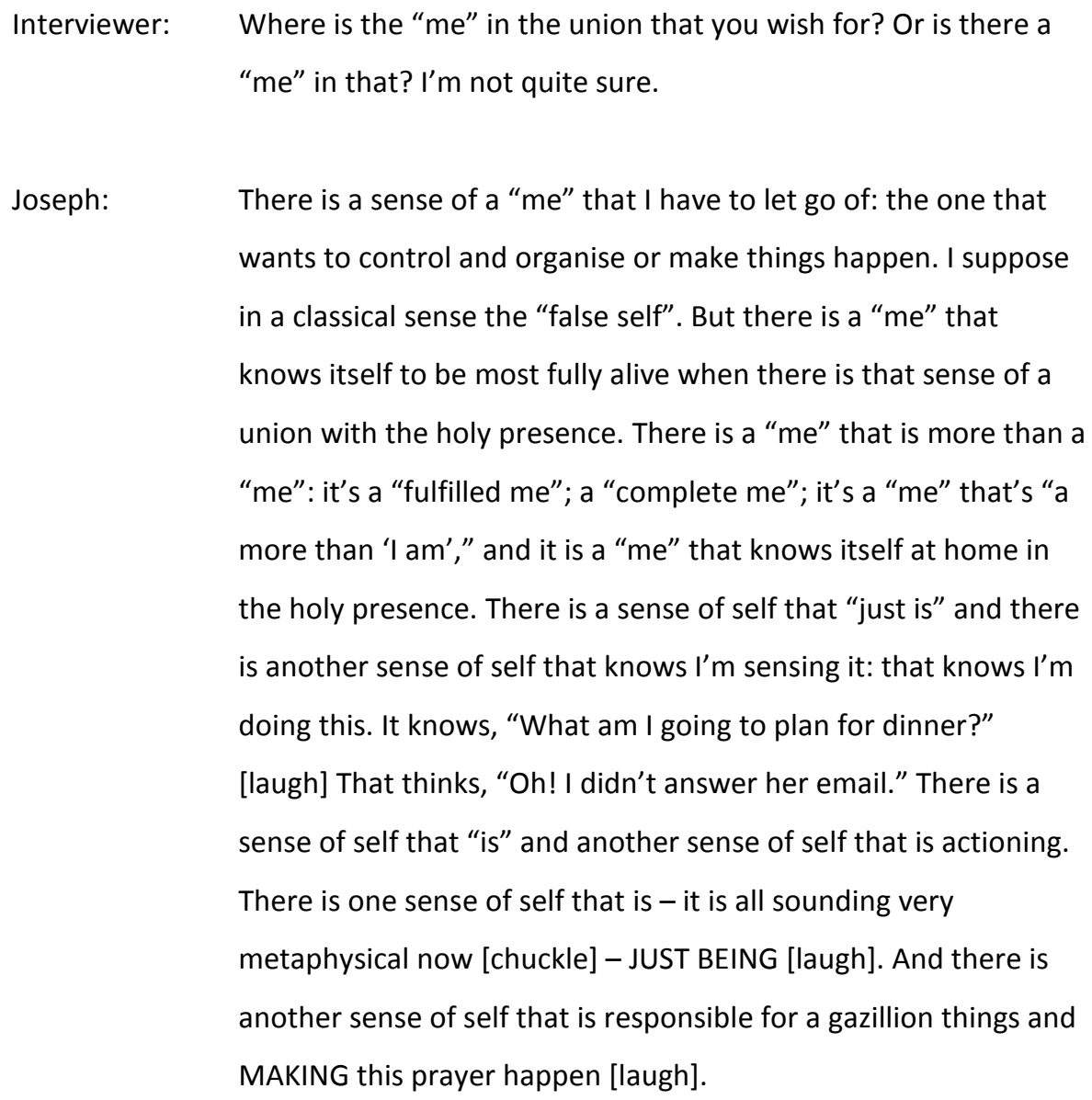

${ }^{556}$ I will discuss the nature of the presence of God in greater detail in Chapters 6-9. 


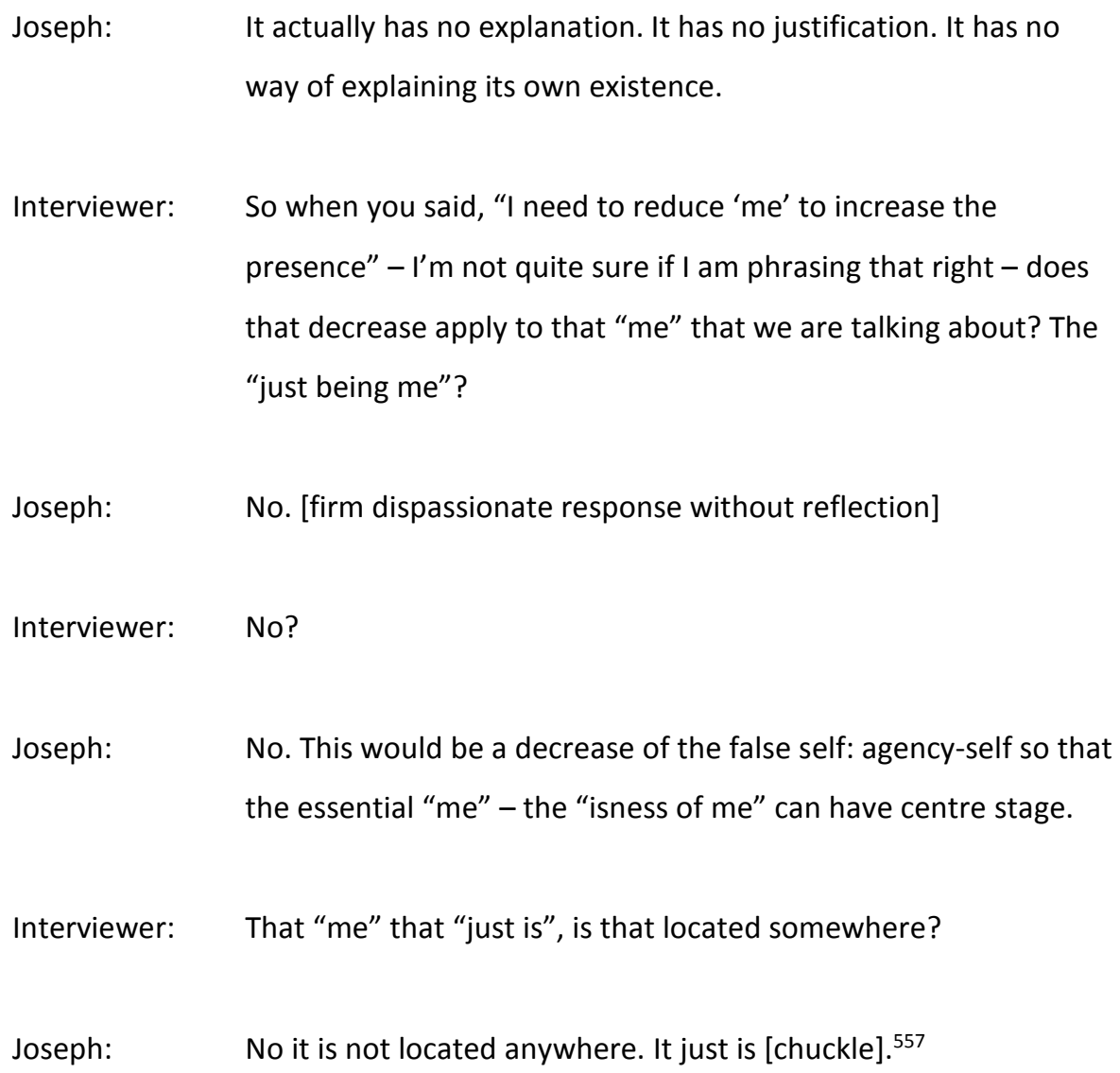

Joseph describes two different senses of self: a sense of agency (the false self) that is immersed in ordinary consciousness and a sense of "isness" or "just being" that "just is" and does not partake in ordinary consciousness. In order to make himself available to God, Joseph lets go of his sense of agency at the ordinary level of awareness so that "just being" can come to the foreground of his experience. I will now explore the relationship that exists between "isness" and the presence of God.

Joseph reports that when he becomes aware of the presence of God, he experiences it as something that has already been there. He says, "You were waiting for me. Here you are." ${ }^{8}{ }^{8}$ His discovery is accompanied by a sense of connectedness alongside a complete loss of his sense of embodiment, being in a body, and any mental activity. His sense of himself also expands. Recall that his sense of “just being” is not localised. Let us analyse Joseph's awakening to a presence-already-there with a focus on structure.

Interviewer: You have been talking about being available, making yourself available, and then you were talking about the discovery of,

\footnotetext{
557 Joseph, Interview \#5.1, pp.13-15.

558 Ibid., p.16.
} 
"Here you are. You have been waiting for me." What did you mean by "you"? Was that yourself or was that the presence?

Joseph: $\quad$ Ah, the presence, waiting for me.

Interviewer: Waiting for you. Does that discovery of the presence typically follow your sense of your own availability or does the presence emerge and then you feel yourself present?

Joseph: It is really impossible to separate out.

Interviewer: Yeah, you just said before that the "isness" and the presence is the same. ${ }^{559}$

Joseph: Yeah. ${ }^{560}$

Interviewer: There seems to be a kind of directionality that you introduce in consciousness, but for something specific, and the problem is, it sounds to me, that the presence is nothing specific, like it's not a "thing"-

Joseph: $\quad$ No.

Interviewer: -that you can aim, right?

Joseph: No. It's not a "thing". It just is [chuckle]. A significant sentence for me in John's Gospel is Jesus' saying, “I go ahead to prepare a place for you." And I have the sense of the everyday-ness of that: Jesus's preparing a place NOW to meet with me [chuckle] so that, "Where I am you may be also. I go ahead to prepare a place so that you may be where I am." And in John's Gospel, "Abide in me as I abide, as I ALREADY abide in you." So my use of the word - and I talk about "putting it out", but paradoxically it's also "a taking it in": "Abide in me as I am already abiding in you."

559 Earlier in the interview Joseph and I discussed his experience of the presence and its relationship to "isness". I present this data in Section 7.6 and discuss the implications in Section 7.7.

560 Ibid., p.17 


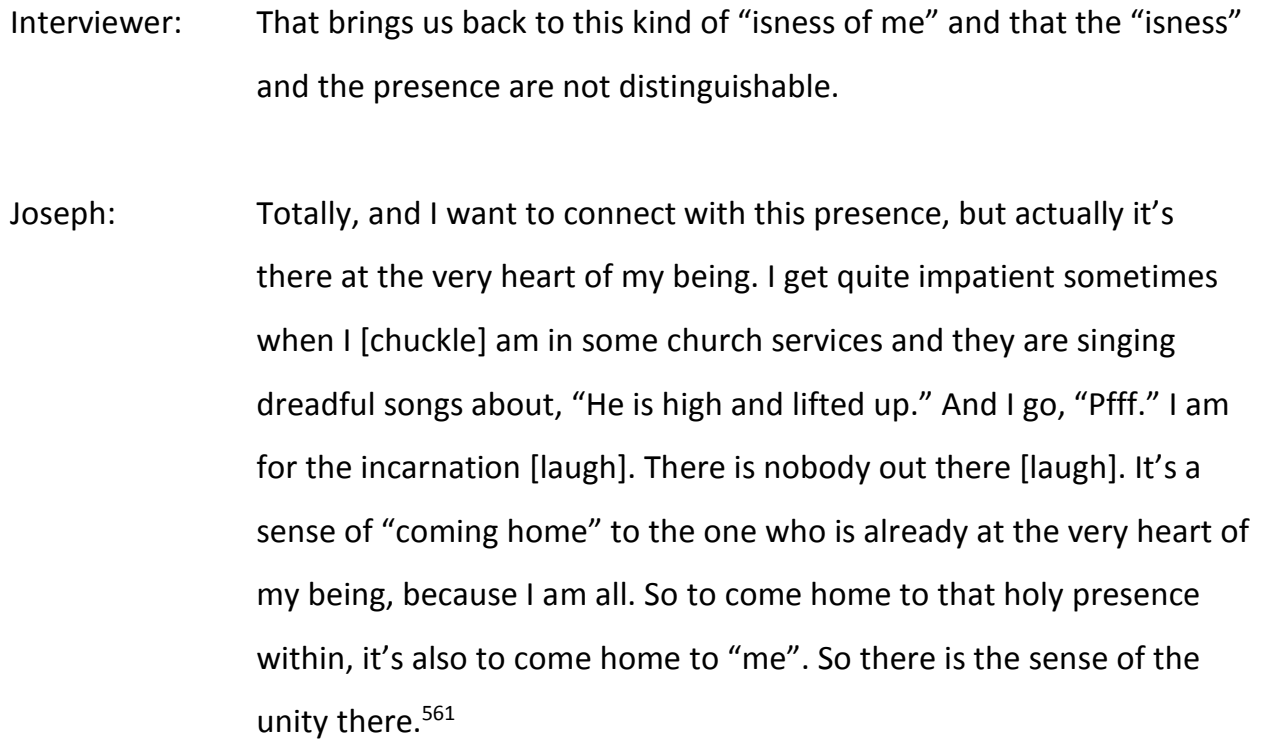

Joseph's awakening to a holy presence is a sense of "coming home", which is a place located "at the very heart" of his being. It is within. It is also not localised yet expanded. It is a type of "me" that is already present there and waiting for him: it is not something new that comes into being. By analogy, the deep waters of awareness are always present but not noticed.

Joseph uses relational language, and, specifically, the term "you", but he rejects the relational implications under questioning. At the outset, I assumed that Joseph's sense of presence was located in his event-perspective (object-side), because he used the term "you". However, collaborative analysis showed that his relational language is an interpretive overlay and not an experiential primitive. In reality, the object he intends - being the presence of God (or "holy presence") - is located in his awareness-perspective (within). It is the same "domain" where his sense of "just being" or "isness" dwells. For this reason, his "reaching out" is a "taking in". Consequently, his intentionality is a matter of "being available" and removing the obstacles to the type of self that "just is".

\subsubsection{Samuel's Implicit Sense of God's Immanence}

Samuel is my second example of how intent is structured. He is a 59-year-old priest of the Episcopal Church from the East Coast, United States, who has pursued prayer for a long time and as a critical part of his ministry. Samuel has been engaged in contemplative prayer for 20 years now and he has practiced centering prayer for 10 years. Samuel's account of his present day prayer contains no reference to "presence" or "presence of God". At the same time, he refers to a "conscious conception of a presence" when he talks about how he practiced centering prayer in his early days.

561 Ibid., pp.24-25. 
[laugh] My sacred word came to have a meaning that brought me - it's kind of recalling myself or reminding myself - to be present to the one who was present to me, and sometimes, in the beginning, it was Jesus and I would have these images of just Jesus sitting right in front of me, waiting for me. Imaginative. Jesus is right there patiently waiting for me to realise that he is patiently waiting for me. [chuckle] And so this was always humorous to me: how l'd think of myself, "Here I am off on these [mind wanderings]... and here is Jesus right in front of me, patiently waiting for me to notice him." 562

Samuel reflects on the early stages of his centering prayer practice and tells us of his imaginings of Jesus sitting in front of him. This is how Samuel first conceived of "presence" during prayer. It was by way of an image conjured by him and it is not how he conceives of "presence” today.

Let's see. Presence. It's really more about MY becoming present. I think it's because I have more of an implicit sense of God's immanence. I mean, it's no longer, you know, "Jesus right in front of me", but there is something within me that I just need to remove the obstacles to. Presence, I guess, in my own thinking, implies an "other" who is present to me, and I no longer - I don't have that sense of "other". 563

Today Samuel's sacred symbol and overall practice is no longer directed towards an "other". His intention for God does not imply that he turns toward a "presence" that is something separate from his own "being present". Let us consider a final example.

\subsubsection{Carol's Sacred Word: "Being as Naked as I Can Be"}

I return to Carol's practice and her reference to a "naked intent towards God". Our focus is the structure of her intent.
Interviewer:
This "naked intent towards God", could you tell me more about that?
Carol: Well, it's an image that I find helpful to being aware of the fuzzy and muck - they are around me. Being able to just strip, or

\footnotetext{
562 Samuel, Interview \#24.1, p.18-19.

563 Ibid., p.19.
} 
allowing that to be stripped off me totally - just stripped off me and leave myself able to be as much in presence as I can be in presence. It's exposing: when I'm naked I am exposing my Godself, imperfect as that may be.

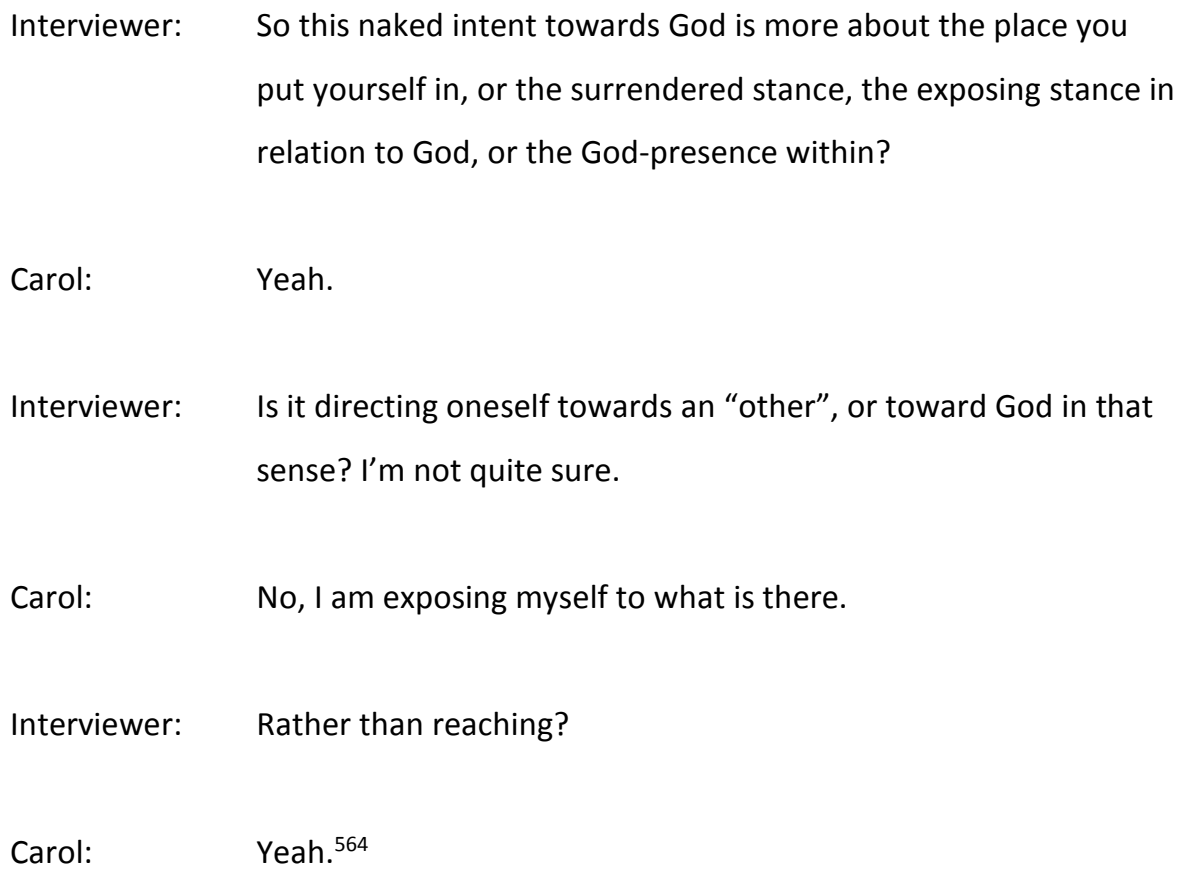

Carol tells us that her "intent" is open. It is a stance of her awareness-perspective (subjectside) that is receptive to, but not directed toward, the horizon of her event-perspective (object-side). She qualifies her intent as being "naked". Her naked intent is the focal point of her experience. In her practice, Carol strips her sense of her own presence from content ("the fuzzy and muck") to bring it to the foreground as much as possible and thus "expose" it. Her intent "toward" is best described as an "internal posture" that makes salient and available the most basic sense of her own presence.

\subsubsection{Discussion: Turning to God's Already Abiding Presence Within}

I have presented three examples (Joseph, Samuel and Carol) to illustrate the structure of practitioners' intent.

I began with Joseph where I explored the relationship between his sense of "isness" and "presence". The way that Joseph talks about his experience is intriguing. He uses language that suggests a directional relationship; however, under scrutiny what he focuses on cannot be separated from himself as the subject, from the "isness" that he is.

${ }^{564}$ Carol, Interview \#11.1, p.16. 
Next, I presented Samuel's implicit sense of God's immanence where God's presence is equivalent to his own "being present". In contrast to Joseph, he does not use the term "presence" to talk about his experience, because he is aware that the word has relational implications that are misleading.

Finally, I discussed Carol's "naked intent" that exposes her "God-self". Even though she uses the phrase "toward God", what she means by "naked intent" clarifies that her internal stance is about exposing herself and making herself available rather than reaching outward towards an "other".

All three examples present to us an affirmative intent that is structurally peculiar. Practitioners often express their intent through relational language but deny the relational structure under scrutiny. I contend that their intent draws consciousness away from a narrow and toward a broad type of intentionality.

Narrow intentionality refers to the vectorial capacity of consciousness, its objectdirectedness. Experiences that have a narrow intentionality are thus experiences of something (a "presence") as distinct from our sense of a present subject.

In contrast, broad intentionality is not defined in terms of object-directedness Rather, it is defined as a kind of "openness to God". It involves God in a way that allows the subject to be affected by Him, although the subject might not directly attend to God. Recall that classic phenomenology allows for a range of experiences that cannot be defined in terms of object-directed intentionality. Joseph's, Samuel's and Carol's intent are an example of this.

Centering prayer contemplatives often use relational language to talk about their intent and sense of "presence", because the method they employ, and the experiences associated with it, cultivate a broad type of intentionality. As practice matures, their intent changes from being directed towards God as "other" to being open towards the expansiveness of God's presence within, which is receptive and non-directional.565

I will discuss why practitioners use paradoxical language in $\underline{\text { Section } 7.7}$ and Section 10.2. I anticipate that their language is informed by the dualistic structure of "prayer of union", which has the "phenomenal character" of being "mutually embracing". 566

\subsection{The Sacred Symbol as Intervention}

I now turn to how the sacred symbol is used to intervene in practice. I divide the act of intervention into two parts: letting go and returning.

\footnotetext{
565 The shift from narrow to broad intentionality, and the eventual breakdown of intentionality altogether at later stages, is how theurgia progressively unfolds.

${ }^{566}$ I define phenomenal character in fn.726 (p.194).
} 
The first part releases attention from fixation on content at the object-side of experience (event-perspective). Practitioners diffuse attention to "abstract away" 567 from the ordinary level of awareness, which is operative when the practitioner's basis of operation (witnessing) is undifferentiated from, and thus immersed in, the prolific flow of content (surface of the river).

The second part returns attention to God's presence at the centre, which is the core or heart of the practitioner's own sense of existence. Practitioners "turn" attention repeatedly back to God's presence within, located at the subject-side of experience (awarenessperspective). Eventually, the practitioner's basis of operation differentiates ("pulls away") from ordinary consciousness and becomes salient at the subject-side of experience (awareness-perspective) now one step removed from ordinary consciousness.

I will present one example to illustrate the first, letting go part of the intervention. I will then illustrate the second, returning part through two further examples.

\subsubsection{The First Part: Letting Go of Content in the Event-Perspective}

\subsubsection{How David "Let's Go" in Prayer}

David is a 35-year-old practitioner from the East Coast, United States. He has engaged in contemplative practices for 15 years and has practiced centering prayer for 3 years. David relies on the breath rather than a word for his sacred symbol. He has past experience with Buddhist meditation practices, but he insists that centering prayer "feels very different from the Buddhist meditation practice" he has practiced. ${ }^{668}$ For him, centering prayer distinguishes itself through its emphasis on intention and its deemphasis of effort in letting go.

\footnotetext{
What made me fall in love with centering prayer is intention. So it feels like the meat of

it, like what's significant in the whole thing. "Can I actually keep the deal?" which is, "I'm going to let go of this really enticing thought and return to my breath." 569
}

David touches on both parts of the intervention: letting go and returning. Both are intricately intertwined with intention. For him the minimal effort involved in letting go is different to other practices, because they rely on effort to concentrate.

\footnotetext{
${ }^{567}$ I discuss the emic phrase "abstract away" in fn.427 (p.97).

${ }^{568}$ David, Interview \#31.1, p.10.

569 Ibid., p.11.
} 
I did both Korean Zen and then I did some Japanese Zen retreats where they just have us count to 10 and then start over. So it is a real concentration practice. But there was the constant sense of effort to keep the mantra in the front of my mind. With centering prayer the only time there is effort is when I notice myself thinking, [then] returning to my breath. I think the reason it feels intentional is that THAT feels like the act of surrender, and so there is also huge relief to sink into a deeper place. ${ }^{570}$

David's centering prayer is only effortful when he applies his sacred word to let go (“surrender") and return ("sink into a deeper place”). He distinguishes this approach from maintaining focus on a mantra, which requires a lot more effort. I will now turn to how David lets go in prayer.

\footnotetext{
When I notice myself wrapped up in the stories I just return to focusing on my breath and that focus eventually just kind of disappears. I think of like having a clenched hand when I am thinking. There is like effort in the decision to let go of that like, "Okay, I'm getting off that one and I have to put my attention on my breath for a moment." It is not "pushing away". The motion of my hand is like "an open palm of letting go". ${ }^{571}$ There is a bodily sensation that goes with the letting go, like dropping to the bottom of the pond. My body will shake a little bit. And so that's the effort; the only effort. ${ }^{572}$ Generally I try and just keep it really simple, and just go to my breath. I try to minimise the dialogues. Not like, "Oh shit, you are doing this again." The very practical way is to avoid the temptation to make any meaning of it, or add anymore commentary. ${ }^{573}$ So I find that the disengagement is the most important thing. The feeling tone of it is a sense of relaxation. Letting go feels like a giving up of control. It is surrender: it's both like a certain amount of fear and relief at the same time. ${ }^{574}$ It happens so quickly one after another. What first comes up is the shame like, "Oh fuck, I've run off on another thing again and like, 'Do I really want to let go of this?'." So there is more negative like, "This again," and, "I don't really want to let it go." And then with the return to my breath there is a physical sense of relaxation that is quite pleasant. So there is the negative followed by the positive. It feels like the turning to God is in the disengagement. Like they are the same. It's an act. It's a turning to God. Really it is just about the disengagement. ${ }^{575}$
}

\footnotetext{
570 Interview \#31.2, p.1.

571 Ibid., p.4.

572 Ibid., p.3.

573 Interview \#31.1, p.10.

574 Ibid., p.11.

575 Ibid., p.12.
} 
David's account shows that returning to his breath involves an act of disengagement. For him, letting go is coterminous with turning to God. By this he means that he does not redirect his attention to God as yet another object, because what is driving the prayer is a surrender-with-intention rather than effort-with-attention. Thus the act of disengaging opens up awareness. Opening up is equivalent to turning to God, because it allows the subject-side of experience to become salient (see below: "It feels like waking."). In this way, he shifts from a narrow mode of intentionality (focus on object) by way of the breath to a broad mode of intentionality, which is a more open and diffuse awareness (see below: "My attention is expanded.").

The broad mode of intentionality is inherently "disengaged". It remains poised in a released stance and does not focus outwardly. Even though David returns his focus to his breath - some may argue that this act constitutes an attentive (subject-object) rather than inattentive (non-directional) consciousness - it is only a stepping stone to releasing awareness from fixation. Consider what happens when David focuses on his breath:

\footnotetext{
I return to my breath and feel it as a sensation just to like expand. ${ }^{576} \mathrm{I}$ have a sense of my body being more expansive. I am more connected to sort of my body as a whole and my breathing and other sensations, and that often goes along with having fewer thoughts. The analogy of thoughts is like the bowl in the field and it's like the field gets bigger and therefore the thoughts slow down because there is more spaciousness around them. So they are not necessarily fewer, but it's like my attention is expanded: their intensity is smaller. ${ }^{577}$ It feels like waking. It feels like every time I return to my breath, it's like waking up again to my intention and then I fall asleep again. The most interesting moment in centering prayer is the moment between attention on the breath and then where does it go? I have no clue. I don't know. ${ }^{578}$
}

When David returns to his breath, he initially focuses on it in a subject-object directed way. However, his mode of awareness in the process changes. He describes that he himself and his awareness expands. Space opens up around his thoughts and the intensity of thought diminishes. I contend that, in phenomenological terms, his awareness-perspective (subjectside) comes into the foreground, because it differentiates (as in "ascertains itself as different") from thought. In absence of fixation, David's basis of operation retracts from the flow of thought at the ordinary level of awareness and relocates itself one step removed in a

\footnotetext{
576 Interview \#31.2, p.5.

577 Ibid., p.1-2.

578 Ibid., p.4.
} 
subjective domain that feels more expansive and spacious. He describes this level of awareness as "a deeper place".

\subsubsection{The Second Part: Returning to a Sense of Presence in the Awareness- Perspective}

I will now discuss the second, returning part of the intervention through two examples that will further illustrate how "turning to God" alters the attentional structure of consciousness.

\subsubsection{Rachel Returns to "I am here" in Prayer}

Rachel is 66 years old. She is a retired teacher and lives in a town in Oregon, United States. Her contemplative life started 20 years ago with a cancer diagnosis. She picked up mindfulness meditation and after 18 months switched to centering prayer, which she has practiced ever since.

After 19 years of practice she says, "I still get caught up in all this ridiculous commentary, and, you know, videos and all kinds of things - I may be down the river before I even, 'Wheee!!' you know.” ${ }^{779}$ However, Rachel's practice has undergone a recent change.

I can disengage. Within the last six months I have been able to observe myself being able to disengage from it and get right back. ${ }^{580}$

Rachel recalls a salient moment when she recognised that she was immersed in thinking followed by disengaged observing.

\footnotetext{
I was engaged in thoughts and the thought came to my mind, "Those are just thoughts." And I could let them go. And it seemed so simple. It's so subtle that change, but it has been so powerful, "Those are just thoughts." Maybe it is telling me that this is not reality. This is not a time to be thinking about that, etc. And it's not like I kind of came up with this. So a gimmick, you know, to help me look [and] to let go of thoughts. It was this deep realisation. I guess I could say that, "Those were ephemeral, and I can let go". 581
}

When prompted to expand on how thought changes appearance (to "ephemeral") she adds: "a sense of detachment"; "nonjudgmental"; "there is ease to it"; and, "a sense of me moving

\footnotetext{
${ }^{579}$ Rachel, Interview \#26.1, p.11.

580 Ibid., p.12.

581 Ibid.
} 
away from the thought rather than me trying to shove the thought away". Her descriptions imply that she experiences a sense of increased distance to thought, which she confirms.

Rachel describes how her awareness-perspective differentiates from her eventperspective (content/thought) and becomes in this way a self-aware vantage point from which she "observes" thought. This is a higher- or second-order state. When her basis of operation shifts, her relationship to thought changes at a structural level (her vantage point is a step removed from thought) and at an affective level (she feels more "ease" and "detachment" towards thought).

Rachel read the book Centering Prayer and Inner Awakening in which Bourgeault discusses how important it is to develop a stable "witnessing presence". ${ }^{82}$ I asked Rachel about a possible parallel to her own experience, and Rachel agreed that this was in her view a valid connection and that it is correct to say that this means that the awareness-perspective stays more easily differentiated and that thoughts in the event-perspective take on a more ephemeral tone. Rachel adds that this capacity "has been alive for me for the last six months". 583

Let us return to the moment when Rachel realises the ephemeral nature of thought. First, she has to sufficiently establish herself as an observer before she can return to her intention. Let us examine what Rachel means by "return to intention".

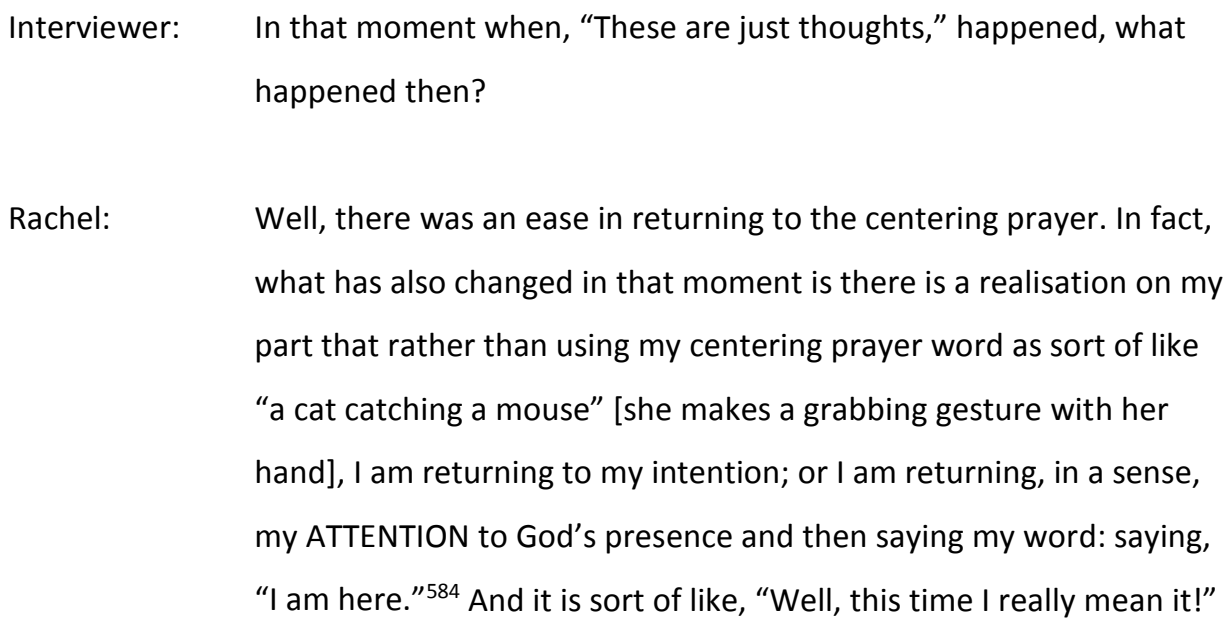

Rachel: Well, there was an ease in returning to the centering prayer. In fact, what has also changed in that moment is there is a realisation on my part that rather than using my centering prayer word as sort of like "a cat catching a mouse" [she makes a grabbing gesture with her hand], I am returning to my intention; or I am returning, in a sense, my ATTENTION to God's presence and then saying my word: saying, "I am here." 584 And it is sort of like, "Well, this time I really mean it!"

Interviewer: So there is a redirection of your attention?

\footnotetext{
582 Bourgeault, Centering Prayer and Inner Awakening, 113-50. For a more detailed discussion of witnessing presence in centering prayer, see "Centering Prayer as witnessing practice," Sewanee Theological Review 53, no. 3 (2010).

583 Interview \#26.1, p.13.

${ }^{584}$ Rachel's "I am here" is very faithful to how Keating presents the symbolic meaning of the sacred word. He says, "This word... it is a way of saying, 'Here I am' to God." Intimacy with God, 17.
} 


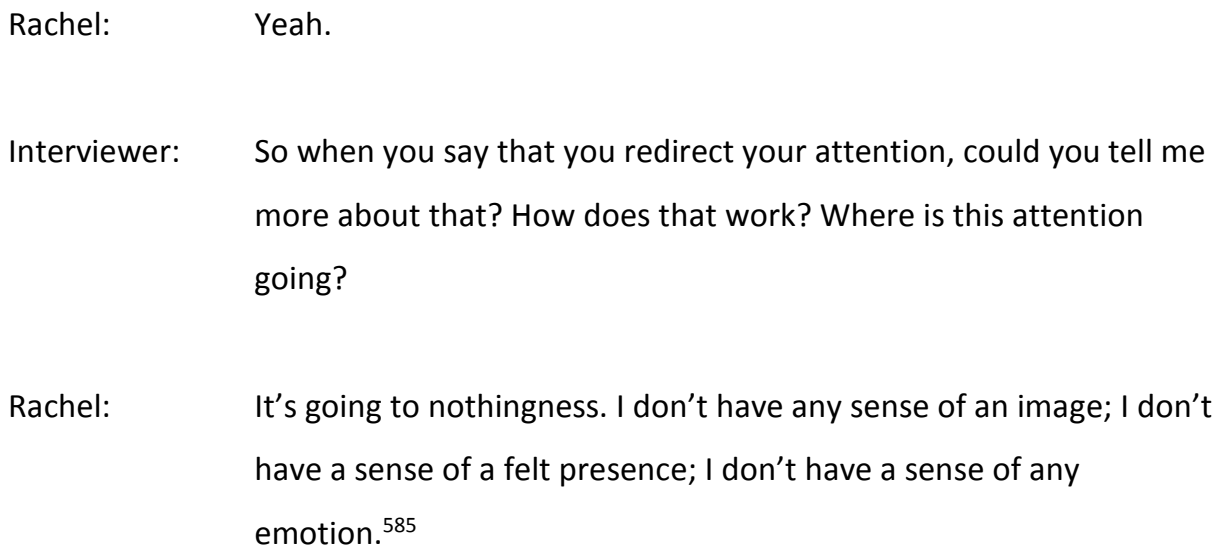

Rachel ends on a strong note here. She goes to "nothingness", which she qualifies in interesting ways. As in David's example (Section 4.5.1.1), it is unclear where attention goes. ${ }^{86}$ For the time being, I will shelve the matter of nothingness (and God's presence) for Chapter 7. What is relevant now are two things Rachel has shared about how she uses the sacred symbol to intervene in the lead up to "nothingness".

First, Rachel tells us that she uses her "sacred word" in a new way. She does not apply it to "catch" thoughts, but to redirect her attention away from thought. She neither stands watch over her thinking process nor immediately responds to thoughts, like a cat would that tries to catch a mouse.

Second, Rachel disengages to reaffirm her primordial intent to "attend to God's presence". When she uses her sacred word, she affirms her differentiated presence. She says that it is like saying, "I am here." Today she is capable of being present in a way that she could not be six months ago.

In sum, Rachel's basis of operation (witnessing) has differentiated itself from the ordinary level of awareness (flow of content). When she redirects attention, it does not latch onto another object. Instead, she abstracts away from ordinary consciousness. Consequently, her sense of her own presence ("I am here") becomes salient. Her witnessing-perspective is now emphasised, one step removed and poised in a mode of broad intentionality (open awareness). 587

\footnotetext{
585 Interview \#26.1, p.13.

${ }^{586}$ I will attend to where her attention goes and what she experiences when she attends to "God's presence" in Section 7.2 .

${ }^{587}$ I will develop this claim further in the next chapter when I discuss "spiritual attentiveness".
} 


\subsubsection{Joseph "Consolidates into the Very Heart of Who I am" in Prayer}

I return to Joseph to illustrate how the sacred word may be used as an intervention to abstract away from ordinary consciousness. I begin with his account of what it is like to be immersed in ordinary consciousness.

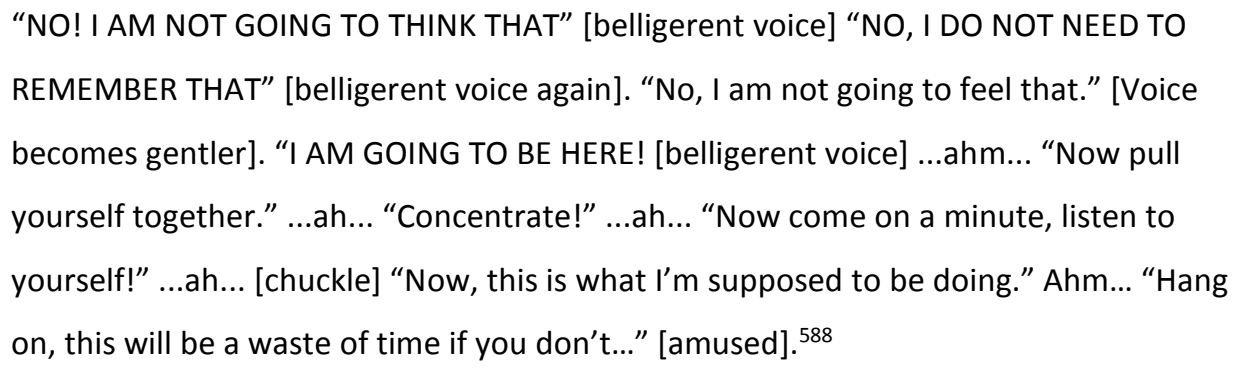

When Joseph attempts to be available while he is still immersed in ordinary consciousness, he engages in internal dialogue. He describes the ordinary level of awareness as "a consciousness of random thoughts I am having; the consciousness of what I am actually doing right now and the awareness, the self-awareness, of 'I am sitting here'." He adds that it is "that stuff I want to get lost, because when I am in that stuff I am not conscious of the holy presence." 589 However, if he attempts to intervene in ordinary consciousness, then it becomes self-defeating.

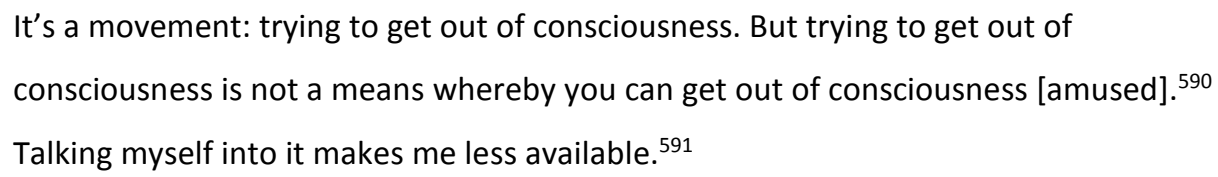

Joseph eventually realises how self-defeating the process is. He comes back to "It's you I want; not all the self-talk; not all this trying to be available; not all this trying to make this happen; not trying to make this TIME USEFUL! [forceful voice again]. Actually, it's you I want [gentler voice].”592

Joseph's first step in applying his sacred word is to detect that an incongruence exists between what is happening and his intent. When he realises this, he returns to his desire for God, which "softens" his practice.

Joseph's second and third steps are to "stay with" the word and "put it out".

\footnotetext{
588 Joseph, Interview \#5.1, pp.18-19.

589 Ibid., p.22.

590 Ibid., p. 21.

591 Ibid., p.19.

592 Ibid.
} 
Joseph: When I become conscious of performance I will just come back to my word and just try to stay with the word and just seek to put it out - not to listen to it, but make offering of it. "Look, you can see in my offering of this little word my desire for you, and, surely, my desire for you is sufficient in itself." I "stay with" my little word in the sense that I try to "just be". I try to just focus on it like, "This is all I'm going to attend to in this moment." By "putting it out" I mean I am reaching up, kind of like I'm talking to you. Like I am wanting to be "in connection with" and "communication with" and "to make contact with".

Interviewer: When you say "with" we are talking about the presence, right?

Practitioner: $\quad$ Yeah, the holy presence. ${ }^{593}$

Interviewer: So what exactly do you mean by "staying with"?

Joseph: Being focused without trying to become too self-conscious about it. Letting it be the only thing I am "thinking" (?) [laugh]. Rather than, "Oh my goodness, yeah my little timer here says I have eight minutes to go. Look, I must remember to..." [laugh].

Interviewer: So when you say, "the only thing you are thinking," you are literally thinking, "You," or are you-

Joseph: No, trying to let this word just echo around in the space within. So it's calling all the space within to attend to God.

Interviewer: Okay, I would be really interested to hear more about "put it out". Joseph: Using the word to kind of flush out everything else I want to think and do [laugh], action [laugh], remember and whatever. Using the word in that kind of a way to make space within to declutter, you know, to prepare the way of the Lord.

593 Ibid., pp.22-23. 


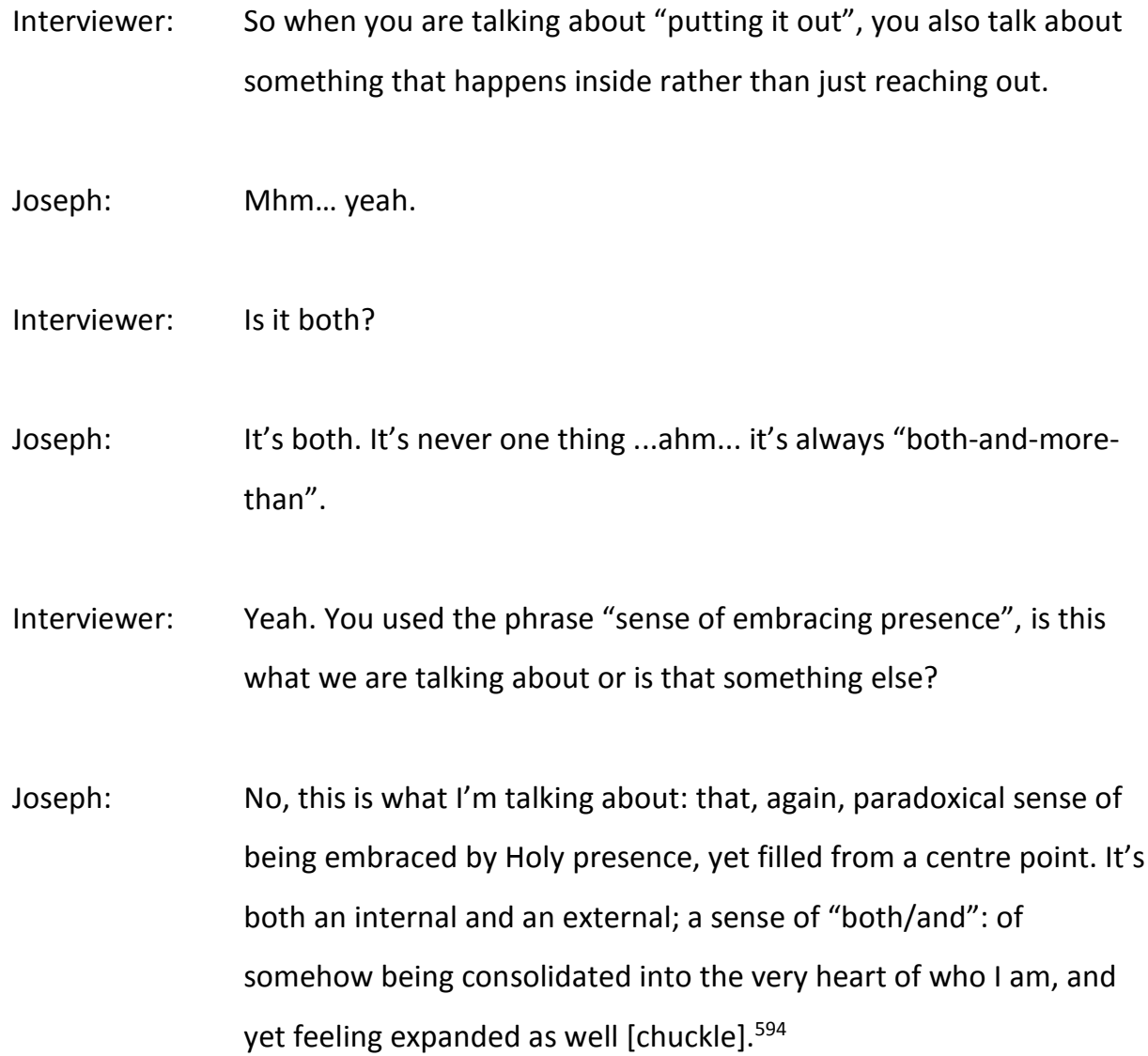

When Joseph uses his word, he first focuses on his desire for God, which is not a "thing" that exists outside of his own being, but is associated with the type of self that "just is" in an expanded way.

Second, once Joseph has reconnected with his intent, he stays with it, which means that he remains focused, but not on an object. Rather, his unspoken sacred word, "You", echoes in the space within and calls all that space to an exclusive non-object directed percipience. To stay with it, Joseph remains poised in this spacious, diffuse attention without being self-conscious about it, or, at least, trying not to introduce self-reflection. By "calling all the space within to attend to God", Joseph means that his attention is fully absorbed in "just being" without self-reflection. Therefore, "to attend to God" means to let attentiveness rest in the "isness" without this attention creating a fissure in consciousness: it does not take itself as an object or "other" itself. 595

Third, Joseph puts his sacred word out. This has both a sense of reaching, because his sense of self expands, and a sense of being inseparable from an "embracing presence". He also "takes in" the sacred word.596 By this Joseph means that he consolidates into the very

\footnotetext{
594 Ibid., pp.25-26.

595 Dan Zahavi, Self-Awareness and Alterity (Evanston, Illinois: Northwestern University Press, 1999), 130.

596 Joseph mentions "taking it in" in Section 4.4.2.1 (p.130).
} 
heart of his being, which he experiences as "coming home" to a holy presence within that has already been abiding there. This echoes Joseph's earlier remark: "Oh my goodness, you were waiting for me. Here you are."

In phenomenological terms, when Joseph's basis of operation is entangled with ordinary consciousness, he neither senses his own presence ("isness") nor the "inexplicable vastness" or "more than factor" (God's indistinguishable presence). When he abstracts away from ordinary consciousness ("gets out of consciousness" of the kind of things that appear in the event-perspective at the ordinary level of awareness), Joseph's basis of operation disentangles itself from the ordinary level of awareness and becomes salient one step removed. The thematic witnessing-perspective emerges as a higher, second-order state. $\mathrm{He}$ identifies this salient presence as "isness", which is accompanied by a sense of expansion. His awareness and sense of "just being" is now available, open and not focused on anything, but it is percipient.

\subsection{Conclusion}

In this chapter, I have presented data to illustrate how the "surrender method" of centering prayer works, which is unlike "concentration methods" or "awareness methods" (refer back to Section 3.6.1). I have shown that the transformation of consciousness effected at this stage is a "relaxed but alert awareness" that emerges as a salient, higher, second-order state. It is achieved through applying the sacred symbol. The sacred symbol is both an intention and an intervention.

The intent of the sacred symbol is affectively a non-object directed desire for God.597 It represents an implicit affirmation of God's presence within. This desire sets the context of the practice and informs the inner workings of the apophatic method. The intention is structurally centred in the practitioner's own sense of presence (God within). This sense of presence is "available" and as such open (but not directed) to otherness (broad intentionality).

The sacred symbol is also used as an intervention to invite ("cause") a change in practitioners' state of consciousness, anchored in the ordinary level of awareness. The change aims to disentangle the awareness-perspective from immersion in ordinary consciousness (surface of the river). The state of consciousness shifts to a more diffuse but differentiated awareness, which becomes the backbone for the development of spiritual attentiveness in Stage Two.

\footnotetext{
${ }^{597}$ Beginners of centering prayer may come to the practice with a view that God is "other". However, contemplatives typically experience a shift in their understanding and experience of God over time and with practice. As Rachel says, “My image of God has eroded over time with centering prayer." Interview \#26.1, p.15.
} 
The sacred symbol puts into practice the "Four R" formula: resist not; retain not; react not; return to the sacred word. I have divided this into: letting go (first three "Rs") and returning (fourth “R”).

Letting go allows the awareness-perspective (the witness) to differentiate from the event-perspective (the "film" or "screen of thinking"). This does not mean ongoing effort to place and hold attention on an object in the event-perspective, or to place and hold the awareness-perspective at a distance to thought. Letting go simply releases attentional fixation and thereby returns without much effort to a self-aware vantage point.

In this way, practitioners extract their basis of operation (modus operandi) from the object-side of experience. Their subject-side of experience ("I am here” presence) gradually becomes self-aware and remains poised (non-resisting; non-retaining; non-reacting) with a quivering intent, which they associate with God's presence. This witnessing-presence is a more diffuse awareness that is open to alterity (broad) and not object-directed (narrow).

In sum, the basic method effortlessly abstracts the basis of operation (modus operandi) of the practitioner away from the object-side (event-perspective) of ordinary consciousness. This "abstracting away" is progressively achieved by letting go content and returning to the sense of presence at the subject-side of experience (awareness-perspective). 


\title{
Chapter 5
}

\section{Spiritual Attentiveness: Cultivating a Dual-Mode Awareness in Prayer}

\author{
It's kind of like on one level I am doing my prayer and then on another level I am sort of like engaged with \\ almost thought-stuff going on." ${ }^{198}$ \\ - Rachel \\ This is, I feel, the answer to my old question, "What does it mean to pray constantly?" To be rooted in that a \\ place of peace and still completely aware of my surroundings and responding to them. ${ }^{599}$
}

- Samuel

\subsection{Introduction}

In this chapter I will focus on the second stage of the contemplative path. Practitioners come into contact with the deeper waters of spiritual awareness, because they have applied the sacred symbol in Stage One to periodically shift their basis of operation from the surface of the river (ordinary consciousness) to the interior depths (spiritual awareness). "Spiritual awareness"6oo is a "higher" or "deeper" level that has its own subject-side (awarenessperspective) and object-side (event-perspective). Its event-perspective also contains objects of a kind specific to its level. My etic term for those objects is "subtle-level" 601 content.

In Stage One practitioners' bases of operation dynamically move in and out of the deep waters. The shift is not stable. But persistent application of the sacred symbol ("Four R" formula) retrains attention, because letting go (first three "Rs") and returning (fourth " $R$ ”) reinforces awareness to open up (i.e., shift from narrow to broad intentionality). Gradually, a transformation of consciousness is effected that sets the conditions for the basis of operation to shift into spiritual awareness for longer periods and eventually stabilise there.

In Stage Two practitioners maintain contact with ordinary consciousness so that ordinary and spiritual levels of awareness run in tandem. The Centering Prayer tradition calls this "spiritual attentiveness". My etic label for this phenomenon is "dual-mode awareness", because it emphasises how the structure of the state grants cognitive access to two levels of awareness at the same time.

To illustrate how dual-mode awareness is experienced, I will present two cases to show how practitioners phenomenally apprehend the subject-side and object-side differently

\footnotetext{
598 Rachel, Interview \#26.1, pp.17.

599 Samuel, Interview \#24.1, p.6.

600 I define "spiritual awareness" (coterminous with "spiritual level of awareness") in Section 3.3 (p.82).

601 I define subtle-level content in Section 3.3, fn.347 (p.82).
} 
when they are spiritually attentive. Specifically, "coarse-level” content changes appearance. ${ }^{602}$ Then I will consider two further cases to highlight the dual-mode awareness that is at work in spiritual attentiveness. Since practitioners' bases of operation are anchored in spiritual awareness, subtle-level content appears at the object-side of experience. Consequently, dual-mode awareness contains both coarse- and subtle-level content in the event-perspective.

\subsection{Stabilising the Basis of Operation in Spiritual Awareness}

The first stepping stone to spiritual attentiveness is stabilising the basis of operation as a salient vantage point in the interior depths, which is one step removed from the surface activity (ordinary consciousness). I will now present sections of prayer sits from two practitioners where the basis of operation begins to stabilise in the subject-side of the deep waters (spiritual awareness). I will discuss how this shift changes the appearance of coarselevel content.

\subsubsection{Lawrence's Disengaged Observing}

Lawrence lives in a town in Minnesota in the United States. He is 70 years old and retired after a successful career in the financial sector. Lawrence has been practicing centering prayer for 7 years.

The morning before our interview, Lawrence had a "just marvellous" and "very good" sit, which is rare for him. I asked him what "good" meant.

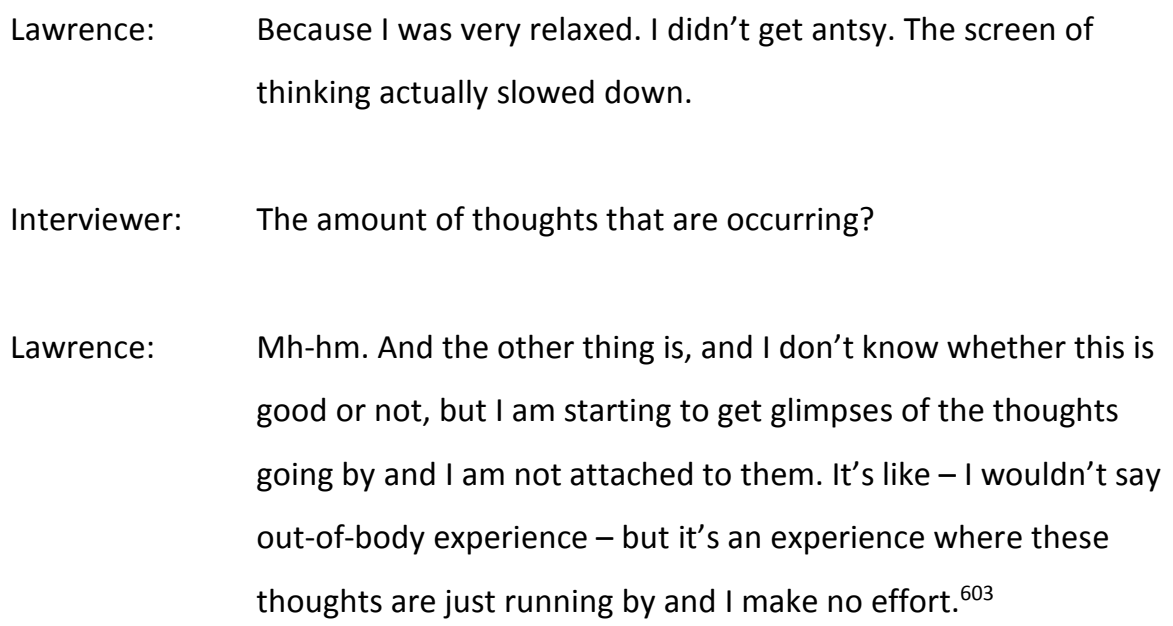

${ }^{602}$ I define coarse-level content in Section 3.3, fn.338 (pp.80-81).

${ }^{603}$ Lawrence, Interview \#21.1, p.11. 
Lawrence started his sit by closing his eyes after the ring of the prayer bowl. Next "thoughts came up". He used his sacred word and then felt like he was "being held", as in sitting on a cloud, just sitting, safely so, without there being any external force to it. He was just unmovably in place. ${ }^{604}$ In our collaborative analysis, Lawrence clarified that his basis of operation shifted from being "in the head" to being "in the heart". By "heart" he means that awareness comes from a more diffuse, "whole body" presence that is not localised in the head region. Let us take a look at Lawrence's different experience with thought.

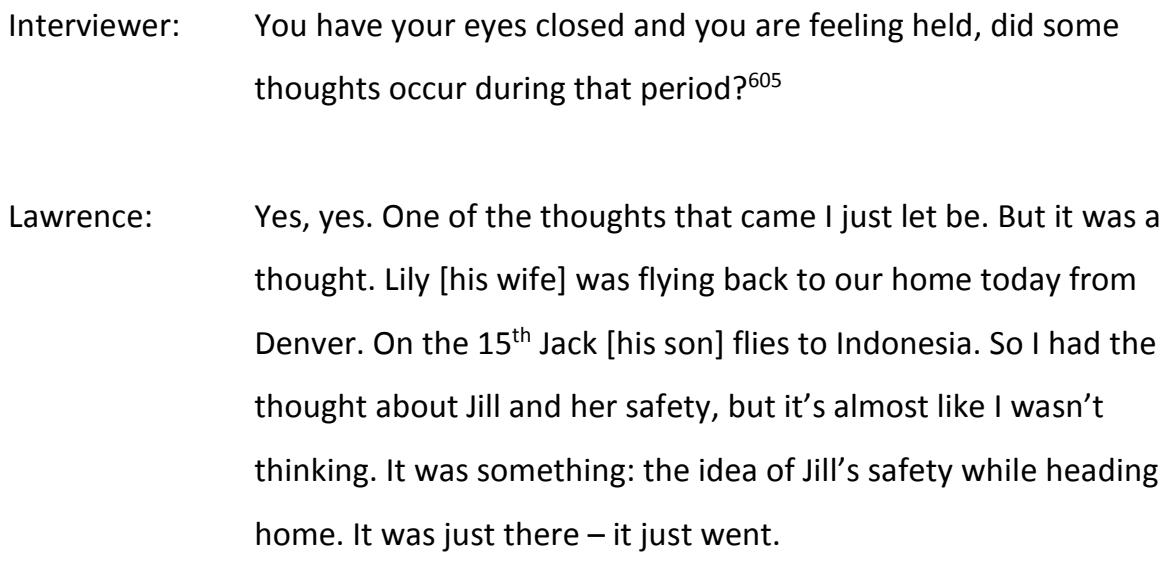

\footnotetext{
${ }^{604}$ My exchange with Lawrence about his feeling of "being held" is in Section 2.7.5.1 (p.61). I have paraphrased it here.

${ }^{605}$ I prompt Lawrence to talk about his thoughts here, but I do not introduce that content, because in the explicitation cycle, Lawrence had already offered this information. I am thus repeating back to him information that he had already shared with me (see Section 2.7.5.1, pp.60-61).
} 


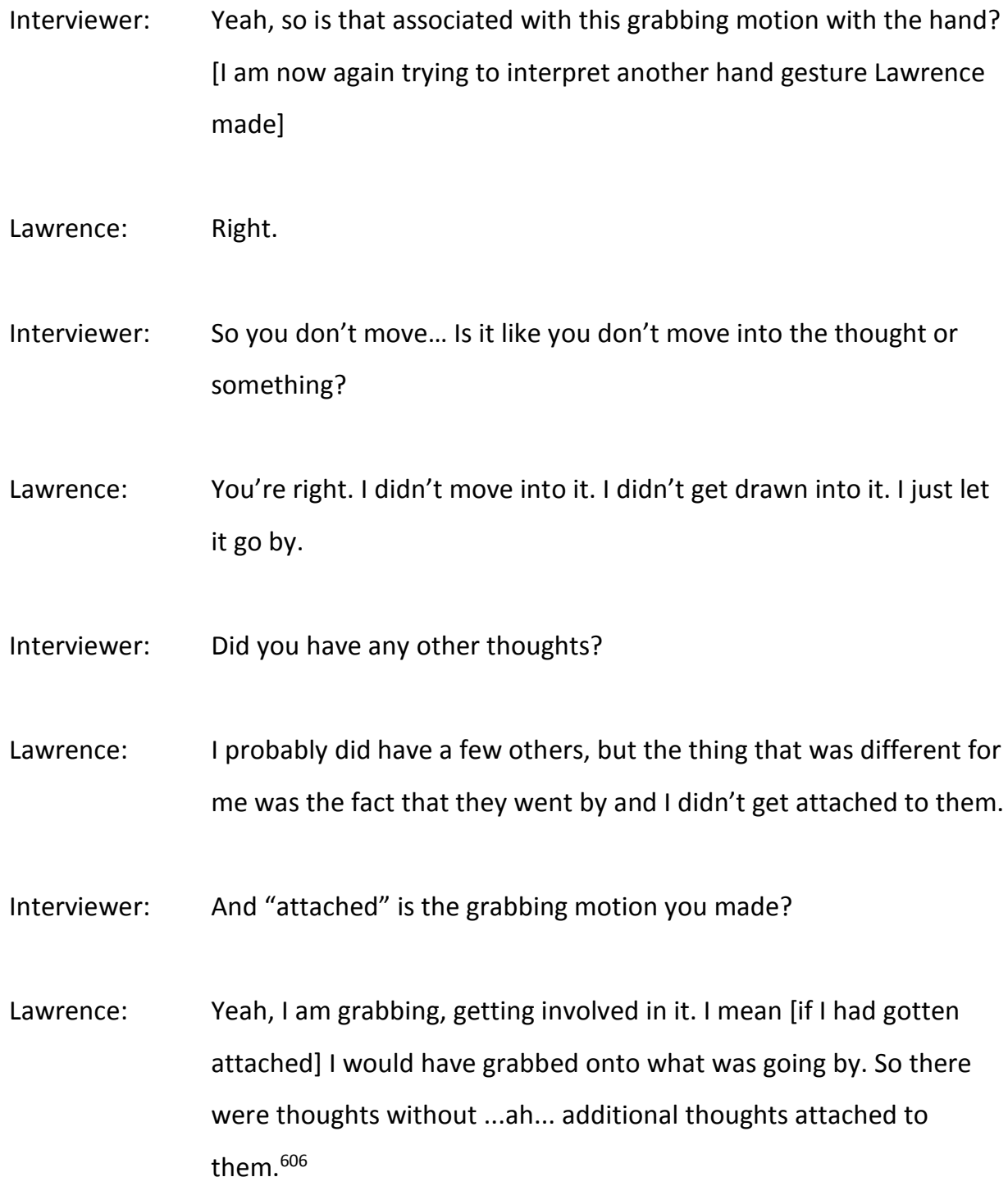

In this sit, Lawrence's basis of operation shifted into the deeper waters where it is a more diffuse presence that is "unmoving" and "held in place". It is stable. He makes it clear that he doesn't get pulled into his thoughts.

Lawrence used two different hand gestures to describe how his basis of operation was stabilised. The first is moving his hand from left to right in front of him, which illustrates thoughts passing before his eyes like on a screen. Here his awareness-perspective remains poised. The second is a grasping motion, which he uses to demonstrate how he would get attached to his thoughts and drawn in by them. In this sit, he didn't get pulled into thought, so, he says, "there are thoughts without additional thoughts attached to them". Thus Lawrence got neither "involved in" nor had additional thought about thought.

Earlier Lawrence tried to describe how he experienced his shifted basis of operation by way of an "out-of-body" metaphor. Let us explore what he meant to convey.

${ }^{606}$ Ibid., pp.14-16. 
Interviewer: So it all passes by, right?

Lawrence: Yeah

Interviewer: Like on a screen you said?

Lawrence: Almost, yeah.

Interviewer: "Almost" ? So can you tell me more about the sense of being disembodied? Sorry "out-of-body" you said?

Lawrence: Well, maybe that is not the right word.

Interviewer: That is describing something though right?

Lawrence: $\quad$ Ah, just disengaged-

Interviewer: "Disengaged"?

Lawrence: $\quad$-from engaging with that thought that went by.

Interviewer: Okay. "Out-of-body". Obviously it wasn't out-of-body but it is trying to describe something. I am wondering, because you described it as a screen and not getting pulled in, grabbing it or getting attached. So is this sense of the notion of "out-of-body" maybe describing the sense of distance to the thought?

Lawrence: $\quad$ Yes, thank you. Yeah, a sense of distance, yeah.

Interviewer: Like you're not getting pulled into-

Lawrence: Right.

Interviewer: $\quad$-you are staying and keeping it at bay. 
Lawrence: $\quad$ Yes. Yes. And when I look back over the years of coming to that place, it is a wonderful place. ${ }^{607}$

In this exchange, Lawrence and I clarify that his out-of-body metaphor serves to point out the sense of increased distance to thought, which then appears like a passing "screen" in front of him. His basis of operation is one step removed, being a more diffuse "place" that he qualifies as "wonderful" and "safe". He also has the feeling that his basis of operation is unmoving, like it is "being held" in place. Let us consider another example of this phenomenon.

\subsubsection{Carmen Stays in a "Centred Space"}

Carmen is 50 years old and lives with her family on a farm in Pennsylvania, United States. She has been engaged in contemplative styles of prayer for 20 years, but has only recently started with centering prayer, which she has practiced for 1 year.

Since she started with centering prayer, and especially during the 10 Day Intensive Retreat at St. Benedict's Monastery, her basis of operation has begun to shift more easily during prayer and for more extended periods of time. She explained this to me at first in more general terms.

Carmen: $\quad$ I can stay in that period where, as Thomas says, the boats are
going by, better, as opposed to looking "in the hold" [of the
boats] and wanting to, you know, engage the boats. And
sometimes, in the beginning, I felt like, "No, I'm standing in the
river. I am... I'm looking at the boats, talking about their colours
and I'm, "bla, bla, bla, bla." Like... it is just, you know, was just
this torrent of thoughts that I just... I felt like I was doing a
...ahm... mantra.
Right, right, right. Were you using a sacred word all the time?
Interviewer:
Right, yeah. Yeah! And the other problem was my sacred word,
which was - I'Il tell you - "holy". So all my favourite songs have
holy in them. So like EVERY song kept coming in and I was like,
"AHH!" [she expresses "going crazy"] So then I had to change it. I

607 Ibid., pp.16-17. 
had to add a word to the holy so that I don't just get into, “Holy, holy, holy, holy," and there be a holy song.

Interviewer: So at the start you had that kind of barrage of thought and this issue with the sacred word, and then when you changed the sacred word, did something change?

Carmen: $\quad$ Yes, it allowed the thoughts to go by easier and [I could] shut out the music.

Interviewer: So when those thoughts go by, is there a difference for you between "being in the barrage of thoughts" in the first instance and "the boats going by"? Is there a difference in terms of your relationship to the thoughts?

Carmen: $\quad$ Oh yeah, absolutely, because I completely engage the thoughts in the barrage. ${ }^{.08}$

Carmen tells us that her ability to "stay" has improved over time. When her basis of operation "stays", the boats (an analogy for thoughts and content) go by without her "looking into the hold". Let us consider an example of this that occurred in one of Carmen's prayer sits on the same day of our interview.

Carmen: $\quad$ I was on the bench and [chuckle] ... in the second session and I
was sitting and all of a sudden I saw light and I thought
[expressing surprise and wonder]. It was just... it... it... I saw the
light and the light got brighter and... but I didn't... my normal
thing would be [in casual tone], “I see a light. I see light and its
getting brighter." But I didn't. I didn't have those thoughts.
You didn't comment?
Interviewer:
No! I didn't! It just was... noticing, like I noticed it, and then I
finally opened my eyes. But I couldn't hear the car - there was a
car coming out of the monastery with high beams on - and so
then I realised it was a vehicle, but for a short while I just saw the

${ }^{608}$ Carmen, Interview \#27.1, pp.5-6. 
light and did not comment in my head on the light, "What's that light? Am I seeing light?" It's, you know, it's just: there was light. You know, so it was kind of cool. ${ }^{609}$

During this sit, Carmen tells us that she did not "look into the hold", because she did not engage the content that appeared in her event-perspective. Thought did not elaborate. The coarse-level content just appeared in her event-perspective without perturbing her internal repose. I continued the interview by prompting her to talk about how her relationship to thought changes when the "boats go by" with ease.

Carmen: When they are going by those [thoughts] are further away... or they seem more fragmented.

Interviewer: What does "fragmented" mean, sorry?

Carmen: They don't have like a continuation to something else, whereas when they're ...ah... you know, where it's, "This leads to this and this is connected to this and it's connected to this," where this is like, you know, "This, which is completely unconnected to this," and, you know, yeah, if that makes any sense.

Interviewer: Is there anything else that happens at this point? That follows from there?

Carmen: Well, as long as they are, you know, going by and I just stay, you know, in that.

Interviewer: So you say that when you don't follow the thoughts, you stay in that?

Carmen: Yeah.

Interviewer: What is the "that"?

${ }^{609}$ Ibid., pp.6. 
Carmen:

The "that" stay-... ...ahm... in that "centred space", in that

centred... centred ...ahm... state. ${ }^{610}$

When Carmen's basis of operation stabilises in the deeper waters, her basis of operation is centred in (subject-side) a sense of mere space (object-side), which she determines to be the state of her awareness. In this "space", coarse-level content passes by at a greater distance (event-perspective) to her position of observation (awareness-perspective) and in such a way that thoughts are no longer narratively connected to each other. She noticed "thought" and "light" without elaborating on it any further. The content emerges and then dissipates again. As the content passes by, Carmen's basis of operation remains unperturbed and poised at the centre of her sense of space.

\subsubsection{Discussion}

I have presented two examples about what happens to experience when the basis of operation shifts and begins to stabilise for a period during prayer. I will summarise them and add a few brief descriptions from other practitioners who share Lawrence's and Carmen's experiences.

Recall Lawrence, my first example in this chapter. Lawrence compares the shift in his basis of operation to an out-of-body experience where his awareness stops coming from the head, but comes from the "heart". By "heart" he means a more diffuse presence that is not localised in his skull. His witnessing (basis of operation) is disengaged and at a greater distance to thought. It also remains "open" because he stops grasping for thought and does not add further thought about thought. During the periods of time when his basis of operation is stable, thoughts in his event-perspective become like "glimpses". Thought also reduces in quantity and stops triggering extended stories. It still passes by as if on a "screen".

In the second example, Carmen tells us that when her basis of operation "stays" for periods of time at the subject-side, she resides "centred" (subject-side) in a "space" (objectside) in which thought passes by more easily. She stops talking to herself about the nature of the content. Thus thought appears more fragmentary. By "fragmented" Carmen means that thought stops being narratively interconnected. Each thought just flows by without being related to another and without that thought elaborating on itself. In this way, she "notices" thought without "naming" it or reflecting on it. Finally, she tells us that she "stays in that centred space”, which is a state of awareness in which thought appears.

${ }^{610}$ Ibid., pp.6-7. 
Lawrence and Carmen are two examples in which the basis of operation retracts from the surface of the river (ordinary consciousness) for a period of time during prayer. They describe changes to their event-perspective. For example, thought stops elaborating and is viewed at a greater distance. In respect to their basis of operation, their accounts echo those of other practitioners in my sample who do not experience stability to arise from an alternative fixation, which is the strategy of concentration and awareness methods (see Section 3.6.1). For example, they do not place attention on the subject-side of their experience instead of the object-side; rather, their stability is born out of opening and relaxing awareness.

Here is another example of this phenomenon. Consider Martin, a 67-year-old contemplative with 20 years of experience, who says:

I want to be more open to the Spirit; more open to let God speak within. The intent of my symbol is that I'm going to be open. It's an opening of the heart and an opening of the eyes of the heart. You are open in the silence."611

Martin talks about "going into silence" and that when his basis of operation "sinks" the volume of internal and external noise decreases in his event-perspective. ${ }^{612}$ Similarly, Carol says, "You've got to leave that [ordinary consciousness] behind at a less reflective level of your being and just go deeper and know something else." In respect to her own practice, she says, "I centre myself in my heart [and] I am stiller." ${ }_{13}$ For both Martin and Carol the shift denotes a "centering" or "sinking" into deeper stillness and silence.

In Chapter 5, David mentioned "sinking into a deeper place", which he described as a sense of being "expanded" and "wakeful". In this deeper place he has an expanded sense of himself such that there is more space around thought. As his field of attention becomes more spacious, thought slows down and appears less intense in his event-perspective.

Finally, Elissa, a 24-year-old practitioner who has practiced centering prayer for 1 year, says that she experiences a "sense of being held or like "rooted"' at the subject-side of experience when she settles her attention through a "process of letting go". ${ }^{614}$ When her attention settles, she experiences a different type of thought in the event-perspective:

It feels like those [subtle thoughts] can kind of like rise up, like moving from the front to like the back, or like moving from conscious to "behind something". They do not take up as much space in my mind. I don't know where they are. It feels more like coming from

\footnotetext{
${ }^{611}$ Martin, Interview \#22.1, pp.9, 15, 19, 26.

612 Ibid., p.17.

${ }^{613}$ Carol, Interview \#11.1, p.11.

${ }^{614}$ Elissa, Interview \#32.1, pp.6-7.
} 
deeper... like it seems like a "steam thing" or a "fog rising", which can become

something. When the fog becomes something I can identify or name it. Then it feels like more of a [coarse] thought, I guess [chuckle]. When I settle it feels like thoughts are not as loud; they do not fill my awareness. I don't necessarily know that they are there, or they are not there. Sometimes they are more subtle "fog thought", like the screen and quieter and more subtle. ${ }^{615}$

Elissa describes how coarse-level thought changes appearance in her event-perspective when her basis of operation feels "held" or "rooted" at the subject-side of a deeper level of awareness. Now thought takes up less space in her mind and she detects its formation as it arises. Thought is less concrete, quieter and more subtle, like steam or fog.

Next, I will discuss three examples that build on these experiences to highlight the dual-mode structure of spiritual attentiveness.

\subsection{The Dual-mode Awareness of Spiritual Attentiveness}

In this final section, I aim to deepen our understanding of the structure of spiritual attentiveness by providing descriptions of the dual-mode awareness at work. I will put forward two examples that similarly describe how coarse-level thought changes appearance when the basis of operation shifts to the deep waters. They also highlight subtle-level content present in those experiences. Thus both coarse- and subtle-level content appear at the object-side in spiritual attentiveness.

\subsubsection{Rachel's Subtle Prayer: "I'm just there! In the silence."}

I return to Rachel's prayer. In Chapter 5, we left open what happens when Rachel redirects her attention. She says that her attention goes to "nothingness". To describe what she experiences in this "nothingness", Rachel draws on an image to highlight by analogy important features of the state.

The image opened up like a sarcophagus. And I walked up to it and there was like an entry in a doorway - and there was NOTHING: it was softly lit; there was no presence [as other]; there were no walls; there was no ceiling; there was no furniture; there was no floor. [It] gives that sense... that the expansiveness... there is this "more" ${ }^{616}$

615 Ibid., pp.7-9.

${ }^{616}$ Rachel, Interview \#26.1, pp.14-15. 
When Rachel redirects her attention, she goes to nothingness where she does not feel any emotion or sense of an external presence, and there are no images. The state is in an interesting way dimensionless, because it has no content (i.e. furniture) apart from "being softly lit" and it has no sense of boundedness (i.e., no walls, ceiling or floor). To the contrary, she talks about a sense of "the more" in which there appears to be no sense of spatial enclosure or boundedness, or images, or any other kind of content, because, as she says, there is "No THING" in the experience.

Earlier Rachel treated "returning to her intention" and "directing her attention" interchangeably. Let us inquire further into the attention component.

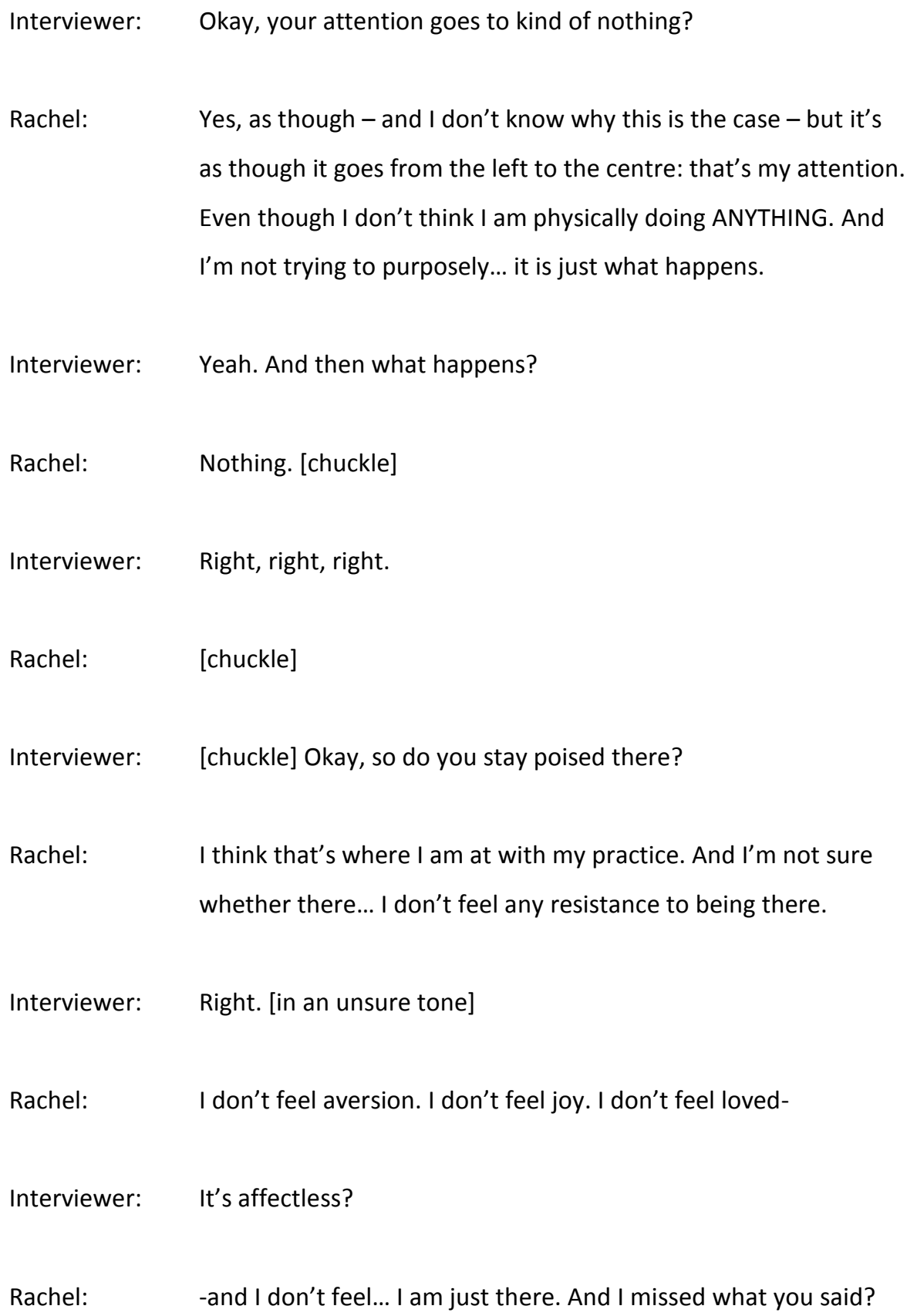


Interviewer: It's affect-LESS?

Rachel: $\quad$ Yes. And then, you know, sometimes it's just: I'm just there! In the silence. And I am okay. ${ }^{617}$

For Rachel, directing her attention means that her internal gaze moves from being placed on the left back to the centre, which is not a matter of moving her head or adjusting her sitting posture. This act is also not done purposefully, which means that when Rachel "returns to her intention" her attention centres itself without that shift to the centre being a purposefully driven act on her part. She locates her sense of agency in her intent, which does not extend to the attention centring itself. "It is just what happens," she says.

When Rachel's attention centres, she "returns to nothing" and is "just there... in the silence". There is no sense of anticipation. In that silence she feels no aversion, joy or love. It is an affectless silence. Rachel clearly remains conscious and she does so in a structured sense: she repeatedly affirms that "I" am there, present. Her awareness-perspective remains "lucid" and her event-perspective appears vacant (silent) and unbounded (without walls). My etic term "lucid" (as in "luminous" and "accessible") here describes how (i) there is something it is like for Rachel to undergo phenomenal apprehension, and (ii) Rachel is "percipient" and "knows" such apprehension is occurring. "Knowing" does not refer to some special epistemic self-awareness, but simply captures how experience presents itself in an obvious and identifiably phenomenal way (as discussed in Section 2.5.3). Thus there is a sense in Rachel's account of conscious awareness continuing - her event-perspective is "softly lit" - but in a vacant silence that is devoid of both content and affect.

As Rachel's prayer deepens, "going to nothingness" integrates with other aspects of her practice.

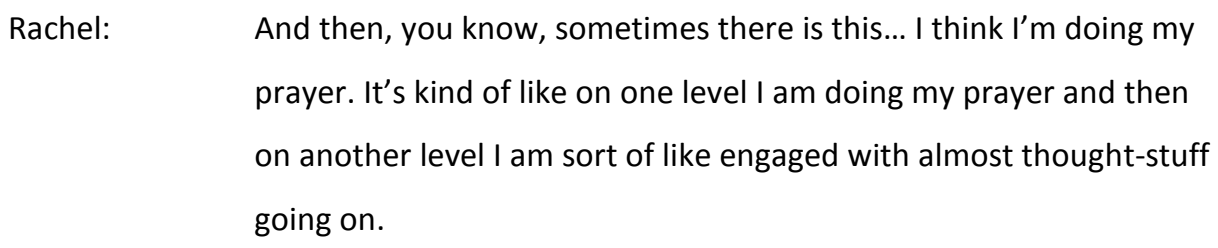

Interviewer: And yet you are somewhere "lower"? [I am trying to interpret a hand gesture Rachel made here to distinguish those two levels in terms of the height of her hand.]

${ }^{617}$ Ibid., pp.15-17. 


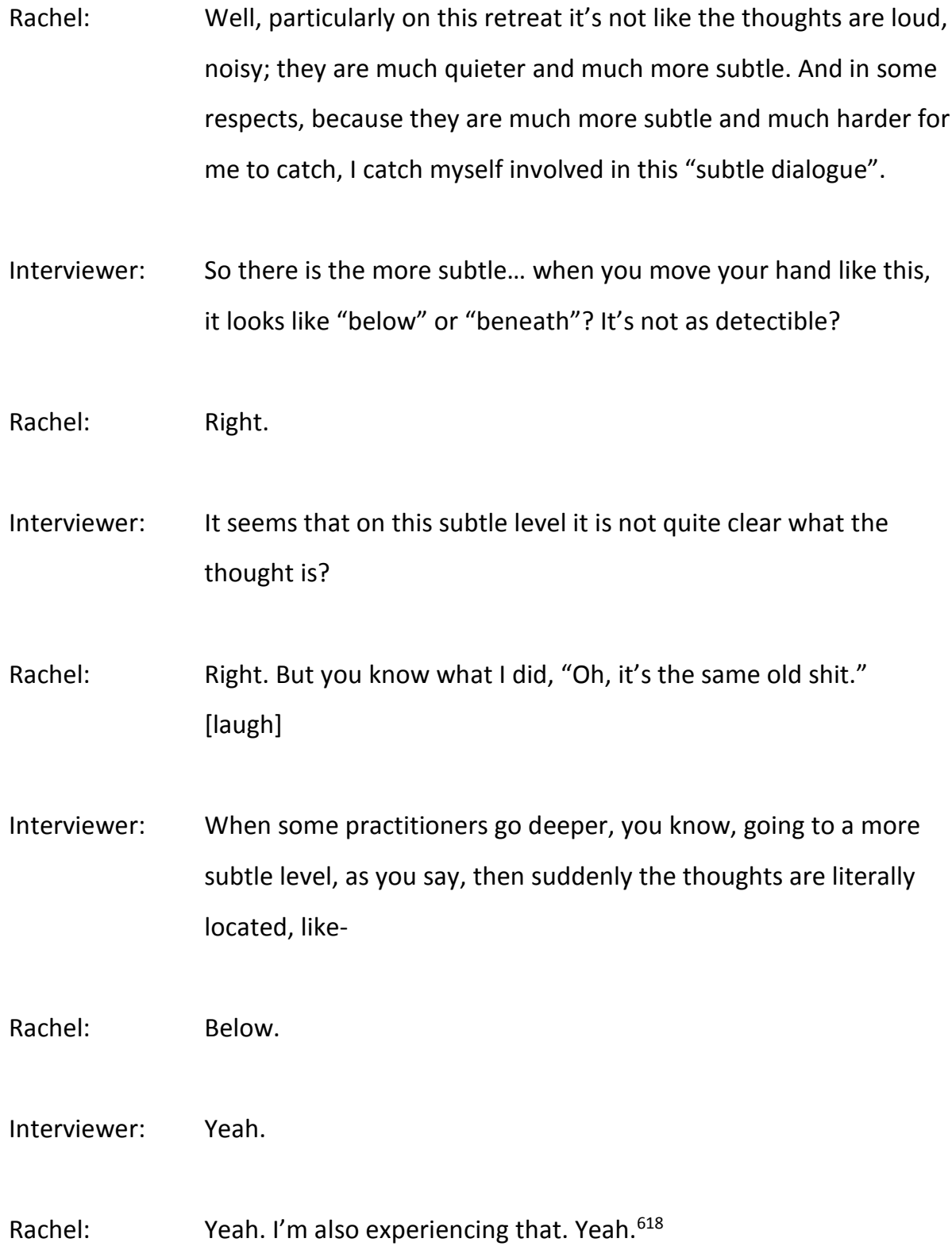

When Rachel's attention centres in nothingness, the silence does not stay contentless until the end of the 20 minute sit. Eventually Rachel's still but lucid awareness-perspective notices content, which now appears differently in her event-perspective. Her thoughts are more subtle and harder to "catch" and they appear located below her vantage point. The fact that those thoughts are less detectable and discernible yet "the same thought-stuff" indicates that they have shifted into the inattentive/nonthematic background of Rachel's experience (I discuss the attentive/thematic versus inattentive/nonthematic distinction in Section 2.5.3).

Rachel is simultaneously aware of two levels of her experience:

At the spiritual level of awareness, Rachel is "doing the prayer", which means that she is centred in a "softly lit" nothingness. The fact that her event-perspective is "softly lit"

618 Ibid., pp.17-18 
indicates that her awareness-perspective (subject-side) is lucid and percipient. Her references to "no THING", "no walls", "expansiveness", "no image", "no feeling” describe the event-perspective of her experience. Specifically, the phenomenal characteristics of inner silence and expansiveness ("unboundedness") are the subtle-level content of spiritual awareness. Therefore, Rachel's spiritual awareness is lucid but empty.

At the ordinary level of awareness, Rachel begins to register that she is also "involved in a subtle dialogue" in the inattentive background of her awareness. Rachel agrees that this type of thinking is difficult to illuminate. Thought is not fully elaborated and discerned. Despite the fact that the activity of ordinary consciousness goes on, Rachel is clear that this activity, which is now nonthematic, does not distract her from her thematic centre.

Rachel's basis of operation (modus operandi) remains rooted in a silent expansiveness at the spiritual level of awareness. Her language suggests that this basis is located at the subject-side of spiritual awareness, because it is the place she uses as a reference point to identify where she is in relation to her sense of expanse (subtle-level content) and the vague "dialogue" (coarse-level content) that happens "below" her. This vague dialogue originates in ordinary consciousness but has changed appearance, because Rachel's basis of operation is now rooted in the interior depths.

Rachel's lucid subject-side of spiritual awareness is thus percipient of both the subtle dialogue and the silent, empty expansiveness at the object-side of her experience. Her awareness does not attentively collapse to either the ordinary or spiritual level of awareness, but stabilises in a dual-mode where both levels of awareness co-occur without conflict.

\section{5•3.2. Samuel's Subtle Prayer: Rooted in a Featureless Expanse}

I revisit Samuel who reports the kind of "subtle prayer" that Rachel describes above. His case provides further description of the dual-mode awareness that is at work in spiritual attentiveness.

Samuel attends to his breath as his sacred symbol. It helps him stabilise for a moment or two in a "clean space", which he also describes as a "featureless expanse". The featureless expanse is a deeper level of awareness that Samuel hopes may one day be able to run in tandem with the coarse-level content of his everyday, psychological experience.

It comes along with a sense of an inward feeling of what it might be like to live from that place. Actually, this is, I feel, the answer to my old question, "What does it mean to pray constantly?" To be rooted in that place of featureless expanse: a place of peace or, I 
don't know what word you use, and still completely aware of my surroundings and responding to them. ${ }^{619}$

Today Samuel comes to this kind of "clean space" in seated prayer more regularly. It started happening for him a couple of years ago, but he did not recognise it the first few times. It was only after he was able to deliberately aid the process of moving into the state that he became fully aware of it.

\footnotetext{
Yeah, I think I only kind of noticed, "Ha! There is something about this," after I had sort

of a period in my prayer several times. And then I noticed that I was able to just by some very subtle way of manipulating my attention remain there for a few beats. ${ }^{620}$
}

Even though Samuel may proactively attempt to move into this state, he is adamant that he does not have any control to enter into or exit it.

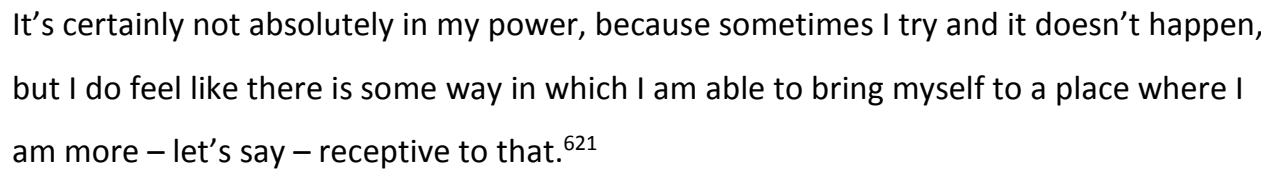

When Samuel is alert and poised for signs of entering into a featureless expanse, his relationship to thought begins to change, "It just becomes much dimmer," he says. ${ }^{622}$ But close investigation shows additional structural changes to consciousness. I will now turn to these changes. Specifically, I will focus on Samuel's vantage point at the subject-side of his experience (awareness-perspective) as it stands in relation to thought during the period when he begins to enter the featureless expanse (not once he is fully established in it). ${ }^{623}$ As he enters, the sense of space and expanse are at the object-side of his experience (eventperspective).

Interviewer: What happens to the thinking?

Samuel: It is as if it's on [the surface]: the images that recurred on this retreat are of Keating's image of, you know, things on the surface of the river. You are kind of below them, or - I can't remember the

\footnotetext{
${ }^{619}$ Samuel, Interview \#24.1, p.6.

620 Ibid., p.10.

621 Ibid.

622 Ibid., p.12.

${ }^{623}$ I discuss Samuel's experience of a fully established "featureless expanse" or "clean space" in Section 8.4.
} 
woman's name, Sylvia - she said she imagined it as a party going on upstairs, but on the downstairs [it is still], or something like that. It's almost a kind of spatial sense that the thoughts are above the space that you are in.

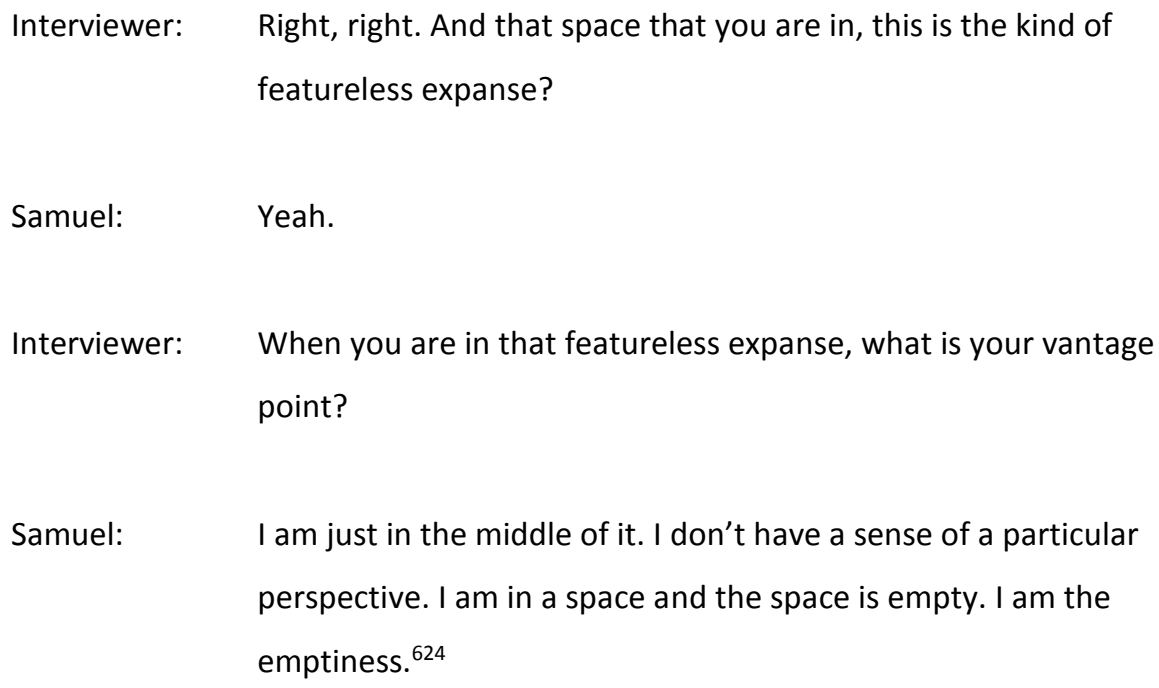

When Samuel begins to enter into a featureless expanse, he offers two metaphors to describe how his relationship to thought changes. The metaphors are borrowed from others, because he believes they are a correct analogy of his own experience. I will discuss each metaphor in turn.

The first metaphor is borrowed from Keating, who refers to the surface of an unruly river as an analogy "for that level of consciousness that we use to attend to daily life." Keating says that there are various things that "flow along the surface of our awareness like boats on a river". ${ }^{625}$ According to Keating, when we pray we come into contact with deeper currents of awareness the depths of which remain undisturbed by the moving stream of consciousness on the surface. This metaphor works for Samuel in two ways: (i) it introduces a spatial sense of distance between where he experiences himself to be and where he experiences thought to happen; (ii) it points to the sense of being located in a deeper level of awareness below the thoughts, which appear on the surface of awareness. Thought no longer occupies his attention as much and becomes "dimmer".

The second metaphor is borrowed from Sylvia, a very experienced centering prayer teacher. Both Samuel and I were present during one of Sylvia's introductions to centering prayer at the 10 Day Intensive Retreat at St. Benedict's Monastery in Snowmass. During this introduction, Sylvia offered a metaphor to describe how her experience of thought changes

\footnotetext{
624 Ibid., p.12.

${ }^{625}$ Keating, Intimacy with God, 25; Open Mind, Open Heart, 19-20.
} 
during prayer. In this analogy, Sylvia is sitting in a chair in a double story house. On the second story above her a party is going on. She is aware of the noise coming through the ceiling, but she doesn't discern or follow it, and she experiences it to be at a distance. Her inner stillness remains uninterrupted by what is happening above. This metaphor, again, captures Samuel's sense of increased spatial distance to thought and that it is no longer as emotionally captivating, or "bright” or “in his face”. Sylvia's account also captures Samuel's sense of being located in the depths below thought.

In terms of the structure of Samuel's experience, he is clear that his basis of operation (vantage point) shifts into the depths as he begins to "enter" a featureless expanse. During this process, his awareness-perspective relocates into the middle of this deeper level (the space) and his new vantage point discloses at the object-side (event-perspective) an "expanse" and "space". He further qualifies this space as "empty", "clean" and "featureless". Earlier he described this domain as "a place of peace". This is subtle-level content that appears at the object-side (event-perspective) of the spiritual level of awareness.

Finally, Samuel's account describes how coarse-level content of ordinary consciousness continues to appear at the object-side of his experience. The coarse-level content has changed appearance in a way similar to Rachel's descriptions: thought is "dimmer" and located “above" the depths. Although Rachel used the term "below", both describe a phenomenon in which the coarse-level content at the object-side of ordinary consciousness recedes into the inattentive background (nonthematic) while the spiritual level of awareness comes into the attentive foreground (thematic).

I conclude that Samuel is simultaneously aware of both coarse- and subtle-level content. He describes how a dual-mode awareness is at work in which both ordinary and spiritual levels of awareness coexist without his state of consciousness collapsing to either level, exclusively. This is spiritual attentiveness.

\subsubsection{Discussion}

I have presented two examples on the dual-mode awareness at work in spiritual attentiveness.

Rachel, my first example of dual-mode awareness, shifts her basis of operation into the deep waters (spiritual awareness) by redirecting her attention away from objects. She "returns" to a state in which "I am just there" at the subject-side of experience, which is placed in a "nothingness" that characterises the open horizon of her subjectivity (the objectside).

When her basis of operation stays at the spiritual level of awareness, she identifies its event-perspective (object-side) as a "nothingness" by which she means formlessness. She 
uses a metaphor of a room without furniture to describe this formlessness. The lack of furniture represents absence of content. She then qualifies the parameters of the room (the formless nothingness): it has no walls, ceiling or floor. In its stead there is a sense of "more" and "expansiveness". This is the subtle-level content of the spiritual level of awareness.

Rachel's awareness-perspective (subject-side) is at the centre of what spiritual awareness reveals and it is characterised by the sense of "I am present". This presence denotes the continuation of her conscious awareness, which is lucid and wakeful. Thus her vantage point reveals a "softly lit" formlessness rather than a blank. It is not unconscious.

At the same time, she remains aware of an ongoing "subtle dialogue" in which there is "thought-stuff". She describes how thought, which is of the kind of her everyday psychological experience (she says, “Oh, it's the same old shit.”), now appears differently. Thought is "quieter", "ephemeral" and "much more subtle". Rachel points out that this coarse-level content has relocated "below" her attentive purview. By "below" she means nonthematic and in the background. Coarse-level content is no longer the topic of her experience.

As Rachel enters into a deeper and more subtle prayer, we can identify the dual-mode awareness at work that is characteristic of spiritual attentiveness. Both subtle-level content (formless depths) and coarse-level content (thought related to our everyday psychological experience) are present in her experience without one concealing out the other. At the same time, coarse-level content is no longer in the foreground of experience and consequently appears differently.

In my second example, Samuel focuses on his breath to stabilise in the middle (subject-side) of a "clean space" that characterises the horizon of his subjectivity (objectside). Samuel further describes the event-perspective of this deeper, spiritual level of awareness as "clean". By "clean" he means to capture the formlessness of this space. He further qualifies this space as a "place of peace" that is "empty" and "featureless". The parameters of this "space" are unspecified, because it is "expansive". Since spiritual awareness is featureless, it is hard for Samuel to locate a specific position from which his awareness comes from (subject-side). But he mentions that his awareness-perspective is "in the middle of it" and it is clear that it is lucid and wakeful, because he is percipient of the "clean space" and "featureless expanse".

Samuel also remains aware of thought in the event-perspective at the ordinary level of awareness, which is no longer in the foreground and has relocated. He describes thought to be "above" the space he is in. Two changes indicate that thought recedes into the nonthematic background of his experience. First, thought relocates from the front to above (Samuel also reports that thoughts pass by in front of him in more coarse-type prayer). Second, thought changes appearance, because it becomes "dimmer". 
As Samuel begins to enter in to a featureless expanse, his prayer deepens. I refer to this deeper kind of prayer as subtle prayer, because it reveals a different type of content in the event-perspective. Like in Rachel's example, Samuel's subtle prayer reveals a dual-mode awareness to be at work in which coarse- and subtle-level content are both present without one concealing the other out. Coarse-level content also changes appearance as it recedes into the inattentive periphery.

\subsection{Conclusion}

In this chapter, I have presented data to illustrate what happens when the basis of operation stabilises in the deeper water of awareness. I have shown that the transformation of consciousness effected at this stage is a dual-mode awareness in which two levels of awareness (ordinary and spiritual) run in tandem.

I began with Lawrence's and Carmen's cases that described how the coarse-level content in the event-perspective of the ordinary level of awareness changes appearance and stops elaborating. Coarse-level content is the surface of the river. In spiritual attentiveness, coarse-level thought recedes into the inattentive periphery ("below" or "above") and becomes "dimmer", more "ephemeral”, "fragmented” (as in "narratively disconnected”), “quieter" and "more subtle".

Next, I presented Rachel's and Samuel's deepening prayer to introduce subtle-level content that is characteristic of the deeper waters of spiritual awareness. In the eventperspective of the spiritual level of awareness is formlessness, interior spaciousness, silence, stillness and peace. These constitute the depths of the river upon which the surface rests. In spiritual attentiveness, this subtle-level content comes into the attentive foreground.

Finally, I showed that a dual-mode awareness is at work in spiritual attentiveness. It allows the activity of ordinary consciousness to continue without being concealed by spiritual awareness. While practitioners maintain access to both levels, coarse-level content becomes more vague compared to subtle-level content, because it recedes into the background (inattentive periphery) of experience and is thus outside of the practitioners' direct attentional purview. ${ }^{626}$

\footnotetext{
626 The way coarse-level thought changes in appearance when a practitioner's vantage point shifts to a deeper level of awareness is similar to how subjects in Hurlburt's work Sampling Inner Experience in Disturbed Affect report "unsymbolised" or "imageless" thought as an activity of their mind that is "known" by awareness but not directly experienced (p.155). His subjects also have by and large a hard time putting into words how exactly they experience these type of thoughts. What is interesting here is that Hurlburt has observed that the frequency of unsymbolised thinking increases as depression increases. Depression results in less perceptual clarity of internal phenomena and higher levels of formlessness. Spiritual awareness is similarly more formless.
} 


\title{
Chapter 6
}

\section{The Stages of Absorption: Infused Recollection and Prayer of Quiet}

\begin{abstract}
I don't know at what point it gets that way, it just does. I do know that the silence is getting more noticeable, and the noise or the thoughts are getting less noticeable. Thoughts always happen but I wasn't in dialogue with them. I wasn't engaging them. I wasn't connecting with them. That was a restful sit. ${ }^{627}$
\end{abstract}

- Martin

I sat through THAT sit motionless. I didn't move my hands. I don't even remember if I swallowed. I felt like I was just being held, right here, you know, and this was fine. And so safe, trusting. It was almost like sitting on a cloud. Just sitting. Just safely. ${ }^{628}$

- Lawrence

\subsection{Introduction}

In this chapter I will focus on the early stages of contemplative prayer. I leave behind the basic method of centering prayer, because it is mainly applied in the first two stages of the path to introduce beginners to a contemplative approach to prayer, which is non-discursive and cultivates a spiritually attentive disposition. ${ }^{629}$ Spiritual attentiveness, in turn, prepares practitioners for the more subtle approach of contemplative prayer and it introduces them to the deeper, spiritual level of awareness. This deeper awareness is the domain where contemplative prayer takes hold.

In contemplative prayer, practitioners withdraw their effort in practice proportional to how much they get "drawn into" spiritual awareness. This is a process not directed by them, but it is "given". It is conceived as "grace" or the "action of the spirit". Prayer takes on a life of its own and leads practitioners through stages of increasing levels of absorption during seated prayer. Those are: infused recollection; prayer of quiet; prayer of union; and prayer of full union - the classic stages of prayer delineated by Teresa of Avila.

In this chapter, I will introduce infused recollection and prayer of quiet as the first two stages of contemplative prayer. I will show how these two initial stages are states of absorption that build on the dual-mode awareness at work in spiritual attentiveness. They

For a discussion of "unsymbolised thought" relevant to the phenomenon reported here, see Sampling Inner Experience in Disturbed Affect, 5-7; 16-18; 75-77; 94-95; 104-05; 25-28; 40-43; 55-56; 67-69; 82-83; 92-93.

627 Martin, Interview \#22.1, p.17.

628 Lawrence, Interview \#21.1, pp.10, 12-13.

${ }^{629}$ Centering Prayer does not consider its method an act of contemplation, but a preparation for it (see Section $\underline{3.6 .3}$, p.102). 
add to spiritual attentiveness a self-sustaining and effortless quality. Thus the manner (not structure) of spiritual attentiveness changes.

I will begin with Pike's concept of "recollection" as a paradigm case for Christian "concentration practice" and contrast this with centering prayer as a "letting go practice". Next, I will consider phases in Carmen's prayer that show how spiritual attentiveness may require effort at the start (=recollection) and then contrast this with Martin's practice in which his spiritual attentiveness is effortless and affectively elevated (=infused recollection).

I will then turn to prayer of quiet. I will share Lawrence's account of being spiritually attentive and so absorbed that he feels unmovably held in place. I will conclude with how God's formless presence manifests in prayer of quiet, which is through spiritual attentiveness and subtle-level content.

\subsection{Recollection}

In Mystic Union, Pike defines recollection as "a nonverbal, nondiscursive activity". It is a type of "meditation" that begins with "dwelling on a single item". The item could be "almost anything - one's navel or one's name". ${ }^{630}$ Pike cites Teresa to have suggested using "an image or a picture of [the] Lord". ${ }^{631}$ My own reading of Teresa differs, because my perspective has been informed by how centering prayer practitioners report to work differently with attention over time.

Teresa says that contemplatives "must at all costs form this habit", which is to "focus your thoughts on God". ${ }^{632}$ Her language shifts from notions of God as personified by Jesus ("God in his Humanity") to more direct references to God simpliciter ("God in his Divinity"). ${ }^{633}$ The latter is relevant for practitioners who develop the kind of contemplative habit she aims for. ${ }^{6} 34$

In respect to the personal notion, Teresa does suggest to "imagine that this Lord Himself is at your side". ${ }^{635}$ She also considers it helpful "to get a picture of this Lord to use regularly when you talk to Him". ${ }^{636}$ However, her pointers appear to be a separate piece of advice, because she primarily urges practitioners to cultivate a habit in which they are directly aware of God's presence within, which appears to have less personal connotations.

\footnotetext{
630 Pike, Mystic Union, 2.

631 Ibid., 2. Cited fn. 2, Teresa, The Way of Perfection, 177 (chap. 26).

632 Teresa of Ávila, The Way of Perfection (Brewster, Massachusetts Paraclete Press, 2000), 110-11.

${ }^{633}$ For Pike's distinction of God "in his Humanity" and "in his Divinity", see Pike, Mystic Union, 4.

${ }^{634}$ Keating uses similar language, but he clearly distinguishes between the presence of God as an

"undifferentiated sense of unity" and a "more personal attention to one or another of the Divine Persons". Invitation to Love, 107.

635 Ávila, The Way of Perfection, 110.

636 Ibid., 114.
} 
For example, she calls spiritual aspirants to "look at Him" and to not "become involved in long and subtle meditations with your understanding and reason". ${ }^{637}$ As Pike points out, recollection is a nonverbal and nondiscursive activity. Here Teresa repeatedly emphasises to "turn the eyes of your soul". ${ }^{638}$ Centering prayer contemplatives prefer the term "heart" over "soul" and use the phrase "eyes of the heart" to refer to this "inward" gaze. This kind of "return" is captured in Teresa's writing by the phrase, "Gaze upon this Lord present within." 639 She qualifies that to do so practitioners must "look away from outward things". 640

Teresa's linguistic ambiguity reflects how centering prayer practitioners mature in their own centering prayer practice. For example, recall Samuel, who initially conceived of a "presence" outside by way of imagining Jesus in front of him. Yet over time Samuel's practice opened his awareness (rather than fixated it on an object). This denotes the "habit" that Teresa speaks of. Keating calls this disposition "spiritual attentiveness". Spiritual attentiveness stabilises the vantage point in a deeper awareness (spiritual level) that does not locate the Divine solely in coarse-level content, like a visual image of Jesus. At the level of spiritual awareness, Samuel says, "It's really more about MY becoming present". ${ }^{641}$ This kind of contemplative habit is rooted in a more impersonal and immanent conception of God's presence.

In respect to recollection, centering prayer does not follow Pike's analysis of how to "collect, or recollect, the mind". His version of recollection requires of practitioners to place attention on an item in the event-perspective "without interruption" and with "considerable effort". ${ }^{642}$ This is a classic concentration style practice, which centering prayer is not.

Nevertheless, the initial stages of centering prayer rely on activity that the practitioner herself does: she applies the basic method (sacred symbol). As Pike says, "The effort is one's own."643 Thus Stage One (sacred symbol) and Stage Two (spiritual attentiveness) do require at least some initial effort. The Centering Prayer tradition recommends this effort be minimal and applied in a way that does not follow the logic of classic "concentration" and "awareness" methods. ${ }^{644}$ Therefore, the first two stages should be considered Centering Prayer's unique approach to recollection, which is rooted in its Christian contemplative heritage.

\footnotetext{
637 Ibid., 111.

638 Ibid.

639 Ibid., 114.

640 Ibid., 111.

${ }^{641}$ Samuel, Interview \#24, p.19.

642 Pike, Mystic Union, 2.

643 Ibid.

${ }^{644}$ I discuss the concentration methods (pp.95-96) and awareness methods (p.96) in Section 3.6.1.
} 
I will now proceed with an example of recollection to show how spiritual attentiveness can be initially maintained through effort.

We return to Carmen's practice in which she "stays in a centred space" while coarselevel content passes by (refer back to Section 5.2.2). When she first encountered this phenomenon, she could only experience a dual-mode awareness if she applied great effort.

Carmen: In the beginning I kind of hurt, because I was trying so hard to stop the barrage of thoughts, you know, but my eyes...

Interviewer: What do you mean by "eyes"? Like literally your eyes, or?

Carmen: $\quad$ My eyes actually hurt. I felt like I was straining, as if you were trying to see something, but you couldn't see. Or you put your glasses on and it was wrong prescription. It felt like right in my eyes, even with my eyes closed. It felt like a strain. And now it doesn't hurt, at all.

Interviewer: And is it correlated to some change that you noticed? The nonstraining?

Carmen: $\quad$ Continuing to do it. Being able to not engage the barrage of thoughts, or not trying to not engage the barrage of thoughts.

Interviewer: Did you say you were "trying"?

Carmen: I almost felt like I was trying to focus on something. Like with my eyes closed. That's the only way I can explain it. See, I mean, I thought I was going crazy because I'm like, “I need some Ibuprofen." I was trying to make it not hurt. It physically hurt.

Interviewer: So where was the focus? Like where was it going?

Carmen: I'm just trying to get to like a centre point.

Interviewer: Is it like in front of you? 
Practitioner: Yeah. ${ }^{645}$

This conversation with Carmen followed her account of being in a centred space and at a distance to thought. Our discussion here presupposed that a dual-mode awareness is operative. She is aware of both a "centred space" (subtle-level content) and thought (coarselevel). In the early stages she maintained this dual-mode awareness with great effort. She even tolerated physical pain to hold onto a centre-point and to avoid getting pulled into thought. Rather than disengaging and abstracting attention away from the event-perspective, she placed it on a centre-point, located in the space (object-side) that she witnessed. This is recollection. Her dual-mode awareness is upheld by her effort.

At this stage Carmen's awareness is not fully relaxed and "grace" has not yet taken hold. This is typical. Practitioners experience "grace" (the absorbing quality of prayer) to be active proportional to how open and receptive their awareness is. Carmen's account tells us that she started out with focusing on a centre-point. This required effort. She then later applied the "letting go" method of centering prayer, which releases rather than mobilises effort. In this way, centering prayer is an alternative approach to recollection. It proceeds by way of surrender, not concentration. Carmen tells us that repeated letting go - or "letting be", because she talks about "not trying" and "being able to not engage" - helped her become spiritually attentive with less effort.

\subsection{Infused Recollection}

"Infused" recollection (equivalent to Pike's "prayer of quiet"646) is the next step on the Christian path according to the Keating School of Centering Prayer. It denotes the onset of contemplative prayer (Stage Three), because prayer becomes "infused". It is an additional ingredient that changes the character of spiritual attentiveness in two ways: (i) dual-mode awareness requires less effort to maintain ("grace”) and (ii) it is affectively elevated.

I will now present an example of infused recollection to highlight the difference between "recollection" and "infused recollection".

Consider Martin, he is 67 years old and was raised Catholic in a big city on the West Coast of the United States. Today he continues his vocation as a priest of the Episcopal Church in a sizable city in Maryland. Martin has practiced centering prayer for 20 years.

\footnotetext{
${ }^{645}$ Carmen, Interview \#27.1, pp.8-9.

${ }^{646}$ Pike discusses prayer of quiet as equivalent to "infused" recollection. He demarcates "recollection" from "prayer of quiet" by the presence or absence of effort (and grace). Thus recollection, in his view, is a matter of the practitioner's effort. In contrast, prayer of quiet is a "gift" (infused). It is "imposed by another - a supernatural being" and therefore a matter of grace. Mystic Union, 2-3. In my presentation of the stages of contemplative prayer, I follow Centering Prayer's outline, because it better fits the first-person data.
} 
Martin's prayer session in question happened when he was at Newark airport. He sat slightly removed from the hustle and bustle. We begin with a general reflection he made about his prayer.

Martin: $\quad$ It has clearly been something that I have felt goes deeper and
deeper AND to the point now that, I mean, I have found myself
able to do a centering prayer sit at a gate at an airport. There is
all of this craziness going on around you and noise and
announcements and all of that and I can just close my eyes and
do a sit. It's like background music in the market. The noise is
there but you're just not engaging in it. You're not noticing it.
You are not getting into dialogue with it.
Interviewer: Could we go back to that experience?
Martin:

Martin and I went through his prayer session at the airport with great detail. I jump to a relevant section for the purpose of our discussion.

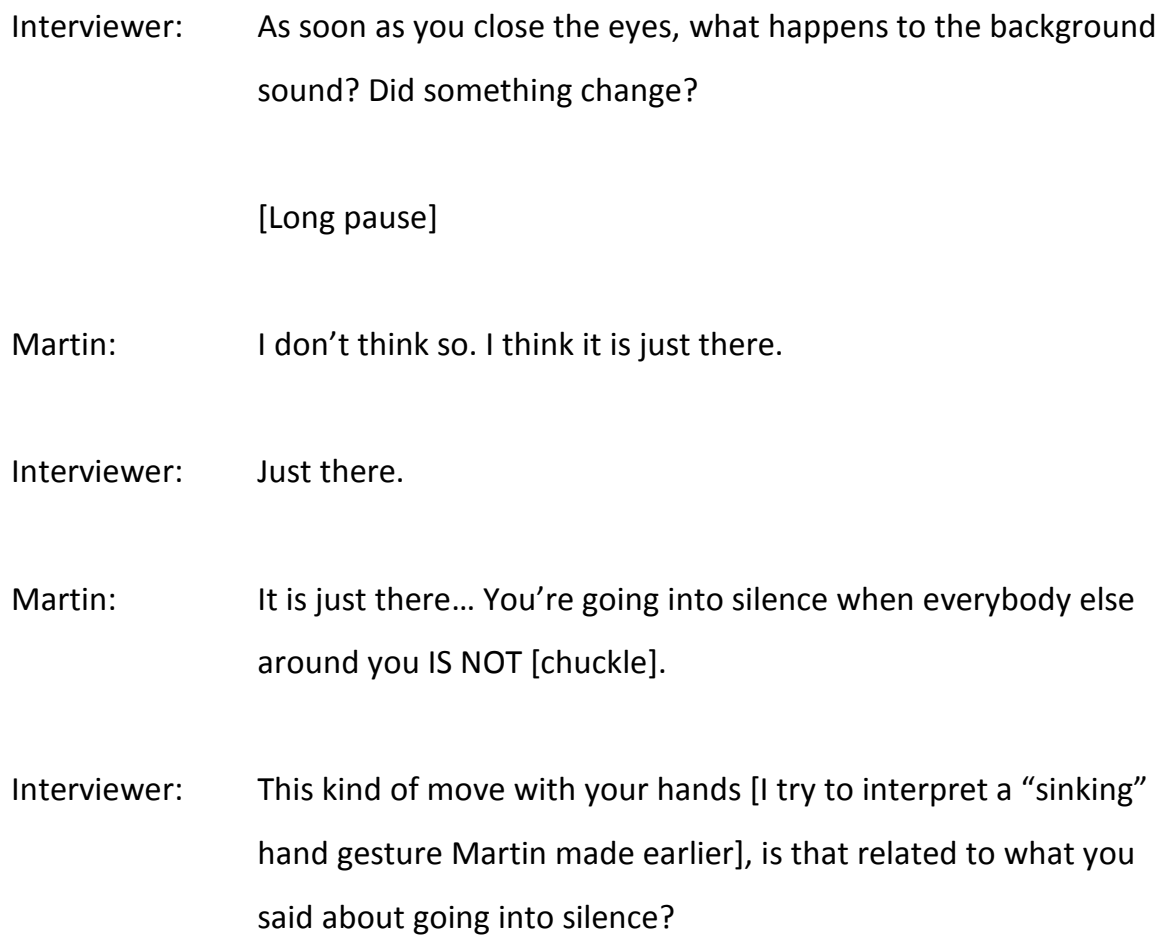

${ }^{647}$ Martin, Interview \#22.1, p.12. 


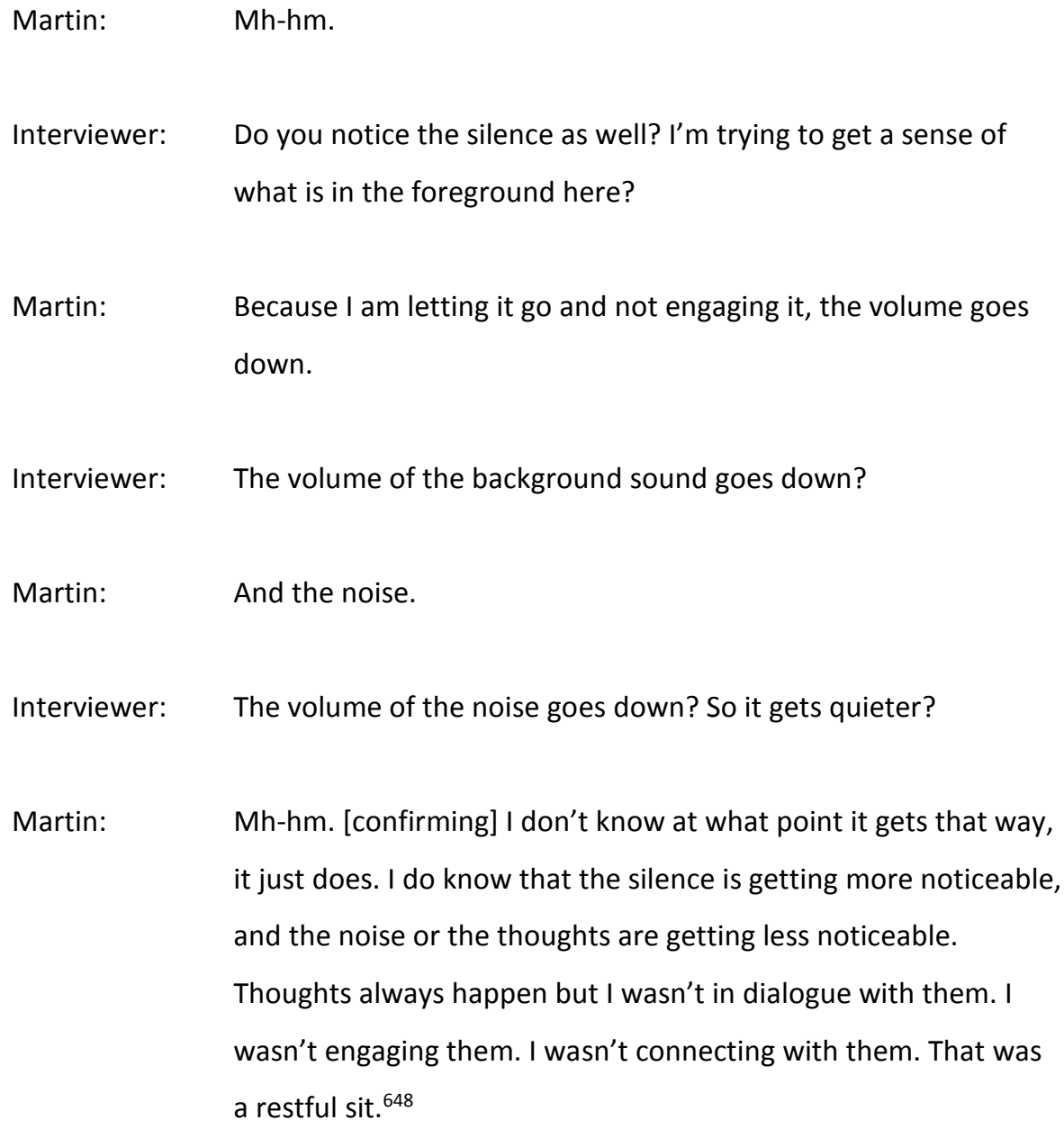

Martin offered this prayer sit as an example of how effortless spiritual attentiveness has become for him. He is able to "restfully sit" in a dual awareness where he is sunk in silence while surrounded by noise. He describes how subtle-level content (silence) effortlessly comes to the foreground while the noise in his environment (external coarse-level content) recedes into the background. He also points out that thought (internal coarse-level content) "happens", but he does not get caught up in it. He remains poised in his prayer without much effort. His prayer is also affectively elevated. By "elevated" I mean that his prayer is neither strained (unpleasant) nor neutral, but positive (pleasant) in some way (see below exchange).

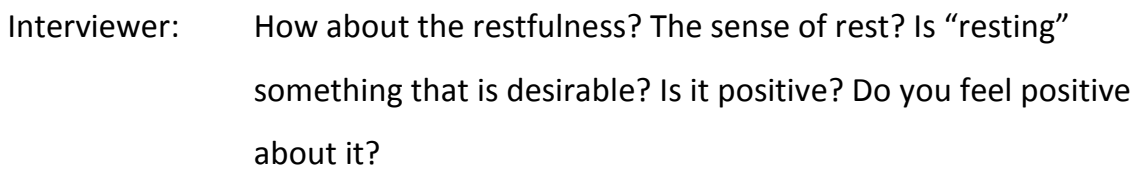

Martin: $\quad$ Oh, I feel good!

648 Ibid., pp.16-18. 
Interviewer: So "restful" is positive?

Martin: Yeah. You know, I mean, the whole idea of centering prayer is to rest in God. ${ }^{649}$

Martin's prayer is a good example of how Keating conceives “infused recollection”.

First, the dryness in prayer brought about by excessive effort in the first two stages is replaced by a "delicious spiritual savour" that "wells up from a source deep within". ${ }^{650}$ Spiritual savour can be described as a sense of consoling rest and peace. ${ }^{651}$ Thus prayer is affectively elevated in the sense that it has shifted from being either negative (unpleasant) or neutral (affectless) to positive (pleasant). Though absorption is still only slight and sensed by being drawn or attracted to the pleasantness and effortlessness. The draw is subtle enough that practitioners can still "get up and walk away", even if they would rather prolong the experience. ${ }^{652}$ Above Martin tells us that his prayer is so affectively elevated. It is restful and feels good. Martin adds that this is the "whole idea" of his practice. Later in the interview, Martin told me that his practice can become "more peaceful" with such a "strong sense of rest" that, when the bell rings, he feels that "it couldn't have been 30 minutes; it had to have been much less - it had gone way too fast." ${ }_{53}$ In such instances he will, when possible, extend his sessions to 40-45 minutes. Here we see that the "spiritual savour" (affective elevation) of his practice attracts him to sit longer.

Second, the human faculties of imagination and memory are still operative. Keating says that the faculties "play with images and memories in order to keep themselves occupied". ${ }^{654}$ Martin tells us that "thoughts happen", but he was not connected to their activity. As Keating would say, "the faculties... are free to roam around."655 Therefore, when Martin's prayer is “infused", then the activity of the faculties does not disturb his interior silence and rest. His dual-mode awareness is effortlessly sustained. This is grace in action.

\subsection{Prayer of Quiet}

The Keating School of Centering Prayer identifies "prayer of quiet" as the next level of contemplative prayer. Like infused recollection, it increases the intensity of absorption while the dual-mode awareness of spiritual attentiveness remains intact. In prayer of quiet, the

\footnotetext{
649 Ibid., p.21.

${ }^{650}$ Keating, Invitation to Love, 106.

651 Manifesting God, 108-09.

652 Invitation to Love, 107.

653 Interview \#22.1, p.7.

654 Invitation to Love, 107.

655 Ibid.
} 
practitioner still has cognitive access to both the ordinary and spiritual levels of awareness. ${ }^{656}$ However, spiritual attentiveness is approaching zenith. By "zenith" I mean that the dual-mode awareness will not be able to take the practitioner much further in seated prayer. Beyond this point, the practitioner starts to lose cognitive access to the ordinary level of awareness in favour of full immersion in spiritual and divine awareness.

Prayer of quiet adds to infused recollection three characteristics:657 (i) a stronger sense of spiritual consolation; (ii) a sense of being "spiritually embraced" (the faculty of will is grasped);658 and (iii) a sense of "God's unseen presence within". ${ }^{659}$ I will turn to an example to illustrate these three characteristics of prayer of quiet.

Consider Lawrence's practice. In Section 5.2.1, Lawrence told us that he uses the phrase "out-of-body" (p.110) to capture how his awareness comes from his heart. By "heart" he means a more whole and diffuse awareness. His phrase "out-of-body" also describes the distance from thought that he experiences when he disengages from ordinary consciousness. When Lawrence detaches from thought, "it's an experience where these thoughts are just running by and I make no effort.”660 He has more to say about disengaged observing.

\footnotetext{
I work at using my sacred word to get me back; to not having attachment to thought. I really work at getting away from that and getting to that point where thought is going by and I'm not attaching to it, or I'm not expanding on it. I use the symbol to get back to that place: to that film that is going on. In the film I am not attached to it: there is comfort that comes from the freedom of not being engaged in those thoughts, and I feel safe. ${ }^{661}$
}

In Lawrence's practice, we see all three characteristics of prayer of quiet at play in spiritual attentiveness.

First, his sense of spiritual consolation is quite strong. In periods when he experiences a more holistic and diffuse awareness (spiritual level), he also dispassionately observes the phantasmagoria of his mental life (ordinary level). Lawrence tells us that when he "returns" to that place where the "film is going on", thoughts pass by without elaborating

\footnotetext{
${ }^{656}$ Manifesting God, 110.

657 Pike's version of prayer of quiet includes all these three characteristics, but he does not distinguish prayer of quiet from infused recollection. Keating inserts another layer here so that his version of infused recollection is a precursor to prayer of quiet and a type of contemplative prayer in which grace is more active than in recollection. I have followed Keating's lead. For Keating's version, see Invitation to Love, 107; Manifesting God, 110-11. For Pike's version, see Mystic Union, 1-7.

${ }^{658}$ Keating, Invitation to Love, 107.

${ }^{659}$ Frenette, The Path of Centering Prayer, 72.

${ }^{660}$ Lawrence, Interview \#21.1, p.11.

661 Ibid., pp.24-26.
} 
and without him getting drawn in. He describes this place as "comforting” (above quote), "wonderful" and "safe". 662

Second, he is quite absorbed. He tells us that he is "unmovably in place". When I asked him about this feeling, he clarified that he feels like he is "sitting on a cloud" rather than held in place by a supernatural or external force. ${ }^{663}$ (We will come across a few more accounts of "spiritual embrace" and no practitioner relates it to an external force or being.) Lawrence's state appears completely effortless. This indicates that grace is active.

Keating describes the activity of grace in terms of the Spirit grasping the will. ${ }^{664}$ For example, for the will to be "grasped" or "absorbed" would mean in Lawrence's case that he finds it increasingly difficult to intend anything else (e.g., the will to move). This is not because an external force disallows his will to stir. Rather, his will is submerged in the consoling quality of prayer. Lawrence says about his prayer, "I sat through THAT sit motionless. I didn't move my hands. I don't even remember if I swallowed."665 Keating calls this overpowering character "spiritual embrace". ${ }^{666}$ Lawrence described it as a feeling of "being held". He said, "I felt like I was just being held, right here, you know, and this was... this was fine. And so safe, trusting." 667

Third, Lawrence identifies his diffuse awareness and "being held" in a wonderful and safe place as the presence of God. He conceives the perfect prayer session as one in which he feels the presence of God and in this way. Thus, when I asked him what the presence of God is like, he said, "I had it for a period of time today." 668 By this Lawrence means the positive quality of the "film" (disengaged observing) that was accompanied by the feelings of "being held", being wonderfully "in the right place" and "comforted". 669

Lawrence's account echoes how Keating experiences the "delicious sense of God's presence" in prayer of quiet. Keating says that, "[God's] presence manifests itself by a certain delight that is subdued but strong enough that one would like to prolong the period of prayer." ${ }^{70}$ In the same way, Lawrence describes how the presence of God manifests for him through affective elevation, which draws and holds him. "It is like sitting on a cloud," he says. ${ }^{671}$

\footnotetext{
${ }^{662}$ Ibid., p.17, 26. Lawrence refers to "wonderful" in Section 5.2.1 (p.151) and "safe" in Section 2.7.5.2 (p.62).

${ }^{663} \mathrm{lbid} .$, p.13. Lawrence mentions "sitting on a cloud" in Section 2.7.5.2 (p.62).

${ }^{664}$ Keating, Invitation to Love, 107.

665 Ibid., p.12.

${ }^{666}$ Invitation to Love, 107.

667 Interview \#21.1, p.13.

668 Ibid., p.27.

669 Ibid., p.12.

${ }^{670}$ Keating, Manifesting God, 110-11.

${ }^{671}$ Interview \#21.1, p.13.
} 
Lawrence's account also accords with Frenette's treatment of prayer of quiet. He emphasises that the dual-mode awareness is effortless, because the will is submerged in, or "held" by, the affective elevation at work in spiritual attentiveness.

This state of contemplative prayer is one in which your will is quiet while you can still experience distracting thoughts as your intellect roams around like a madman within you... You are aware of the surface of your mind and the depths of awareness at the same time. The thoughts continue roaming around the surface of awareness like madmen, but when you quiet your will in the immediacy of God's presence in awareness, the mad thoughts are just surface noise... you open to two levels of awareness at the same time. ${ }^{672}$

Lawrence's account of prayer of quiet shares Frenette's feature that his faculty of the will is quiet ("unmoved" and "held in place") while at the same time his other faculties roam freely (the "film").

Lawrence also identifies the wonderful place in his heart, which is a more whole and diffuse awareness, as the presence of God. This accords with Frenette's account of "God's unseen presence" that is "within" or "in awareness". ${ }^{673}$ In fact, Frenette's term "in" is coterminous with the terms "as" and "through", because he acknowledges that, experientially speaking, God's presence does not denote an additional feature or ingredient apart from the "awareness" itself. ${ }^{674}$ For example, Frenette says, "God's indwelling presence... manifests through spiritual attentiveness," and, "you cannot experience God directly, but the radiance of God's formless presence is sometimes experienced as interior silence, interior stillness, or interior spaciousness [italics added]." 675 Therefore, in prayer of quiet the presence of God is encountered by way of the subtle-level content present in spiritual awareness, which is: formlessness, spaciousness, stillness, silence and awareness itself.

\subsection{Conclusion}

Contemplative prayer adds to spiritual attentiveness an absorbing quality. In traditional sources this quality is described as "infused". The term "infused" attempts to capture the activity of grace. The balance between effort and grace shifts towards the latter such that the Spirit begins to take over and do the heavy lifting.

\footnotetext{
672 Frenette, The Path of Centering Prayer, 46.

673 Ibid., 47, 62, 72.

674 Ibid., 81.

675 Ibid., 17, 81. For a discussion of three "formless ways of apprehending God's presence", see ibid., 64.
} 
At the first stage of contemplative prayer, infused recollection adds an effortless and affectively elevated quality to the dual-mode awareness that is at work in spiritual attentiveness.

At the second stage of contemplation, prayer of quiet increases the intensity of the prayer's consoling character. Absorption in the spiritual level of awareness is intense enough so that practitioners now feel "spiritually embraced" by the state. The embrace "grasps" or "quiets" their will so that it becomes difficult for them to desire anything else.

In prayer of quiet, practitioners begin to speak of "God's presence" in ways that exclude an additional and unique ingredient in what is phenomenologically given. They do not go beyond experiential primitives. Thus practitioners' speak of God's "unfelt" or "unseen" presence and identify it by pointing to various ways it manifests in their experience. For example, they point to features of spiritual attentiveness that are present in the eventperspective of the spiritual level of awareness (as Lawrence has above). This includes subtlelevel content, such as interior stillness, silence and spaciousness.

In Martin's and Lawrence's prayer we can see centering prayer's apophatic mode of contemplation taking effect (I discuss apophasis in Section 3.2.1). They work on doing-awaywith the human faculties to prepare for mystical consciousness of God. Their regimen disengages from their human faculties and begins to "pass beyond" 676 or "bypass" 677 them (e.g., reason, memory, imagination). Thus they refuse to seek out God as yet another "thing" or "image" that can be detected by those means. (I will return to this claim in Chapter 8 where I discuss Martin's and Lawrence’s experiences of “full union”).

In respect to God's presence in prayer of quiet, I contend that practitioners (alongside Pike, Keating and Frenette) talk about God's presence, because the "infused" quality of prayer is strong enough to bring into the foreground the features of the spiritual level of awareness (subtle-level content). Absorption is also strong enough so that practitioners' feel "embraced" and "consoled" by the state, which, in turn, makes palpably present the features of spiritual awareness. Those features are now available for identification as the way in which God's formless, unfelt and unseen presence manifests at that stage of contemplative prayer. 678

\footnotetext{
676 Keating, Open Mind, Open Heart, 5.

677 Bourgeault, Centering Prayer and Inner Awakening, 32.

678 This identification of subtle-level content as God's formless, unfelt and unseen presence takes place despite there being no specific or additional "God-identification" element in the phenomenologically given, which, according to Pike's theory of theistic mystical experience, must be present. I will return to this claim in Chapter 9. To review Pike's theory of the "God-identification" element in theistic mystical experience, see Mystic Union, 136-53.
} 


\section{Chapter 7}

\section{The Stages of Absorption: Prayer of Union}

My image of God has eroded over time with centering prayer. I realised, "Nothing is left." It wasn't like, "Damn, there is no God." The image and the thought was, "No THING."679

\section{- Rachel}

Union with the presence of God: that paradoxical sense of being embraced by holy presence, yet filled from a centre point. It's both an internal and an external. A sense of somehow being consolidated into the very heart of who I am and yet feeling expanded as well. It's hard to say where one begins and the other starts. There is both... but they are one and the same thing really. ${ }^{680}$

- Joseph

\subsection{Introduction}

Prayer of union is a more intense level of absorption than prayer of quiet. Practitioners are so absorbed that they lose cognitive access to ordinary consciousness. This renders them unaware of any internal or external coarse-level content so that the union state is worldexcluding. Additionally, practitioners' bases of operation are so deeply drawn into the interior depths that they either touch or shift into the divine level of awareness at the centre. This is the place where God dwells and it is characterised by a "sense of presence". In Centering Prayer, "presence" is the way God's presence-absence manifests in divine awareness. In this chapter, I will explore how practitioners phenomenally apprehend this "sense of presence" in prayer of union and discuss why they use paradoxical language to describe their experiences of God's presence-absence.

"Union" is always dualistic, unlike "unity". ${ }^{681}$ However, union states may differ in how explicit their dualistic structures are. For example, a strong dualistic structure instantiates God's presence-absence by way of a strict subject-object polarity (subject is directed at object) and practitioners only sense "presence" in their awareness-perspective (subject-side). In contrast, a weak dualistic structure instantiates God's presence-absence by way of a more diffuse openness (subject is receptive to, and affected by, a horizon). Pike's "doubleinclusion" relation obtains so that practitioners sense "presence" in their awarenessperspective (within) and event-perspective (without). Whether the dualistic structure is strong or weak, the divine level of awareness is structurally bifurcated. Given this structural

\footnotetext{
${ }^{679}$ Rachel, Interview \#26.1, p.34.

680 Joseph, Interview \#5.1, p.26.

${ }^{681}$ To review the term "unity" see Section 3.5 (p.90) and Section 3.7.2 (pp.111-118).
} 
divide, I will pay specific attention to where "presence" is sensed to be in respect to this subject/object divide.

I will present three cases to illustrate how "God's presence-absence" is phenomenally apprehended in prayer of union. My first example, Rachel, has a strong dualistic structure; my second, Carol, and third, Joseph, have a weak dualistic structure. None of them report a "God-identification" element in the phenomenologically given: this means they do not single out an additional and unique phenomenological ingredient as the presence of God. Instead, they point to experiential primitives as the ways in which God manifests in their experience.

I will conclude this chapter with two claims. First, practitioners access God's presence-absence through an apophatic mode of contemplation that "cognises-without" the ordinary human faculties (I discuss apophasis in Section 3.2.1). Therefore, the consciousness involved is typically described as "formless", "imageless" or "of no thing". It contains no "God-identification" element in the phenomenologically given.

Second, the "sense of presence" is an experiential primitive and most likely originates in the practitioner's modus operandi. This aligns with Albahari's phenomenological framework in which witnessing-consciousness: (i) has intrinsic phenomenal character independent of objects; and (ii) is an innate capacity that originates in the subject-side of experience. Albahari's core concept of awareness is the "subjective sense of presence" or just "presence" (see end of Section 2.5.6). In Centering Prayer this "sense of presence" is coterminous with God's presence-absence, being the manifestation of "God in His Divinity" as, and at the centre of, human consciousness.

\subsection{Rachel's Experience of God's Presence in Nothingness}

My first case of prayer of union is Rachel. I introduced her practice in Chapter 4 (Section 4.5.2.1) where she told us that she repeatedly redirects her attention to God's presence.

I am returning to my intention; or I am returning, in a sense, my ATTENTION to God's presence and then saying my word: saying, "I am here."682

When I asked Rachel where her attention goes, she said:

It's going to nothingness. I don't have any sense of an image; I don't have a sense of a felt-presence; I don't have a sense of any emotion... ${ }^{683}$

\footnotetext{
682 Rachel, Interview \#26.1, p.13.

683 Ibid.
} 
Rachel's experience of nothingness is affectless and devoid of coarse-level content: no images, thoughts or emotions. Rachel refers to subtle-level content only to describe the nothingness. For example, she mentions a sense of "the more", an "expansiveness" and "silence". She also has no sense of presence "out there" that is specifically and uniquely "of God” (i.e., Pike's "God-identification" element). When Rachel is spiritually attentive, she is poised in this nothingness while simultaneously aware of a "subtle dialogue" in her eventperspective. This dialogue contains "ephemeral" or "partial" coarse-level content located "below" the centre of her attention. It does not distract her from the features of nothingness (subtle-level content). 684

I will now take a step back to consider the larger picture of Rachel's prayer. My aim is to locate her experience of "God's presence in nothingness" within the dynamics of her practice.

Rachel's prayer typically cycles through the following phases: She is (i) immersed in ordinary consciousness (she says, "It's... the river stuff and I'm way down the stream and I'm kind of bringing myself back." ${ }^{855}$ ); then (ii) slightly retracted from ordinary consciousness (she says, "It's more of... the video going by." ${ }^{686}$ ); then (iii) centred in God's unfelt presence (she is poised in "nothingness", as discussed in Section 5.3.1); (iv) she then detects a subtle dialogue below, which continues to run in tandem with the nothingness (she says, "And then... sometimes there is this... I catch myself involved in this 'subtle dialogue'." 687 ); finally (v) she may eventually get caught up in the dialogue and this will return her to phase one (she says that her practice is about shifting between phases (iii) and (iv) "more or less successfully". When it is less successful, she adds, "Sometimes I get right caught up, immediately, and without even realising it." $\left.{ }^{688}\right)$.

In phases (i)-(ii), Rachel begins to abstract away from ordinary consciousness. In phase (iii), she exclusively apprehends spiritual awareness. In phase (iv), the coarse-level content of ordinary consciousness (surface) returns, but it doesn't result in Rachel losing cognitive access to the spiritual level of awareness (deep waters). This is spiritual attentiveness. Her practice may then go back and forth between being spiritually attentive and submerged in nothingness-only (my term).

I will now continue to explore the third phase of Rachel's prayer where she is submerged in spiritual awareness for periods of time (nothingness-only), and in a way that excludes cognitive access to ordinary consciousness and its coarse-level content (the subtle

\footnotetext{
${ }^{684}$ This paragraph summarises Rachel's spiritual attentiveness discussed in Section 5.3.1.

685 Ibid., p.19.

686 Ibid.

687 Ibid., p.17.

688 Ibid., p.20.
} 
dialogue). Specifically, I will attend to how nothingness is structured and what its relationship to God's presence-absence is.

I begin with structure. Rachel says that in order to return to nothingness, she redirects attention back to the centre. Below, Rachel clarifies where this centre is located.

I have to say, I don't feel like it [the centre] is "here" [as in or around the chest area]. I don't have a sense of physical centre. It's almost like in front of me. And, you know, all this about the Divine within. But I don't have a feeling or even a sense of - when I am practising - of that is happening here [chest], physically. It's kind of like in front of me; in my visual field I guess you could say. 689

When Rachel returns to God's unfelt presence in nothingness, she does not sense or feel "God's presence" (i.e., the unbounded, empty and silent expansiveness) "here physically" (inside her). Rather, she observes nothingness at a distance. She says, "It's kind of like in front of me; in my visual field." Therefore, her awareness-perspective (subject-side) is differentiated from the "nothingness" in front of her, which is located in her eventperspective (object-side). She is a witness to it.

Rachel then expresses confusion about the doctrine of the "Divine within", because she points to an "unbounded, empty and silent expansiveness" in her event-perspective to locate God's unfelt presence. It is what she is aware "of". Therefore, Rachel experiences a felt-separation between herself as a subject, located in her awareness-perspective, and God's unfelt presence, located in her event-perspective.

Throughout my interview with Rachel, I noticed that she only used the phrase "God's presence" once to refer to her experience of "nothingness". I shared this observation with her.

Well, I'm almost tearing up when you said that because I don't. I am grounded. I feel like I am. So I feel like I'm present. I guess, when you use the word "presence" - and I don't know what to make of this either - but I feel like, "I am present to myself. That 'I am' residing in a place within me that is more authentic." So I don't have "felt-presence" - I guess that is what that word means. Well, I could also say my ideas - this goes back to my idea of God rather than being kind of concrete [like], "There is God [she taps a plastic box on the table]." It's like this diffuse sense of, "I am here. I have a presence. I am in this, even though I am not saying, 'I feel like a presence out there."' It's very hard for me to put words to this.

689 Ibid., p.20. 
I will now discuss in greater detail what Rachel told us here.

First, when Rachel attends to God's presence in nothingness she does not feel a presence "out there". There is no additional or unique phenomenological ingredient in her event-perspective that specifically identifies itself as "of God”. Therefore, Rachel's account of God's presence in nothingness contains no "God-identification" element over and above what is already phenomenologically given by the subtle-level content in her eventperspective, which is: silence, empty expansiveness and the like.

Second, God is not present as a specific thing in her event-perspective, like a plastic box would be. Rachel is only willing to affirm "presence", if at all, as a "diffuse sense of I am here. I have presence. I am in this." This means that there is "presence", but it has two important caveats. The first caveat is that this presence is coterminous with Rachel as the subject. It originates in her own realised capacity to be aware (her modus operandi) at the subject-side of experience. The second caveat is that "presence" lacks God-identification. Rachel conceptually affirms this kind of presence to be "of God", but experientially it does not have a unique God-identification feature in the way that it is phenomenologically given.

Third, according to Frenette, who is a well known senior teacher and representative of the Keating School of Centering Prayer, Rachel's experience is an instance of "prayer of union". Consider the following description Frenette offers of prayer of union:

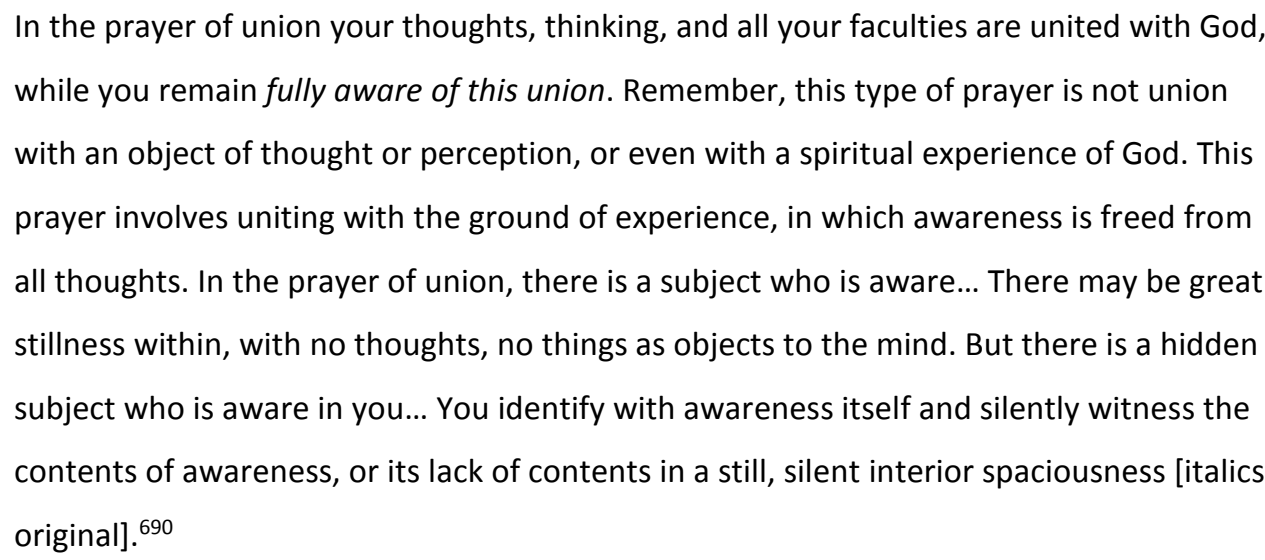

If we accept Frenette's account of prayer of union, then Rachel, who is unacquainted with Frenette's work, is perfectly right to claim two things. First, there is no presence "out there". Frenette agrees that union is not about "a spiritual experience of God". Second, subtle-level content is "in front of her" and "in her field of vision". She, is a self-aware "I-am-herepresence" that silently witnesses an empty expanse. In Frenette's view, "interior

${ }^{690}$ Frenette, The Path of Centering Prayer, 91. 
spaciousness" is a quality of God's formless, unseen and unfelt presence in awareness manifested at the spiritual level of awareness. ${ }^{691}$

Rachel has reflected on her experience of God's unfelt presence in nothingness and she took the opportunity to discuss it during a 10 Day Intensive Retreat with Father Reggie, a Centering Prayer teacher and senior monk at St Benedict's Monastery.

I have talked to Father Reggie about it: I had this image - Why were we talking about God? I can't remember what the context was [she is being self-reflective here] - But, what has changed is my image of God over time. So I had this image - maybe it's because of the mountains; I live near mountains - of eroding. And then I thought my image of God has eroded over time with centering prayer. I realised, "Nothing is left." But then, when I was journaling about it, it wasn't nothing. Like, "Damn, there is no God." The image and the thought was, "No THING." ${ }^{692}$

Later in our interview, I prompted Rachel to tell me more about her encounter with Father Reggie.

Rachel:
Well, I had a walk and talk with Father Reggie. I talked about the fact
that I had this image of God erode away and there is nothing there
[chuckle
Interviewer: $\quad$ Reggie must have been happy?
Rachel:
experience!
Interviewer: $\quad$ [laugh]
Rachel:
In fact, he laughed.
Interviewer: $\quad$ That's what I mean!
Yes. [chuckle]

691 Ibid., 81.

${ }^{692}$ Rachel, Interview \#26.1, p.15. 
Interviewer: I think that is also what Father Thomas means by, "Christian Centering Prayer is about meeting God as He really is, and not as the image we have of Him."

Rachel: Yes! Yes! ${ }^{693}$

Rachel has engaged in sense making about how God is phenomenologically given in her prayer. Her conversation with Father Reggie tells us that her experience speaks true to how the tradition understands God to be phenomenologically given. Rachel's experience of God's unfelt presence in nothingness is orthodox in Centering Prayer. In fact, I would argue that her experience encapsulates Keating's central message for his school of Centering Prayer, namely to meet God as God is and not by way of images of Him. ${ }^{694}$

\subsection{Pike's and Frenette's Accounts of "Prayer of Union"}

We can see centering prayer's apophatic mode of contemplation at work in Rachel's practice. Whatever "God" is in her experience, it is not a "thing" or "object". Her consciousness of God's presence-absence is one that "cognises-without" and bypasses the human faculties of reason, memory and imagination. As McGinn says, apophasis reveals the "absence of God". ${ }^{695}$ It is a way of "seeing" without the human faculties and its object is "God's unseen presence within". 696

According to Pike, union states are phenomenally given with "God-identification". 697 But Rachel's nothingness does not agree with his analysis, because she conceives nothingness to be God's presence even though it is phenomenally given without "Godidentification".

In contrast, Rachel's account of God's presence-absence is consistent with Frenette's treatment of prayer of union (as discussed above) in the following six ways: ${ }^{698}$

First, Frenette considers both the path and the summit of union to be "colored by nothing". ${ }^{699}$ Union is not a "spiritual experience of God", he says. ${ }^{700}$ Therefore, there is no

\footnotetext{
693 Ibid., p.34.

${ }^{694}$ Keating, Consenting to God as God is.

695 McGinn, The Foundations of Mysticism (1300-1500). Vol. I of The Presence of God, xviii.

${ }^{696}$ Frenette, The Path of Centering Prayer, 72.

${ }^{697}$ Pike, Mystic Union, 113-15.

${ }^{698}$ Refer back to fn.690 (p.182) for Frenette's quote. Rachel is unacquainted to Frenette's work and teachings. So her experience could not have been influenced by Frenette's conceptual framework.

${ }^{699}$ Frenette, The Path of Centering Prayer, 77.

700 Ibid., 91.
} 
additional and unique "God-identification" element present through which God's presence is uniquely, phenomenologically given.

Second, Rachel's union has a strong dualistic structure. She retains an eventperspective (object-side) "in front of her" and identifies subtle-level content in that location, such as formlessness and spaciousness. They are in her "field of vision". Therefore, her awareness-perspective (subject-side) in the union state is directed toward the eventperspective (object-side) in a straightforward, subject-object kind of way.

Third, Rachel does not have access to coarse-level content, such as thoughts and environmental stimuli. She is submerged in the deep waters of awareness and has lost touch with ordinary consciousness.

Fourth, Rachel is a silent witnesses in awareness, which is a product of the dualistic structure at work. Frenette and Rachel both concur that prayer of union retains a "hidden veil of self" at the subject-side of experience. This differentiated "I" witnesses subtle-level content at the object-side, such as Rachel's empty expanse.

Fifth, Rachel's basis of operation has touched the divine level of awareness at the centre. This manifests as a "sense of presence" in the subject-side of her experience (without a "God-identification"). She says that she has a "diffuse sense of, 'I am here. I have a presence." This sense of presence is coterminous with her as a subject and it originates in her awareness-perspective (subject-side). It is an experiential primitive. Her presence is the core phenomenal characteristic of her prayer of union, because it is what is most salient: it is the one "thing" that stands out in a backdrop of nothing.

Finally, Rachel does not experience "felt-presence" by which she means a sense of presence "out there" in her event-perspective. Her sense of presence has not spilt over into her event-perspective. Instead, she observes subtle-level content in her event-perspective (interior silence, spaciousness and stillness), which is not a "spiritual experience" of God.701 According to Frenette, this is the way that God's presence-absence manifests at the spiritual level of awareness.

I will now move on to two examples in which the dualistic structure of prayer of union is weak rather than strong. The consequence of a weaker dualistic structure is that the sense of presence extends into the event-perspective.

\subsection{Carol's Witnessing-Presence is God's Presence}

My second case is Carol. I briefly introduced her practice in Chapter 4 (Section 4.3.1). Carol described her practice as an "in and out" dynamic. When she is "in" she talked about "just

\footnotetext{
${ }^{701}$ No practitioner in this study has reported a "sense of presence" exclusively in their event-perspective.
} 
being" or "being in the present"; when she is "out", she wanders off and her prayer gets tough.

I will now focus on the "just being" phase of Carol's prayer. Below Carol reflects on her "in" or "being" phase.

I have a few phrases that indicate what I think centering prayer is, and I think one of them is, "just being", "just being with"; "in the presence of" the Holy, of the Divine; of the Oneness; of the Cosmos; of just BEING. Letting go: totally, totally letting go. Just naked intent... that mean[s] that you just have got to open a bit more to get right down into silence. So it is a naked intent... I see centering prayer as an allowing; a releasing of the Divine that is in me. Of, "I am in God and God is in me." So I see it as a releasing of that, of love. Sometimes I just plain rest in love. ${ }^{702}$

Carol's reflections on the nature of centering prayer offer some insight into her conceptual frame, but we have not accounted for her experience. I prompted Carol about her notion of "presence".

Carol: Well, right now I am looking out the window at a camellia tree covered in red things, and I found myself yesterday looking at that, sensing without having to think about it, just sensing "presence", "wholeness", "oneness", you know, in that camellia bush - that sort of thing.

Interviewer: So when that sense of presence emerges or becomes noticeable, where are you or who are you in that?

Carol: $\quad$ Being the "real me". Being my "true self".

Interviewer: Mh-hm. Is there a sense of you being a witness to that presence?

Carol: I wondered about the internal witness, or whatever it is called. Ahm... yes, I am witnessing it. There is something there that is witnessing that. Definitely yeah.

${ }^{702}$ Carol, Interview \#11.1, pp.4-5. 
Interviewer: $\quad$ Mm... mm... So you definitely have a sense of being in relationship with that presence in that sense - that you are

witness to it?

Carol:

Yes, yeah. ${ }^{703}$

Carol offers this example of how she phenomenally apprehends a "sense of presence" to clarify what she means by "presence" and "being in presence". Let us consider how "being in presence" is structured. Carol says that she has thought about the "internal witness" and that she has related this concept to her own experience. Her teacher, Cynthia Bourgeault, has a great deal to say about the witness in her book Centering Prayer and Inner Awakening, which Carol has read attentively. ${ }^{704}$ Bourgeault even conceives centering prayer as a kind of "witnessing practice".705

Although Carol talked about "just being" earlier on to refer to her sense of presence, her phrase is coterminous with "in the presence OF" and "being WITH". The terms "of" and "with" suggest to me that Carol's "just being" is somewhat structurally differentiated. Consequently, I inquire into her awareness-perspective (subject-side). Carol replies that she is a witness to this presence. Her sense of presence is in some way "other". She has a relationship with it. This means that Carol's sense of the presence is, at least in part, located in her event-perspective (object-side).

I infer from Carol's clarification that her term "just" is not a structural qualifier of her experience, but describes its manner. "Just being” or "being with presence" appears simple: there is no "technique" or "method" involved in sensing presence. For example, she doesn't have to think about it and she says that she "just senses" it.

I will now gather more data from Carol to then return to the question of how "being with presence" or "just being" is structured.

After four to five years of centering prayer, Carol noticed a natural deepening process in which she moved out of the gut and into the heart. ${ }^{706}$ She doesn't think that it happened deliberately. What she does know is that she feels more authentic in her heart.

Interviewer: When this "being with presence" deepens, how do you know that it deepens? What is the characteristic of it deepening?

\footnotetext{
${ }^{703}$ Carol, Interview \#11.1, pp.6-7.

704 Bourgeault, Centering Prayer and Inner Awakening, 113-50.

705 "Centering Prayer as witnessing practice," 261-73.

${ }^{706}$ Interview \#11.1, p.13.
} 
Carol:

I am stiller... I often feel a coming out from the area of my heart...

Yeah. Now I find that I centre myself in my heart. I feel more authentic

in my heart... There is a place in your actual physical heart that is

where the holy is, where God is.707

Interviewer: I am very interested in being "authentic in the heart". When you talk

about being "with presence", and you talk about "being in the heart",

and you talk about "feeling authentic in the heart", how personal does

that feel? How "personal" is the feeling of "you" in that? ${ }^{708}$

Carol: I think it is totally personal.

Interviewer: Right. Do you experience "God being in you", this "God being in me" aspect when you are "being with presence"?

Carol:

Yes, that is the same thing. ${ }^{709}$

When Carol's practice deepens, she centres in her heart and feels more authentic and present in a totally "personal" way. ${ }^{710}$ This personal, subjective sense of presence is the same thing as "being with presence". Furthermore, Carol says, "being with presence" is coterminous with "God being in me". Therefore, Carol's "just being" blurs the lines between the awarenessperspective (subject-side) and event-perspective (object-side).

The fact that Carol describes a "sense of presence" to be located in her eventperspective and in her awareness-perspective (subject-side) indicates that her payer of union has a weak dualistic structure: the divide between subject- and object-side of experience is vague. Most importantly, Carol's sense of presence is not exhausted by it being located "out there". She is clear that this quality is also "in me".

I will now consider what relationship exists between "God being in here" at the subject-side and Carol being a witness to a presence at the object-side of her experience.

\footnotetext{
707 Ibid., pp.11-12.

${ }^{708}$ I used the term "personal" in the ordinary, pre-theoretical sense that pertains to "the identity or felt-being of the experiencing subject". I did not use the term in a special, theoretical sense that relates to notions or experiences of God where the term "personal" indicates "having the qualities of a person". I interpret Carol's reply below to be consistent with my use of the ordinary, pre-theoretical sense of "personal". 709 Ibid., pp.13-14.

${ }^{710}$ I mean the ordinary, pre-theoretical sense of "personal" as defined in $\mathrm{fn} .708$ above.
} 


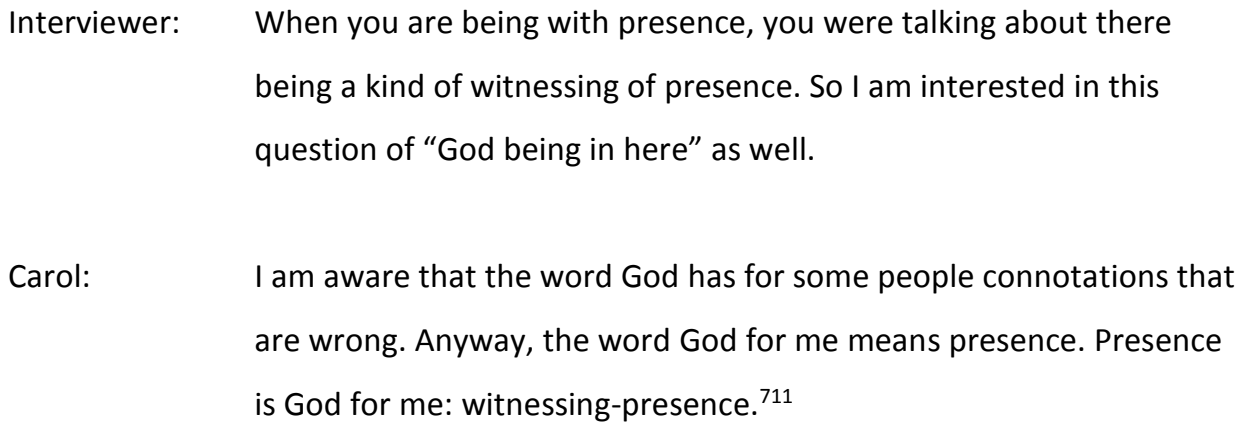

Carol tells us how her personal and authentic witnessing-presence is related to her phrase, "I am in God and God is in me". Earlier on, she said that in her experience of "being with presence" there is something that witnesses that presence. This refers to this witness as her own authentic personal presence. Her experience is clearly dualistic and relational, but not in a straightforward way.

Carol told us that when her practice deepens, she centres in the heart: that is where she feels herself being. ${ }^{712}$ She also says that this is the same place where God is (see second to last exchange). Finally, in the exchange above, Carol tells us that her subjective witnessingpresence (that senses God's presence) is itself God. ${ }^{13}$

Carol's experience of presence is dualistic. Her awareness-perspective (subject-side) is differentiated from her event-perspective, because she senses, at least in part, "presence" at a distance to her vantage point. I suggest that "presence" has extended into her eventperspective (object-side). At the same time Carol centres in the heart during deep prayer. This is where God is. It is also place from which she witnesses God's presence. Therefore, God's presence is both within and without; it is at a distance from her heart and located in her own witnessing-presence that originates in her heart.

In Chapter 4, I discussed how Carol uses her sacred word. Carol explained that she allows herself "to be as much in presence as I can be in presence". She said that it is exposing rather than reaching. "When I'm naked I am exposing my God-self," she said. Since Carol frequently refers to "being naked" as a matter of her own being present, and because she phenomenally apprehends her own personal witnessing-presence as God's presence, I suggest that Carol's sense of presence is mediated by a weak dualistic structure (broad type of intentionality).

In intentional terms, weak dualism is broad at the divine level of awareness. Carol's sense of presence definitely includes a quality of "otherness", but it is not solely located in her event-perspective. The way she is available to "presence" also indicates that her attention

\footnotetext{
711 Ibid., pp.14.

712 Ibid., 11, 13, 17.

${ }^{713}$ Carol is an avid reader and student of Bourgeault. The way Carol is treating witnessing-presence here is consistent with Bourgeault's treatment of the concept.
} 
is not directed towards an "other" in a straightforward way. Specifically, Carol's "being with" and "just being" appears relational (as in "available", "open" and "present to") but not directed (as in "reaching outward") to a sense of presence in her event-perspective. Therefore, Carol's subject-side is open (broad) rather than directed outward (narrow).

The picture that Carol paints is consistent with Pike's account of "full union with God" (henceforth, "prayer of union").714 According to Pike, a dualistic structure persists in prayer of union, but both the awareness- and event-perspectives are "drenched through" in a "mutual embrace" or "double-inclusion relation".

The "double-inclusion" relation captures two things about a dualistically weak type of prayer of union. First, it describes how a "sense of presence" is apprehended within and without. Specifically, Pike says that in prayer of union, "God is not only within the soul's domain but within the entity itself." 715 This is true in Carol's experience. She is both witness to God's presence and God is in her witnessing-presence.

Second, the divine level of awareness is not a singularity. It remains structurally bifurcated into a subject- and object-side despite God's presence being located at each side of the divide at the same time. Yet the gap has been closed. It has been closed in phenomenal character, not structure: both perspectives are "penetrated" or "drenched through" by a sense of presence that unifies the phenomenal quality of each side of the divide. ${ }^{716}$

\subsection{The God-identification Element in the Phenomenologically Given}

Like Rachel, Carol's account is consistent with Pike's structural analysis, but not his critical "God-identification" theory about its phenomenal character.

Pike argues that union states are theistic experiences. By "theistic" Pike means that the phenomenal character of union is uniquely and specifically "of God". Thus union includes as part of its phenomenology "an identification element of consciousness" in which "God in his Divinity" is non-inferentially "given", "known" and "experienced". Godidentification is a phenomenological matter and not an epistemic inference. ${ }^{17}$

Carol's case does not support Pike's theory. She tells us that her sense of her own "witnessing-presence" is God. Her account does not appeal to anything other than a "sense of presence" that is an experiential primitive and coterminous with her own subjective sense of presence.

\footnotetext{
${ }^{714}$ Pike's "full union with God" is equivalent to "prayer of union" in Centering Prayer. I use the latter to remain consistent with the terminology of the Centering Prayer tradition.

715 Pike, Mystic Union, 10.

716 Ibid., 7-11; 29; 115; 57.

717 Ibid., 136-53.
} 
Carol adds an important clarification: In her view, people understand God in ways that are wrong. She insists that God is not uniquely phenomenologically given. Rather, her own witnessing-presence and, alongside it, a more holistic sense of presence is given - that is what she means by God.

\subsection{Joseph's Sense of Presence in Prayer of Union}

My final case of prayer of union is Joseph. I introduced his practice in Chapter 4 (Section 4.3.2). Joseph's practice negotiates two different senses of self: a sense of self that is responsible and acts (the "reductionist me") and a sense of self that "just is" (the "bigger-selfI-am", “isness" or "just being”).

Joseph treats "just being" as coterminous with God's presence. He says that there is no real difference between the two and that they are hard, if not impossible, to separate out. ${ }^{18}$ Furthermore, Joseph is aware of God's presence when his own sense of "just being" or "isness" is available. They go hand in hand. Consequently, Joseph's seated prayer focuses on "being available", which involves losing cognitive access to the ordinary level of consciousness. Below is a summary of Joseph's musings about this, and the relationship that exists between "isness" and God's presence during seated prayer.

\footnotetext{
I have experienced myself trying to make myself available! [amused] But it would seem to me that my actual availability is my being in that "isness". The attempts to make myself available sometimes do not generate availability because they are conscious actions. $^{719}$

At some part of my being, I try to let it go: the consciousness that this isn't happening - the "I am not connecting". It's a movement, trying to get out of consciousness. A consciousness of random thoughts I am having; the consciousness of what I am actually doing right now and the awareness, the self-awareness, of, "I am sitting here. Look! This is the current number [chuckle]." It is THAT STUFF I want to lose; that stuff I want to get lost, because when I am in that stuff, I am not conscious of the holy presence. ${ }^{720}$
}

I knew it [union] had happened, because it was "just there" and this IS part of me: what is expanded - not the slightest bit conscious of anything physical or mental. ${ }^{721}$

\footnotetext{
718 To review Joseph's identification of "just being" (p.128) and his "bigger-self-I-am" (p.127) with the "presence of God" refer to Section 4.4.2.1 and Section 4.4.1.1.

719 Joseph, Interview \#5.1, p.18.

720 lbid., pp. 21-22.

721 Ibid., p.17.
} 
It's not a "thing". It just is [chuckle]. "Abide in me as I am already abiding in you." 722

I want to connect with this presence, but actually it's there at the very heart of my being. There is nobody out there [laugh]. It's a sense of "coming home" to the one who is already at the very heart of my being, because I am all. So to come home to that holy presence within, it's also to come home to "me". So there is the sense of the unity there. ${ }^{723}$

It's both. It's never one thing. It's always "both-and-more-than". This is what I'm talking about: that, again, paradoxical sense of being embraced by Holy presence, yet filled from a centre point. It's both an internal and an external; a sense of "both/and": of somehow being consolidated into the very heart of who I am, and yet feeling expanded as well [chuckle]. ${ }^{724}$

Above, Joseph tells us that conscious actions are actually counterproductive, because they detract him from "just being". Consequently, he focuses on short-circuiting self-defeating processes. To this end, he "lets go" of cognitive access to the ordinary level of consciousness in which such actions occur. When Joseph succeeds, he loses touch with ordinary consciousness. He says that he is "not the slightest bit conscious of anything physical or mental". Thus he is not aware of internal or external coarse-level content.

At the same time, Joseph's basis of operation feels expanded and senses "presence". Presence is not a "thing" in his event-perspective. To the contrary, his sense of presence is "within", "abides in me", and it is "there at the very heart of my being". Therefore, his sense of presence is located, at least in part, in his awareness-perspective (subject-side).

When Joseph senses presence, he feels consolidated in the very heart of who he is and "more than". He talks about a paradoxical sense of "being embraced" and "filled from a centre point". This indicates that a double-inclusion relation is structurally at work. Both the subject-side and object-side of his experience are drenched through, or sopped by, a sense of presence.

Joseph's language suggests that his prayer of union has a weak dualistic structure. First, his attention appears open rather than directed to the other in a subject-object way. For example, his term "embrace" suggests that his subjectivity is open and affected rather than directed toward an "other" in a subject-object manner. When Joseph refers to an "external" sense of presence, he does so in a way that suggests he is affected by it rather than attending to it.

\footnotetext{
722 Ibid., p.24.

723 Ibid., pp.24-25.

724 Ibid., p.26.
} 
Second, he talks about "isness" filled with a sense of presence from a centre point (internal, subject-side). This felt sense of presence extends into the "more than" (external, object-side). Thus he speaks of a "bigger-self-I-am" that feels expanded and which blurs the boundary between self and other (the horizon of his subjectivity).

The fact that Joseph's sense of presence in prayer of union is dependent on, and in some way coterminous with, his own sense of availability (his “isness" or "bigger-self-I-am"), coupled with the fact that the dualistic structure in question appears openly intentional rather than narrow, suggests to me that his "sense of presence" (or "divine presence", or God's presence") originates in Joseph's awareness-perspective (subject-side) and not in his event-perspective (object-side).

The hypothesis that God's presence originates in the practitioner's basis of operation (subject-side) conflicts with Pike's analysis of prayer of quiet in which God's presence is phenomenologically and exclusively given in the practitioner's event-perspective (objectside) and in a subject-object directed way (narrow intentionality).

But no practitioner in this study has reported a sense of presence outside without also sensing presence inside. If God's presence-absence is reported to be "outside" in the eventperspective only, then God's "presence" refers to the subtle-level content of spiritual awareness, which is an experiential primitive without an objective "sense of presence". Such an objective "sense of presence" has only been reported by practitioners if and only if they also have a subjective sense of presence - being present as subjects - that is explicit.

Finally, Joseph's account suggests that God's presence is not identified by him through an additional and unique phenomenological ingredient separate from his own presence as a subject. There is no "God-identification" element in the phenomenologically given. Joseph's terms refer to basic experiential primitives, such as his sense of "isness" and "just being". This should caution us from inferring more about the phenomenal character of "presence" than is reported. This is especially the case if God's presence is by and large held by practitioners to be coterminous with their own felt sense of being present (subjective presence).

\subsection{The Dualistic Structure of "Prayer of Union" and Joseph's Paradoxical}

\section{Language}

Joseph's account and Pike's analysis suggest that when "prayer of union" has a weak dualistic structure, "presence" is experienced as a "double-inclusion" relationship. Doubleinclusion is prima facie paradoxical. On the one hand, Joseph indicates that union involves an awareness of himself and another. On the other hand, Joseph rejects any distinction between the sense of presence in his event-perspective (object-side) and his sense of "isness" 
in his awareness-perspective (subject-side). Therefore, "isness" and presence are both consolidated at the centre of his being and expand his being. He says that they are "bothand-more-than". The "more than" aspect suggests a lingering sense of "otherness".

I have two suggestions about this tension between Joseph's relational ("dualistic") language and his claims that there is no-separation or no-distinction in respect to the relationship that exists in his experience between his subjective sense of presence and his objective sense of presence. 725

First, I suggest that practitioners' language reflects the complex double-inclusion relationship that is at work in prayer of union with weak dualistic structure. In doubleinclusion, the "phenomenal structure" of union is separated, but the "phenomenal character" is unified. ${ }^{726}$ Pike argues, on the one hand, that, the phenomenal character of the awarenessand event-perspectives are "drenched through" with a sense of God's presence in prayer of union. Hence they are in a "mutual embrace" or "double-inclusion" relation. On the other hand, the phenomenal structure between subject-side and object-side does not completely collapse. The self retains a sense of itself while being in "mutual embrace" with a vague sense of "otherness". Therefore, both perspectives remain structurally differentiated while also "penetrated" or "sopped” by a sense of God's presence, which unifies their phenomenal character. In this way, "double-inclusion" has a complex phenomenology. In sum, I hypothesise that this unitive phenomenal overlay across both sides of the divide encourages Joseph (and other contemplatives) to resist separating their subjective sense of presence (in their awareness-perspective) in nature from their objective sense of presence (in their eventperspective), because both are imbued with the same felt-quality of "presence".

Second, I suggest that Joseph's dualistically weak structured prayer of union creates a vague sense of "otherness", which further blurs the lines between subject-side and objectside. Recall that Joseph's sense of presence embraces, penetrates and expands him. This reflects a "broad" type of intentionality that renders his consciousness structurally open to a non-physical "inner" horizon. His broad (open) intentionality gives him a more diffuse sense of outer horizon than a narrow (directed) intentionality would afford (strong dualism). Therefore, when subjectivity is "open", awareness is more diffuse. A diffuse awareness coupled with Joseph's feeling of being expanded make it more difficult for him to clearly

\footnotetext{
${ }^{725}$ To review Joseph's claims that there is no-separation/no-distinction refer back to Section 4.4.2.1 (p.130).

726 "Phenomenal structure" refers to the architectural aspects of consciousness, which include: (i) its mode, being intentional (narrow or broad) or nonintentional; (i) how many levels of awareness are operative; and (iii) where the basis of operation is located. "Phenomenal character" refers to the qualitative aspects of consciousness and its content. This includes: (i) how lucid awareness is; (ii) how intense and vivid its features are; and (iii) how clearly content appears and its characteristics. I discuss the "intrinsic" phenomenal character of witnessing in Section 2.5.6 (pp.40-41).
} 
demarcate the contact point between awareness- and event-perspectives. This is reflected in his language.

If we approach Joseph's paradoxical language with my two suggestions in mind that (i) "drenched through" awareness- and event-perspectives phenomenally unify their nature, and (ii) weak dualism is governed by a more diffuse, and sometimes expanded sense of, awareness, then Joseph's language is prima facie paradoxical but intelligible under scrutiny.

\subsection{Conclusion}

In this chapter I have explored where God's presence-absence is located and how it is phenomenally apprehended in prayer of union. I discussed Rachel's, Carol's and Joseph's experiences of prayer of union, which they encounter only during seated prayer. It is a deep level of absorption that diminishes cognitive access to ordinary consciousness. They do not phenomenally apprehend internal or external coarse-level content, which renders them unaware of an event-perspective (object-side) at their ordinary level of awareness. Internal coarse-level content (thought) is absent, because their faculties are submerged in absorption and no longer act on their own terms. External coarse-level content (sensory awareness) is absent too, because the conditions that seated prayer provides minimises bodily selfawareness and causes scarcity of external sensory stimuli.

Prayer of union may be instantiated by way of a strong or weak dualistic structure. In strong dualism, a practitioner's basis of operation touches the divine level of awareness and thus phenomenally apprehends a vivid, subjective sense of presence within only. At the same time, the awareness-perspective is directed towards (in a subject-object kind of way) the event-perspective of the spiritual level of awareness. This brings into view subtle-level content, such as: interior silence, interior spaciousness and interior stillness. These features are the ways that centering prayer teachers and practitioners view God's presence-absence to manifest in their experience. They experience such subtle-level content without an additional and unique "God-identification" element in the phenomenologically given. In weak dualism, a practitioner's basis of operation shifts into the divine level of awareness. Consequently, she apprehends a salient sense of presence within and without. The awareness-perspective is available and open to the event-perspective by way of a more diffuse awareness. For example, Carol reports being "naked" in a state of awareness that is receptive rather than reaching outward.

Pike's double-inclusion relation also obtains in weak dualism. First, Joseph reports how his perspective-lending locus (awareness-perspective) feels expanded and available. He cannot clearly demarcate his subjective sense of presence (in here) from his objective sense of presence (out there). Consequently, he feels as if the sense of presence "out there" is a part 
of him, and that his sense of presence "in here" is a part of the "more than". Second, Carol's and Joseph's accounts suggest that the divine level of awareness is structurally differentiated. At the same time, both sides are overlaid with a unifying phenomenal character of "presence". Each side appears to share in this same nature. The phenomenal character is of a "sense of presence" equivalent to practitioners' subjective sense of existence, which is an experiential primitive. It does not reflect an additional and unique "Godidentification" element in the phenomenologically given.

Finally, when practitioners' bases of operation touch or shift into the divine level of awareness at the centre they phenomenally apprehend a "sense of presence", either within (touch) or within and without (complete shift). Never outside only. I thus hypothesise that the sense of God's presence-absence originates in the awareness-perspective (subject-side) and may spill over into the event-perspective (object-side), rather than the other way around. This aligns with Albahari's phenomenological framework in which the "subjective sense of presence" or just "presence" is an experiential primitive and the core concept of awareness that originates in practitioners' modi operandi at the subject-side of their experience. 


\section{Chapter 8}

\section{The Stages of Absorption: Prayer of Full Union}

The realisation of nothingness is not when I am in it. It's when I come out of it. ${ }^{727}$

- Lawrence

[Before] I get back to consciousness, I am in between. No sense of time! No sense of self. None. I have a sense of space when the bell rings. Then I know that I'm sitting where I am. ${ }^{728}$

- Martin

In that featureless expanse, there is no subject-object. It's just being: just being there. There is no sense of my being there as "me". There is no self-consciousness or self going on. It's existence. In a kind of pure state. ${ }^{729}$

- Joseph

\subsection{Introduction}

Prayer of full union is the highest level of absorption practitioners experience during seated prayer. Their basis of operation not only touches or shifts into the divine level of awareness at the centre, but is completely lost in it. Thus the subtle sense of self that persisted in prayer of union disappears. Keating says, "Grace takes away all self-reflection... Not only does the Spirit suspend the ordinary reflective faculties, but even suspends the sense of an individual self." $7{ }^{\circ}$ Consequently, the "phenomenal structure" of full union collapses the gulf between self (soul) and God's presence. ${ }^{731}$

Full union occurs in relatively short intervals. Pike conceives it as the "mystical peak" or "climax" of contemplative prayer. ${ }^{732}$ It is time limited and not always realised.733 Keating concurs. "Full Union does not last long," he says, "however, it may be repeated at various levels of intensity in the same period of prayer." 734 Even though full union is a climax interval of prayer, Keating has observed that "it may happen only once or twice in one's lifetime," or "it may also subside after a period of great frequency and then stop altogether." 735 Both agree that full union is short lived.

\footnotetext{
727 Lawrence, Interview \#21.1, pp.20-21.

728 Martin, Interview \#22.1, pp.18, 20-22, 24.

${ }^{729}$ Samuel, Interview \#24.1, p.13, 15, 19-20.

${ }^{730}$ Keating, Manifesting God, 112.

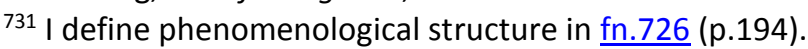

732 Pike uses the phrase "union without distinction" to refer to "full union". Mystic Union, 115.

733 Ibid.

${ }^{734}$ Keating, Manifesting God, 112.

735 Ibid.
} 
In this chapter, I will examine the phenomenal character of this climax interval by way of three examples. Specifically, I will focus on two points of interest. First, I will explore how lucid and wakeful practitioners are during an interval of full union. By "lucid" I mean how percipient practitioners are of the state of consciousness they are in. I consider this a matter of "state-awareness". Second, I will attend to the degree to which practitioners phenomenally apprehend a sense of separate and individual self in full union. I consider this a matter of their "awareness of self-as-subject".

My strategy will be to present three cases of full union. Those are: Lawrence (nonlucid), Martin (non-lucid) and Samuel (lucid). I will then review the phenomenal character and structure of full union and suggest that lucidity tracks the degree to which stateawareness is operative and that this moderates the phenomenal character but not structure of prayer of full union. Finally, I will conclude that God's presence manifests in full union as a featureless and pure awareness that is phenomenologically of an unidentified reality.

\subsection{Lawrence's Realisation of Nothingness}

My first case of non-lucid full union is Lawrence. In Chapter 5 (Section 5.2.1) I introduced his practice session, which he completed on the day of the interview. Lawrence said that he lost sense of time. Nevertheless, some thought occurred in his prayer. He observed those thoughts from a distance with a differentiated awareness-perspective. He was spiritually attentive and for periods of time in prayer of quiet (see Section 6.4).

Something else happened in his prayer session. There were moments when he had "no thoughts". Lawrence says that this is a rare phenomenon.

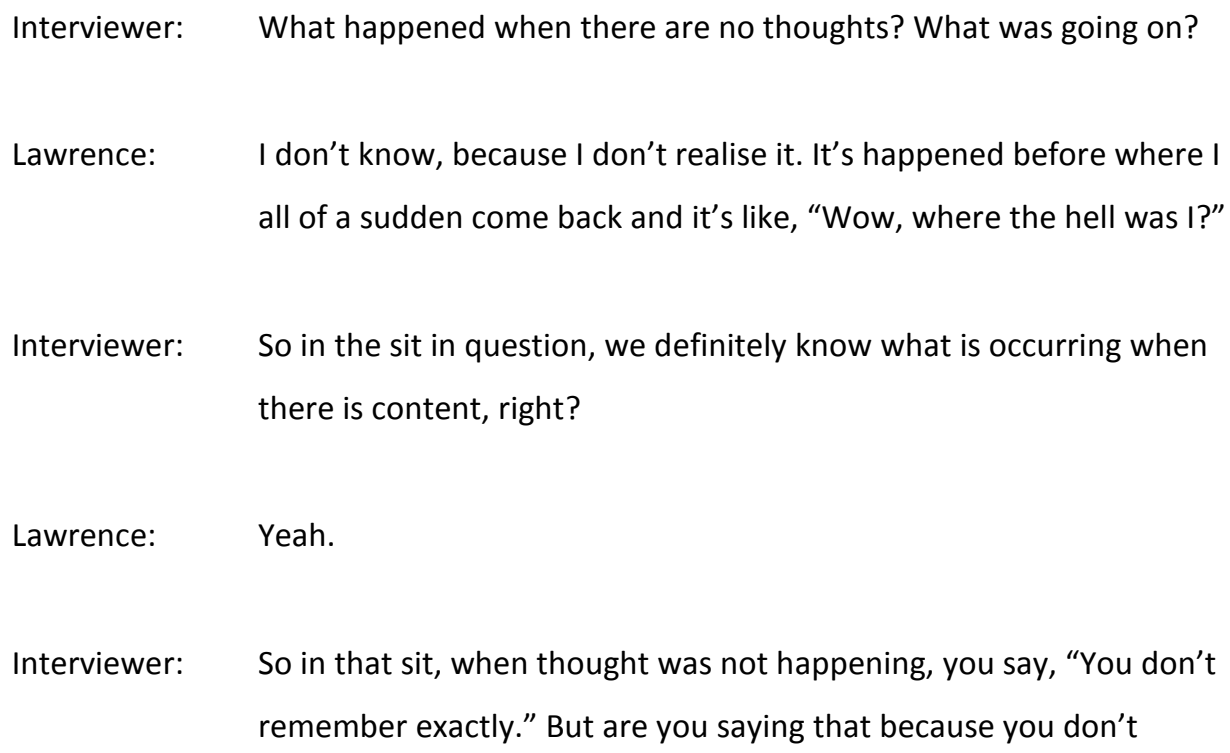


remember thinking something in between, or because it is too difficult to describe?

Lawrence: $\quad$ Oh...

Interviewer: I'm trying to get a sense of what might have happened between the thoughts. Another way of asking: When thought "suddenly" occurred, was it then that you suddenly knew that you were there and before you-

Lawrence: $\quad$ Say that again!

Interviewer: You suddenly knew that you were there and you were aware and you didn't know that before?

Lawrence: $\quad$ Yes. Yes.

Interviewer: Right.

Lawrence: $\quad$ Yeah, the realisation of... of - I will call it "nothingness".

Interviewer: Alright. Mh-hm.

Lawrence: The realisation of nothingness is not when I am in it. It's when I come out of it. And it's a rare occurrence.

Interviewer: So the realisation of nothingness, right, are you conscious while that is happening? While the nothingness is happening, are you awake?

Lawrence: $\quad$ Oh... wow......ahm... I don't know. Usually it feels, because it is a rare thing, usually it feels like I am coming out of a sleep.

Interviewer: Is it like you are also becoming aware?

Lawrence: $\quad$ Yes.

Interviewer: Has that kind of realisation of nothingness happened before? 
Lawrence: $\quad$ Yes.

Interviewer: Was there a moment when it happened that was salient?

Lawrence: $\quad$ Yes. $^{736}$

We will return to Lawrence's salient moment below. I will first comment on what Lawrence has shared so far. He has told us that his prayer contained episodes he labels "nothingness". During those intervals he is unaware and appears (in his own eyes) absent. He then realises that he has been in a state of nothingness when he becomes aware again (I cannot determine whether he realises or infers that he was absent). The process of "becoming aware" is similar to coming out of sleep, but sudden. This indicates that the interval is not lucid or wakeful.

I will now consider Lawrence's particularly salient moment of "nothingness". In the interview, Lawrence and I returned to the first time he experienced this "nothingness". He was facilitating a prayer sit for a men's group at the time, in a meditation room at $\mathrm{St}$ Catherine's.

The first time it happened it was very distinct, probably three to five years ago. I started the session with a strike (a gong) and a reading. It was very similar to today. I was gone. I was just gone. And all of a sudden just "boom” I was present again. And I wasn't asleep! Maybe I was asleep, I don't know. [laugh] But it was that feeling again of being just in the right place. I became aware with a bit of a shock like, "Ugh, where was I?" The shock is like somebody sneezing and me coming back to thoughts. Maybe "shock" is not the right word: it's the sudden end or the sudden realisation that I was someplace else. So I would say from this morning's experience to past experiences - and it is rare - it's also the same. Then the whole pattern: thoughts coming into my head and using the sacred word. So awareness comes into being with thought and I am not aware before. Then the lights are turned on. I use the symbol to get back to the place of non-awareness. ${ }^{737}$

In Lawrence's second account, he reconfirms that "nothingness" is characterised by phenomenological paucity. By "phenomenological paucity" I mean that there is little to nothing that a subject is aware of such that experience is hardly about anything - only few, if any, noteworthy features define conscious awareness. I observe the following.

First, Lawrence told me earlier in the interview that "nothingness" is rare, but he values it enough to orient his practice around returning to it.

\footnotetext{
${ }^{736}$ Lawrence, Interview \#21.1, pp.20-21.

${ }^{737}$ Ibid., pp.21-25.
} 
Second, Lawrence describes nothingness as a state of non-awareness. He is not aware of nothingness when he is in that state. He is not lucid. He says, "I am not aware before... awareness comes into being with thought." He describes his subjective sense of presence (our core concept of "awareness") as absent and then present. It is not the case that his awareness persists but without content. Therefore, Lawrence's nothingness does not mean that " $\mathrm{X}$ is devoid of $\mathrm{Y}$ " where " $\mathrm{X}$ " stands for his awareness and " $\mathrm{Y}$ " for content. Rather, his nothingness means " $\mathrm{X}$ is devoid of $\mathrm{X}$ " or simply " $\mathrm{X}$ is void". I suggest that " $\mathrm{X}$ is devoid of $\mathrm{X}$ " phenomenologically entails " $\mathrm{X}$ is devoid of $\mathrm{Y}$ ".

Third, despite being in a non-aware state of nothingness (" $\mathrm{X}$ is devoid of $\mathrm{X}$ "), Lawrence claims that he is not asleep. He is not certain about this, but he is reluctant to consider sleep.

Fourth, his return to awareness is sudden and it is concomitant to regaining cognitive access to content. He says that he "all of a sudden" becomes aware again. "Just 'boom', I was present." He then specifically uses thought (internal coarse-level content) as an example of the kind of content that ignites awareness. But the content could also be something like the gong (external coarse-level content) at the end of a sit.738

In sum, Lawrence's nothingness is marked by strong phenomenological paucity, because he is not particularly lucid. The absence of lucidity in Lawrence's state stops him from having cognitive access to subject- and object-sides of all levels of awareness (ordinary, spiritual and divine).

\subsection{Martin's "Liminal Space” When He Rests in God}

Martin is my second case of prayer of non-lucid full union. I briefly mentioned him in Chapter 5 (Section 5.2.3). Martin has been a contemplative for 20 years and his centering prayer practice shifts between being spiritually attentive and entering into union states, specifically full union, which may last for the entire 20 to 30 minute prayer session.

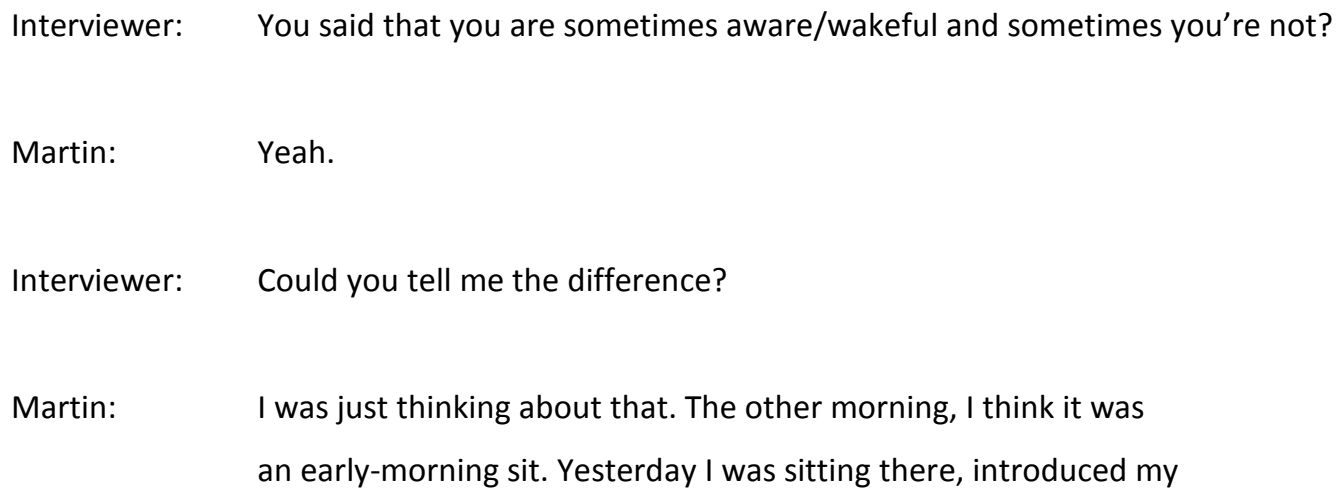

${ }^{738}$ Ibid., pp.13-14. 
sacred word and then the next thing I remember was the bell... I didn't have any recollection of having snored. No sense of time! None. None at all!

Interviewer: Are you telling me that you weren't necessarily wakeful either?

Martin: $\quad$ I'm not sure. I think you go into a liminal space at times when you are sitting in silent prayer. You get to a place where you are not asleep and you're not awake. And that would be a sign that I possibly have just entered into contemplative prayer experience. I mean, the whole idea is to rest in God. I mean that is the whole point of centering prayer: resting in God.

Interviewer: Right, right, right. Do you experience your body sitting?

Martin: It's unconscious. I'm in a comfortable position, seated position, so that I won't notice it.

Interviewer: And do you have a sense of self?

Martin: $\quad$ No. No sense of self. None.

Interviewer: Is stillness in that liminal space?

Martin: $\quad$ There is nothing moving in that liminal space. It's very still.

Interviewer: What about space? Is there a sense of space?

Martin: I have a sense of space when the bell rings. Then I know that I'm sitting where I am. When I know that, "Oh yeah, I sat down 20, 30 minutes ago to do a Centering prayer session."

Interviewer: Yeah, yeah. And then your sense of self returns, in that sense?

Martin: $\quad$ Mh-hm [confirming]. And THAT's why... that's why Thomas recommends the two minutes of waiting before you... you don't just bounce up and get going. You know. You just kind of, “Oh, okay, let me get back into the space-time continuum here." 


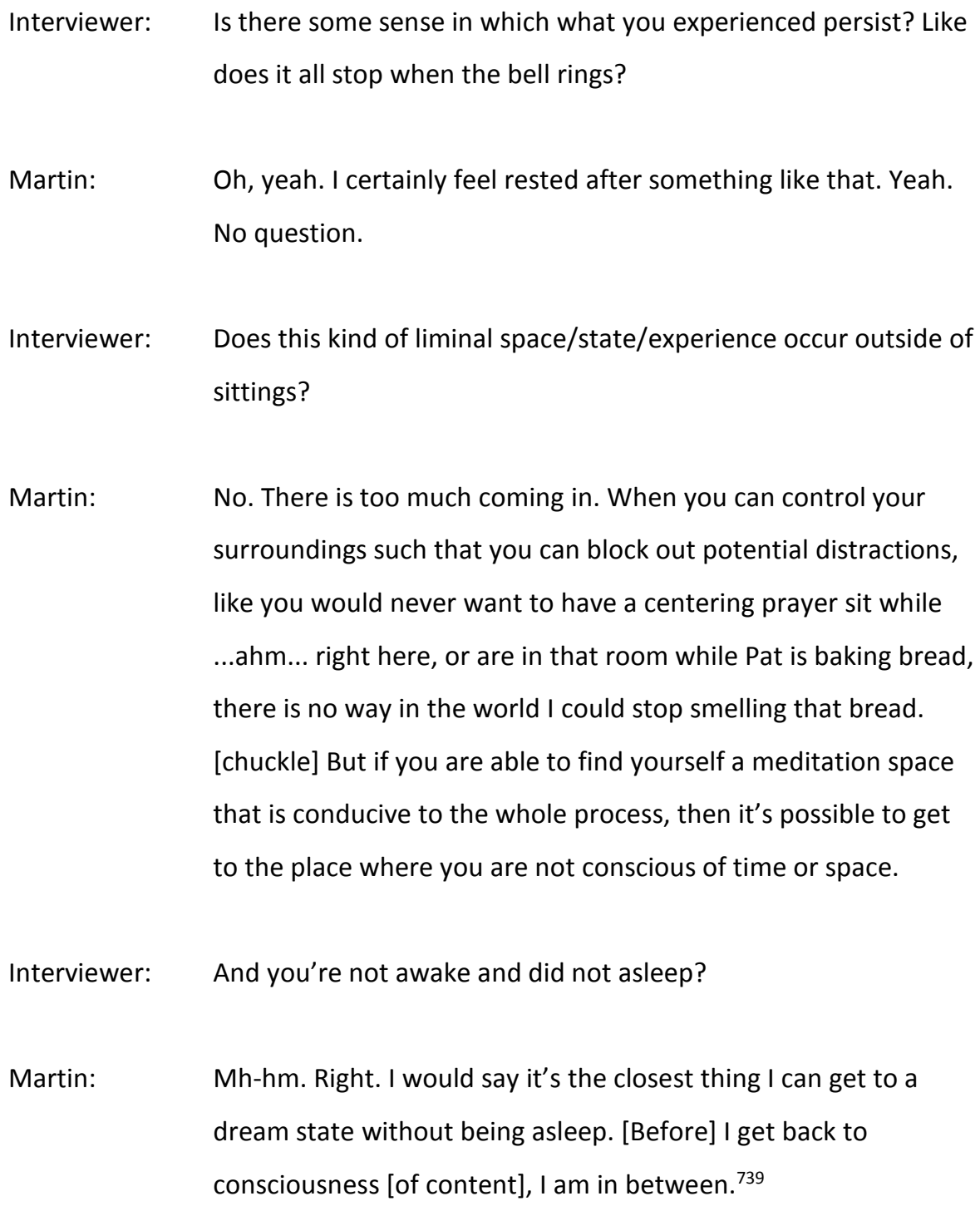

In the above exchange, Martin discusses how resting in God involves a "liminal space" in which he loses cognitive access to all levels of awareness: ordinary, spiritual and divine.

In respect to the ordinary level of awareness, Martin tells us that he does not notice any coarse-level content. He is unaware of his body and environment. He also insists that he can only experience this liminal space if and only if there is no sensory input from his environment. Consequently, he recommends that practitioners seek out suitable environments for prayer.

In respect to the spiritual level of awareness, Martin is not aware of space or time. The state is completely still and this fact supports his inability to be aware of anything. Movement would appear to bring him back into conscious awareness and grant him cognitive access.

${ }^{739}$ Martin, Interview \#22.1, pp.18, 20-22, 24. 
In respect to the divine level of awareness, Martin senses neither "presence" in his awareness-perspective (subject-side) nor in his event-perspective (object-side). In fact, his capacity to be aware (modus operandi) appears unrealised.

Martin's "liminal space" is marked by a peculiar lack of wakefulness and phenomenological paucity. For example, he is adamant that he does not notice anything, even the fact that he is in this liminal space. As for Lawrence, his liminal space appears to mean " $\mathrm{X}$ is devoid of $\mathrm{X}$ and $\mathrm{Y}$ ". It is not lucid.

However, Lawrence's account seems to imply that, if his state were not so still, he would notice this and emerge out of the liminal space. Because it is thus at least possible for him to notice something, i.e. become aware, it is not an "unconscious" state. Like Lawrence, he insists that he is not asleep. So he describes this liminal space as an "in between" state that is neither entirely conscious, nor unconscious as in sleep.

I observe two critical facts about Martin's prayer of union:

First, he only becomes aware that he is sitting in prayer when the bell rings. This calls him back into consciousness. Before that moment, he neither senses time passing nor is aware simpliciter (lucid). He does not have cognitive access to the state he is in. Therefore, one peculiar feature of his "in between" state is that it is not cognisant of itself: "X is devoid of X”.

Second, the state is not only non-self-aware in the sense that Martin lacks stateawareness, but he is also non-self-aware in the sense that he is not reflectively aware of himself as a subject. He has no sense of self (subject-side of experience). Thus his modus operandi appears inoperative and he lacks a subjective sense of presence (our core concept of awareness). Consequently, his liminal space excludes both an awareness- and eventperspective. Martin's conscious awareness ("state-awareness") and his self-reflection ("awareness of self-as-subject") only return when content enters the picture. This turns the lights back on.

I will now turn to my final case of prayer of full union. This example is different, because the state is lucid and wakeful: " $\mathrm{X}$ is devoid of $\mathrm{Y}$ " only, but " $\mathrm{X}$ " is not itself void.

\subsection{Samuel's "Featureless Expanse"}

Samuel is my third case of prayer of full union, but in his case, the state is lucid. I introduced his prayer in Chapter 4 (Section 4.4.2.2). I return to the period in Samuel's prayer when he begins to enter into a "featureless expanse" and remains aware of thought passing by on the surface "above" his vantage point (I discussed this in Section 5.3.2). Samuel is spiritually attentive during this process of "entering". He is simultaneously aware of coarse- and subtlelevel content. 
I will now explore what happens in Samuel's prayer when he is fully established in a "featureless expanse".

Samuel is proactive about moving into this state. But he insists that he does not have control over entering into or exiting it. Nevertheless, Samuel does feel that he can make entering more likely. To this end, he becomes "receptive". How exactly this works is unclear, but there are signs that he looks out for.

\begin{abstract}
There's sometimes a feeling in my scalp. Like something physically moves in the top of my head and the experience of consciousness/awareness feels different. It's like it goes through a different part of my brain or something - maybe a third eye kind of feeling. [There are] kind of subtle, physical manifestations that go with it, like the feelings in the head. Also sometimes I will feel a pain and then I realise it's my shoulders relaxing [chuckle]. They are so unused to relaxing that it feels painful to kind of relax, but sometimes I will feel that, just spontaneously. Then the heart opening: kind of a sense of opening in my chest, a kind of warmth. Yeah, those are the kind of sensations that are associated with it. It's not like I can make those things happen, but it's as if I can instead of thinking about whatever, if I kind of look for those things and be, you know, just like kind of - I don't know - waiting for a bird to fly out of the weeds or something like that. $^{740}$
\end{abstract}

Samuel's receptivity is a matter of watching out for features that he associates with the featureless expanse. He cannot cause those features to appear in his experience, but being on the lookout seems to facilitate the relevant shifts. Let us now consider what happens when he is fully established in the featureless expanse.

Interviewer: $\quad$ And when you are in the featureless expanse, are you still kind of a
spectator, but at a greater distance, or something?
Samuel: $\quad$ In the thoughts there is a kind of subject-object, I mean [chuckle],
the performances and the object, I am kind of watching it,
engrossed in it, and then I realise, "Wait a minute. Here I am
watching this and that is not what I want to be doing." So you
wake up and you realise you are in the movie theatre. But in that
featureless expanse, there is no subject-object. There is no... it's
just being: just being there. ${ }^{741}$

\footnotetext{
740 Samuel, Interview \#24.1, p.11.

741 Ibid., p.13.
} 
When Samuel is fully established in the featureless expanse, it is unlike prior phases in his prayer, because it has a different structure. Let us, then, take a step back and review Samuel's prayer to consider this comparison.

Samuel's prayer goes through a cycle with three main steps. First, he is engaged in thought, which, he says, has a subject-object structure. The film is in front of him.

Second, he consciously looks out for signs of the featureless expanse as part of his process of "entering" into it. As he becomes more receptive, his relationship to thought changes. His awareness-perspective differentiates and becomes salient. He becomes spiritually attentive and thought dims as it recedes into the background of his eventperspective. Now thought is no longer in front of him, but further away and "above" his attentive purview. Samuel's spiritual attentiveness retains a subject-object structure.

Third, he settles into the featureless expanse. But he still says, "I don't have a sense of a particular perspective." At first, he is in the middle of a space that is empty. But then thought stops. He is "just being there". In "just being" there is no subject-object structure. The "clean space" is expansive, featureless and nonperspectival.

I will now shift our attention to the affective dimension of Samuel's featureless expanse and the extent to which he is lucid and self-aware as a subject. So far, Samuel's account appears very cognitive and conveys no feeling tone. I direct Samuel to this. He said:

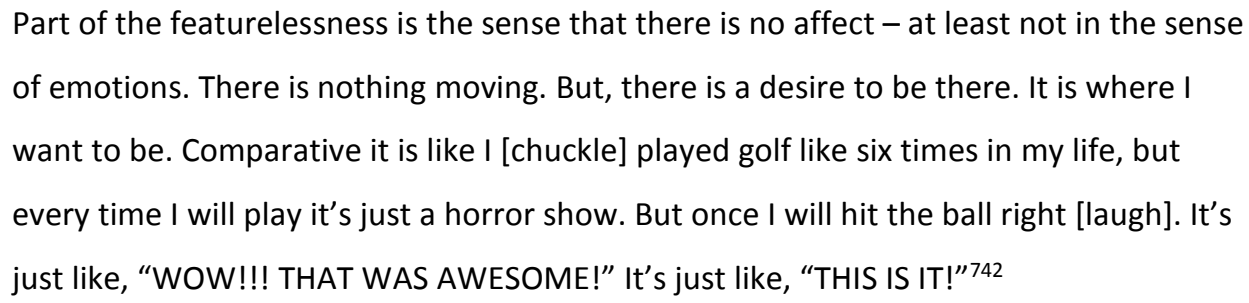

Samuel tells us that the clean space is devoid of affect. But he is still attracted to it and for some reason feels that "this is it". I will clarify his reason for this shortly. First, I will consider how wakeful and self-aware he is in this clean space.

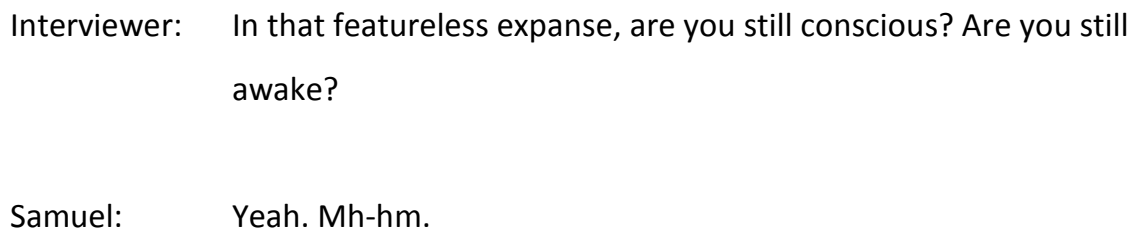

742 Ibid., p.14. 


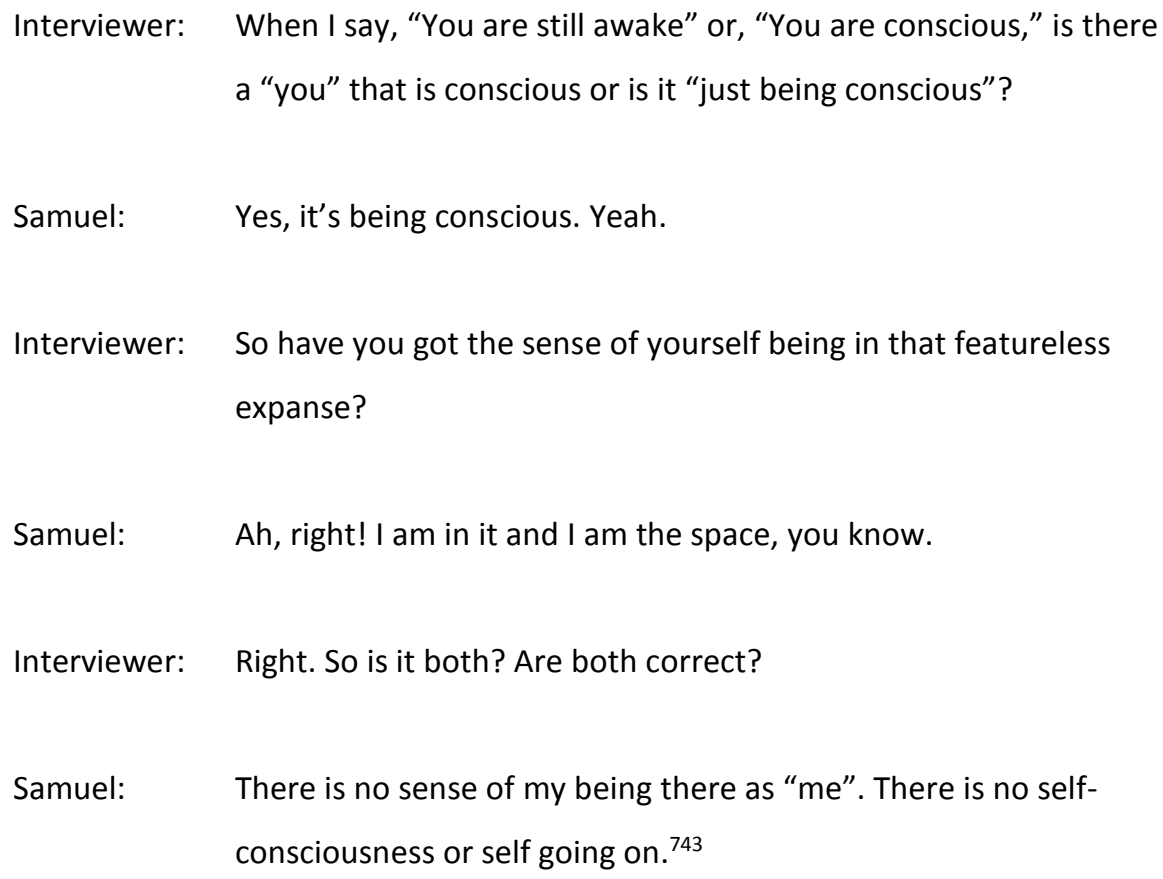

When Samuel is fully established in a featureless expanse, his state is: (i) affectless; (ii) not reflectively self-aware; and (iii) lucid.

In respect to (ii), he does not experience himself to be present in that state as a subject. His lack of self-reflection explains his feeling that "this is it" despite no positive feeling-tone. Samuel says, "It's so perfectly egoless. What's there in that featureless expanse is the disappearance of subject-object." 744 One the one hand, Samuel's state has no differentiated subject-side (awareness of self-as-subject). On the other hand, it has no object side, because the state is not intentional in either the broad (open to otherness) or the narrow (subject-object) sense. Therefore, the phenomenal structure of Samuel's clean space is monistic - of a singularity.

In respect to (iii), his state is percipient of the featureless expanse, even though there is no subject who is aware of it. He says, "It's being conscious." Therefore, Samuel's state is not a form of nonconsciousness. He is state-aware, which means that " $\mathrm{X}$ is devoid of $\mathrm{Y}$ " only such that " $\mathrm{X}$ " (his ongoing awareness) obtains and " $\mathrm{Y}$ " (content in his event-perspective) does not.

But what about God's presence, or Samuel's "sense of presence"? In Chapter 6, Samuel told us that he understands the notion of "presence" to be "really more about MY becoming present". He pointed out that he has an "implicit sense of God's immanence". Therefore, he does not experience "presence" as something "other". At face value, it appears

\footnotetext{
743 Ibid., pp.14-15.

744 Ibid., p.20.
} 
to be the case that Samuel's notion of "presence" is structured like the featureless expanse. It is not dualistic and there is no "other".

Let us, then, more closely examine the relationship between Samuel's featureless expanse and his notion of "presence".

Interviewer: So would it be fair to say that you don't have that kind of sense of presence or anything in that featureless expanse?

Samuel: $\quad$ That is true. That is correct.

Interviewer: Would you still say that your sense of your own existence is there in that featureless expanse? It could be a more objective, independent existence, or it could be just-

Samuel: It's existence.

Interviewer: So you do have that sense of existence?

Samuel: $\quad$ Yes. Oh yeah! In a kind of pure state.

Interviewer: Would you identify that pure state as God or the Divine, or something like that? Do you have a sense of that in that state?

Samuel: $\quad$ Ahm... I can say yes because Cynthia [Bourgeault] has given me language, and Thomas Keating also. There is a poem that one of her students wrote that she quotes, and I think the line is, "Christ is no longer the object of my love, but has become the subject of my loving." So, again, it's not God as this awesome presence - this AWESOME "OTHER" that "I" become aware of - but that having opened up someplace within me, I am not having this experience of, "God is the subject of my awareness. God is this consciousness."

Interviewer: Right, right, right. Yeah. And would you identify this featureless expanse as basically the subjectivity of, you know, God or the light of God, consciousness, even though it is affectless? 
Samuel, like Rachel, offers information relevant to whether God is identified in and through an additional and unique phenomenological ingredient. Samuel reconfirms that he does not experience God as an "awesome presence" or "awesome other". In pure existence he does not have the experience that "God is this consciousness". Nevertheless, he would still identify the featureless expanse as "of God", but this is a non-phenomenological fact.

Similar to Lawrence's nothingness and Martin's liminal space, Samuel's featureless expanse is marked by phenomenological paucity, especially in respect to a "Godidentification" element. It is only through language given to him by Keating and Bourgeault that he identifies his experience to be "of God". Samuel does this despite, or possibly because, his state is utterly affectless. I will now attend to this affective component (our conversation continues from the above).

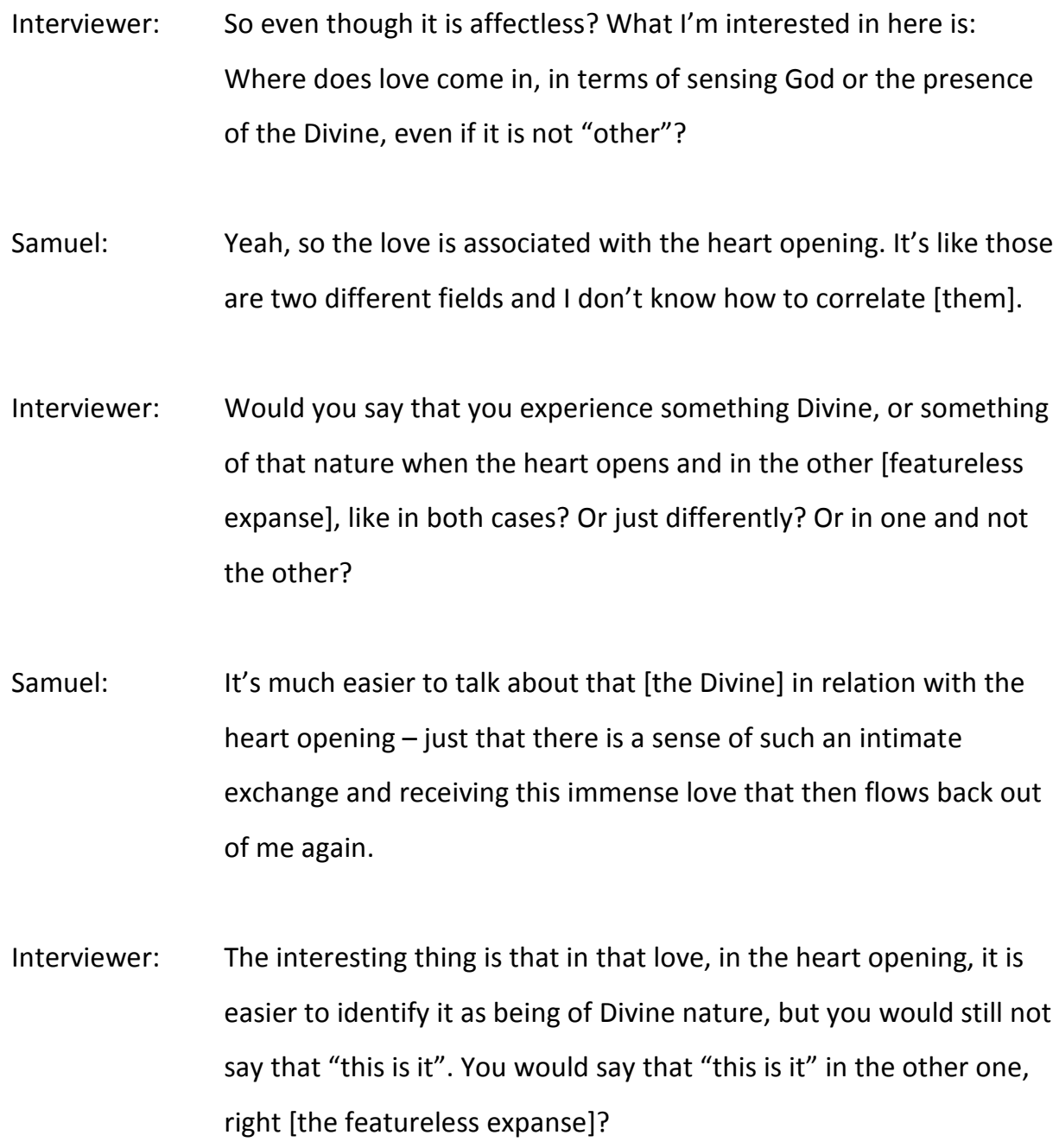

${ }^{745}$ Ibid., pp.19-20. 
The featureless expanse is significant for Samuel, because it entails a complete structural transformation of consciousness. It is, he says, "perfectly egoless", and this feature makes him feel like, "This is it."

Samuel does not have the same feeling when his heart opens during practice, because the intimate exchange of love affirms his personal being. Despite his feelings of "immense love”, Samuel feels that states of prayer which cultivate strong positive emotions only reaffirm his subjective sense of presence (self) as distinct from an objective sense of presence (other). However, his experience of love retains and reinforces a dualistic structure. For this reason, Samuel thinks that he "hit[s] a zenith" with affect-oriented prayer. It does not lead to a complete structural transformation of consciousness. In other words, intimate exchanges of love in union with dualistic structure never peak into intervals in which that affectoriented prayer takes on a monistic structure of full union ("union without distinction").

I will now move on to my three discussions for this chapter. I will begin with an analysis of the phenomenal character and structure of full union based on the three cases I have presented.

\subsection{Lucidity and the Phenomenal Character and Structure of Full Union}

In this section, I aim to achieve two things: First, I will claim that all three cases I have presented are instances of full union. To this end, I will review each case and relate phenomenology to how the Centering Prayer tradition presents the phenomenal character and structure of full union. Second, I will suggest that lucidity moderates the phenomenal character but not structure of prayer of full union. I will also draw on the concept of lucidity to distinguish my first two examples (Rachel and Martin) from my third (Samuel).

I will now review my first two examples (Lawrence and Martin), to then compare their accounts to Keating's and Frenette's treatment of prayer of full union.

I begin with Lawrence, my first case, who rarely enters into a "climax interval" during seated prayer. He calls it "nothingness": a temporally limited peak marked by strong phenomenological paucity that affects both the awareness-perspective and the event-

${ }^{746}$ Ibid., p.20. 
perspective. Therefore, a peculiar type of non-awareness is at play (" $\mathrm{X}$ is devoid of $\mathrm{X}$ and $\mathrm{Y}$ " where " $\mathrm{X}$ " is awareness and " $\mathrm{Y}$ " is content). He is neither asleep nor unconscious.

Lawrence's state appears to lack lucidity and thus self-awareness. He is non-selfaware in two senses: (i) He is not aware of the state he is in; and (ii) he is not aware of himself as a subject. The "lights turn back on", so to speak, when either internal (thought) or external (a gong) coarse-level stimuli trigger his faculties to process information and reignite self-reflective consciousness. Thus he refers to the end of the interval as a "realisation of nothingness". The "realisation" component kicks in only after the fact and when selfreflective consciousness reasserts itself.

In my second case, Martin experiences a "liminal space" ("resting in God") for periods of time during seated prayer. It is a "climax interval" that comes and goes, but it can also last for the entire sit. Like Lawrence, Martin's liminal space is marked by phenomenological paucity that renders him unaware of an awareness-perspective (subjectside) and event-perspective (object-side) at all levels of awareness. Therefore, Martin also "experiences" a peculiar type of non-awareness. Thus he describes his state to be "in between" consciousness ("not asleep") and unconsciousness ("not awake").

Like Lawrence, Martin's liminal space lacks lucidity and self-awareness. He insists that he has no "sense of self" and that he is not aware simpliciter, because he is an "in between" state. He, too, returns to full self-reflective consciousness only when the bell rings, or when his environment prompts his faculties to process information.

I will now compare these accounts with how the Centering Prayer tradition conceives the phenomenal character and structure of prayer of full union.

I begin with Keating. First, he says that in prayer of full union the "ordinary reflective faculties" are completely suspended such that the state has no coarse-level content in the event-perspective. 747 Therefore, practitioners have no cognitive access to ordinary consciousness. This is consistent with Lawrence's and Martin's accounts.

Second, Keating says that practitioners are "not even aware that [they are] in this state until it is over. Afterwards, one knows." ${ }^{48}$ This means that practitioners do not phenomenally apprehend the state they are in. They are not percipient of it. This renders them non-self-aware in the "state-aware" sense. This is also consistent with my first two examples.

Third, Keating adds that prayer of full union "takes away all self-reflection" such that "the sense of an individual self" is also suspended.749 This means that the subject who was aware in union is no longer present at the subject-side of experience. This renders

\footnotetext{
${ }^{747}$ Keating, Manifesting God, 112.

748 Ibid.

749 Ibid.
} 
practitioners non-self-aware in the sense that they are not cognisant of themselves as a subject of experience. This, too, is consistent with Lawrence's descriptions ("I was gone.") and with Martin's (“No sense of self. None.”).

In sum, Keating conceives prayer of full union to be marked by a strong phenomenological paucity that affects both subject- and object-sides of all levels of awareness. Therefore, strong paucity is marked by a lack of lucidity or wakefulness that renders practitioners non-self-aware in two relevant senses: no state-awareness and no awareness of self-as-subject. Since practitioners are not percipient simpliciter, I suggest that their modus operandi (i.e., Albahari's "realised capacity to be aware") is inoperative when their contemplative prayer peaks.

I will now turn to how Frenette conceives prayer of full union. He says that non-selfawareness demarcates prayer of full union from prayer of union. ${ }^{750} \mathrm{He}$ explicitly spells this out in his work.

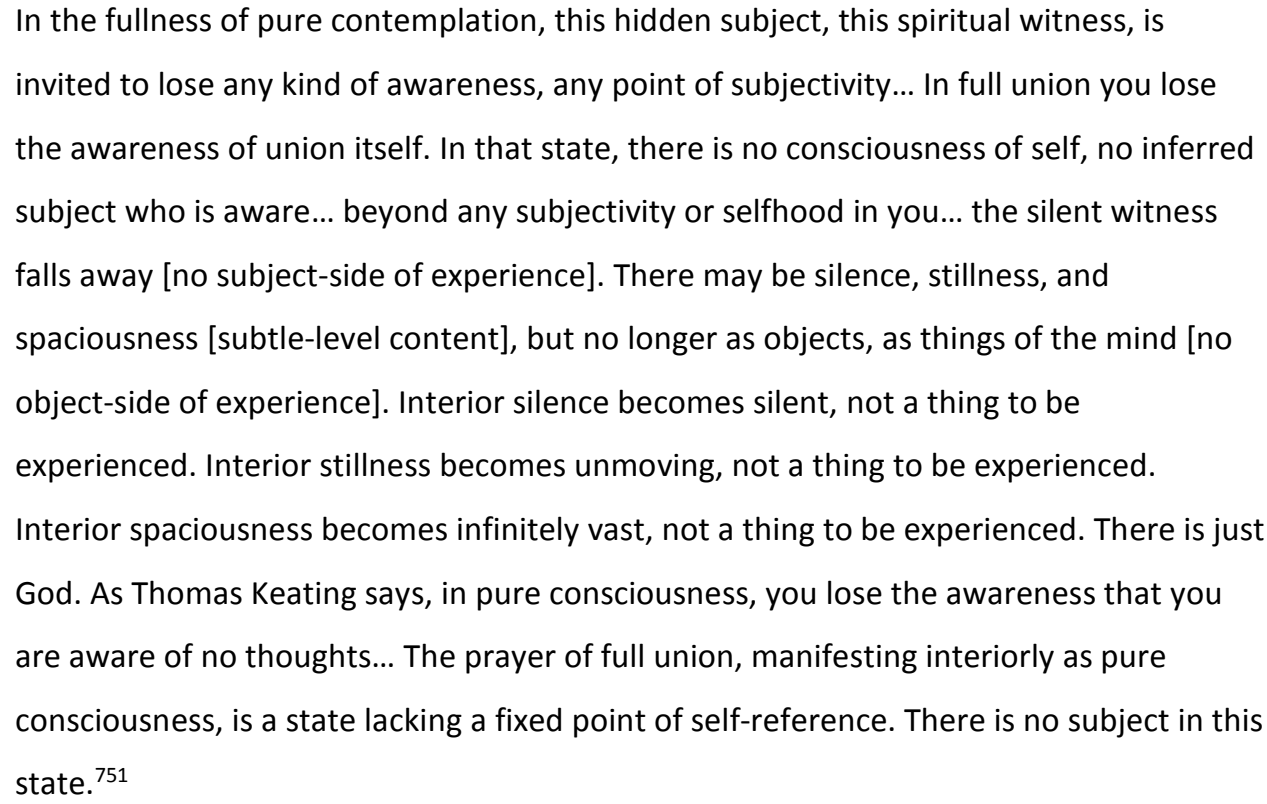

In the above, Frenette uses the term "pure consciousness" a few times. I will not consider this now, but I will make pure consciousness the focal point of discussion in Chapter 10 (Section 10.6). Now I direct the reader to the fact that Frenette discusses two different types of non-self-awareness.

\footnotetext{
${ }^{750}$ Frenette, The Path of Centering Prayer, 89-99.

751 Ibid., 92-93.
} 
The first type of non-self-awareness, is "a form of nonconsciousness" in which "you lose the awareness that you are aware of no thoughts". Specifically, Frenette says, "in full union you lose the awareness of union itself."752 I refer to this as lack of "state-awareness".

The second type of non-self-awareness is a state in which "there is no consciousness of self, no inferred subject who is aware." It is "beyond any subjectivity or selfhood in you."753 Frenette concludes that it "is a state lacking any fixed point of self-reference" such that "the silent witness falls away."754 I refer to this as lack of "awareness of self-as-subject".

In the above exposition, we see that prima facie Frenette agrees with Keating, Lawrence and Martin that prayer of full union is marked by strong phenomenological scarcity. 755 Strong scarcity lacks lucidity or wakefulness such that practitioners are non-selfaware in both senses: no state-awareness and no awareness of self-as-subject. Therefore, the practitioner's realised capacity to be aware (modus operandi) is inoperative.

But this is not all that Frenette has to say about prayer full union. Frenette qualifies his own account.

\footnotetext{
With time, this complete non-self-awareness becomes integrated into the fully alert, waking state [state-awareness]. Consciousness and non-self-awareness are at one in God at the same time. In both instances there is no self being conscious [awareness of self-as-subject], no duality of a self being aware of not thought, no things, nada. ${ }^{756}$
}

Frenette tells us that prayer of full union can be experienced in two different ways. The first way is through strong phenomenological scarcity in which both types of non-self-awareness are operative. The second way is through weak phenomenological scarcity in which awareness of self-as-subject remains unrealised while, at the same time, the practitioner remains state-aware. Therefore, lack of self-awareness of self-as-subject is fundamental to full union, but not state-awareness. Prayer of full union can be lucid.

I will now review my third example of prayer of full union in which Samuel remains state-aware (lucid) during prayer of full union.

Samuel enters into a "featureless expanse" that lacks a dualistic structure. It is not intentional in either a broad (open) or narrow (subject-object) sense. Unlike Lawrence and Martin, he is percipient of the state of full union: he lacks awareness of self-as-subject, but he

\footnotetext{
752 Ibid., 92, 95.

753 lbid., 92.

754 Ibid., 92-93.

755 Lawrence and Martin are unacquainted to Frenette's work. Therefore, the correlation is decidedly not due to their familiarity with Frenette's thinking on the subject.

${ }^{756}$ Frenette, The Path of Centering Prayer, 96.
} 
is still state-aware. He has no awareness of coarse-level content. Therefore, he has no cognitive access to ordinary consciousness.

At the same time, Samuel's lucidity now affords him cognitive access to subtle-level content at the spiritual level of awareness. He is aware of the "clean space" and the "featureless expanse". But they are no longer objects to be experienced, because he is unaware of himself as a differentiated witness at the subject-side of experience. Therefore, the state is no longer structurally bifurcated. It also excludes an object-side. Thus Samuel describes it as a pure and undifferentiated state in which he remains aware of existence in a way that is "perfectly egoless" and affectless.

Finally, Samuel's lucidity grants him cognitive access to the divine level of awareness: he is aware of a "sense of presence", but this fact must be qualified. First, he is not aware of a "presence" that is "other". Rather, he is aware of "presence" as pure existence. Second, he considers this sheer existence to be "of God" despite the fact that in the state there is no unique God-identification element in the phenomenologically given.

In sum, what distinguishes Samuel's from Lawrence's and Martin's accounts is that Samuel is wakeful and alert. He is lucid in a state in which interior spaciousness is no longer an object. As Samuel says, "I am the emptiness," and there is no "self-consciousness going on”. In Frenette's terms, consciousness (state-awareness) and non-self-awareness (lack of awareness of self-as-subject) have become integrated.

\subsection{Lucidity in the Wider Centering Prayer Tradition}

The Centering Prayer tradition is made up of two main schools. Each school is headed by a well -known teacher of the tradition whose published works have been widely received. The two schools are the "Keating School" (headed by Keating) and the "Wisdom School" (headed by Bourgeault). ${ }^{757}$ I will now shift my discussion to the question of lucidity in the wider Centering Prayer tradition. I intend to point out relevant differences between the two main schools of Centering Prayer and suggest that those differences may affect how state-aware (lucid) practitioners are during prayer of full union. To this end, I will take into account the reports of all the practitioners that have participated in this study and who belong, more or less, to one of the two main Centering Prayer schools. I will focus on noteworthy contextual factors that practitioners of each camp share. Specifically, I will consider what prior experience and exposure the practitioners bring to their centering prayer practice.

Let us, then, consider some of the practitioners. Lawrence and Martin are strictly Keating School practitioners. Samuel has a foot in each camp and Rachel is acquainted with

${ }^{757}$ I discuss the "Keating School" and "Wisdom School" of Centering Prayer in Chapter 1 (p.13). 
Bourgeault's published work, but has not been exposed to the community and methods of the Wisdom School. Rachel is also a certified presenter of centering prayer in the Keating School. Prima facie, there are no obvious differences in terms of how the method of centering prayer is practiced by practitioners across schools.

However, there are two trends that distinguish the two groups. Wisdom School practitioners are more likely to: (1) be awake and lucid in deep and subtle states of prayer than Keating school practitioners; and (2) have complex faith backgrounds and come to centering prayer practice with an already existing set of meditation skills gained from having practiced in other traditions.

In respect to trend (1), practitioners from the Keating School are less likely to have cultivated a strong "witnessing presence" (Frenette's, "fully alert, waking state”) prior to picking up centering prayer, after they begin practice and anytime thereafter. They are also more likely to report entering a state in which there is no content (i.e., no world, no felt sense of self and no sense of being embodied) and no conscious awareness. They often describe this state through apophatic language, such as "darkness", "unknowing”, "nothingness", "nonawareness", etc. To make this point tangible: 7 out of 12 Keating School practitioners in this study (58\%) report "experiencing" states from which they suddenly emerge and they are confident that they had not been fully conscious but also not asleep. They report a peculiar lack of lucidity.

In contrast, none of the practitioners in my study who were exposed to Bourgeault Wisdom School (o out of 8) reported entering a state of prayer in which they were not stateaware. Even contentless states were state-aware (lucid) and, for example, identified by practitioners as "pure", "clean”, "featureless", "naked” or just as "presence”.

My observation here connects to four themes I consider relevant: First, Bourgeault's encourages centering prayer practitioners to develop a strong "witnessing presence" outside of their prayer practice. ${ }^{75}$ Second, Frenette's new vision of centering prayer, which comes from within the Keating School and is championed by Keating as a further and suitable development of centering prayer for advanced practitioners, specifically addresses the issue of lucidity in prayer, both "on the cushion" and "off the cushion". ${ }^{759}$ Third, Forman's work on pure consciousness describes states similar to "prayer of full union" discussed here (see Section 10.6). Fourth, in the early days, the founding fathers of Centering Prayer were exposed to Transcendental Meditation, especially Keating and Pennington.760 Due to space constraints, I point out here that these four themes have explanatory value in making intelligible the observation I have made in this study.

\footnotetext{
758 Bourgeault, Centering Prayer and Inner Awakening, 126.

759 Frenette, The Path of Centering Prayer, 92-98.

${ }^{760}$ Consider also Frenette's treatment of pure consciousness, which builds on Keating's work. Ibid., 89-99.
} 
Let us, then, turn to trend (2) in which practitioners' backgrounds between schools appear to significantly differ. In this study, practitioners who affiliate with the Wisdom School have more exposure to teachings and practices of other traditions, both within the Christian tradition itself and outside of their Christian faith. This confirms the general perception that Bourgeault's Wisdom School is more eclectic in its teachings and methods and thus not restricted to centering prayer. Practitioners also interpret their practices and experiences more liberally and universally in relation to the other faiths they have been exposed to.

For example, I interviewed 12 practitioners of the Keating School. Out of those 12, 4 (33\%) had at least some exposure to practices of other traditions: specifically, Zen Buddhism (two of the monks at St Benedict's Monastery); secular mindfulness meditation (Rachel); and Theravada Buddhism by way of Insight Meditation (one of the staff members who runs the 10 Day Intensive retreats in Snowmass).

In contrast, of the 8 practitioners in this sample who were in some way exposed and sympathetic to Bourgeault's Wisdom School, 7 (87.5\%) had at least some exposure to the practices of other traditions. Of those 7 practitioners, 5 (62.5\%) had extensive exposure to the faiths and practices of other traditions.

For example, one monk at St Benedict's Monastery who had a strong relationship with Cynthia Bourgeault spent a few years as a full-time Zen practitioner before he found his way to cloistered life and centering prayer. Another New Zealand female practitioner was a Theravadin nun for 16 months and then practiced Tibetan Buddhist Dzôg-chen for many years under a lama. She even completed the extensive ngöndro preparatory practices. A teacher of the Wisdom school spent 10 years with a Gurdjieff group and then many years in Sufi circles. One young male practitioner spent three months at a Tibetan Buddhist monastery in Mongolia and then lived in a Zen centre in the United States for one year. Finally, Samuel was exposed to a lot of meditation practices in college. He also has a strong yoga background since childhood.

These contextual influences act on Wisdom School practitioners when they consider Keating's thinking and approach, and also appear to interact with how wakeful their centering prayer practice is.

Interestingly, none of the four practitioners of the Keating School who had been exposed to practices from other faith traditions report low levels of lucidity in their prayer or any states they may "enter" as part of their prayer practice. This data supports the hypothesis that context influences experience. However, the influence is arguably due to the actual practices undertaken, rather than any beliefs adopted.

In sum, Keating characterises prayer of full union by a peculiar lack of lucidity and this is reflected in the actual experiences of at least $58 \%$ of Keating School practitioners in 
my study (see Lawrence and Martin). However, Frenette's recent work, which has been approved by Keating, offers a subtle corrective about the phenomenal character of prayer of full union for advanced practitioners. Now practitioners can integrate non-self-awareness with consciousness (e.g. Samuel in Section 8.4).

\subsection{Conclusion}

Prayer of full union manifests through a featureless and pure state in seated prayer and without a God-identification element in the phenomenologically given. The non-selfawareness of the self-as-subject type may or may not be integrated with an alert and wakeful consciousness (state-awareness). Here lucidity appears to track whether or not the practitioner's modus operandi (Albahari's "capacity to be aware”) is operative or not. Therefore, lucidity moderates the extent to which the "event" is phenomenally apprehended.

In cases where prayer of full union is not lucid, it is questionable whether there is something it is like to live through the state. If total non-self-awareness obtains, where there is neither a self-as-subject nor state-awareness, full union might not be a phenomenological event. I suggest that there is little sense in which God-identification could take place in nonlucid prayer of union, and there is no sense at all in which God-identification could be phenomenologically given in a non-phenomenological "event".

In cases where full union is lucid, only one type of non-self-awareness obtains, namely the self-as-subject kind. Therefore, non-self-awareness is integrated with consciousness (state-awareness). Now practitioners cognitively access the divine level of awareness and phenomenally apprehend a "sense of presence" by way of an undifferentiated phenomenal structure that is phenomenologically of an unidentified reality. ${ }^{761}$

\footnotetext{
${ }^{761}$ I develop the claim that full union is phenomenologically of an unidentified reality further in Chapter 10 , Section 10.3.
} 


\title{
Chapter 9
}

\section{World-Involving Union with God: The Temporary Dualistic Awareness of God's Presence}

\begin{abstract}
It really was all about presence: experienced like the sound of a great organ; like a sense of vibration; like a sense of the stars that were like organ pipes sounding something; and the sense of presence enfolding me. ${ }^{762}$ There was this little bit of "me" that was aware that this was happening, but "most of me" was not aware of being any other than what this presence was. ${ }^{763}$
\end{abstract}

\section{- Joseph}

\subsection{Introduction}

Union states may be temporarily experienced outside of seated prayer. I call such temporary union states "union with God”. Union with God shares with other union states (e.g., prayer of union) the feature that its phenomenal structure is dualistic. However, union with God is also "world-involving”. In "world-involving” union practitioners retain cognitive access to ordinary consciousness while they are in the union state. At the same time, their awareness of multiplicity (environment) is drenched through by a "sense of presence", which unifies the phenomenal character of their awareness- and event-perspectives. ${ }^{64}$

In this chapter I will explore how God's presence-absence may be phenomenally apprehended outside of in seated prayer and during temporary states of world-involving union. My purpose for discussing world-involving union is to: (i) show how complex union states can be when they are less absorbing and do not compromise cognitive access to ordinary consciousness; (ii) offer a glimpse into a type of union state that, while temporary, is indicative of the phenomenal structure and character of abiding union states (e.g., transforming union) that signify the farther reaches of the Christian journey; and (iii) lay the groundwork for later discussion of Stace's distinction between introvertive (world-excluding) and extrovertive (world-involving) types of mystical experience and how they can be applied to Centering Prayer (see Section 10.4 and Section 10.5).

I will continue with Joseph's prayer as an in-depth example of union with God to convey how "God's presence-absence" may be phenomenally apprehended outside of formal prayer. Since union states are dualistic, his divine level of awareness is differentiated into an awareness-perspective (subject-side) and an event-perspective (object-side). Given this

\footnotetext{
762 Joseph, Interview \#5.1, p.11.

763 Ibid., p.12.

${ }^{764}$ I consider this equivalent to Stace's extrovertive type of mystical experience, as discussed in Section 10.4.
} 
structural divide, I will pay specific attention to where Joseph senses "presence" to be in respect to the subject/object divide of his experience.

\title{
9.2. Joseph's World-Involving Sense of God's Presence
}

I now turn to a world-involving union experience that Joseph had when he was about 18 or 19 years old. He walked home one night from the bus stop in suburban Auckland and looked up at the stars, which appeared almost dreamlike. He felt that "anything is possible".

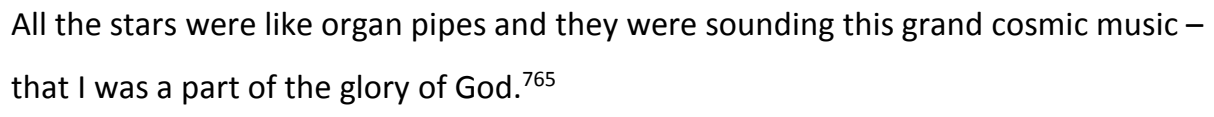

Joseph had just been to a symphony concert in the Auckland Town Hall and had taken the bus home. When he got off of the bus, it was past 10pm. "It was a very clear, crisp night, inasmuch as Auckland can do crisp," he says. He was walking home on the footpath. After half a kilometre something changed.

\begin{abstract}
It came completely unbidden. I don't remember having any thoughts or heartmovements [chuckle]. Suddenly this awareness of this huge, huge vast sky above me just resounding like some magnificent organ [chuckle]. What arises within me [in the interview context] is the echo of a feeling of complete exhilaration: a sense of profound excitement and a profound sense of belonging. It is interesting all these decades later it is still so clear [chuckle] - a sense of the unity of all things and the sense that I am part of that unity. In later years I kind of talked about it this way, as saying that, you know, "In my baptism I was caught up into the Holy Trinity and each person of the Holy Trinity just throws me around." And this sense of exhilaration, playfulness [chuckle]... ${ }^{766}$
\end{abstract}

Interviewer: So that a sense of exhilaration and playfulness, was that located somewhere in your body?

Joseph: It was in my body inasmuch as I felt bigger than I was, and it was a sense of in-the-fullness-of-my-body. Like it's impossible to differentiate my body from any other part of this experience. I mean it was all of me in this.

\footnotetext{
765 Ibid., p.1.

766 Ibid., p.9.
} 


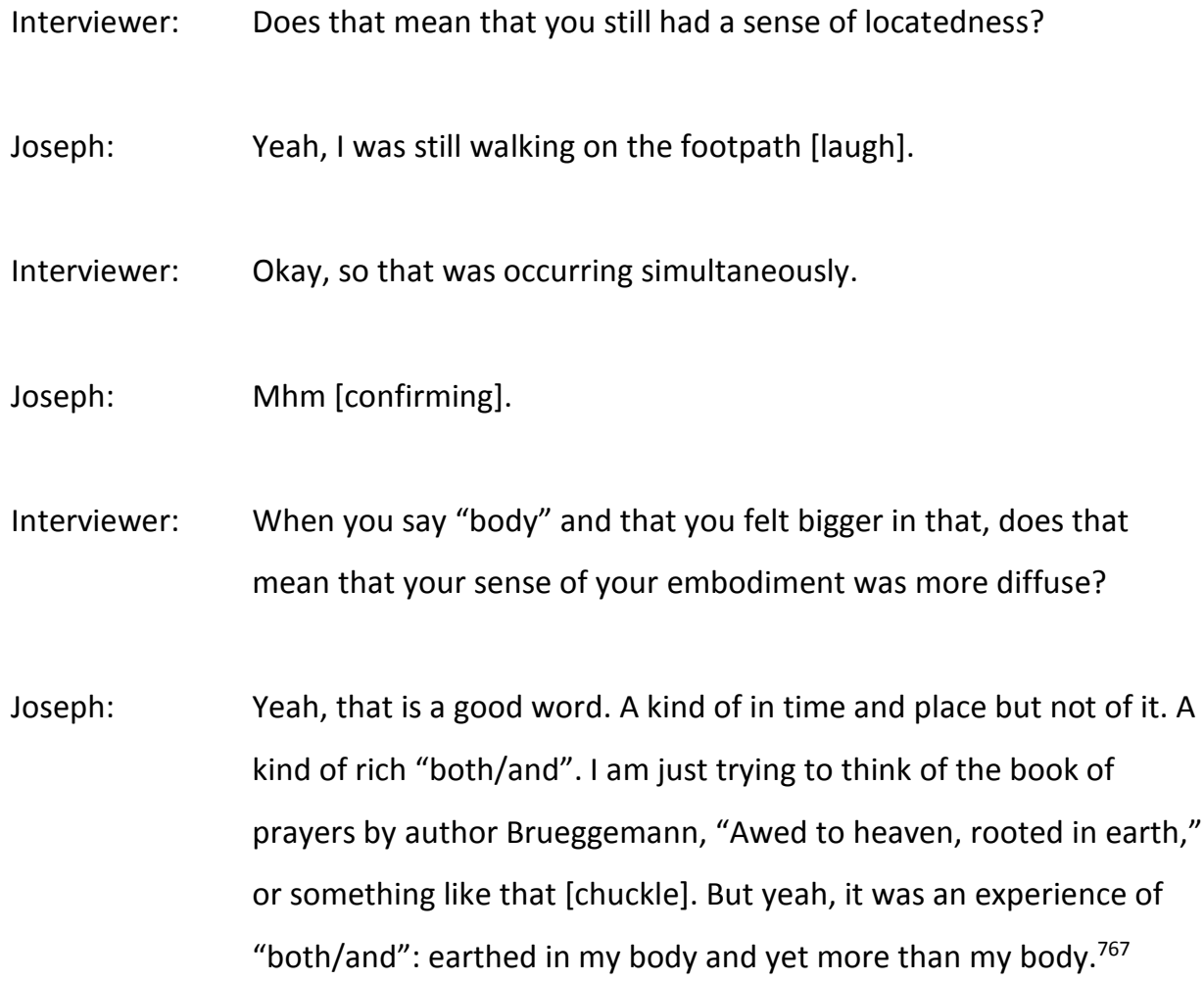

In respect to Joseph's account, I direct our attention to three things. First, Joseph's union state retains cognitive access to ordinary consciousness. He is aware of his environment by way of external coarse-level content. He sees the stars and he continues to walk on the footpath, and he is fully conscious of the fact. He does not report internal coarse-level content. He does not mention thoughts of any kind. Thus his coarse-level faculties are not roaming freely of their own accord, but they are activated by sensory stimulation.

Second, his basis of operation (witnessing) occupies more space. His perspectivelending locus has expanded. He says that he did not lose his sense of being embodied, but it expanded. He felt bigger than he typically experienced himself to be; he could not really separate his body-sense from anything else in the experience.

Third, he has a sense of unity while at the same time being aware of the multiplicity in the event-perspective of his ordinary consciousness. Both awareness of multiplicity and awareness of unity are simultaneously operative. Therefore, the phenomenal structure of his union state is differentiated while the phenomenal character of his subject- and object-side of experience are "drenched through" or "sopped by" a sense of presence ("unity"). This includes the external environment he is aware of, which is imbued with a unifying phenomenal character of "presence". Consider the following exchange about how Joseph's sensory-like perceptions relate to his felt sense of God's presence and unity.

${ }^{767}$ Ibid., pp.9-10. 


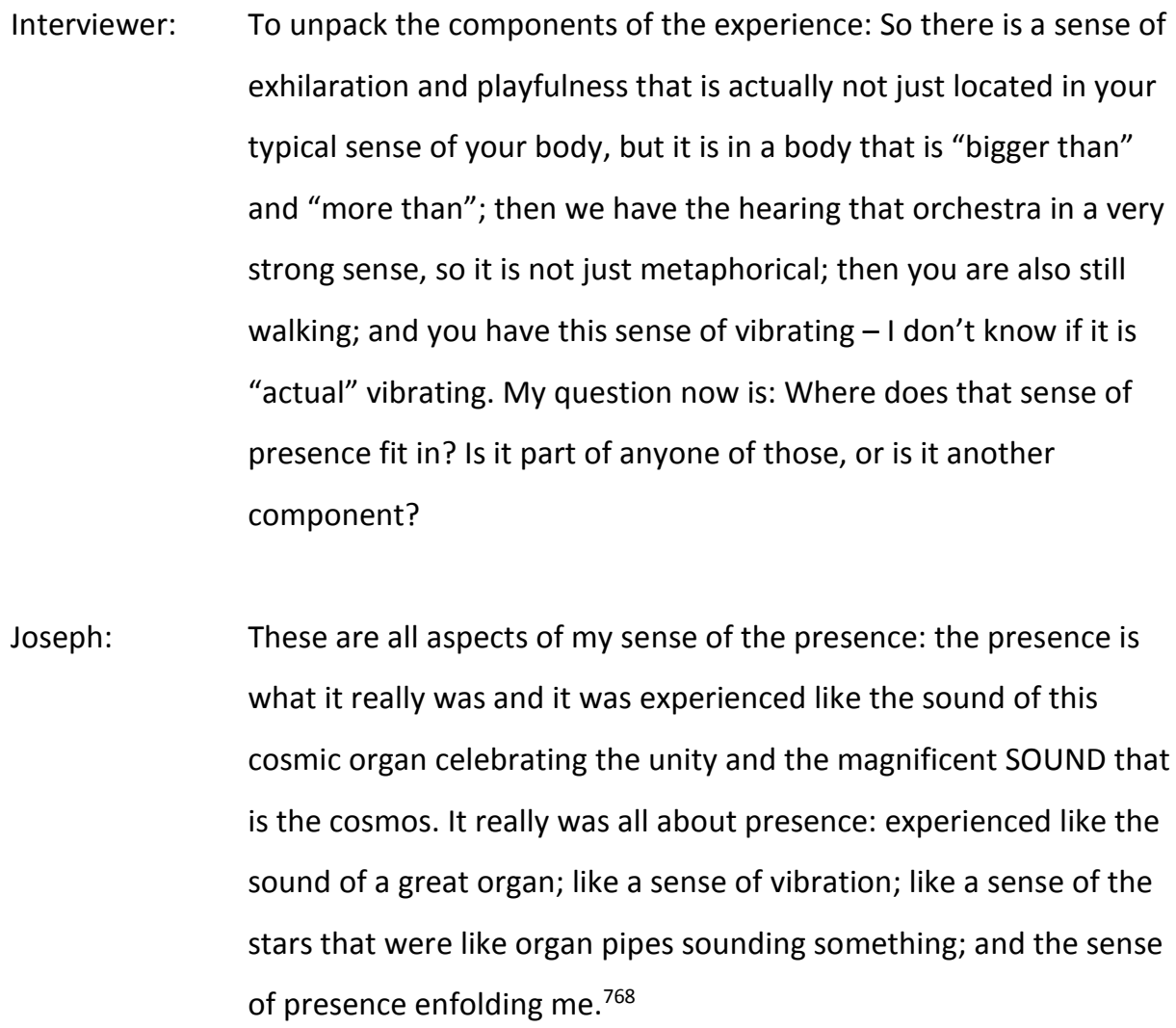

Joseph indeed experienced the presence by way of sound and vibration. He also felt “enfolded" by presence. There was some sense in which Joseph's sense of presence was located in his event-perspective (object-side).

Earlier, Joseph said that his sense of presence "was in my body inasmuch as I felt bigger than I was, and it was a sense of in-the-fullness-of-my-body. Like it's impossible to differentiate my body from any other part of this experience.” Here Joseph's sense of presence is located in his awareness-perspective (subject-side). It is in the same place where Joseph experiences himself to be. He says, "In my body."

Additionally, Joseph relays to us how his subjective sense of presence extends out, because he feels "bigger". This diffuse sense of expansion (open intentionality) made it difficult for him to demarcate where his awareness-perspective ended and the sense of presence in his event-perspective began. Thus we find a "double-inclusion" relation at work, which is characteristic of a weak dualistic structure.

\subsection{The Structure of Joseph's World-Involving Union with God}

I will now examine in greater detail the structure of Joseph's world-involving union. I begin with an inquiry into Joseph's awareness-perspective.

\footnotetext{
768 Ibid., p.11.
} 
Interviewer: Where were you in that experience as you were sensing that presence? I'm trying to get a sense of what your relationship to the presence was in that experience?

Joseph: $\quad$ Ah, I like that. My relation to the presence was multiple dynamics. A sense of the wonder of being aware of it; a sense that somehow I was a part of this; a sense that life was so much more than I had ever begun to perceive or wonder about; a sense that somehow this being that I was fitted into all of this.

Interviewer: So there is a sense of "being aware of that". So in that walking home and sensing that presence as a kind of cosmic orchestra, you are aware of it - of that presence - and you were feeling a part of it as well. In that experience, were you self-aware? Like, I mean, did you denote that you were having that experience or did it just occur and you reflected on it after the fact?

Joseph: I am mainly aware of it in a self-conscious way after. There is some part of me that's aware "this is happening" but that little part of me is not analysing or trying. There is a part of me that is aware that "this is happening" but reflection on it or consciousness of what has happened does not happen until afterwards.

Interviewer: Right, so even though you feel part of it and you are aware of it there is awareness of the presence - there is not a sense of you looking back on yourself and, "Yeah, I am having this experience and I'm in it." So there is no sense of reflective denoting? I am being a bit cheeky. I want to explore the structure of consciousness. So what was aware in that experience of the presence?

Joseph: $\quad$ Yeah, yeah. In my Christological world view, and my framing, it was kind of like the Christ in me that was expanding me to make room for "Christness", which is what I think I mean by that sense of unity and connectedness. As I say, there was this little bit of "me" that was aware that this was happening, but that little bit of "me" - but "most of me" was not aware of being any other than what this presence was. It was kind of like a feeling that somewhere at the 


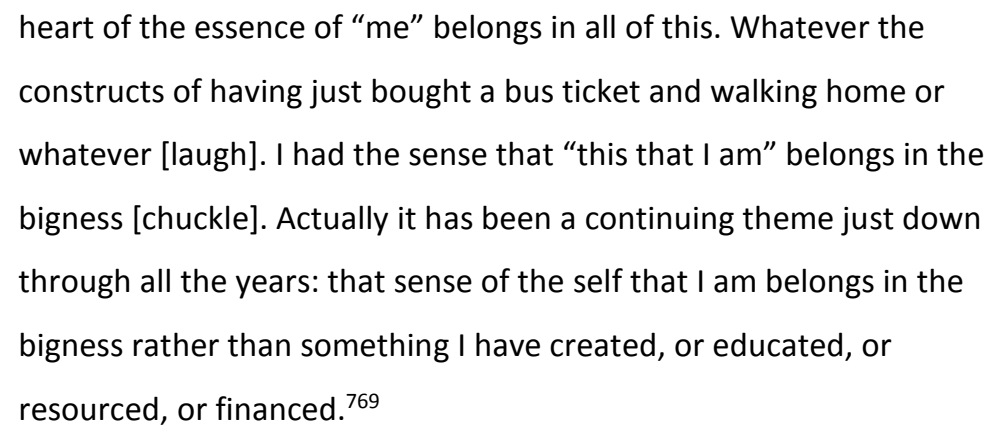

Towards the end of this exchange, Joseph offers us valuable information about the structure of consciousness.

First, Joseph says that there is a little bit of him that is aware of a presence located, at least in part, in his event-perspective (object-side). Joseph retains a sense of self-as-subject distinct from an objective sense of presence, even if it is marginal. Frenette refers to this as the hidden subject who is aware in union. This renders Joseph's union dualistic.

Second, Joseph experienced most of himself to be nothing other than the presence. Hence his sense of presence is also located in his awareness-perspective (subject-side). Pike would say that the presence is located in that place "where one normally experiences oneself to be". ${ }^{770}$ I understand Pike to mean "within the entity of the soul", which is coterminous with the self-as-subject.

Third, Joseph's sense of presence is located in the awareness-perspective and the event-perspective. Hence there is a gloss of unity that covers both sides of Joseph's experience. I use the term "gloss" to indicate that each side of the divide is imbued with the phenomenal character of "felt-presence". Therefore, union does not completely obliterate all any distinction between Joseph's subjective sense of presence (God within self) and his objective sense of presence (God outside of self). ${ }^{771}$

Fourth, Joseph's description suggests that a "double-inclusion" relation obtains, which closes the gap between subject- and object-side through the unifying phenomenal character of "presence". ${ }^{72}$ Pike uses a sponge metaphor to capture this. In union the self is "less like a fish than like a sponge in water. The soul [self] is not just submerged, it is also sopped with God."773 Pike would say that God's presence has entered into the domain of the self-as-subject or the "centre": it "pierces", "penetrates" or "invades" the subject-side. ${ }^{774}$ Joseph indicates that such a double-inclusion relation obtains when he says, "It was in my

\footnotetext{
769 Ibid., pp.11-12.

770 Pike, Mystic Union, 159.

${ }^{771}$ To consider Joseph's identification of subjective sense of presence with God's presence, see fn.718 (p.181).

772 Pike, Mystic Union, 10.

773 Ibid.

774 Ibid.
} 
body," and, "it was kind of like a feeling that somewhere at the heart of the essence of 'me' belongs in all of this," and "that sense of the self that I am belongs in the bigness".

\subsection{The Phenomenal Structure and Character of World-Involving Union}

The Centering Prayer tradition agrees with Pike's account of union in so far as the realisation of God's presence within occurs when the basis of operation shifts into the divine level of awareness (the centre or heart). In this study, the phenomenology of this shift is characterised by two things: (i) a felt sense of presence located in the subject-side of experience (presence has "sopped" the practitioner's basis of operation); and (ii) the felt sense of presence located in the event-perspective.

Having considered Rachel's, Carol's and Joseph's (among other participants') experiences of union, I interpret what is happening here in a slightly different way than Pike.

I begin with Pike's analysis. In his system, God's presence is first identified in the event-perspective (object-side), which is outside of the self-as-subject. For example, in prayer of quiet, God's presence is located in the vicinity of, but not in, the self's centre. God's presence is also apprehended through a unique "God-identification" element in the phenomenologically given. Thus there is an additional ingredient in the experience that is responsible for presenting to the practitioner God's presence with unique phenomenological character.

In this study, no practitioner reported this ingredient. What I have found in practitioners' reports is what Frenette identifies as the various ways in which God's unfelt and unseen presence manifests in awareness at the spiritual level. For example, the subtlelevel content of God's silence, stillness and spaciousness.

The only "presence" reported as an experiential primitive is the presence of the practitioner's own sense of existence as subject that, during specific states of prayer, becomes salient. This presence of "I am", "I am here" and "I have presence" is then identified as divine. This "identification" does not take place through a unique feature in the phenomenologically given. It is a view adopted - a way that practitioners contextualise their own experience within the context of the teachings of their tradition. True to this interpretation, Lily, a senior Wisdom School teacher, says, "Divine presence or "presence" just call it presence: all presence is divine."775

Therefore, the descriptions I have come across suggest that the "sense of presence" as an experiential primitive actually originates in the subject-side of experience and then extends out or "penetrates" by way of a broad type of intentionality the event-perspective

${ }^{775}$ Lily, Interview \#33.1, p.2. 
(object-side), rather than the other way around. Consistent with this, no practitioner in my study has reported a sense of presence, as an experiential primitive, to be located exclusively in their event-perspective. Rather, an objective sense of presence is always concomitant with a broad intentionality at work (a weak dualism) in which awareness appears to be more diffuse and open (but not directed) to a horizon.

\subsection{Conclusion}

I have considered Joseph's experience of union with God, which he experienced outside of formal prayer and with cognitive access to ordinary consciousness. His ordinary consciousness continued to operate with a narrow type of intentionality (subject-object). He phenomenally apprehended external coarse-level content. Since he walked on the footpath, he had not created a situation that minimised his bodily self-awareness (a still posture) and external sensory input (eyes closed in a controlled environment). This rendered him aware of his environment by way of sensory awareness and awareness of multiplicity. Therefore, his awareness included an event-perspective (object-side) at the ordinary level. Nevertheless, internal coarse-level content (thought) was still absent, because his faculties were absorbed enough in union to no longer roam freely.

Joseph's union with God also had a weak dualistic structure at the spiritual and divine levels of awareness. We can see this in the double-inclusion relation. His perspectivelending locus felt expanded and Joseph could not clearly demarcate where his subjective sense of presence ended (awareness-perspective) and his objective sense of presence began (event-perspective). Thus we find that Joseph's world-involving union was structurally differentiated, but phenomenally unified.

The fact that Joseph felt expanded and "part of the bigness" suggests to me that his objective sense of presence originated in his expanded subjective sense of presence. I contend that his sense of "isness" (awareness-perspective) "reached out" and "spilled over" into his event-perspective. I have multiple reasons for suggesting this:

First, Joseph's sense of "just being" or "isness" is an experiential primitive consistent with Albahari's "sense of presence" as her core concept of awareness. This experiential primitive phenomenally exhausts Joseph's “isness".

Second, Joseph's objective sense of presence (the "more than" or "the bigness") has the same phenomenological character as his experiential primitive. My exchange with Joseph made clear that there is no additional or unique "God-identification" element in the phenomenologically given.

Third, Joseph clarified that his use of theological terms, such as "Christ" or "Holy Trinity", do not "identify" some phenomenal feature specific to God's presence. He told us 
that those are terms he uses to refer to an unidentified reality marked by experiential primitives, such as his sense of "unity" and "connectedness".

Fourth, Joseph reports that his awareness-perspective felt expanded. If there is any direction that "presence" might be moving "toward", it is from the subject-side to the objectside, not the other way around.

Fifth, no practitioner in my study has reported a "sense of presence" solely located in their event-perspective. If practitioners experience a "presence out there", it is only in situations in which "presence" is also sensed "in here". Practitioners do report a "sense of presence" to be solely located in their awareness-perspective (subject-side) (see Rachel's case in Section 7.2 and Section 7.3).

In sum, Joseph's temporary, world-involving union with God has a more complex phenomenal structure and character than world-excluding union states encountered in seated prayer only. Since world-involving union states are lived through off the cushion, they share with spiritual attentiveness the feature that multiple levels of awareness run in tandem. Specifically, union with God has a multi-mode awareness, because ordinary, spiritual and divine levels of awareness are simultaneously operative. 


\section{Chapter 10}

\section{Implications for the Philosophy and Comparative Study of Mysticism}

Contemplative literature cannot but be encountered as text, and a whole host of issues emerges. Similar to the problematic study of mystical experience through "mystical literature", there are issues with studying contemplative practice and contemplative experience through contemplative literature. ${ }^{776}$

\section{- Komjathy}

If one wants to dispute the reality of... consciousness, one should do so by means of more convincing phenomenological descriptions. ${ }^{777}$

- Zahavi

The most promising strategy may well be to defend a version of the Experience Condition, which privileges the first-person perspective. On this principle, clashes between theory and experience will be resolved in favour of the latter. ${ }^{778}$

- Albahari

\subsection{Introduction}

Contemporary philosophical dialogue in the comparative study of mysticism has to date relied on limited evidence to discuss the metaphysical ("phenomenal") nature of mystical states of consciousness. Limited evidence constitutes data ("datum passages") extracted from primary sources that lack first-person accounts. Thus "datum passages" discussed have not been obtained through rigorous data collection methods and validation procedures. The hermeneutical strategies employed involve guesswork for the reasons I discussed in Section 2.7.3, Section 2.7.5 and Section 2.8.1. Three examples critical to this study are Katz, Stace and Pike.779 I will introduce each in turn.

Contemporary philosophy of mysticism has broadly divided itself into two major camps, which hold incompatible views about the etiology of mystical states of consciousness. ${ }^{780}$ The structure of the debate resembles the nature-nurture debate in psychology. ${ }^{781}$ Katz represents the Constructivist position (equivalent to the nurture side of the latter debate), which holds mystical experiences to be fully determined, shaped and

\footnotetext{
776 Komjathy, "Contemplative traditions," 72.

777 Zahavi, "The experiential self: Objections and clarifications," 72.

778 Miri Albahari, "Nirvana and ownerless consciousness," ibid., 110.

${ }^{779}$ For a discussion on why such philosophical works have verification issues and are phenomenologically suspect, see Katz, "Language, epistemology and mysticism," 22-25. For a discussion of why Katz's work is phenomenologically nugatory, see Pike, Mystic Union, 194-207.

780 Wulff, "Mystical Experience," 426-27.

781 Ibid., 427.
} 
produced in mysterious and unverifiable ways by contextual factors, such as tradition, culture, beliefs and doctrine, among many others. ${ }^{782}$ Katz also claims, specifically, that Christians: (i) do not experience an unidentified reality in union states, which they then label "God";783 (ii) necessarily experience the "mystic reality" as the personal God;784 and (iii) necessarily experience "God" by way of "a relational state in which the finite self encounters a saving or loving transcendental Being”. ${ }^{785}$ Katz makes these universal phenomenological claims on the basis of his personal hermeneutics and a priori faith in his constructivist thesis.

Stace is considered by most the main representative of the Essentialist position (equivalent to the nature side of the debate), which holds mystical experiences to be immediate encounters with something "real", "objective" or "inherent". The "real" is either a metaphysical reality that transcends - but also includes - the subject, or is a "fundamental internal mechanism" or "innate capacity”. ${ }^{866}$ Stace, specifically, accepted a version of essentialism in which mystics across traditions and cultures shared in one and the same type of mystical experience. He called this mystical experience the "introvertive type" that for all intents and purposes is a "pure consciousness event" as formulated by Forman. ${ }^{787}$ Stace also famously argued that the Christian peak interval of prayer of full union is just such an introvertive type of mystical experience, which is of an unidentified reality.

Pike disagrees with both Katz and Stace. He rejects Katz's Constructivist thesis that all mystical experiences are mysteriously overdetermined by unverifiable contextual factors. However, he agrees with Katz that Christians do not experience an unidentifiable reality in their union states. To the contrary, all union states, including the peak interval of full union, are phenomenologically and specifically of the individual God. Pike's argument to this effect is aligned with a more collective effort on the side of Christian philosophers and theologians to argue for a unique "theistic" mystical experience. This project generally takes issue with Stace's argument that full union is of an unidentified reality.

In this chapter, I will marshal the evidence I have presented in Chapters 4 to 9 to engage this arena of contemporary philosophical debate. I consider the evidential base I have prepared unprecedented for this purpose, because, in my view, it offers for the first time high quality, descriptively rich and theoretically relevant first-person data. Therefore, I consider the evidence at my disposal a sound basis for reasoning.

\footnotetext{
782 Ibid., 426; Katz, "General editor's introduction," 5.

783 "General editor's introduction," 5.

784 Ibid.

785 Ibid., 8.

${ }^{786}$ For the "fundamental internal mechanism" thesis, see Wulff, "Mystical Experience," 427. For the "innate capacity" thesis, see Forman, "Introduction: Mystical consciousness, the innate capacity, and the perennial psychology," 3-41.

787 "Introduction: Mysticism, constructivism, and forgetting," 8.
} 
I will proceed as follows. First, I will discuss why practitioners use paradoxical language to describe their experiences of God's presence-absence. I will then argue against Katz's hermeneutic strategy, which assumes terms used by practitioners to be consistent with his personal hermeneutics and to mirror their phenomenology one-on-one. Second, I will argue against Pike's theistic reading of union states that renders them phenomenologically and specifically "of God" as he conceives Him. Third, I will discuss world-involving union as a paradigm instance of Stace's extrovertive type of mystical experience. Fourth, I will then turn to prayer of full union and argue on behalf of Stace's view that the mystical peak of seated prayer is consistent with his introvertive type of mystical experience, which is of an unidentified reality. Finally, I will examine the relationship between full union and Forman's "pure consciousness event". I will argue that for all intents and purposes, prayer of full union is a "pure consciousness event". Consequently, God's presence manifests in full union as "pure consciousness" or "pure awareness", which is phenomenologically of an unidentified reality.

\subsection{Theological Language in Description and the Critical Error of Constructivism}

I will now return to Joseph's case, and consider a specific example of how practitioners use theological terms to describe their experience.

First, in Section 9.3 Joseph frontloads that his descriptions of world-involving union, which he experienced when he was 18-19 years old, are now framed within the context of his current Christological worldview. For example, he says, "It was the Christ in me that was expanding me to make room for "Christness'." But he immediately adds that "Christness" means in phenomenological terms "that sense of unity and connectedness" that he experienced when he was 18 or 19, and he had not yet been theologically trained at the time.

Second, in Section 9.2 Joseph tells us that he started using theological language to talk about this experience later in life. Specifically, it was a few years after he had the notable experience that he went to theological seminary in the United States. Thus he explained, "In later years I kind of talked about it this way, as saying that, you know, 'In my baptism I was caught up into the Holy Trinity and each person of the Holy Trinity just throws me around." Consequently, when Joseph uses theological terms, be it "Christness" or the "Holy Trinity", to talk about his experience of world-involving union, he applies them post hoc. His terms do not reflect any additional and unique phenomenological ingredient over and above the experiential primitives he himself identifies, such as a "sense of unity" and a "sense of connectedness". 
Let us take a step back. I suggest that we can better understand how Joseph uses language if we follow Panikkar and distinguish between "terms" and "words". Panikkar defines the former as "epistemic signs" and the latter as "living symbols". I will discuss each in turn.

"Terms" are epistemic signs that "orient us to the world of objects... and stand for an empirically or logically verifiable object". Verification, then, requires being able to point out an object in, or an aspect of, one's experience. This can then be intersubjectively corroborated. According to Panikkar, terms are translatable, at least in respect to the natural world, because the world contains "objectifiable objects". Terms in this domain can be readily "differentially reinforced". 788

In contrast, "words" are not epistemic signs, because they are not referential in the same sense. They are not objectifiable. Words, according to Panikkar, cannot be separated from the meaning they have been imbued with. "Each of us in fact gives different shades of meaning to the same word", he says. This is also why words are not as easily translated. To truly translate those words, we must "transplant them along with a certain surrounding context [worldview] that gives them meaning and offers a horizon over against which they can be understood, that is, assimilated within another horizon." 789 Even more radically, in the area of contemplative states of consciousness, "translation of insights cannot be done unless the insight that has originated that word is also transplanted". ${ }^{790}$ This means that the meanings of words are dependent on the state of consciousness that originates them.

Let us now return to Joseph's terms. We have to understand that his theological terms - for example, "Christness" - are both referential (a term) and informed (a word).

In respect to his use of "Christness" as a term, Joseph uses it as an epistemic sign, which is intended to stand for his experiential primitives of "unity" and "interconnectedness". It is decidedly empirical (based on experience) and epistemic (referential).

In respect to his use of "Christness" as a word, he goes further, and places his experience within the context of his theological worldview. At the same time, the word has also originated in the state he experienced at that moment. So the correct interpretation of Joseph's word "Christness" must take into account that his word is imbued with meaning rooted in his insight and experience. Therefore, to understand "Christness", as Joseph uses the term, we have to transplant his "insight that has originated the word". ${ }^{791}$

\footnotetext{
788 Raimon Panikkar, The Intra-religious Dialogue (New Jersey, Mahwah: Paulist Press, 1999), 20.

789 Ibid.

790 Ibid., 21.

791 Ibid.
} 
Let us consider how this example relates to claims made by Constructivist scholars of mysticism. I will begin with Katz, who is the main representative of Constructivism.

Katz's version of Constructivism holds that the worldview and prior theological training of the mystic determine the experiences that follow. More importantly, Katz's entire argument for Constructivism rests on the premise that, "the datum passages from the mystical literature... are purely descriptive phenomenological reports rather than items that should be classified as doctrinal interpretation." ${ }^{792}$ Hammersholt recently discussed this line of reasoning in Katz.

\begin{abstract}
It is essential to notice that this [Katz's] argument is built on the premise that a close connection between the mystical description and the mystical experience exists. Katz's argument actually presupposes that the description found in the mystical report to a large degree mirrors the phenomenological mystical experience "behind" the report in a, more or less, one-on-one relationship. This is vital in an evaluation of the strength of Katz's overall argument and so this relatively unacknowledged layer in his thinking should be pondered more in the future." ${ }^{793}$
\end{abstract}

I will now consider this layer of Katz's thinking.

In his most recent anthology Comparative Mysticism (2013), Katz restated his Constructivist position as originally outlined in his 1978 paper "Language, Epistemology and Mysticism”. ${ }^{794}$ Katz continues to make claims radically at odds with the state-of-the-art thinking in consciousness science. Consider the following:

\begin{abstract}
To flesh this out, what is being argued is that, for example, the Hindu mystic does not have an experience of $x$ that he or she then describes in the familiar language and symbols of Hinduism but rather, has a Hindu experience. That is, the experience is not an unmediated experience of $x$ but is itself, at least partially, the preformed anticipated Hindu experience of Brahman. Again, the Christian mystic does not experience some unidentified reality, which he or she then conveniently labels 'God', but rather has at least partially prefigured Christian experiences of God, or Jesus, or the like. Moreover and importantly, based on the evidence supplied by great mystics of the world, the Hindu experience of Brahman and the Christian experience of God are not the same. ${ }^{795}$
\end{abstract}

\footnotetext{
792 Pike, Mystic Union, 202.

793 Torben Hammersholt, "Steven T. Katz's philosophy of mysticism revisited," Journal of the American Academy of Religion (2013): 19-20.

${ }^{794}$ Katz, "Language, epistemology and mysticism." For the state of the art debate of the philosophy of mysticism see Gellman, "Mysticism".

${ }^{795}$ Katz, "General editor's introduction," 5.
} 
Here Katz makes three strong claims based on assumptions for which he provides no independent reasons.

First, Katz claims that contemplative practitioners do not use familiar language and symbols to describe their experiences after the fact. He also claims that contemplatives do not "conveniently label" their experience with certain theological concepts. Contrary to Katz's claim, every case I have presented in this study shows that practitioners in fact do this, and they are frank about it in interview situations where they are not under pressure to concede.

Let us consider Katz's view more closely. He claims that all Christian mystics must immediately identify a personal and loving God in their experience, because that is how "God" is conceived in the Christian tradition. He makes this normative claim about the Divinity of God and the phenomenological content of contemplatives' experiences, because in his view Christian doctrine demands this. Consequently, practitioners must create this kind of experience for themselves.

Empirically, this is not the case. For example, Rachel labels her phenomenologically non-God identified experiences of "nothingness" as God's presence. She has even thought in distressing ways about her experiences of God's presence, because her experiences do not match such expectations. Another example is Carol. She says that "God" is the label she uses to refer to her "witnessing-presence" at the subject-side of her experience. Rachel and Carol disconfirm the predictions Katz would make about their experience. According to his image of God, they should experience God's presence as an external entity that is personal and loving.

Second, Katz claims that, "Mystics do not experience some unidentified reality."796 Let us consider the empirical evidence. Lawrence, Rachel, Carol and Joseph do in fact experience an "unidentified reality" and they are self-aware about how they apply theological terms to their non-God identified experiences. In fact, their view of God is different than Katz's because of their experiences. Their own expectations have been disappointed and they have instead concluded that they have, through practice, come to a different, and possibly more accurate, view of God.

In this discussion, we should not lose sight of the fact that these informants are Christians since birth and relatively monolithic in their religious context. They remain Christian identified. Despite this fact, Rachel says that her images of God have eroded over time because of practice. Therefore, we might consider the possibility that she (and other practitioners) do in fact experience God, just not in the way Katz would have us believe God 
should be experienced.797 This is the position that the Centering Prayer tradition adopts and, on top of this, it recommends to "meet God as He is in Himself and not as the image you have of Him". ${ }^{798}$

If Pike and Katz are indeed wrong about how God must be phenomenologically given, then it is also futile for them to attempt, as they both do, to show that Christians have unique theistic experiences, and thereby, to show that contemplatives from different traditions and cultures can in no sense have experiences similar in content and structure.

Third, Katz claims that the evidence we have available from the great mystics shows that experiences across traditions are not the same. However, as Pike points out, "Katz fails to tell us exactly what they [the evidences] are or where to find them." It seems implied in Katz's account that such passages are those where "God" is mentioned and the "soul" is claimed to be "united with" this "God". ${ }^{799}$ He then assumes that those terms - as interpreted by his personal hermeneutics - mirror one-on-one the phenomenal character of the experiences. This assumption in essence rejects Stace's proposal to distinguish experience from report, because Katz assumes that reports mirror one-on-one the phenomenology of mystics' experiences.

Katz's assumption is untenable in contemporary consciousness science, as demonstrated by Hurlburt and Schwitzgebel's influential study Describing Inner Experience and two decades' worth of discussion on the subject in the Journal of Consciousness Studies. ${ }^{800}$ The interview techniques adopted in this study also show time and again that Hurlburt and Schwitzgebel (and Stace) are right to treat descriptive reports of experience with caution. There are many reasons to be careful: our terminology to describe internal states is often inadequately differentially reinforced; our self-theories frequently impede accurate description; we may report false generalisations; we lack expertise in describing experience; we fail to faithfully describe our experience; and, finally, we creatively use terms to refer to our experience, which, even Katz acknowledges, are "surface grammar".801

Interestingly, Katz admits that "like-sounding descriptions are not, in actuality, similar descriptions and do not indicate the same experience... because language is itself

\footnotetext{
797 Ibid., 9.

798 In my interview with Father Reggie, a monk at St Benedict's Monastery in Snowmass, he insisted on the significance of "emptiness" and that this practice helps us get a clearer understanding of God as God is in contrast to how we might imagine Him. Keating shares his view: "Our idea of God expands and God ceases to relate to us at the other levels." Intimacy with God, 69. Keating also believes that it is important to purify our idea of God and that as this process ripens, God can be experienced as impersonal. Invitation to Love, 114. Keating also says that the purpose of the sacred word is to go beyond and "into union with that to which it points - the Ultimate Mystery, the presence of God beyond any conception we can form of Him." Thus Keating conceives centering prayer as "a training in being content with God as He is" and not how we wish him to be. Open Mind, Open Heart, 36, 42.

799 Pike, Mystic Union, 202.

${ }^{800}$ Hurlburt and Schwitzgebel, Describing Inner Experience.

${ }^{801}$ Katz, "General editor's introduction," 10.
} 
contextual and words 'mean' only in context. The same words... can apply and have been applied to more than one object." ${ }^{\circ 2}$ But if this is indeed true, then Katz cannot point to "datum passages" that refer to "God" and "Christ" and argue that these terms have a specific experiential correlate determined by his personal hermeneutics.

In sum, I consider the empirical data presented conclusive counter evidence against the assumption that terms contemplatives use mirror one-on-one the phenomenology of their experiences. This is impossible, because textual hermeneutics cannot account for how terms are differentially reinforced for individuals. Consciousness science has also shown that "shared" contexts do not guarantee consistency in description. ${ }^{803}$

\subsection{Prayer of Union and Full Union are not Phenomenologically Theistic}

Centering prayer contemplatives report either non-lucid "climax intervals" in which both their personal presence and God's presence as "other" disappears, or lucid peaks in which they sense "presence" in a "pure" way without structural differentiation. The time period of these intervals is always limited and restricted to seated prayer.

This picture is by and large consistent with Pike's "union without distinction" (or "prayer of full union"), which he describes as a "mystical peak" that lacks a dualistic structure and objects of any kind. ${ }^{804}$ This peak distinguishes itself from prayer of union in the following two ways: (i) the practitioner "is no longer aware of God as Other"; and (ii) the state is "vacant of the spiritual perceptions characteristic of its dualistic stage [prayer of union]". ${ }^{805}$ In sum, prayer of full union is characterised by phenomenological scarcity.

In this chapter, I have put forward examples that are by and large consistent with Pike's account with one exception: the descriptions do not support his view that prayer of full union is "phenomenologically theistic" in the sense that it is phenomenologically given as "of God".806

Still, Pike argues that prayer of full union is in fact theistic, even though this mystical peak is "devoid of a subject-object structure and thus involves no awareness of either oneself or another”. Pike acknowledges that the phenomenological character and structure of full union raise serious doubt about "how it could be a theistic experience, an experience phenomenologically and specifically of the individual God". ${ }^{807}$ Nevertheless, Pike argues that union experiences are in fact theistic, in interesting ways.

\footnotetext{
802 Ibid.

${ }^{803}$ I define "differential reinforcement" in Section 2.7.2 (p.52).

804 Pike, Mystic Union, 29; 115; 55-61.

805 Ibid., 160.

806 Ibid., 162.

807 Ibid.
} 
I will now draw on the first-person data I have presented here to argue against Pike's theistic reading of full union.

Let us consider Pike's argument first. It rests on comparison with two hypothetical cases where a baseball hurtles towards an innocent bystander and hits her on the forehead. In case 1 , the bystander did not see the ball coming, and in case 2 , she did. Pike argues that in the first case, a later description that, "I was hit by a baseball" expresses something the bystander believes but did not perceive. However, in the second case, because of the "closing interval of a phenomenological sequence... made up of perceptions that were recognized as a baseball making its way to a point of contact with my forehead", the same description, "I was hit by a baseball" does in fact describe the phenomenological content of something the bystander directly experienced. Pike's thesis is that “it is the phenomenological ancestry in case 2 that accounts for the fact that it was, phenomenologically, of being hit with a ball." 808

Pike then draws a parallel from these to baseball cases to union states. He argues that the mystical climax, in which there are no distinctions, is still specifically a theistic experience, and therefore "of God", because the peak follows on from the perception of a gradual eclipse where there is a "perception of two that have become one". He says, "With respect to this final moment of awareness, one might say that its phenomenological ancestry has survived as an ingredient in its phenomenological content," and in this way the experience is phenomenologically one of "identity with God". 809

In sum, Pike's argument has two critical steps. His first step is to establish that the initial dualistic stage of prayer of union is phenomenologically and specifically of the individual God. His second step is to argue that the "God-identification" element in the phenomenological ancestry in the first step survives and lives on in the mystical peak of prayer of full union.

If my analysis is correct, then the accounts of practitioners in this study are inconsistent with both steps of Pike's argument.

In Chapter 7, I showed that a practitioner's "sense of presence" in prayer of union does not contain a "God-identification" element in how it is phenomenologically given. Therefore, the initial dualistic stage lacks the necessary phenomenological ingredient required to set up a theistic "phenomenological ancestry" for the mystical peak that follows. According to Pike, this ancestry would somehow change an "undifferentiated" and "vacant" experience into one that is phenomenologically and specifically "of God in his Divinity".

\footnotetext{
808 Ibid., 162-63.

${ }^{809}$ Ibid., 164.
} 
In $\underline{\text { Chapter } 8}$, I showed that prayer of full union, too, is devoid of Pike's "Godidentification" element in the phenomenologically given. ${ }^{810}$ First, Lawrence's and Martin's prayers of full union are marked by strong phenomenological paucity. They lack lucidity. Therefore, there is no sense of presence, whatsoever. If God were present, his presence could not be phenomenally apprehended by them. Second, Samuel's lucid prayer of full union is marked as a "sense of presence", but it must be qualified. On the one hand, he does not have the experience of, "God is this consciousness," or that "God is this awesome presence - this AWESOME 'OTHER'.” On the other hand, Samuel does experience a sense of presence, that is, "MY becoming present", as a "pure state" of "existence".

In sum, practitioners use the term "God" to refer to their sense of "presence", "existence”, “isness”, “just being”, "nothingness”, "liminal space”, "featureless expanse”, "clean space", and so forth, despite the fact that their mystical peak - and the lesser developed union states leading up to it - are phenomenologically and specifically neither "of the individual God" nor "of God simpliciter". Rather, they are of an unidentified reality. ${ }^{811}$

\subsection{World-Involving Union and Stace's Introvertive and Extrovertive Types of Mystical Experience}

In Mysticism and Philosophy, Stace distinguishes between two types of mystical experience. The first is introvertive and "event-perspective excluding" (monistic); the second is extrovertive and "event-perspective including" (nondual). I will first explain what it means for the event-perspective to be "included" or "excluded". I will then build on this clarification to define the difference between Stace's intovertive and extrovertive types of mystical experience.

I use the term "event-perspective including" to refer to the object-side of all levels of awareness. Therefore, when the event-perspective is excluded, the practitioner's experience is utterly undifferentiated such that there is no object-side to his experience regardless of level of awareness. The paradigm instance of this type of experience is "prayer of full union", which I discussed in Chapter 8.

I use the phrase "world-involving" or "world-excluding" to refer to the object-side of the ordinary level of awareness only. Therefore, when I say that the world is excluded in

\footnotetext{
${ }^{810}$ For a discussion of why "union without distinction" is not phenomenologically theistic even if preceding states of contemplative prayer (e.g., prayer of union) were characterised by "God-identification", see Daniel Zelinski, "On Pike on 'union without distinction' in Christian mysticism," Philosophia: Philosophical Quarterly of Israel 39, no. 3 (2011): 503-08.

811 William James alluded to this when he concluded that the metaphysical attributes of God discussed by theologians are a "metaphysical monster" and "an absolutely worthless invention of the scholarly mind". James, The Varieties of Religious Experience, 487.
} 
prayer of union, I mean that the practitioner has no sensory awareness of his physical environment (external coarse-level content). In this case, the spiritual and divine levels of awareness may still be structurally differentiated such that they include an event-perspective at the spiritual and divine levels but not the ordinary level. The paradigm instance of this is "prayer of union" during seated prayer.

We are now in a position to consider Stace's distinction between introvertive and extrovertive mystical experiences.

Stace's extrovertive mystical experience is one in which the subject has cognitive access to ordinary environmental stimuli: he or she still perceives natural objects; for example, seeing trees and hearing cars. Therefore, the extrovertive state includes sensory awareness. However, the objects perceived in the event-perspective are not considered separate in nature from the subject. There is a gloss of unity that overrides, or is concomitant to, the awareness of multiplicity. Hence the awareness- and event-perspectives are, although differentiated through the continuation of ordinary experiencing, a unified whole ("nondual"). In this way, the extrovertive state is "world-involving". ${ }^{812}$ The paradigm case for this type of mystical experience is Joseph's "union with God”, which I discussed above and will continue to focus on for the remainder of this chapter.

In contrast, the introvertive mystical experience does not involve the world at all. It is also "event-perspective excluding". There is no distinction between self (subject-side) and the presence of God (object-side). The awareness- and event-perspectives are not differentiated at any level of awareness. Therefore, the introvertive state is "stripped of all psychological content" and it is a "pure" state "from which the manifold itself has been obliterated". ${ }^{813}$ All that remains is awareness-only.

Awareness-only makes obsolete the terms "unity" or "nondual”. They are actually misleading, because there is nothing present in the experience to be unified or known as inseparable by nature. Therefore, the phenomenological structure and character is of a singularity ("monistic"). ${ }^{814}$ The experience is, phenomenologically, neither dual nor nondual, because it completely lacks a dualistic structure in either the narrow/strong (subject-objectdirected) or broad/weak (open towards otherness) senses. ${ }^{815}$ The paradigm instance of this is "prayer of full union".

Joseph's experience above was world-involving. He recounts sensory awareness of natural objects and an awareness of multiplicity that is transcended by a sense of unity. The sense of unity made Joseph feel part of the cosmos. No component in the experience could

\footnotetext{
812 Stace, Mysticism and Philosophy, 61-62; 132-33; Pike, Mystic Union, 158.

813 Stace, Mysticism and Philosophy, 86.

814 Ibid.; Pike, Mystic Union, 89-91; 110-11.

${ }^{815}$ Mystic Union, 157.
} 
be separated from his own sense of himself. Therefore, Joseph's awareness- and eventperspectives were structurally differentiated while at the same time their phenomenal character was felt to be inseparable in nature.

Joseph's account of "union with God” is consistent with Stace's extrovertive type of mystical experience. This is orthodox in Centering Prayer. For example, Keating says that union states can and do occur in "any experience with the senses as well as in prayer". ${ }^{816}$ In this research, I have separated these two types of union states for the purpose of analysis. I have also labelled them for convenience as "prayer of union" (world-excluding) and "union with God" (world-involving).

Joseph's world-involving union is a paradigm case of union that is experienced outside of prayer and world-involving. This is unlike Rachel's, Carol's and Joseph's own "prayer of union", which is a union state encountered during seated prayer and worldexcluding.

With respect to the world-involving feature of Joseph's union, he retains cognitive access to the event-perspective of the ordinary level of consciousness. Specifically, he is only aware of external coarse-level content processed by way of his sense faculties, because they are stimulated by the external environment. Since his union state is still very absorbing, he is by and large unaware of internal coarse-level content. He does not discuss internal mental objects of any kind. Keating explains that, "Imagination and memory grow still... God, as it were, calls these faculties to Himself." 17 Thus Joseph's faculties react to external stimuli, but do not roam freely on their own terms.

In this way, world-involving "union with God" is unlike "prayer of union". In prayer of union, practitioners are absorbed during seated prayer and lose cognitive access to ordinary consciousness. Their faculties are temporarily suspended and no external stimuli prompt the senses. They sit still and with eyes closed. Therefore, seated prayer is a situation that minimises sensory stimulation, which is typically scarce, if not completely absent.

In sum, Joseph's example of world-involving union provides an initial first-person evidential base for Stace's extrovertive/introvertive distinction. Specifically, Stace's extrovertive type of mystical experience identifies a type of union state that is in fact experienced by centering prayer practitioners when they are outside seated prayer.

\footnotetext{
816 Keating, Open Mind, Open Heart, 34.

817 Invitation to Love, 107-08.
} 


\title{
10.5. Prayer of Full Union as a Paradigm Instance of Stace's Introvertive Type of Mystical Experience
}

In this section I will argue that practitioners' accounts in this study support the thesis that prayer of full union is a paradigm instance of Stace's introvertive type of mystical experience. I will begin by defining Stace's introvertive category. I will then consider Pike's position on the phenomenal character of full union and conclude with my own view, which favours Stace's position over Pike's.

Let us first revisit Stace. Consider his reasoning below, which lead him to establish the "introvertive" category.

\begin{abstract}
Suppose that one should stop up the inlets of the physical senses so that no sensations could reach consciousness... Suppose that, after having got rid of all sensations, one should go on to exclude from consciousness all sensuous images, and then all abstract thoughts, reasoning processes, volitions, and other particular mental contents; what would there then be left of consciousness? There would be no mental content whatever, but rather a complete emptiness, vacuum, void... what emerges is a state of pure consciousness-'pure' in the sense that it is not conscious of any empirical content. It has no content but itself... That there are no distinctions in it or outside it means there are no boundary lines in it between anything and anything... This undifferentiated unity is the essence of the introvertive mystical experience. ${ }^{818}$
\end{abstract}

Stace's reasoning is consistent with my claim that the introvertive type is "event-perspective excluding". This means that the object-sides of all levels of awareness are absent (awarenessand event-perspectives are not structurally bifurcated). In prayer, this renders consciousness utterly undifferentiated without distinction between self (subject-side) and the presence of God (object-side). What persists is a "pure" state "stripped of all psychological content". Even "the manifold itself has been obliterated". ${ }^{819}$ The state is world-excluding (no ordinary consciousness) and of awareness-only: " $\mathrm{X}$ is devoid of $\mathrm{Y}$ " where " $\mathrm{X}$ " is awareness simpliciter and "Y" is content.

In respect to Albahari's framework (see Section 2.5.3 and Section 2.5.6), Stace's introvertive mystical experience is coterminous with aperspectival witnessing where awareness persists with phenomenal character and without consciousness of objects. Therefore, awareness is more fundamental than consciousness. In her framework, " $\mathrm{X}$ is

\footnotetext{
818 Stace, Mysticism and Philosophy, 85-87. This quote follows Zelinski's edit of Stace's words, see "On Pike on 'union without distinction' in Christian mysticism," 500.

${ }^{819}$ Mysticism and Philosophy, 86.
} 
devoid of $Y$ " means that " $X$ " has intrinsic phenomenal character and may persist without "Y". " $\mathrm{Y}$ " is not required, because it only adds to witnessing an event-perspective. However, awareness does not require a perspective. Consequently, " $\mathrm{X}$ is devoid of $\mathrm{Y}$ " can be reformulated as "awareness is devoid of consciousness" where "awareness" is intrinsic phenomenal character (i.e., "presence") and "consciousness" is cognitive access to a perspective, specifically the event-perspective at any or all levels of awareness.

We can now better appreciate my claim that Stace's introvertive type is "eventperspective excluding". I consider his reasoning to establish the following two necessary conditions for the introvertive category:

(i) It is a state of pure consciousness that persists. Stace's "consciousness" is equivalent to " $\mathrm{X}$ ": it is witnessing with phenomenal character.

(ii) It is a state without empirical content. Stace's "empirical content" is equivalent to "Y": it excludes an event-perspective regardless of level of awareness.

Together, conditions (i) and (ii) constitute aperspectival witnessing.

Now Pike agrees that the phenomenal character and structure of "union without distinction" is just as Stace defines the introvertive type of mystical experience, but with one critical difference: its phenomenological ancestry renders it phenomenologically and specifically of the individual God. Thus the phenomenal character of aperspectival witnessing is marked by "God-identification".

Zelinski disagrees with Pike. He considers passages that Pike cites to discuss prayer of full union and comes to a different conclusion. He says:

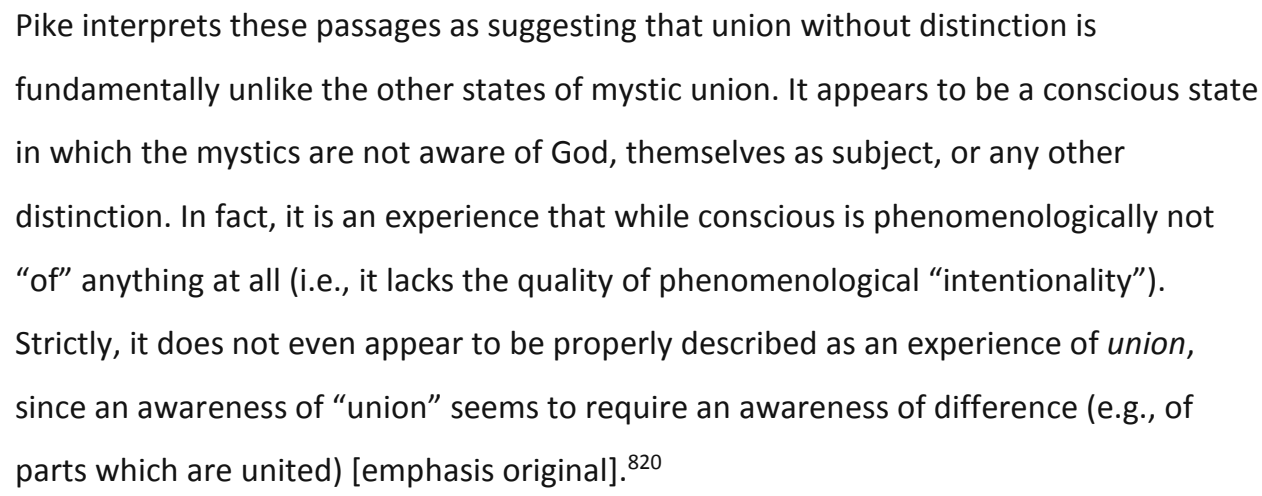

The empirical data of this study supports Zelinski's observation that, "Mystics are not aware of God." Prayer of full union excludes a God-identification element in the phenomenologically given (see Section 10.3 above). It is not theistic. For example, when Samuel is fully established in prayer of full union (a "featureless expanse") he says, "I am not having this experience of, 'God is this consciousness."' Centering prayer contemplatives

${ }^{820}$ Zelinski, "On Pike on 'union without distinction' in Christian mysticism," 499. 
speak in one voice on this matter. They also agree that the phenomenological ancestry in the lead up to this climax interval is devoid of "God-identification".

When centering prayer contemplatives report lucid intervals of prayer of union, then their descriptions are consistent with Stace's two conditions. Prayer of union is:

(i) Witnessing with phenomenal character ("presence") where "phenomenal character is an experiential primitive without "God-identification"; and

(ii) event-perspective excluding (of a singularity or "monistic").

Therefore, "lucid" prayer of full union is aperspectival witnessing as Albahari defines it and as such it is a paradigm instance of Stace's introvertive type of mystical experience.

\subsection{Prayer of Full Union as a "Pure Consciousness Event"}

Robert Forman properly introduced the notion of a "pure consciousness event" (hereafter, "PCE") into the comparative study of religion through his edited volume The Problem of Pure Consciousness. He defined a PCE as, "a wakeful though contentless (nonintentional) consciousness". ${ }^{821}$ In his later publication The Innate Capacity, he defined it as "what persists when the human being persists without content." 222 In his final and most important work Mysticism, Mind, Consciousness, Forman offered another definition. A PCE is "a condition of being entirely without any sensory or mental content, or without any intentional content for the awareness. One simply persists 'without support'." 823 He then added a few descriptors, such as: "one continues void of conceptions"; 824 it is "contentless yet open and alert";825 and it is "a nonintentional, yet wakeful moment". ${ }^{26}$

Forman's PCE is an important reference for this study for two reasons. First, the case studies I have presented prima facie indicate that centering prayer contemplatives have experiences similar to the PCE. They are also referred to in the source literature as instances of "pure consciousness" or "pure awareness". Second, the PCE is a paradigm instance of

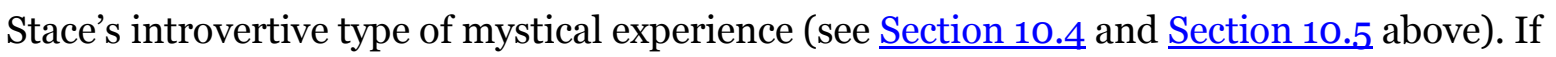
prayer of full union is consistent with the PCE, this strengthens the case that Stace's introvertive type of mystical experience is correctly applied to Centering Prayer's account of full union.

I will now consider a characteristic of the PCE that I consider key to this comparison. It is reflected in Lawrence's, Martin's and Samuel's accounts in this chapter. My concern is

\footnotetext{
${ }^{821}$ Forman, "Introduction: Mysticism, constructivism, and forgetting," 8.

822 "Introduction: Mystical consciousness, the innate capacity, and the perennial psychology," 16.

${ }^{823}$ Mysticism, Mind, Consciousness, 13.

824 Ibid., 12.

825 Ibid., 15.

826 Ibid.
} 
how "lucid" Forman conceives his PCE to be. How awake are practitioners during such "experiences"? If they are not, should we still treat PCEs as phenomenological "events"?

To consider these questions, I will begin with Forman's own autobiographical account of a PCE that he "experienced" while practicing a Neo-Advaitin form of meditation (most likely TM):

Occasionally my thoughts drift away entirely, and I gain a state I would describe as simply being awake. At those times I'm not thinking about anything. I'm not particularly aware of any sensations. I'm not aware of being absorbed in anything in particular. Yet I know (after the fact) that I haven't been asleep. I am simply awake, simply present. ${ }^{827}$

Forman's account raises the obvious question: How awake or alert was Forman in his "experience"? Forman anticipates this issue and explains himself as follows:

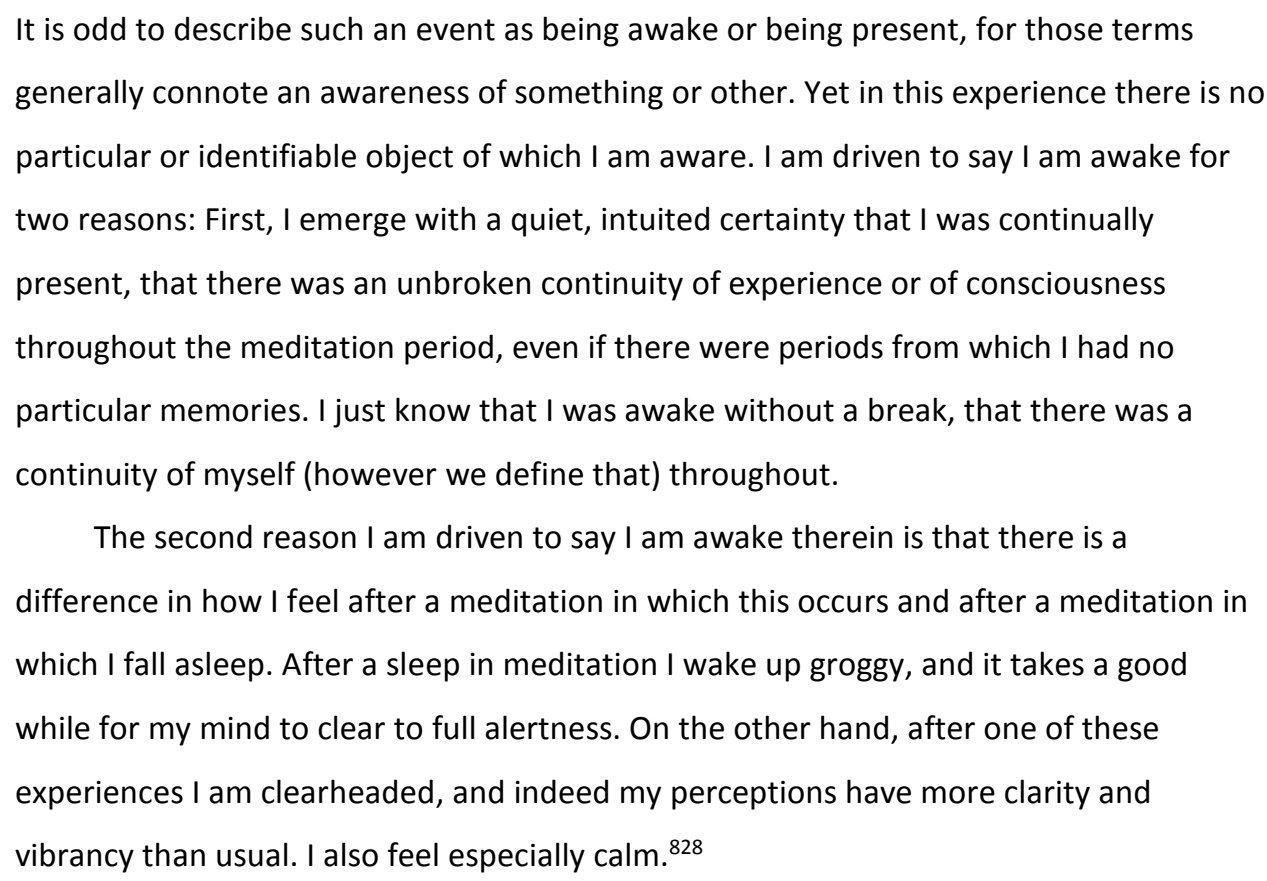

According to Forman's account, he only becomes aware of the state he was in after the fact. When he emerges from the PCE, he infers that he was not asleep, because, typically, when he falls asleep he feels different. Nevertheless, he doesn't have a clear memory of any specific experience or any sense of duration.

\footnotetext{
827 Ibid., 20.

828 Ibid., 20-21.
} 
Let us consider two further reports that Forman puts forward. They are reports Forman gathered through interviewing practitioners. The practitioners in question are a Zen Abbot and a Siddha Yoga practitioner.

I begin by quoting a relevant section of the Zen Abbot's account:

Q. I want to be real exact here. [Did] you become aware of how good you felt [during the event? Or after it?] During [it] would you say there was any particular awareness?

D. No. No awareness at all. No reflection on it at all.

Like Lawrence and Martin in this study, the Zen Abbot here reports having had no particular awareness of anything at all, not even feelings.

Let us move on to the Siddha Yoga practitioner.

Q. Would you say [during this experience that] you were thinking?

D. No. I mean, I was completely out. I didn't, well, no.

Q. Can you describe anything about that experience... during the four hours?

D. No. The only thing I know is just that I was sitting there. I was very very comfortable but I didn't know I was sitting there. It was like I wasn't even there...

Q. Where you asleep?

D. No.

Q. How do you know?

D. 'Cause I know when I'm asleep. My head falls and I start dreaming or whatever. But, it was still up and I [just know I] wasn't.

She was quite adamant that she was not asleep. She reiterated it several times. So I wondered:

Q. [Did] you have the sense that you had been awake?

D. I don't know if I was awake. I wasn't sleeping. 
Q. So, you weren't awake in the usual way?

D. No, not really.

Q. Did you have an experience like being in another world?

D. I didn't have any experiences. I didn't feel anything...

The Siddha Yoga practitioner tells us that she had no particular experience and that she was not awake in the usual sense, but she was also not asleep. Her reply, "I was not aware, but I was also not asleep" is the most typical answer I have received from centering prayer practitioners when they try to explain what sometimes happens to them in their seated prayer - during their "mystical peak".

The various labels for this "experience" range from "nothingness" to "God's presence" and it is decidedly marked by an absence of all affect, just like Samuel reported in Section 8.4. It is also a state of non-self-awareness, which Samuel identified as "perfect egolessness". The only difference I have encountered is how lucid the state is. Practitioners appear to differ in how alert and wakeful they are during such contentless states of consciousness (refer back to $\underline{\text { Section } 8.5 \text { and Section 8.6). }}$.

Specifically, Samuel's experience of a "featureless expanse" shares four characteristics with Forman's own PCE:

(i) it is marked by non-self-awareness of the self-as-subject type (egolessness);

(ii) it is affectless;

(iii) it has no content;

(iv) it is monistic because its structure is neither dualistically strong (subject-object) nor dualistically weak (open to alterity).

Forman's account of the PCE suffers from inconsistency. He defines it as a "wakeful moment" that is alert. But his own autobiographical account and the qualitative evidence he puts forward calls into question the lucidity of the PCE. Many, even Forman himself, report not being awake in the usual way. They indicate a loss or lack of awareness; they do not appear to know they are in the state they are in (no state-awareness); and they do not appear to have cognitive access to any content. Rather, the state appears dull and a form of nonconsciousness.

Interestingly, this is consistent with Keating's treatment of prayer of full union: practitioners do not know they are in the respective state. Frenette then adds that with 
extended practice this state of non-self-awareness can be integrated with a fully alert and wakeful consciousness, which I would call "lucid".829

My discussion shows that it is unclear what Forman intends by the PCE, because his definition and first-person data leave ambiguous how lucid the PCE is meant to be and whether the state is in fact non-state-aware. By "non-state-aware" I mean that those who undergo the "experience" have no cognitive access to the state of consciousness they are in.

Whatever the case may be, Samuel's "featureless expanse" is decidedly marked by all the characteristics listed above (i-iv) plus lucidity. Samuel is fully conscious of the state he is in and does not need to rely on memory after the fact, or a comparison to other situations to infer that he was, or might have been, "awake”. Samuel's "lucid” prayer of union is consistent with Forman's account of the PCE conceived as a "wakeful moment" and alert.

On the other hand, Lawrence's and Martin's "non-lucid” climax intervals of prayer of union also share characteristics (i) to (iv) minus lucidity. Their accounts are not consistent with how Forman defines the PCE, but they are consistent with the first-person descriptions Forman puts forward as evidence for PCEs.

In sum, whether the PCE is meant to be lucid or not, or both, I consider prayer of full union for all intents and purposes coterminous with a "pure consciousness event".

\subsection{Conclusion}

I consider the empirical data I have presented in Chapters 4 to 9 conclusive counter evidence against: (i) Katz's claim that Christians do not experience an unidentified reality in union states and then use terms available to them, from their tradition, to refer to experiential primitives in their non-God identified phenomenology; and (ii) Pike's "God-identification" theory that argues for a theistic rendering of all union states so that they are phenomenologically and specifically of the individual God.

Finally, I suspect that "lucid" full union is how Forman intends the PCE. If this is true, and my phenomenological analysis of prayer of full union is correct, then Centering Prayer's mystical peak during seated prayer is a paradigm instance of Stace's introvertive type of mystical experience. Stace is also correct to claim, by implication, that God's presence in full union is phenomenally apprehended as "pure consciousness" and that this featureless and undifferentiated state is phenomenologically of an unidentified reality.

${ }^{829}$ Keating, Manifesting God, 112. 


\section{Chapter 11}

\section{Conclusion}

"As the authority of past tradition tends more and more to crumble, men naturally turn a wistful ear to the authority of reason or to the evidence of present fact. They will assuredly not be disappointed if they open their minds to what the thicker and more radical empiricism has to say. I fully believe that such an empiricism is a more natural ally than dialectics ever were, or can be, of the religious life." 830

- William James

As I reflect on the Contemplative Responses to the Sense of Self project, and the material I have presented in this study on Christian Centering Prayer, I am convinced that the philosophy and comparative study of mysticism must rely on sound evidence in its theorising, and this requires a return to empiricism by way of the methodological progress made in the science of consciousness over the last thirty years.

In this study, I have utilised state-of-the-art second-person methods developed in consciousness science, such as the Explicitation Interview Technique and Expositional Interviewing, to facilitate this empirical turn and create an impetus for change in the way the field produces evidence and conducts theorising. My empirical turn acknowledges that a close relationship exists between description and theory when we investigate the metaphysical (phenomenal) nature of consciousness. This renders first-person descriptions a basic source of evidence, if not the only source. Consequently, sound reasoning about contemplative states of consciousness is possible if and only if the evidential base it draws from is of the appropriate kind and trustworthy.

Appropriate evidence for the philosophy and comparative study of mysticism should be descriptively faithful, analytically transparent and theoretically useful phenomenological accounts of the contemplative states of consciousness in question, which are derived from first-person data that originate in contemporary practices of lived traditions. Thus my primary aim in this study has been to develop trustworthy phenomenological accounts on the basis of nuanced phenomenological analyses that can be scrutinised and verified by recipients of this research.

To this end, in Chapter 2 I have given reasons to reject classic phenomenology as a philosophy and, in its stead, to adopt an eclectic, but discerning, conceptual framework to guide analysis in a way that does not a priori rule out the possibility of certain states of consciousness contemplatives report having. I then outlined a framework for this study grounded in pre-theoretical facts of the first-person (experiential) perspective, as follows:

${ }^{830}$ William James, A Pluralistic Universe (Massachussetts: Harvard University Press, 1977), 142. 
I began with Albahari's phenomenological ideas about subject and object and her suggestion that our realised capacity to be consciously aware (modus operandi) originates in the subject-side of our experience. Thus our subject-side has an intrinsic phenomenal character, which we experientially know by way of our "sense of existence" or "subjective sense of presence" that is independent of the object-side. This means that our intrinsic capacity to be aware, also referred to as our "basis of operation" or simply "witnessing", can be realised with a perspective on a world (perspectival witnessing) or persist without such a perspective (aperspectival or "pure" witnessing). Finally, I have adopted Albahari's "sense of presence", which constitutes our "background phenomenology" or the "background hum" of our experience, as this study's core concept of awareness.

My conceptual framework then linked Albahari’s intellectual scaffolding with Brown's, Pike's and DiPerna's phenomenological approaches to subject-object style analyses of contemplative states of consciousness in Pointing Out Way Tibetan Buddhist

Mahamudra, classic Christian mysticism, and the study of religious experience in general. This laid the groundwork for discussing the idea that there are multiple "levels of awareness" and that contemplative practitioners progress on their respective paths by learning how to navigate them. I concluded my conceptual framework by presenting Brown's basic set of meditation skills. Specifically, I pointed out that practitioners can shift their bases of operation into "deeper" or "higher" levels of awareness through exercising "mental pliancy".

In $\underline{\text { Chapter } 3}$ I continued to lay the conceptual groundwork for the phenomenological analyses in this study by discussing the theoretical context of the Centering Prayer tradition. First, I pointed out that Centering Prayer is an apophatic and path-oriented contemplative practice. It is apophatic, because the method of centering prayer "does away with" the human "faculties" and related imagery to prepare for, mediate and react to, consciousness of God's presence-absence. It is a path-oriented practice, because Centering Prayer as a larger system has: (i) a soteriological goal ("unity consciousness"); a developmental trajectory with identifiable stages (the path); and (iii) a twofold system of training that consists of a psychological stream, which navigates the psychodynamics of the self, and a phenomenological stream, which navigates the phenomenal structure and levels of consciousness. I clarified that the focus of this project is the phenomenological stream of Centering Prayer's system of training.

Second, I discussed how Centering Prayer uses the "centre" as its leitmotif and Sprengmetapher to develop new forms of speech and ways to talk about the relationship between human and divine, which I have called "language of the centre". Specifically, the Centering Prayer tradition conceives God's "presence” or "being” to already aboriginally and substantially exist at the centre of human consciousness. Thus Pennington's soteriological vision of "unity", which supersedes "union", entails God being experienced and known as 
pure consciousness. Pennington makes the additional and more radical claim that pure consciousness is what God is.

Third, I synthesised a complete map of Centering Prayer's (Keating School) contemplative path from available primary sources and with the help of the monks at St Benedict's Monastery in Snowmass. This included: (1) a delineation of the levels of consciousness (ordinary, spiritual and divine) and the identification of each level's unique type of content (coarse, subtle and very subtle/divine presence); (2) definitions for each type of self (false, true and separate-self sense); and (3) an outline of the stages of the contemplative path that covers three major phases: the beginning phase, which includes the sacred symbol (Stage One) and spiritual attentiveness (Stage Two); the intermediate phase, which includes the absorptions in seated prayer (Stage Three), namely, infused recollection, prayer of quiet, prayer of union and prayer of full union; and the advanced phase, which constitutes the further reaches of the Christian contemplative journey in which practitioners experience abiding union states in and outside of seated prayer through transforming union (Stage Four) and the soteriological goal identified as unity consciousness (Stage Five).

Due to space constraints I proceeded to only present first-person data on the first three stages of the path traversed in seated prayer and which culminate into temporary union states (e.g., union and full union). In Chapters 4 to 9 I front-loaded the first-person data and then developed phenomenological accounts by way of transparent analyses.

Specifically, in Chapter 4 I turned to the first stage of the path, in which practitioners apply their "sacred symbol" as prescribed by the basic method of centering prayer, that is, as a preparatory practice for contemplative prayer. To clarify the method, I described different aspects of the sacred symbol and how it evolves over time from being a "word" in the literal sense to a formless intent and intervention that changes the structure of experience. As an intent, the sacred symbol is a non-object directed desire for God and implicit affirmation that drives the apophatic method. As an intervention, the sacred symbol is a "return" to the presence of God within through "letting go" of coarse-level content in ordinary consciousness. Such repeated acts of "letting go" shift the state of consciousness to a structurally diffuse but differentiated awareness in which the practitioner's basis of operation (modus operandi) becomes salient as a self-aware "I am here" presence at the subject-side of experience.

In $\underline{\text { Chapter } 5}$ I then turned to the second stage of the path and described how practitioners come into contact with the deep waters of spiritual awareness by way of spiritual attentiveness. I showed that practitioners' bases of operation shift into the spiritual level of awareness for longer periods and eventually stabilise there. At the same time, practitioners retain cognitive access to the surface activity of the ordinary level of awareness. In this way, ordinary and spiritual levels run in tandem. I have applied the etic label "dual- 
mode awareness" to this state of consciousness, because it describes how the structure of experience grants simultaneous cognitive access to two levels of awareness. Each level has its own unique type of content. On the one hand, coarse-level content at the ordinary level of awareness consists of sense perceptions, thoughts and internal dialogue, and the like. In spiritual attentiveness, this type of content recedes to the inattentive background.

Consequently, practitioners perceive coarse-level content with less clarity and they describe it as "dimmer", "quieter", "ephemeral" and "fragmented" (as in "narratively disconnected"). On the other hand, subtle-level content at the spiritual level of awareness, such as formlessness, interior spaciousness, silence, stillness and peace, occupy the attentive foreground of spiritual attentiveness.

In Chapter 6 I introduced the third stage of the path through the first two levels of absorption, which are infused recollection and prayer of quiet. The absorptions identify the onset of contemplative prayer and signify an increased activity of "grace" as the driver of prayer. In infused recollection, practitioners report that their dual-mode awareness requires less effort to maintain (="grace") and that it is affectively elevated. In prayer of quiet, spiritual attentiveness approaches zenith, because a dual-mode awareness ceases beyond this point. Practitioners who experience prayer of quiet add three characteristics to infused recollection: (i) a stronger sense of spiritual consolation, that is, they extract more hedonic reward from the depths of spiritual awareness; (ii) a sense of being "spiritually embraced" in such a way that their will is "grasped" by the state they are in; and (iii) a sense of "God's unseen presence within". Thus practitioners begin to speak of "God's presence" at this stage and I showed that practitioners phenomenally apprehend God's "unfelt" or "unseen" presence in a way that excludes an additional and unique ingredient in what is phenomenologically given. This means that practitioners do not go beyond experiential primitives to describe God's presence-absence. The experiential primitives consist of the subtle-level content present in the event-perspective (object-side) of their spiritual level of awareness, such as interior stillness, silence and spaciousness.

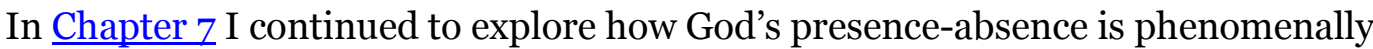
apprehended in prayer of union, which is so absorbing that practitioners lose cognitive access to ordinary consciousness. Since practitioners are unaware of both internal (e.g., thoughts) and external (e.g., sense-perceptions) coarse-level content, the union state is world-excluding. At the same time, practitioners' bases of operation either touch or shift into the divine level of awareness at the centre. A new type of content is phenomenally apprehended. The very subtle content of divine awareness is a "sense of presence", being an experiential primitive. It is by way of this "presence" - which is also this study's core concept of awareness - that God's presence-absence experientially manifests at the deepest level of consciousness. 
I proceeded to show that union may have a strong or weak dualistic structure. A strong dualistic structure obtains when a practitioner's basis of operation touches the divine level of awareness and phenomenally apprehends a vivid, subjective sense of presence within only (subject-side). At the same time, the practitioner perceives (in a subject-object kind of way) subtle-level content in the event-perspective (object-side), which includes interior silence, spaciousness and stillness. These are the ways in which God's presence-absence experientially manifest at the object-side of the spiritual level of awareness. Finally, the content of both spiritual and divine levels of awareness are experienced without an additional and unique "God-identification" element in the phenomenologically given.

A weak dualistic structure obtains when a practitioner's basis of operation completely shifts into the divine level of awareness and apprehends by way of a diffuse and nondirectional awareness a salient sense of presence within and without. Pike's "doubleinclusion relation" describes the phenomenal structure and character of this state of consciousness well. On the one hand, the phenomenal structure of the divine level of awareness is bifurcated such that there is a subjective (within) and objective (without) sense of presence. On the other hand, both sides of the experiential divide are overlaid with the unifying phenomenal character of "presence". Thus each side is phenomenally apprehended to be of the same nature. The "sense of presence" described is coterminous with practitioners' subjective sense of existence and is as such an experiential primitive that is not phenomenologically given by way of an additional and unique "God-identification element".

Since practitioners phenomenally apprehend a "sense of presence" either within (touch) or within and without (complete shift), but never outside-only, I suggest that the sense of God's presence-absence originates in the awareness-perspective (subject-side of experience) and may spill over into the event-perspective (object-side), rather than the other way around, as suggested by Pike in Mystic Union. This observation is consistent with Albahari's core concept of awareness, which conceives our "subjective sense of presence" or "presence" to have "intrinsic phenomenal character" and to originate in the subject-side of experience.

In Chapter 8 I considered prayer of full union, which is the most intense level of absorption that practitioners undergo during peak intervals of seated prayer. In full union, a practitioner's basis of operation is completely lost in the divine level of awareness.

Consequently, the phenomenal structure of full union is no longer bifurcated and no sense of self (=“awareness of self-as-subject”) remains.

My phenomenological analyses showed that full union can be either "non-lucid" or "lucid". The term "lucid" tracks how percipient practitioners are of the state of consciousness they are in (="state-awareness"). In non-lucid full union, practitioners appear completely non-self-aware in both the self-as-subject and state-aware senses. Thus it is unclear whether 
there is something it is like to live-through this state. This could disqualify full union from being a phenomenological event. It follows that there is little sense in which Godidentification can take place in non-lucid prayer of union, because God-identification cannot be phenomenologically given in a non-phenomenological "event".

In lucid full union, practitioners have no awareness of being a self-as-subject, but they are state-aware. The Keating School of Centering Prayer considers this type of full union to be a more mature contemplative state of consciousness, because non-self-awareness (of the self-as-subject kind) is integrated with fully alert and wakeful consciousness (stateawareness). This renders full union a phenomenological event wherein practitioners cognitively access the divine level of awareness at the centre of human consciousness. This divine awareness has the phenomenal character of a "sense of presence", being an experiential primitive that is given through an undivided phenomenal structure consistent with Forman's "pure consciousness event”, which is phenomenologically of an unidentified reality.

In Chapter 9 I focused on a "world-involving" type of union that can be spontaneously and temporarily experienced at any stage of the path and outside of formal practice. I call this state of consciousness "union with God", because, as in prayer of union, God's presence-absence has a dualistic phenomenal structure, and, specifically, a doubleinclusion relationship in which God's presence manifests within and without. However, unlike prayer of union, practitioners retain cognitive access to ordinary consciousness in such a way that their awareness of multiplicity (environment) is drenched through by a "sense of presence". Hence a subjective and objective sense of presence unifies the phenomenal character of practitioners' awareness- and event-perspectives at every level of awareness. This renders union with God a multi-mode awareness in which ordinary, spiritual and divine levels of awareness run in tandem. My purpose in discussing worldinvolving union was to demonstrate how phenomenologically complex union states can be when they are experienced outside of seated prayer. The structure of world-involving union is also (i) critical for evaluating Stace's distinction between introvertive (world-excluding) and extrovertive (world-involving) types of mystical experiences, and (ii) indicative of the phenomenal structure and character of abiding union states that constitute the farther reaches of the Christian journey.

Following this exposition and analysis of first-person data, I turned to theoretical concerns in Chapter 10 and re-evaluated four important theses advanced in the philosophy and comparative study of mysticism.

The first thesis I considered is Stace's distinction between extrovertive and introvertive types of mystical experience, which he considered to be universally experienced across traditions, cultures and time. I showed that the first-person data of Centering Prayer 
practitioners supports his distinction, because world-involving union is a paradigm instance of his extrovertive type, and full union is consistent with his introvertive type.

The second thesis I considered is Katz's claim that Christians necessarily experience "union with God" as an encounter with a personal God that is a loving transcendental being. He grounds this claim in an interpretive strategy that assumes terms used by mystics to be consistent with his own personal hermeneutics and to mirror their phenomenology one-onone. Thus union states must be theistic, since practitioners' "premystical" conditions, as determined and interpreted by Katz, construct the experiences. I showed that this approach is deeply flawed, because terms are differently reinforced for individuals despite shared contexts. Furthermore, I have observed that the practitioners in this study do not have uniform contexts. Their contexts actually vary significantly from one to another even though they practice in a common tradition. At the same time, Centering Prayer practitioners offer convergent descriptions that hold true when double-checked through collaborative analyses. This shows that Katz relies too heavily on hypothetical "textual traditions" to determine the context of practitioners and then infer what practitioners mean to describe by the terms they use. The fact that individuals' experiences can differ despite shared contexts, and the fact that experiences can converge despite variations in context, renders meaningless Katz's emphasis on context as a causal determinant and indicator of phenomenal variation.

The third thesis I reevaluated is Pike's claim that union states are theistic in the sense that they are phenomenologically of the individual God. Pike claims this on the basis of hypothetical thought experiments in which union states have an additional, phenomenally apprehended ingredient, which he calls the "God-identification element". Pike also claims that prayer of full union is theistic even though it is characterised by phenomenological paucity. Since full union is a peak interval of prayer of union, and union for him has the required "God-identification element", Pike believes that this phenomenological ancestry survives in full union. The first-person data I have presented disconfirms Pike's view: both prayer of union and prayer of full union lack a "God-identification element" in the phenomenologically given. Hence there is no additional phenomenal ingredient in prayer of full union and there is no phenomenal ancestry available that could render the peak interval phenomenologically of the individual God.

The fourth thesis I revisited is Forman's "pure consciousness event”. The first-person data gleaned from Centering Prayer practitioners show that God's presence-absence is "experienced" and "known" in prayer of full union as "pure existence", a "clean space" or a "featureless expanse". The phenomenal structure is of a singularity ("monistic") and the phenomenal character lacks an additional and unique "God-identification element". When full union is lucid, I consider it for all intents and purposes a "pure consciousness event" as Forman intends it and phenomenologically of an unidentified reality. Further, some 
Centering Prayer practitioners in this sample have expressed distress and deep sorrow about the absence of a specific "God-identification element" in how they experience God's presence-absence, further supporting Forman's claim that mystical experiences frequently upset rather than realise the expectations that practitioners bring to their practice. ${ }^{831}$

The first-person data I have presented in this study, and the phenomenological accounts I have developed of contemplative states of consciousness (as experienced by Centering Prayer practitioners), pave the way for more in-depth analyses of advanced stages of contemplative practice that permanently restructure consciousness. In this area, I consider my conceptual framework and method of analysis to come to full fruition. To demonstrate this, I provided a glimpse of the capabilities of my approach in Chapter 9 where I discussed a more complex, world-involving type of union, which I called "union with God".

Forman and Roth have already started work on developing basic models of abiding contemplative states of consciousness, at least as they are described in Neo-Advaita circles and classic Daoist sources. ${ }^{832}$ Both consider advanced states to have more complex phenomenal structures in which multiple levels of awareness run in tandem. Specifically, they agree that abiding contemplative states integrate critical features of Stace's introvertive (world-excluding) and extrovertive (world-involving) types of mystical experience into a single but more complex multi-mode contemplative state of consciousness.

My discussions of Stace's and Forman's analyses have shown that their phenomenological proposals are supported by the first-person data of Christian Centering Prayer practitioners. Furthermore, the first-person data of the final stages of Centering Prayer's contemplative path (excluded here due to space limitations) also support Forman's and Roth's basic phenomenological models, which build on Stace's proposals. It is my hope that my methodological aim to offer a sound second-person method for collecting data from contemplative practitioners, and my descriptive aim to provide an effective framework for developing phenomenological accounts, will lay the groundwork for future phenomenological research on advanced and abiding contemplative states of consciousness that is descriptively faithful, analytically transparent and theoretically useful.

In this respect, I intend my study to set a precedent in the philosophy and comparative study of religion and mysticism, because it: (i) relies on a method that is good enough to warrant the conclusion that the descriptions I have put forward have more evidential power than other descriptions so far relied upon in the field; (ii) relies on phenomenological accounts that are faithful to practitioners' first-person perspective so that

\footnotetext{
${ }^{831}$ Forman, "Introduction: Mysticism, constructivism, and forgetting," 19-21.

832 Mysticism, Mind, Consciousness, 153-67; Harold D. Roth, "Daoist apophatic meditation: Selections from the classical Daoist textual corpus," in Contemplative Literature, ed. Louis Komjathy (New York, Albany: State University of New York Press, 2015), 112-14.
} 
the central features of experience described provide prima facie confirmation of the key arguments I have made about the metaphysical (phenomenal) nature of contemplative states of consciousness. Therefore, I consider my conclusions strong enough that significant and novel counterevidence would be required to overturn them.

The scope and magnitude of this contribution still has limitations. First, my project has relied on a limited sample size of 20 practitioners. Hence it is a pilot study that aims to contribute new data through novel methods. In so doing, it is a first step toward an alternative approach to the way we theorise in the philosophy and comparative study of mysticism. Specifically, my approach demonstrates what we can do if we shift debate on the phenomenal nature of contemplative states of consciousness away from textual sources and towards descriptively rich first-person data, originating in contemporary practices of lived traditions. My conclusions may, however, not be generalizable on a larger scale, because the sample size is modest and the practitioners have not been randomly sampled. Next, my project is limited to qualitative design so that the analyses and conclusions herein focus on how phenomena are described while leaving the underlying causes unaddressed. Finally, my data collection has relied on the application of interview techniques for which I have received modest training. Consequently, more expertised interviewers who may undertake a similar project in the future could improve upon the quality of descriptions obtained from contemplative practitioners.

Notwithstanding these limitations, my main claims about the phenomenal nature of contemplative states of consciousness are that practitioners in the Centering Prayer tradition phenomenally apprehend union states, specifically prayer of full union, through experiential primitives, such as a "sense of presence", and without a "God-identification element". Consequently, union states are phenomenologically of an unidentified reality. Additionally, the "sense of presence" most likely originates in practitioners' modi operandi. This aligns with Albahari's core concept of awareness, which has intrinsic phenomenal character independent of objects, and is an innate capacity that originates in the subject-side of experience. The Centering Prayer tradition considers this "sense of presence" to be coterminous with God's presence-absence, being the manifestation of "God in His Divinity" as, and at the centre of, human consciousness.

Although union states are not theistic in the sense that Katz's and Pike's theologies require, there might be some sense in which they are phenomenologically of God, because they could be practitioners' consciousness of God as God is; which empirically disconfirms received views of how God should be experienced. Thus Lily says, "Divine presence or 'presence' - just call it presence. All presence is divine." 833 This finding challenges arguments

${ }^{833}$ Lily, Interview \#33.1, p.2. 
for a unique theistic experience made to uphold a fundamental distinction between theistic and nontheistic types of mystical experiences. Since at least some Christian practitioners do not have unique theistic experiences in union, the possibility remains open for contemplatives from different traditions and cultures to have experiences similar in content and structure. 


\section{References}

Albahari, Miri. Analytical Buddhism. New York: Palgrave Macmillan, 2006.

--_. "Nirvana and ownerless consciousness." In Self, No Self? Perspectives from Analytical, Phenomenological, and Indian Traditions, edited by Mark Siderits, Evan Thompson and Dan Zahavi, 79-113. Oxford, New York: Oxford University Press, 2011.

- - . "Witness-consciousness: Its definition, appearance and reality." Journal of Consciousness Studies 16, no. 1 (2009): 62-84.

Ávila, Teresa of. The Way of Perfection. Brewster, Massachusetts Paraclete Press, 2000.

Blaschke, Benno A. "The contemplative mind and life: First-person methods and the challenge of pure consciousness and phenomenal selfhood for the "neurophenomenological” research program." Victoria University of Wellington, 2011.

Block, Ned. "Perceptual consciousness overflows cognitive access." Trends in Cognitive Sciences 15, no. 12 (2011): 567-75.

Bourgeault, Cynthia. Centering Prayer and Inner Awakening. United Kingdom: Cowley Publications, 2004.

-—-. "Centering Prayer as witnessing practice." Sewanee Theological Review 53, no. 3 (2010): 261-74.

---. The Heart of Centering Prayer. Boston, Massachusetts: Shambhala, 2016.

Brown, Daniel P. Pointing Out the Great Way. Boston: Wisdom Publications, 2006.

Buehler, Arthur F. "The twenty-first-century study of collective effervescence: Expanding the context of fieldwork." Fieldwork in Religion 7, no. 1 (2012): 70-97.

Callinicos, A. Theories and Narratives. Durham, NC: Duke University Press, 1995.

Cattoi, Thomas "Redeeming the particular: Maximos the confessor's critique of Oirgenism and the Tibetan debates on practice." PhD Dissertation, Boston College, 2006.

Corbin, Juliet, and Anselm Strauss. Basics of Qualitative Research. Thousand Oaks: Sage Publications, 2007.

Creswell, John W. Qualitative Inquiry and Research Design. 3rd ed. Thousand Oaks: Sage Publications, 2013.

Damasio, A. R. Self Comes to Mind. New York: Pantheon Books, 2010.

Dennett, Daniel. "Who's On First? Heterophenomenology Explained." Journal of Consciousness Studies 10, no. 9-10 (2003): 19-30.

DiPerna, Dustin. "Differentiating phenomena from identity in religious and meditative experience." Master's Thesis, Harvard University, 2012.

Edey, Mait. "Subject and object." Journal of Consciousness Studies 4, no. 5/6 (1997): 526-31. 
Flick, Uwe. An Introduction to Qualitative Research (Edition 5). Thousand Oaks, California: Sage, 2014.

Flood, Gavin. Beyond Phenomenology: Rethinking the Study of Religion. London and New York: Cassell, 1999.

Fonagy, Peter, György Gergely, Elliot Jurist, and Mary Target. Affect Regulation, Mentalization, and the Development of Self. New York: Other Press, 2004.

Forman, Robert K. C. "Introduction: Mystical consciousness, the innate capacity, and the perennial psychology." In The Innate Capacity, edited by Robert K. C. Forman, 4-41. New York: Oxford University Press, 2004.

---. "Introduction: Mysticism, constructivism, and forgetting." In The Problem of Pure Consciousness, edited by Robert K. C. Forman, 3-49. New York: Oxford University Press, 1990.

-_-. Mysticism, Mind, Consciousness. New York: State University of New York Press, 1999.

Frenette, David. The Path of Centering Prayer. Boulder, Colorado: Sounds True, 2012.

Froese, T., C. Gould, and A.K. Seth. "Validating and calibrating first- and second-person methods in the science of consciousness." Journal of Consciousness Studies 18, no. 2 (2011): 38-64.

Froese, Tom. "Interactively guided introspection is getting science closer to an effective consciousness meter." Consciousness and Cognition 22, no. 2 (2013): 672-76.

Froese, Tom, Cassandra Gould, and Adam Barrett. "Re-viewing from within: A commentary on first- and second-person methods in the science of consciousness." Constructivist Foundations 6, no. 2 (2011): 254-69.

Gellman, Jerome. "Mysticism." http://plato.stanford.edu/entries/mysticism/. Accessed 6th of February, 2017.

-_-. "Mysticism and religious experience." In The Oxford Handbook of Philosophy of Religion, edited by William J. Wainwright, 138-67. New York: Oxford University Press, 2005.

Gimello, Robert M. "Mysticism in its contexts." In Mysticism and Religious Traditions, edited by Steven T. Katz, 61-88. Oxford: Oxford University Press, 1983.

Giorgi, Amedeo. The Descriptive Phenomenological Method in Psychology. Pittsburgh, Pennsylvania: Duquesne University Press, 2009.

-_-. Phenomenology and Psychological Research. Pittsburgh, PA: Duquesne University Press, 1985.

Goldman, Alvin I. "Epistemology and the evidential status of introspective reports." Journal of Consciousness Studies 11, no. 7-8 (2004): 1-16. 
Gordon, Susan, ed. Neurophenomenology and Its Applications to Psychology. New York: Springer, 2013.

Hammersholt, Torben. "Steven T. Katz's philosophy of mysticism revisited." Journal of the American Academy of Religion (2013).

Hasenkamp, Wendy, Christine D. Wilson-Mendenhall, Erica Duncan, and Lawrence W.

Barsalou. "Mind wandering and attention during focused meditation: A fine-grained temporal analysis of fluctuating cognitive states." NeuroImage 59, no. 1 (2012): 75060.

Hass, Robert. Time and Materials: Poems 1997-2005. New York: Ecco, 2007.

Hendricks, Marion. "Experiencing level: An instance of developing a variable from a first person process so it can be reliably measured and taught." Journal of Consciousness Studies 16, no. 10-1 (2009): 129-55.

Hurlburt, R. T. Sampling Inner Experience in Disturbed Affect. New York: Plenum Press, 1993.

---. Sampling Normal and Schizophrenic Inner Experience. New York: Plenum Press, 1990.

Hurlburt, Russell. "Descriptive experience sampling, the explicitation interview, and pristine experience in response to Froese, Gould and Seth." Journal of Consciousness Studies 18, no. 2 (2011): 65-78.

Hurlburt, Russell, and E. Schwitzgebel. "Presuppositions and background assumptions." Journal of Consciousness Studies 18, no. 1 (2011): 206-33.

Hurlburt, Russell, and Eric Schwitzgebel. Describing Inner Experience. Cambridge, Massachusetts: The MIT Press, 2007.

Husserl, Edmund. The Crisis of European Sciences and Transcendental Phenomenology. Translated by C. Carr Evanston. Evanston, IL: Northwestern University Press, 1970.

-- - Logical Investigations I-II. Translated by J. N. Findlay. London: Routledge, 2001.

James, William. A Pluralistic Universe. Massachussetts: Harvard University Press, 1977.

-- - The Principles of Psychology I-II. New York: Henry Holt and Company, 1893.

---. The Varieties of Religious Experience. New York: The Modern Library, 2002.

Johnston, William. The Cloud of Unknowing. New York: Image Books, 1996.

Katz, Steven T. "General editor's introduction." In Comparative Mysticism, edited by Steven T. Katz, 3-22. Oxford, New York: Oxford University Press, 2013.

--—. "Language, epistemology and mysticism." In Mysticism and Philosophical Analysis, edited by Steven T. Katz, 22-74. New York: Oxford University Press, 1978.

Keating, Thomas. Consenting to God as God is. New York: Lantern Books, 2016.

-_- "Contemplative Outreach: Vision and foundations." Sewanee Theological Review 50, no. 3 (2007): 367-72. 
--- Intimacy with God. Snowmass, Colorado: The Crossroad Publishing Company, 2012.

---. Invitation to Love. New York: Boomsbury, 2014.

---. Manifesting God. New York: Lantern Books, 2005.

---. Open Mind, Open Heart. New York: Bloomsbury Academic, 2006.

---. Reflections on the Unknowable. New York: Lantern Books, 2014.

---. The Spiriutal Journey: A Guide Book (Being A Contemporary Presentation of Christian Growth and Transformation). Contemplative Outreach, unpublished.

Komjathy, Louis. "Approaching contemplative practice." In Contemplative Literature, edited by Louis Komjathy, 3-51. New York, Albany: State University of New York Press, 2015.

- - - "Contemplative traditions." In Contemplative Literature, edited by Louis Komjathy, 53-86. New York, Albany: State University of New York Press, 2015.

Kvale, Steiner, and Svend Brinkmann. InterViews. 2nd ed. US: Los Angeles: Sage Publications, 2009.

Legrand, Dorothée. "Pre-reflective self-as-subject from experiential and empirical perspectives." Consciousness and Cognition 16, no. 3 (2007): 583-99.

Lincoln, Yvonna S., and Egon G. Guba. Naturalistic Inquiry. California: Beverly Hills: Sage Publications, 1985.

Lindahl, Jared Ronald. "Paths to luminosity: A comparative study of ascetic and contemplative practices in select tibetan Buddhist and Greek Chrisitan traditions." PhD Dissertation, University of California Santa Barbara, 2010.

Lutz, Antoine, John D. Dunne, and Richard J. Davidson. "Meditation and the neuroscience of consciousness: An introduction." In The Cambridge Handbook of Consciousness, edited by Philip D. Zelazo, Morris Moscovitch and Evan Thompson, 499-551. New York: Cambridge University Press, 2007.

Madagáin, Murchadh Ó. Centering Prayer and the Healing of the Unconscious. New York: Lantern Books, 2007.

Mannes, Elena, and Peter C. Jones. Thomas Keating: A Rising Tide of Silence. Temple Rock, 2014. DVD Documentary.

Martin, Paul C. "The Art of Mysticism: An Inquiry into the Notion of Ineffability in (Cataphatic) Mystical Experience." University of Queensland, 2006.

Maurel, Maryse. "The explicitation interview: Examples and applications." Journal of Consciousness Studies 16, no. 10-1 (2009): 58-89.

Maxwell, Joseph A. A Realist Approach for Qualitative Research. Thousand Oaks, California: Sage Publications, 2012.

McGinn, Bernard. The Foundations of Mysticism (1300-150o). Vol. I of The Presence of God. New York: The Crossroad Publishing Company, 1991. 
---. The Harvest of Mysticism in Medieval Germany (1300-150o). Vol. IV of The

Presence of God. New York: The Crossroad Publishing Company, 2005.

Miles, Matthew B., A. Michael Huberman, and Johnny Saldana. Qualitative Data Analysis.

United States: Sage Publications, 2014.

Miller, Jeffrey C. The Transcendent Function: Jung's Model of Psychological Growth through Dialogue with the Unconscious. New York: State University of New York Press, 2004.

Moran, Dermot. Introduction to Phenomenology. London and New York: Routledge, 2000.

Moustakas, Clark. Phenomenological Research Methods. Thousand Oaks: Sage Publications, 1994.

Overgaard, Morten. "On the naturalizing of phenomenology." Phenomenology and the Cognitive Sciences 3, no. 4 (2004): 365-79.

Overgaard, Morten, and Kristian Sandberg. "Kinds of access: different methods for report reveal different kinds of metacognitive access." Philosophical Transactions of the Royal Society B: Biological Sciences 367, no. 1594 (2012): 1287-96.

Panikkar, Raimon. The Intra-religious Dialogue. New Jersey, Mahwah: Paulist Press, 1999.

Patton, Michal Quinn. Qualitative Research and Evaluation Methods. United States: Sage Publications, 2002.

Pennington O.C.S.O., M. Basil. Centered Living. Liguori, Missouri: Liguori/Triumph, 1999.

---. Centering Prayer. New York: Image Books, 1982.

Perovich, Anthony N., Jr. "Mysticism and the philosophy of science." The Journal of Religion 65, no. 1 (1985): 63-82.

Petitmengin-Peugeot, Claire. The Intuitive Experience. edited by F. Varela and J. ShearUK: Imprint Academic, 1999.

Petitmengin, Claire. "Describing one's subjective experience in the second person: An interview method for the science of consciousness." Phenomenology and the Cognitive Sciences 5, no. 3 (2006): 229-69.

--—. "Describing the experience of describing? The blindspot of introspection." Journal of Consciousness Studies 18, no. 1 (2011): 44-62.

Petitmengin, Claire, Anne Remillieux, Béatrice Cahour, and Shirley Carter-Thomas. "A gap in Nisbett and Wilson's findings? A first-person access to our cognitive processes." Consciousness and Cognition 22, no. 2 (6// 2013): 654-69.

Pike, Nelson. Mystic Union. Ithaca, NY: Cornell University Press, 1992.

Proudfoot, Wayne. Religious Experience. Berkley: University of California Press, 1985.

Ramm, B. J. "Dimensions of Reliability in Phenomenal Judgment." Journal of Consciousness Studies 23, no. 3-4 (// 2016): 101-27. 
Reininger, Gustave. "The Christian contemplative tradition and Centering Prayer." In Centering Prayer in Daily Life and Ministry, edited by Gustave Reininger, 26-46. New York: The Continuum Publishing Company, 1998.

Roth, Harold D. "Daoist apophatic meditation: Selections from the classical Daoist textual corpus." In Contemplative Literature, edited by Louis Komjathy, 89-143. New York, Albany: State University of New York Press, 2015.

Sartre, Jean-Paul. Being and Nothingness. Translated by H. E. Barnes. New York: Philosophical Library, 1956.

Seidman, Irving. Interviewing as Qualitative Research. 4th ed. New York: Teachers College Press, 2013.

Sells, Michael A. Mystical Languages of Unsaying. Chicago and London: The University of Chicago Press, 1994.

Sharf, Robert H. "Buddhist modernism and the rhetoric of meditative experience." Numen 42, no. 3 (1995): 228-83.

Siewert, Charles. "Socratic introspection and the abundance of experience." Journal of Consciousness Studies 18, no. 1 (2011): 63-91.

Skinner, Burrhus Frederic. Science and Human Behavior. New York: Macmillan, 1953.

Spener, Maja. "Using first-person data about consciousness." Journal of Consciousness Studies 18, no. 1 (// 2011): 165-79.

Stace, Walter T. Mysticism and Philosophy. London: Macmillian, 1961.

Steinbock, Anthony J. "Evidence in the Phenomenology of Religious Experience." In The Oxford Handbook of Contemporary Phenomenology, edited by D. Zahavi, 584-606. UK: Oxford University Press, 2012.

Studstill, Randall. The Unity of Mystical Traditions: The Transformation of Consciousness in Tibetan and German Mysticism. Leiden: Brill, 2005.

Sutton, John. "Time, experience, and descriptive experience sampling." Journal of Consciousness Studies 18, no. 1 (2011): 118-29.

Taves, Ann. Religious Experience Reconsidered. Princeton, New Jersey: Princeton University Press, 2011.

Thompson, Evan. Mind in Life. Cambridge: The Belknap Press of Harvard University Press, 2007.

-_-. "Reply to commentaries." Journal of Consciousness Studies 18, no. 5-6 (2011): 176223.

--—. Waking, Dreaming, Being. New York: Columbia University Press, 2015.

Travis, F., and Jonathan Shear. "Focused attention, open monitoring and automatic selftranscending: Categories to organize meditations from Vedic, Buddhist and Chinese traditions." Consciousness and Cognition 19, no. 4 (2010): 1110-18. 
Turner, Edith. "The anthropology of experience: The way to teach religion and healing." In Teaching Religion and Healing, edited by Linda Barnes and Ines Talamantez. London: Oxford University Press, 2006.

Van Manen, Max. Researching Lived Experience. 2nd ed. Ontario, Canada: The Althouse Press, 1997.

Vermersch, Pierre. "Describing the practice of introspection." Journal of Consciousness Studies 16, no. 10-1 (2009): 20-57.

---. "Introspection as practice." In The View From Within: First-Person Approaches to the Study of Consciousness, edited by F. Varela and J. Shear, 17-42. UK: Imprint Academic, 1999.

---. L'Entretien d'explicitation en formation initiale et en formation continué. ESF Editeur, 1994.

Vogeley, K., and S. Gallagher. "Self in the brain." In The Oxford Handbook of THE SELF, edited by Shaun Gallagher, 111-36. Oxford, New York: Oxford University Press, 2011. Wallace, B. Alan. The Taboo of Subjectivity. New York: Oxford University Press, 2000. Williams, J. P. Denying Divinity: Apophasis in the Patristic Christian and Soto Zen Traditions. Oxford: Oxford University Press, 2000.

Woodruff, David Smith. "Phenomenology." http://plato.stanford.edu/entries/phenomenology/. Accessed 16th of August, 2010.

Wulff, David M. "Mystical Experience." In Varieties of Anomalous Experience, edited by Etzel Cardeña, Seven Jay Lynn and Stanley Krippner, 397-430. Washington, DC: American Psychological Association, 2007.

Wynn, Mark. "Phenomenology of religion." http://plato.stanford.edu/entries/phenomenology-religion/. Accessed 16th of August, 2010.

- - - "Towards a broadening of the concept of religious experience: some phenomenological considerations." Religious Studies 45, no. 02 (2009): 147-66.

Zahavi, Dan. "The experiential self: Objections and clarifications." In Self, No Self? Perspectives from Analytical, Phenomenological, and Indian Traditions, edited by Mark Siderits, Evan Thompson and Dan Zahavi, 56-78. Oxford, New York: Oxford University Press, 2011.

---. Self-Awareness and Alterity. Evanston, Illinois: Northwestern University Press, 1999. Zelinski, Daniel. "On Pike on 'union without distinction' in Christian mysticism." Philosophia: Philosophical Quarterly of Israel 39, no. 3 (2011): 493-509. 